\title{
Comparisons of modern pollen deposition with vegetation abundance and landscape pattern in NE-Germany
}

\author{
Dissertation \\ zur Erlangung des mathematisch-naturwissenschaftlichen Doktorgrades \\ "Doctor rerum naturalium" \\ der Georg-August-Universität Göttingen \\ im Promotionsprogramm Biologie \\ der Georg-August University School of Science (GAUSS)
}

\author{
vorgelegt von \\ Isabelle Matthias \\ aus Stadthagen \\ Göttingen, 2014
}




\section{Betreuungsausschuss}

Dr. Thomas Giesecke, Abteilung Palynologie und Klimadynamik, Fakultät für Biologie und Psychologie, Georg-August Universität Göttingen

Prof. Dr. Hermann Behling, Abteilung Palynologie und Klimadynamik, Fakultät für Biologie und Psychologie, Georg-August Universität Göttingen

\section{Mitglieder der Prüfungskommission}

Referent/in: Dr. Thomas Gisecke, Abteilung Palynologie und Klimadynamik, Fakultät für Biologie und Psychologie, Georg-August Universität Göttingen

Korreferent/in: Prof. Dr. Hermann Behling, Abteilung Palynologie und Klimadynamik, Fakultät für Biologie und Psychologie, Georg-August Universität Göttingen

\section{Weitere Mitglieder der Prüfungskommission:}

Prof. Dr. Erwin Bergmeier, Abteilung Vegetationsanalyse \& Phytodiversität, Fakultät für Biologie und Psychologie, Georg-August Universität Göttingen

Prof. Dr. Gerhard Gerold, Abteilung Landschaftsökologie, Fakultät für Geowissenschaften und Geographie, Georg-August Universität Göttingen

Prof. Dr. Hans Ruppert, Abteilung Sedimentologie und Umweltgeologie, Geowissenschaftliches Zentrum, Georg-August Universität Göttingen

Prof. Dr. Dirk Hölscher, Waldbau und Waldökologie der Tropen, Fakultät für Forstwissenschaften und Waldökologie, Georg-August-Universität Göttingen 
Für Karl Erik 


\section{Contents}

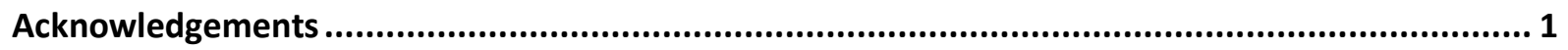

Preface

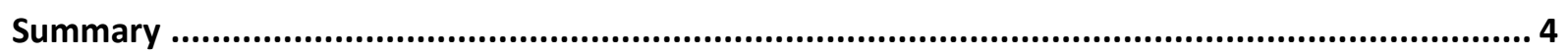

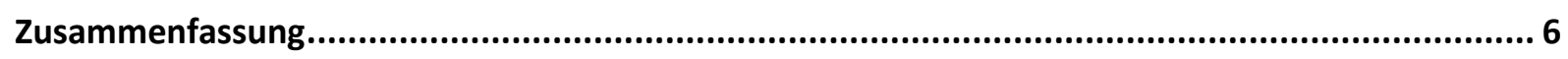

\section{Chapter 1}

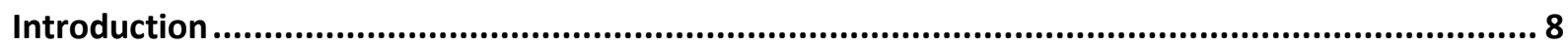

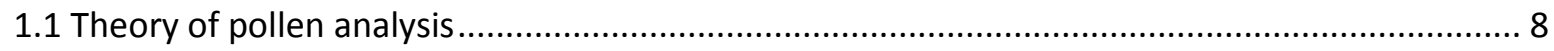

1.1.1 Percentage data and relative pollen production rates .................................................... 8

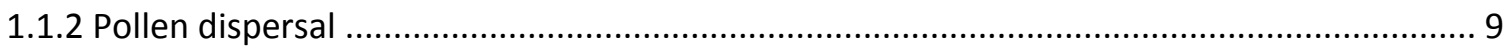

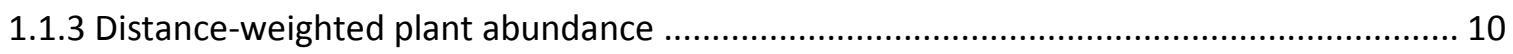

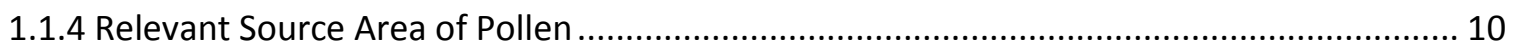

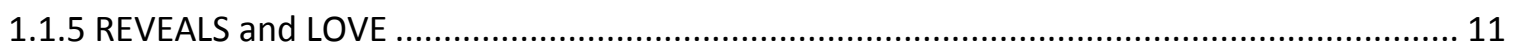

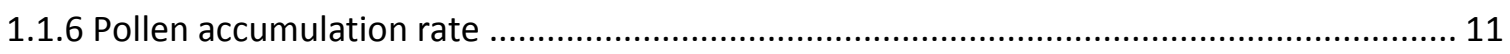

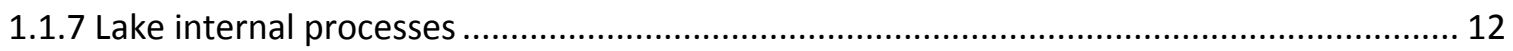

1.1.8 Calibration of PAR and vegetation abundance ................................................................ 12

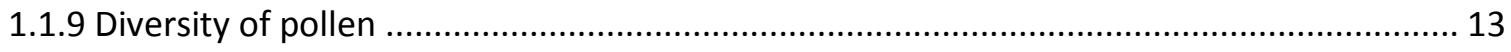

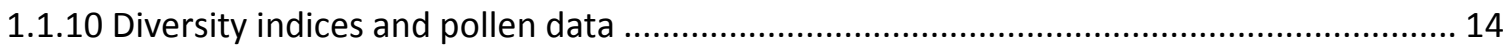

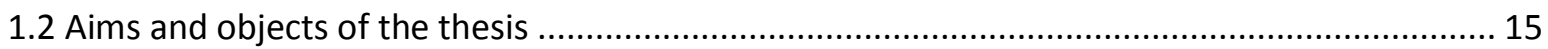

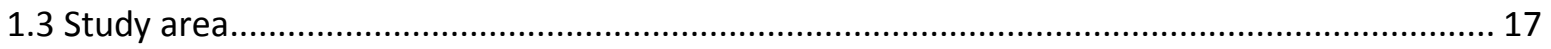

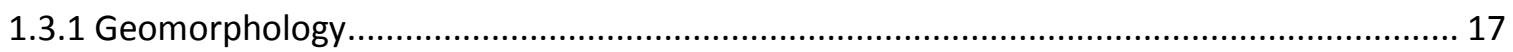

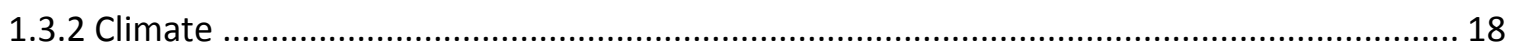

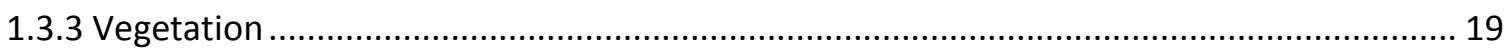

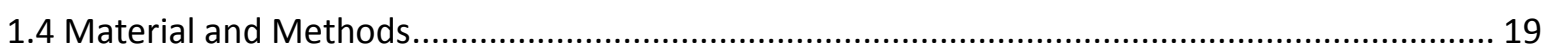

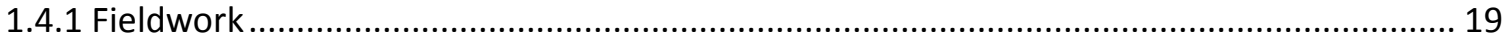

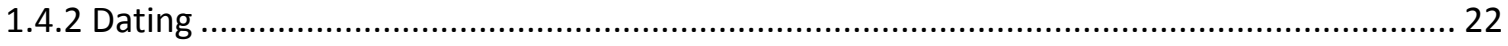

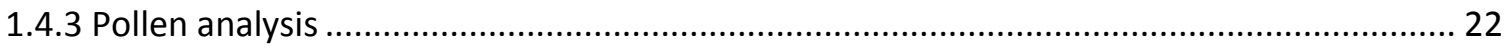

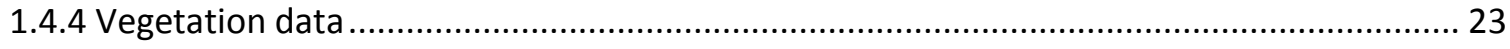

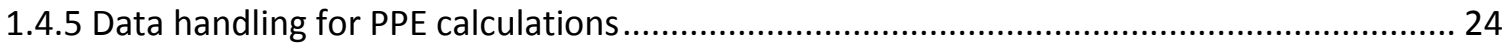

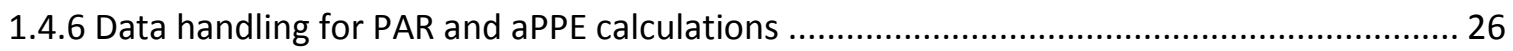

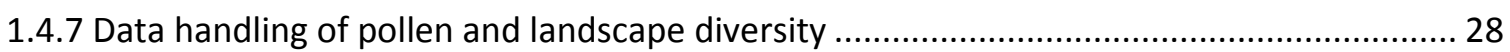




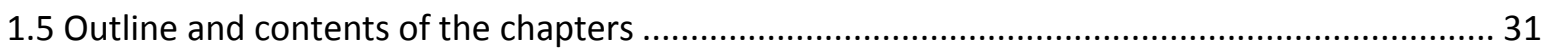



\section{Chapter 2}

Evaluating the effect of flowering age and forest structure on pollen productivity estimates........ 39

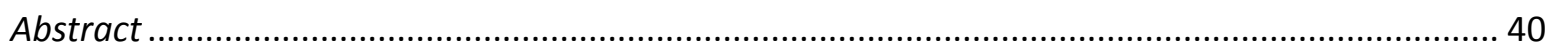

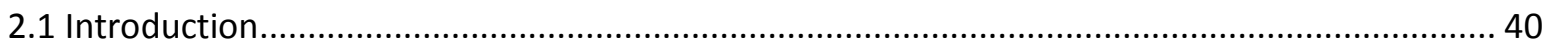

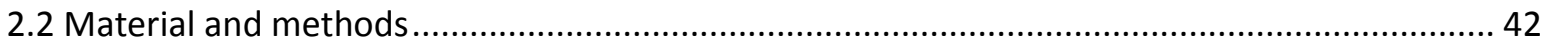

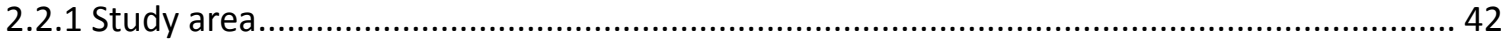

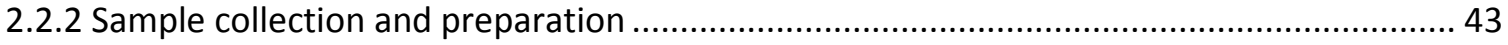

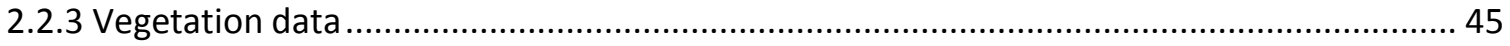



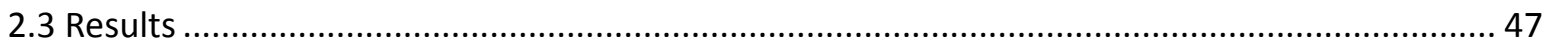

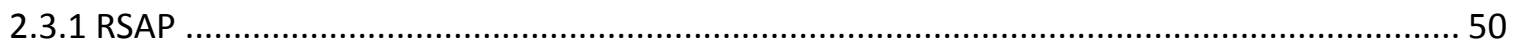

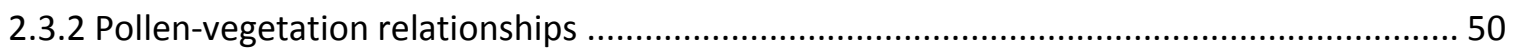

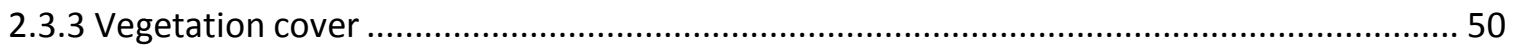

2.3.4 Reference taxon and the representation of herb pollen .................................................. 52

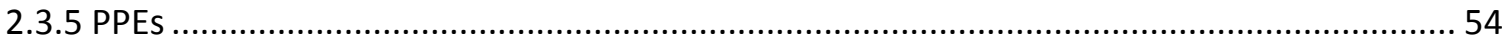

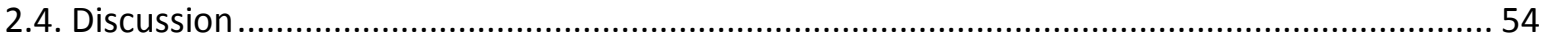

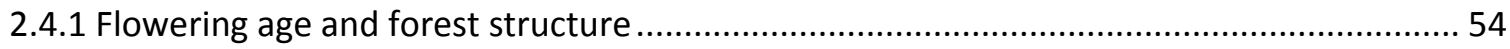

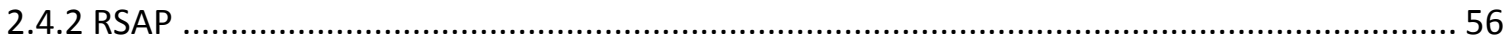

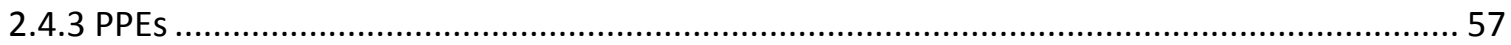

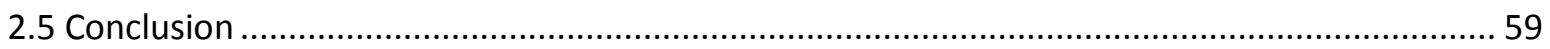

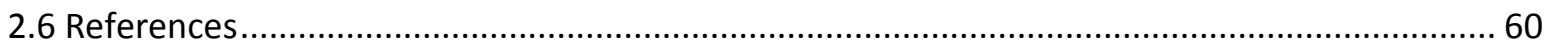

\section{Chapter 3}

Insights into pollen source area, transport and deposition from modern pollen accumulation rates

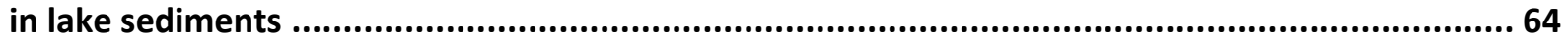

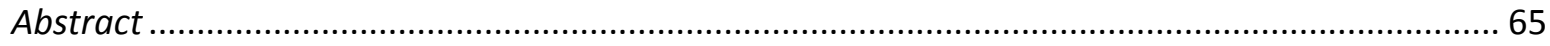

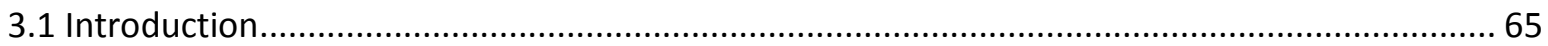

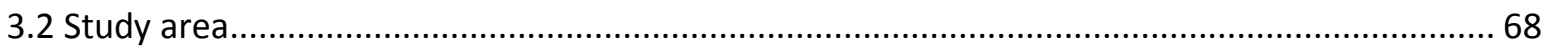

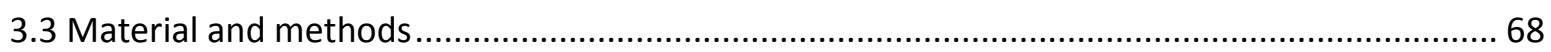

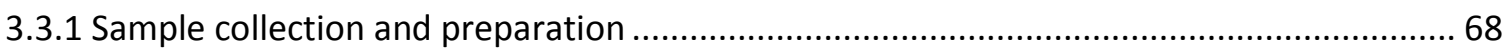

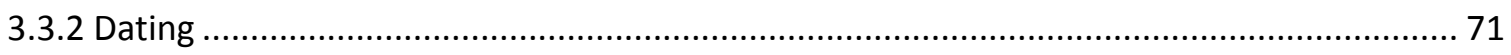

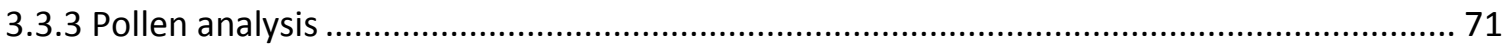

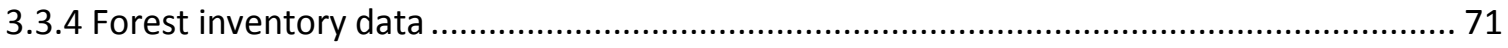




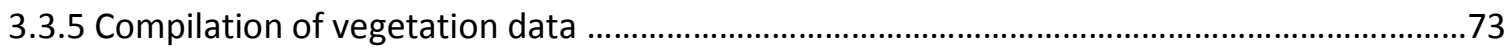

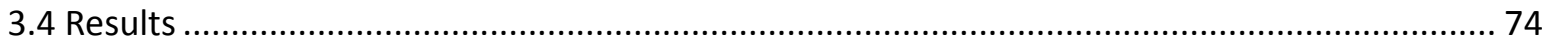

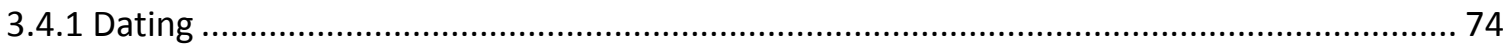

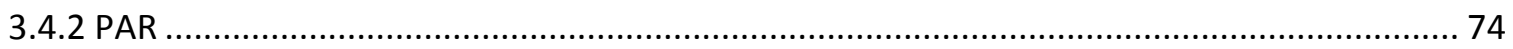

3.4.3 Comparison of PAR to non-weighted vegetation data ….................................................... 76

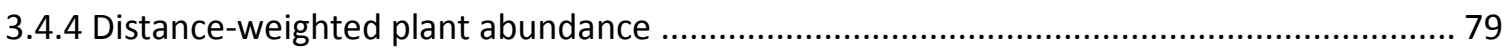

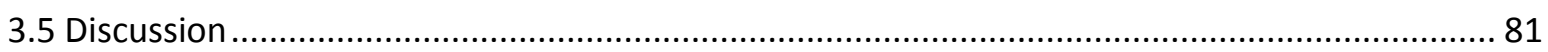

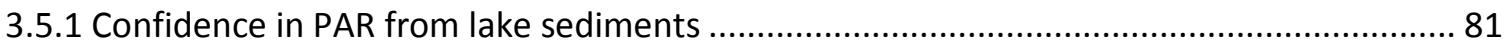

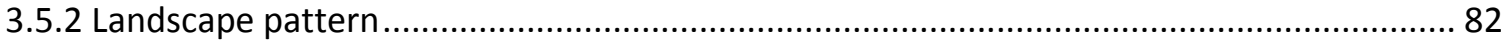

3.5.3 The importance of local vegetation and the trunk-space component ................................ 83

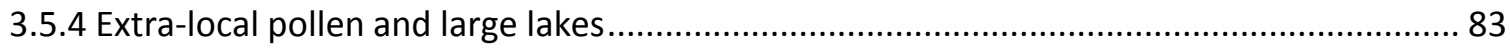

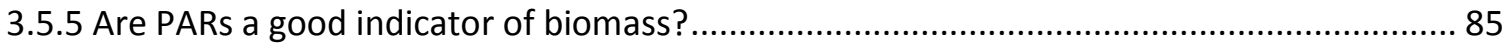

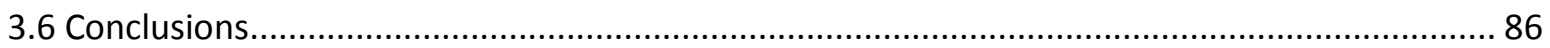

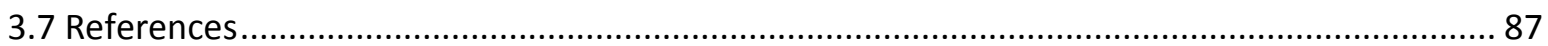

Supplementary material: Absolute pollen productivity estimates .............................................. 91

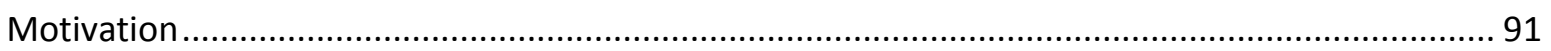

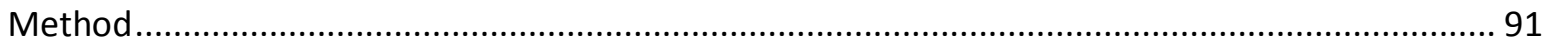

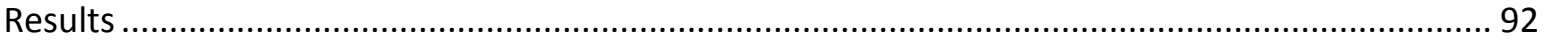

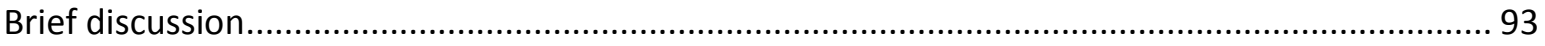

Differences in aPPEs between 1993 and 2009 and the DWPA ................................................. 93

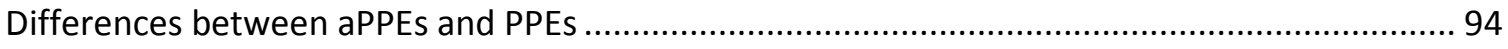

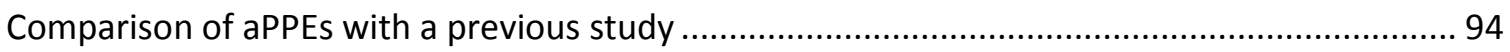

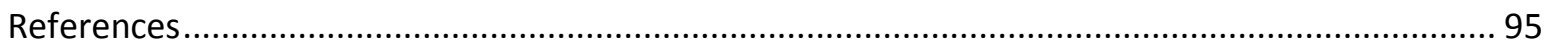

\section{Chapter 4}

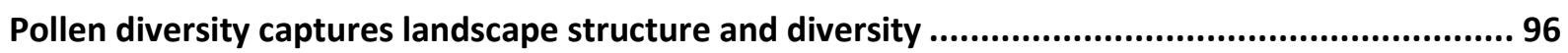

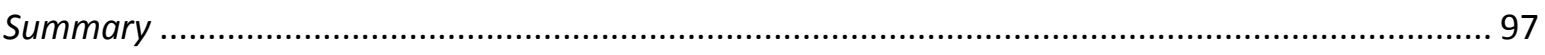

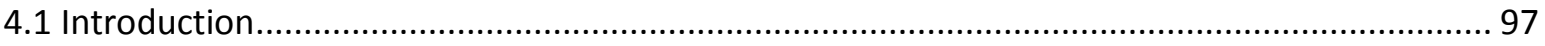

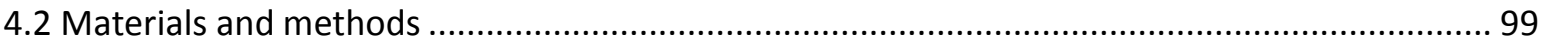

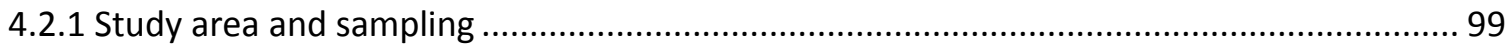

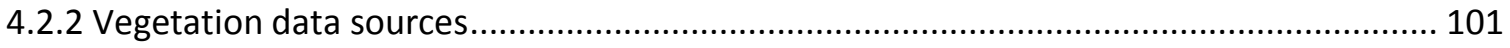

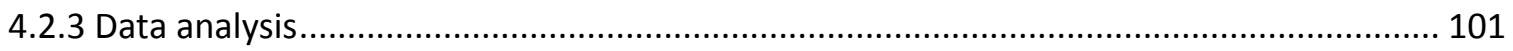



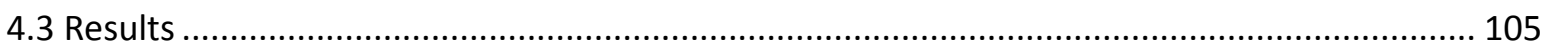

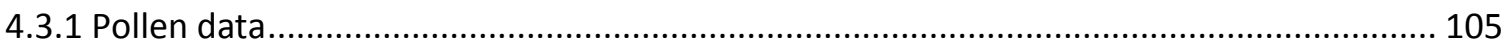




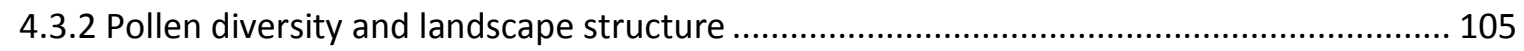

4.3.3 Comparisons of restricted and adjusted pollen data ......................................................... 107

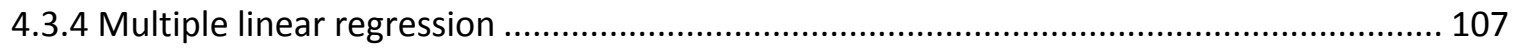

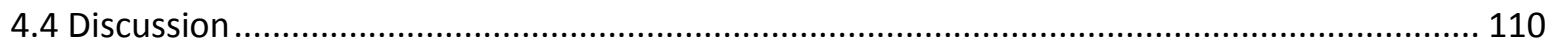

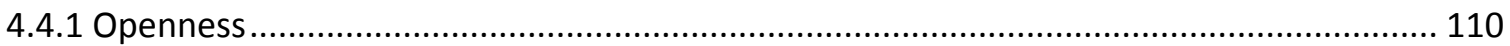

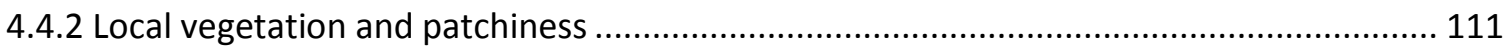

4.4.3 Adjusting for pollination mode and production dispersal bias ......................................... 111

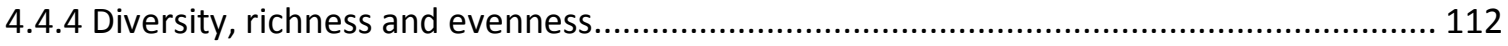

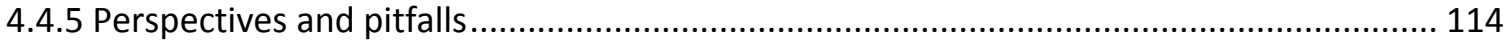

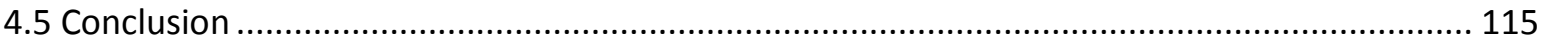



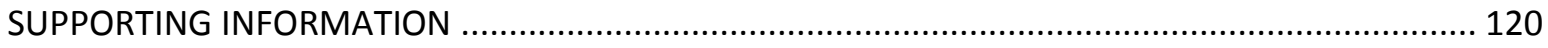

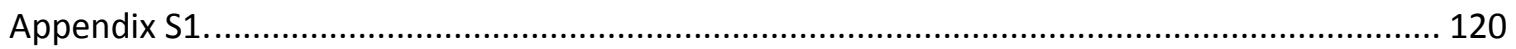



\section{Chapter 5}

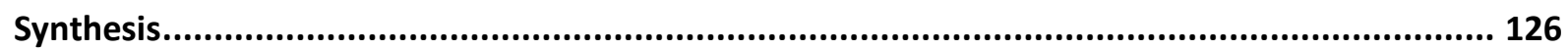

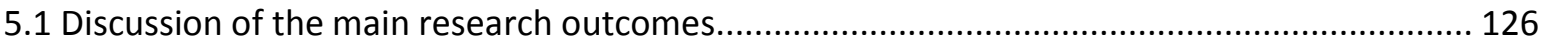

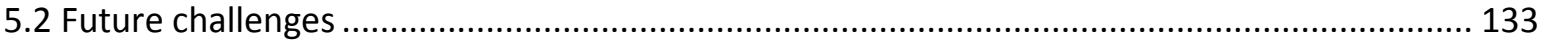

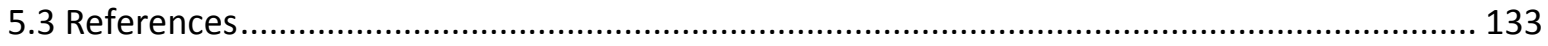

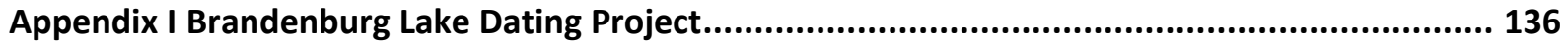

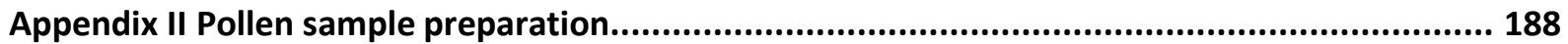




\section{Acknowledgements}

The last years I have passed working on my Ph.D. thesis have been a very intensive time for me, gaining new experience in scientific work and learning to manage new challenges and overcoming difficult phases. This work would have never been finalized without the help and motivation from different people I want to thank here.

First of all I will give my biggest thanks to my first supervisor Dr. Thomas Giesecke, who introduced me into quantitative vegetation reconstructions and encouraged me to continue discovering further aspects in the theory of pollen analysis. Thank you for your patience and the fruitful discussions that contribute to my thesis! I would also like to thank my second supervisor Prof. Dr. Hermann Behling, who always motivated me in my work and gave me advice for preparing the $\mathrm{PhD}$ thesis.

I would like to thank the DFG for funding the project "Quantitative reconstructions of past land cover change - A basis for evaluating consequences of Global change for vegetation" that formed the framework for my position and my thesis. I am very grateful to the Faculty of Biology and Psychology and to the Albrecht-von-Haller-Institute for Plant Sciences for providing a completion scholarship.

Thanks to Prof. Dr. Bent Odgaard for letting me use the HON-Kajak sediment corer. A lot of thanks go to Dr. Anne Birgitte Nielsen for assisting in the field and her great advises in handling pollen data for relative pollen production estimates. Many thanks to Prof. Dr. Shinya Sugita who always took time answering my questions about the LRA and providing his programs. Thanks to Sabine Busch (Landesbetriebes Forst Brandenburg) and Ralf Köhler (Landesumweltamt in Brandenburg) for the support in getting licenses for the field work. The work would have never been conducted without the availability of forest inventory data with the aid of Konrad Müller (Landesbetrieb Forst Brandenburg) and Georg Balk (Bundesanstalt für Immobilienaufgaben), and many other foresters who helped me collecting forest inventory data, thank you! Special thanks go to Martin Theuerkauf for helping to handle the forest inventory data and being a good partner for discussions about pollen production, dispersal, and deposition. Many thanks to the Department of Landscape Ecology in Göttingen for the free use of the lab where I could prepare my samples for the ${ }^{210} \mathrm{~Pb}$-dating, with special thanks to Dr. Jürgen Grotheer, Petra Voigt, and Anja Södje who advised me in the lab. Thanks a lot to my student assistants Jonas Müller and Lars Schmidt for their work, digitizing old forest maps, and helping in the organisation of getting data. Thanks a lot to Uta Nüsse-Hahne, who helped me to prepare samples for pollen analysis and Ursula Grothmann for her advises in administrative questions. 
I would like to thank a lot the entire staff of the Department of Palynology and Climate Dynamics for their help and motivation to finalize this thesis. Special thanks go to my colleagues Dr. Waheed Murad and Malte Semmler for sharing the office and spending a great time. A very special word of thanks goes to Dr. Jörg Christiansen for the support with running my computer all the time and to Dr. Barbara Hermanowski for introducing me to Illustrator and Photoshop and her patience and open ear in difficult stages. I would like to thank Dr. Vivian Jeske-Pieruschka for her positive infectious atmosphere and her encouragement to continue the work. Thanks a lot to Dr. Nele Jantz, Dr. Lisa Schüler and Inke Achterberg for their open ear and their helpful advises.

I am very thankful to my wonderful neighbours Nira, Sophie, Jens, Made, and Putu for the great relaxing time, especially thanks to Nira who always takes time caring Karl in emergency cases.

Thanks to Anna, Dorothee, Alex, Sandra, Lisa, Babsi, Franzi, Karin, Jessi and Stefan, Michel, Alexandra, Anne and Dirk, Ella, Smara, Steffi, Wiebke and Tobi, Stefan, Hannes and Anna, Katrin, and Martin, Hermann and Uli, Lea and Toni, Jenny, Dany and Jan, Caren and Benedikt, Fancis and Nadine, Julia and Sven, Malte, Caro, Steffen and Gundula for your friendship and your help and strength you gave me all the time.

Thanks a lot to my family, my parents Carmen and Ulrich, my sisters Johanna and Laura, my aunt and uncle Margret and Jürgen and my grandmother Hildegard. They always believed in me and gave me strength in managing all steps in my life. My greatest thanks go to my partner Pierre and my son Karl who enriched and fulfilled my life.

Thank you all! 


\section{Preface}

This Ph.D. thesis was prepared in the Department of Palynology and Climate Dynamics at the GeorgAugust Universität, Göttingen, between April 2009 and June 2014. The thesis was arranged as a cumulative work and consists of three scientific manuscripts that were prepared for publishing in international scientific journals (peer-review). Please note that the respective publisher holds the following articles copyright.

- First manuscript (chapter 2): Matthias, I., Nielsen, A.B. and T. Giesecke (2012): Evaluating the effect of flowering age and forest structure on pollen productivity estimates. Vegetation History and Archaeobotany, 21: 471-484.

- Second manuscript (chapter 3): Matthias, I. and T. Giesecke (2014): Insights into pollen source area, transport and deposition from modern pollen accumulation rates in lake sediments. Quaternary Science Reviews, 87: 12-23.

- Third manuscript (chapter 4): Matthias, I., Semmler, M.S.S. and T. Giesecke (2015): Pollen diversity captures landscape structure and diversity. Journal of Ecology, DOI: 10.1111/13652745.12404

Additional material and results are presented that are connected to the second manuscript. The Ph.D project was initiated by Dr. Thomas Giesecke and formed part of the Emmy-Noether-project (DFG): "Quantitative reconstructions of past land cover change - A basis for evaluating consequences of Global change for vegetation". The first and second manuscripts follow the questions outlined in the original proposal. However, in both cases I was able to find new aspects and detailed questions which I addressed in these manuscripts. I developed the scope of the third manuscript. I conducted the analyses that are considered in the papers and in this thesis, except the analysis for the Tegeler See presented in the last manuscript. I developed and led the writing of the manuscripts. The manuscripts are arranged similar to the layout of a single journal. The reference style follows the formatting guide and varies between the chapters in which the manuscripts for publishing are presented, only the numbering of the headings was aligned throughout the whole thesis.

Additionally, the thesis offers in the first part a general introduction into the topic, introduces the aims and scopes of the thesis and describes the used material and methods. After that the manuscripts and the supplementary material to the second manuscript are presented. The final part of the thesis consists of a synthesis in which the results of the manuscripts are summarized and discussed. This is a revised version including changes of the third manuscript as well as updates of points arisen during and since the defence in July 2014. 


\section{Summary}

Since the introduction of pollen analysis for vegetation reconstruction, scientists have been concerned about the influence of different pollen productivities of individual taxa. A second long standing question focuses on the special extent represented by the pollen content of a sample. In addressing these two questions, surface samples were collected from lake sediments in Brandenburg (NE-Germany) and compared with vegetation data from a forest inventory database and a biotope mapping. In addition to pollen percentages, pollen accumulation rates (PAR) obtained from ${ }^{210} \mathrm{~Pb}$ dated short sediment cores were used in the comparison.

Important results of this thesis are relative and absolute pollen productivity estimates (PPE and aPPE). PPEs describe the pollen production of the different taxa relative to a reference taxon, and aPPEs estimate the production per unit of vegetation, in this case per standing volume. The results demonstrate for Pinus and Fagus similar PPE-values and show that the obtained PPEs for Brandenburg are in general similar to values that were calculated in earlier studies for different regions. However, the obtained aPPE values are much higher compared to a study from northern Finland, where the value for Pinus is ten times lower than the one from Brandenburg. These differences might be explained by a higher net primary production of the same biomass in Central Europe. In addition, the effects of flowering age and forest structure on PPE calculations were evaluated. Results show the strongest influence for slow growing and/or late flowering trees like Fagus and Carpinus and a minimal effect for species that start flowering early in their development as Betula and Alnus do.

In order to estimate the relative and absolute PPEs, it is necessary to determine a particular area on the site for which the vegetation can be compared to the pollen. For the relative PPE this is termed the "relevant source area of pollen" (RSAP). The RSAP is defined as the area where pollen percentage data and vegetation data fit to each other best and the fit does not improve when considering the vegetation over a larger area. The obtained RSAP of seven kilometres is larger than in similar studies. This can be explained by the landscape structure, which is in Brandenburg characterised by large vegetation patches that are determined by the different soil substrates left by the last glaciation. The results of the thesis demonstrate for the first time that PAR of the major tree taxa are linearly related to the biomass surrounding the lake, as is generally assumed. In contrary to the RSAP the source area that explains most of the variation of PAR ranges between a few hundred metres up to 2.5 kilometres from the lake basin. This area varies between the taxa, due to differences in pollen dispersal and individual abundance patterns. The finding that a large amount of pollen in small lakes 
originates from the nearby vegetation confirms earlier considerations which defined this as the "trunk space" component. Currently used pollen dispersal models largely ignore this component and by empirically demonstrating its importance, this study contributes to refining these models.

The collected datasets were further used to compare different measures of pollen diversity to aspects of landscape diversity. While nearby vegetation determines mainly the pollen diversity, "palynological richness" is influenced by a larger area of at least seven kilometres. The evenness of pollen grains might be described by the ratio between pollen diversity and "palynological richness", where a higher number would suggest a higher evenness of distribution of the taxa and vice versa. The results of this thesis demonstrate that the relevant area for a pollen sample depends on the question that is asked of the data. The wider area around the site is desrcibed by the pollen percentage composition and pollen type richness, while PARs and pollen-type diversity reflect the nearby vegetation abundance and diversity. 


\section{Zusammenfassung}

Seit der Einführung der Pollenanalyse für Rekonstruktionen vergangener Vegetationsbedeckung befassen sich Wissenschaftler mit dem Einfluss von unterschiedlichen Pollenproduktionen der verschiedenen Arten sowie der Fragestellung, wie welches Gebiet in den Pollendaten widergespiegelt und interpretiert werden kann. Ziel dieser Arbeit war es den Zusammenhang zwischen Pollen und Vegetation weiter zu untersuchen. Dazu wurden Pollendaten von Oberflächenproben aus Brandenburger Seesedimenten sowie Pollenakkumulationsraten (PAR) von bleidatierten Sedimentkurzkernen mit Vegetationsdaten aus Waldinventurdaten und Biotopkartierungen verglichen.

Zu den wichtigen Ergebnissen der vorliegenden Arbeit gehören die Berechnungen von relativen und absoluten Pollenproduktionsraten (PPE und aPPE). Während die PPEs die verhältnismäßige Pollenproduktion der Arten zu einem Referenztaxon beschreiben, ist unter den aPPEs die Pollenproduktion pro Vegetationseinheit, in diesem Fall pro $\mathrm{m}^{3}$ (Biomasse), zu verstehen. Die Ergebnisse zeigen gleich hohe PPE-Werte für Fagus und Pinus und bestätigen im Allgemeinen die PPE-Werte aus Studien, die für andere Regionen Europas erhoben wurden. Die berechneten aPPEWerte unterscheiden sich dagegen deutlich von den aPPE-Werten in Finnland, wo die aPPE für Pinus um ein zehnfaches geringer ist als in Brandenburg. Dieser Unterschied lässt sich möglicherweise mit einer höheren Nettoprimärproduktion der gleichen Biomasse in Zentraleuropa erklären. Darüber hinaus wurde der Einfluss von Blühalter und Waldstruktur auf PPE Berechnungen evaluiert. Die Ergebnisse zeigen, dass die Berücksichtigung beider Faktoren den größten Einfluss auf die Baumarten hat, die relativ spät den Kronenbereich bzw. ihr Blühalter erreichen, wie z.B. Fagus und Carpinus. Der geringste Einfluss dieser Faktoren zeigt sich für Arten, die bereits nach wenigen Jahren mit der Pollenproduktion beginnen, wie z.B. Betula und Alnus.

Für die Berechnung von PPEs und aPPEs muss ein Gebiet um den See (oder das Moor) ermittelt werden, in dem die Pollendaten mit der Vegetation verglichen werden können. Dieses Gebiet für die Berechnung von PPEs wird als "relevant source area of pollen“ (RSAP) bezeichnet. Die RSAP ist definiert als das Gebiet, in dem Pollenprozentdaten und Vegetationsprozentdaten den stärksten Zusammenhang zueinander aufweisen und es zu keiner besseren Korrelation der beiden Variablen in einer weiteren Distanz kommt. Die hier ermittelte RSAP für Brandenburg liegt bei sieben Kilometern und ist damit im Vergleich zu den meisten vorherigen Studien relativ groß. Diese relativ große RSAP lässt sich durch die Quartäre Landschaftsstruktur in Brandenburg erklären, welche durch großräumige Bestände einer Art oder Artenzusammensetzung charakterisiert ist. Des Weiteren zeigen die Ergebnisse dieser Arbeit erstmals, dass PAR für die einzelnen Hauptbaumarten in einem 
linearen Zusammenhang mit der seeumgebenen Biomasse stehen. Im Gegensatz zu der RSAP ist das Gebiet, welches am stärksten die Variationen der PAR erklärt, relativ klein und erstreckt sich von wenigen Metern bis maximal 2,5 Kilometer vom Seeufer. Die Größe dieses Gebiets variiert zwischen den Arten, was mit der Verbreitung des Pollens und der Abundanz der einzelnen Arten erklärt werden kann. Die Beobachtung, dass der Großteil des Pollens von der nahen Vegetation kommt, bestätigt den Einfluss einer „trunk space“-Komponente eines früheren konzeptuellen Pollenverbreitungsmodells. Die heute genutzten mathematischen Pollenverbreitungsmodelle berücksichtigen diese Komponente jedoch nicht. Nach den Erkenntnissen dieser Studie würde die Berücksichtigung dieser Komponente jedoch zu einer Verbesserung der angewandten Pollenverbreitungsmodelle führen.

Die oben genannten Datensätze wurden darüber hinaus für Vergleiche von verschiedenen Pollendiversitätsindexen mit Aspekten der Diversität der Landschaft genutzt. Die Ergebnisse zeigen, dass die Diversität der Pollen zu einem großen Teil mit der Diversität der Landschaft innerhalb eines Kilometers um den See herum erklärt werden kann. Während die nahe Vegetation hauptsächlich die Diversität erklärt, welche sich aus der Anzahl der Arten und deren Abundanz zusammensetzt, ist die „Palynological richness" von einem größeren Gebiet beeinflusst (sieben Kilometer). Die Gleichverteilung von Pollenkörnen kann somit durch das Verhältnis zwischen der Diversität der Pollen und der „Palynological richness" beschrieben werden, in dem ein größerer Wert eine größere Gleichverteilung der Arten beschreibt und umgekehrt.

Die Ergebnisse dieser Doktorarbeit zeigen, dass die Pollendaten in Abhängigkeit zur Fragestellung ein unterschiedlich großes Einzugsgebiet widerspiegeln. Ein größeres Einzugsgebiet der Pollen wird durch die Komposition der Pollenprozentdaten sowie der Anzahl der Pollentypen beschrieben. Die absolute Abundanz sowie die Diversität der ufernahen Vegetation kann dagegen durch PARs und die Diversität der Pollen interpretiert werden. 


\section{Chapter 1}

\section{Introduction}

Pollen analysis was introduced as an instrument for past vegetation reconstructions from fossil pollen sediment samples nearly 100 years ago (von Post, 1918). Since the beginning, studies focused on the question of the origin of pollen and how local and regional vegetation is reflected in lake or mire sediments (e.g. Tauber, 1965; Jacobson and Bradshaw 1981, Bradshaw and Webb, 1985, Janssen 1966; Jackson 1990, Davis 2000). Since that time results from different studies have contributed to the understanding of the theory of pollen production, dispersal and deposition (e.g. Tauber, 1965; Anderson, 1970; Prentice, 1988).

\subsection{Theory of pollen analysis}

\subsubsection{Percentage data and relative pollen production rates}

The production of pollen varies between different species which consequently effects the representation of pollen data in a percentage diagram. Whereas high pollen producers are generally overrepresented in a pollen percentage diagram, low pollen producers (including insect pollinated taxa) are generally underrepresented (e.g. Davis, 1963; Odgaard, 1999; Weng et al., 2006). Further, if the abundance of one taxon increases in percentage values also the abundance of the remaining taxa shift to a different value even if their absolute abundances did not change. The closure effect of percentage data is strongest when a high pollen producer supresses a low pollen producer (Fagerlind, 1952). This non-linearity between pollen percentage and vegetation percentage cover is called the "Fagerlind effect". However, to correct reduce the over and underrepresentation of the taxa, Davis (1963) introduced the idea of the R-value, in which percentage abundances of pollen taxa are corrected by relative pollen production estimates (PPE) which are related to a reference taxon that is set to have a pollen production of one. Nevertheless, the calculated R-values vary widely between sites (Parsons and Prentice, 1981; Broström et al., 2008). The difficulty for the R-value was the determination of a source area of pollen. Andersen (1970) introduced the idea of a background component (or "representation factor"), with that the regional pollen loading is considered and reduces site to site variations but it does not solve the non-linearity between pollen-vegetation data. However, a background component was considered in the more sophisticated extended R-value (ERV) models 1, 2, and 3. In these models the aspect of the non-linearity between pollen and vegetation data was considered using different weightings (Parsons and Prentice, 1981; Prentice and Parsons, 1983; Sugita, 1994). The ERV models vary mainly in their handling of the background 
component, keeping the background variable adjusted or fixed for the pollen or vegetation data (Parsons and Prentice, 1981; Prentice and Parsons, 1983; Sugita, 1994):

- ERV model 1: ERV 1 adjusts the percentage proportion of the vegetation, using a constant background pollen loading in proportion to the total pollen loading at the pollen sample (Parsons and Prentice, 1981).

- ERV model 2: ERV 2 adjusts pollen proportions using a species-specific background loading (Prentice and Parsons, 1983).

- ERV model 3: pollen data are adjusted similar to ERV 2. The advantage of the ERV 3 is that vegetation abundances are used in absolute terms. This model calculates pollen productivity and background loading without additional assumptions (Sugita, 1994).

\subsubsection{Pollen dispersal}

A first conceptual model that considers aspects of pollen loading deriving from forest vegetation into lake basins was designed by Tauber (1965). The model consists of three main components: Pollen that is transported within the trunk space $\left(C_{t}\right)$, above the canopy $\left(C_{c}\right)$ and deposited by the rainout $\left(C_{r}\right)$ (Tauber, 1965). Furthermore, a waterborne component $\left(C_{w}\right)$ is included that might be important for some lakes (Tauber, 1977; Bonny, 1980). Further studies that focused on the pollen-vegetation relationship suggest that the source area of pollen is influenced by the size of the lake (e.g. Jakobson and Bradshaw 1981; Bradshaw and Webb, 1985). Jacobson and Bradshaw (1981) proposed a model that shows the importance of pollen loading deriving from local, extra local and a regional sources and its importance with regard to lake size. With increasing basin size more pollen from regional sources is reflected in a pollen sample, whereas pollen assemblages of small basins are more affected by local vegetation (Jacobson and Bradshaw, 1981; Bradshaw and Webb, 1985; Sugita, 1993). Most pollen grains in forest hollows derive from vegetation within a distance of a few hundred meters (Jacobson and Bradshaw, 1981). However, the pollen source is also influenced by different wind velocities (e.g. Tauber, 1965; Andersen, 1974). Thus, pollen grains from herbs are more limited in their dispersal efficiency in forest stands compared to an open area because of lower wind-velocities within the trunk space layer and/or the filtration efficiency of twigs and leaves (e.g. Andersen, 1970; Raynor et al., 1974; Tauber, 1965, 1977). Further, fall speed varies between pollen types, because of different size and shapes (Eisenhut, 1961; Gregory, 1973) and single pollen types differ in transport and dispersal efficiency (e.g. Sugita, 1993; Jackson, 1990). In general, smaller pollen grains are assumed to travel across larger distances than pollen grains of larger size (e.g. Tauber, 1965; Prentice, 1985; Sugita, 1993). 


\subsubsection{Distance-weighted plant abundance}

Pollen of sediment samples is a distance-weighted measure of plant abundance (DWPA). In general, more pollen is deposited in the catchment basin (or deposition point) from the closer surroundings than from distant vegetation (Prentice, 1988; Sugita, 1993; Davis, 2000). The importance of local vegetation is demonstrated in the simulation from Magraret B. Davis (Davis, 2000). Introducing DWPA aimed for handling vegetation in its relationship to the pollen loading of a sediment basin. With the simple DWPA, the mean vegetation abundance for different distances can be weighted according either to the mean distance to the lake $(1 / d)$ or to the square of the mean distance $\left(1 / d^{2}\right)$ (e.g. Schwartz, 1989; Calcote, 1995). A further and a more complex DWPA model is the Prentice model (Prentice, 1985, 1988). It considers aspects of pollen production, spatial distribution of vegetation and pollen dispersal (fall velocity of pollen and the wind velocity of the study area).The latter is based on Sutton's equation (Sutton, 1953) and considers only pollen loading deriving from above the canopy layer (Prentice, 1985). The Prentice model describes the pollen loading to a point and is therefore appropriate for pollen deposition calculations in bogs and fens (Sugita, 1994). This model was developed in the Prentice-Sugita model which additionally considers the size of a basin. This model, which assumes a complete mixture of the received pollen, integrates the pollen loading over the lake basin and is therefore suitable to predict the pollen loading of lakes (Sugita, 1994; Sugita et al., 1999).

\subsubsection{Relevant Source Area of Pollen}

The goodness of fit between pollen and vegetation data increases with an increasing distance of the vegetation up to a distance where no further improvements can be achieved. The distance at which the relationship between pollen and vegetation (distance weighted) shows no further improvement is described as the "relevant source area of pollen" (RSAP) (Sugita, 1994). The size of the RSAP is influenced by basin size, characteristics of the pollen-type (e.g. size), and vegetation patchiness (Sugita, 1994). Because of the best pollen-vegetation composition relationship in this area, vegetation within the RSAP has been used for PPEs calculations (e.g. Nielsen, 2003; Soepboer et al., 2007; Mazier et al., 2008).

During the last decade, several studies were conducted to calculate PPEs. As a result PPEs based on lake and moss samples were realized. For northern Europe this has been carried out for e.g. Norway (Hjelle, 1998), Finland (Räsänen et al., 2007), Denmark (Nielsen, 2003), Sweden (Broström et al., 2004; von Stedingk et al., 2008), Mecklenburg-Vorpommern (Theuerkauf et al., 2013), and England (Bunting et al., 2005). For Eastern Europe, studies have been conducted in Estonia (Poska et al., 2011) and the Czech Republic (Abraham and Kozáková, 2012) and for Central Europe in the Swiss 
Jura (Mazier et al., 2008) and the Swiss plateau (Soepboer et al., 2007). The results for PPEs vary between the studies. These variations are explained by e.g. different climate conditions, soils, plant succession or human impact (Broström et al., 2008; Hjelle and Sugita, 2012; Abraham and Kozáková, 2012).

\subsubsection{REVEALS and LOVE}

The Regional Estimates of Vegetation Abundance from Large Sites model (REVEALS model) and the Local Vegetation Estimates model (LOVE model) have been developed for the Landscape Reconstruction Algorithm (LRA) (Sugita, 2007a, 2007b). Within these models both, the correction of relative pollen production based on the ERVs and the dispersal functions of the pollen to the basin (e.g. Prentice-Sugita model), are considered. The REVEALS model is most suitable to reconstruct regional vegetation composition, and is based on large lakes of $>=100$ ha (Sugita, 2007a). The LOVE model was developed to reconstruct vegetation composition of the local vegetation from pollen of small lakes, where the background loading is required from calculations of large lake(s) of the REVEALS model (Sugita, 2007b).

The evaluation of the REVEALS model with recent material has demonstrated the adjustment of the pollen data to be more accurate than pollen percentage data (Hellmann et al., 2008; Sugita et al., 2010a). Therefore, the models have been applied to past vegetation reconstructions (e.g. Cui et al., 2013; Fredh et al., 2012).

\subsubsection{Pollen accumulation rate}

Pollen percentage data are biased in in the above described way with respect to absolute vegetation abundance (e.g. Davis and Deevey, 1964; Prentice, 1988; Giesecke and Fontana, 2008). Pollen accumulation rate (PAR) describe the accumulated pollen on a defined area within a defined time (e.g. Prentice, 1988; Seppä et al., 2009) expressed as grains* $\mathrm{cm}^{-2 *} \mathrm{a}^{-1}$. PARs are independent and might be useful as indicators for abundances of single taxa (Davis and Deevey, 1964), if the accumulation of pollen is understood (Davis and Deevey, 1964; Davis, 1967a).

The use of PARs for past vegetation estimates was first proposed by Welten (1944). He calculates PARs from laminated lake sediments and compares the PAR values from the Betula-Pinus-Period with values to PARs in peat samples located at a present Betula-Pinus-area (Finland/Lapland), and obtained similar values. Further, he supports the idea that an increasing PAR is not only influenced by a larger abundance of a certain tree but also by a larger pollen production of the same tree because of "better" climate conditions (Welten, 1944).

Studies on PARs have been limited due to the availability of laminated lakes. Therefore, PARs for different vegetation types in different climate zones were observed from pollen traps, to understand 
past PAR (e.g. Hicks, 1992; Hicks et al., 2001). However, with the development of the radio carbon dating technique in the 1950ies (Libby, 1955) PARs for non-laminated lake sediments could be calculated. This was first applied for the Rogers Lake, Connecticut (Davis and Deevey, 1964). The information of PARs from the obtained lakes does not contradict the information of the pollen percentage data and was therefore proposed as a measurement for further palynological information of past vegetation abundance (Davis and Deevey, 1964; Davis, 1967a).

\subsubsection{Lake internal processes}

Nevertheless pollen deposition in a lake might be biased by different lake internal processes. To reveal how pollen is deposited in a basin, several studies were realized discovering the nature of pollen deposition in lakes and their variances and determining factors (e.g. Davis and Burbaker, 1973; Pennington, 1973; Bonny, 1980; Beaudin and Reasoner, 1992). The results demonstrate that sedimentation is influenced by lake size (e.g. Davis 1967b; Pennington, 1973) as well as by the morphometry of the lake (Pennington, 1973). Furthermore, pollen composition and accumulation in shallower water close to the lakeshore are more influenced by lakeshore vegetation compared to the pollen signal in deeper and more central parts of the lake (Bonny, 1978). The importance of pollen inflow from streams and surface run-off to the basin was demonstrated by the installation of pollen sedimentation traps in two lakes. They showed an influence of these components up to $89 \%$ (Bonny, 1976). Based on pollen data from sediment traps at Frains Lake (Davis and Brubaker, 1973) it was further observed that pollen morphology influences the deposition of a pollen grain. Whereas Quercus pollen sank rapidly through the water column in the centre of the basin, higher accumulation of Ambrosia pollen occurs at the lakeshore, affected by wind patterns (Davis and Burbaker, 1973). However, the transport of littoral sediment to the centre of the lake reduces the difference between pollen sorting. Additionally, annual variation of pollen and sediment inputs is reduced by the mixing of pollen with "older" sediments (Davis, 1973). Further studies focusing on lake sedimentation rates address the problem of inhomogeneous sedimentation within a lake and demonstrate sediment focusing, which describes a higher sedimentation rate in some parts (mostly deepest) of a lake and a different collection of sediment (e.g. Likens and Davis, 1975; Odgaard, 1993; Davis et al., 1984).

\subsubsection{Calibration of PAR and vegetation abundance}

For the first attempt to calibrate PARs from lake sediments utilizing tree abundance, 29 lakes of different sizes within different vegetation pattern were chosen (Davis et al., 1973). The results indicate a general trend between tree population dominance and PAR, but with a weak relationship between species abundance and corresponding PAR (Davis et al., 1973). The lacking relationship was 
attributed to the use of limited and insufficient vegetation data (Davis et al., 1973). However, lake internal processes such as sediment focussing were later proposed as the general limiting factor using PARs as a direct measurement of plant abundances (Davis, 2000).

However, within the framework of the Pollen Monitoring Program (PMP), PARs for different taxa were monitored for a longer time span and an area reaching from north eastern to south eastern parts of Europe (Hicks et al., 2001; Giesecke et al., 2010). Results observed from Tauber traps as well as from surface sediments suggest threshold values of PARs for different abundances of trees (e.g. Hicks, 2001; Seppä and Hicks, 2006), and absolute pollen productivity estimates (aPPE) based on PARs from Tauber traps could be realized (Sugita et al., 2010b).

Younger studies have encouraged the use of PARs from lake sediments as direct measurements for vegetation abundance. They demonstrate, that PARs from lake surface samples are comparable with observed values from Tauber traps (Seppä and Hicks, 2006; Giesecke and Fontana, 2008) and can be used to define specific threshold values for the abundances of different tree taxa (e.g. Seppä and Hicks, 2006; Seppä et al., 2009). When using PARs from lake sediments as quantitative measurements for past vegetation, recent PARs for the single taxa need to be correlated with quantitative vegetation data of the same time. So far only one study compared PARs from lake sediments with the absolute abundance of trees of the corresponding time span in two lakes (Seppä et al., 2009).

\subsubsection{Diversity of pollen}

Scientists are simulating future scenarios of climate change focusing on the change of biodiversity under different conditions (Thomas et al., 2004; Thuiller et al., 2005; Dawson et al., 2011). Here, palaeoecological studies are a useful tool for understanding the past and to give insights into future development, which can be used for ecosystem management strategies (Willis et al., 2010). Reconstruction of past vegetation and landscape diversity based on palynological analysis is limited by at least three major factors: First, the lag of taxonomy in palynological analyses and the connected limited reflection of species richness, second the bias in reflecting vegetation abundance, and third the source area of pollen (Giesecke et al., 2014).

However, pollen analytical results have documented that the number of different pollen types per sample varies through time (e.g. Tinner et al., 1999; Giesecke et al., 2012; Colombaroli et al., 2013). It could be demonstrated that an increase of palynological richness can be connected with early human impact on landscape (Poska et al., 2004; Colombaroli and Tinner, 2013). Further, the data suggest that highest pollen diversity is connected to intermediate values of landscape disturbance (Odgaard, 1994; Colombaroli et al., 2013; Colombaroli and Tinner, 2013). According to the measurement of pollen diversity, it is assumed that the number of pollen taxa in samples alone will provide a measure 
of palynological richness, if samples are based on a standardised number of pollen grains or using rarefaction analyses (Birks and Line, 1992). Further, Odgaard (2008) introduced the idea of evenness within pollen samples and proposed the use of rarefaction-analysis to small pollen counts as a measurement for this indicator. Additional, the inverse slope of the log abundance on the rank of abundance, which has relatively large independence from other measures (Smith and Wilson, 1996) was applied to estimate pollen evenness (Giesecke et al., 2012). This index can be visually exanimated and flexibly applied by restricting it to the abundance of taxa that exceeding a set threshold in the sample and makes it interesting for pollen data (Giesecke et al., 2014).

\subsubsection{Diversity indices and pollen data}

Most of the common used vegetation diversity estimates like the Shannon-Index are based on the number of taxa as well as on their relative abundance (Hill, 1973; Tuomisto, 2012). These indices have been assumed to be insufficient for palynological diversity estimates because of the mentioned biases in pollen production, transport, and deposition (Birks and Line, 1992). Regarding to the drawback of the lack in taxonomic identification in pollen analysis (e.g. Odgaard, 2007) it was demonstrated that determination to higher taxonomic levels is sufficient for estimating floristic richness (Mazaris et al., 2010). In tropical forests with a high diversity of plant families, the family level may be adequate to evaluate diversity based on pollen (Jantz et al., 2014). Thus taxonomic precision might not to be the limiting factor for palynology diversity estimates. A further limitation of pollen data is their reflection of vegetation abundance because of the biases through pollen production, transport, and deposition (Odgaard, 1999; Birks and Line, 1992). However, differential pollen production also affects the probability of detecting new pollen taxa in a given count and thus palynological richness (Weng et al., 2006; Giesecke et al., 2014). Further, if a low pollen producer e.g. Tilia is replaced by a high pollen producer e.g. Pinus the proportion of all other pollen taxa in the sample will be affected, regardless of an actual change of these taxa in the vegetation (Fagerlind, 1952). Finally, the source area of pollen is affected by lake size (Bradshaw and Webb, 1985; Sugita, 1993) and transport efficiency of single pollen types (e.g. Sugita, 1993). Pollen from vegetation in a close distance to a lake basin is better reflected than vegetation further away (Davis, 2000; Matthias and Giesecke, 2014). As mentioned above, models have been developed during the last decades to reduce the bias of pollen production, transport, and deposition. Therefore, the extended R-values (ERV) can be used to calculate relative PPE and which reduces the bias caused by different pollen production rates (Parsons and Prentice, 1981; Prentice and Parsons, 1983; Sugita, 1994). The bias in pollen production, transport and deposition can be limited using the REVEALS and LOVE model (Sugita 2007a, 2007b). If pollen abundances are equal to vegetation abundances, direct diversity estimates using the e.g. Shannon-Index are possible, at least for taxa that are reflected in the pollen 
assemblage. First studies have been conducted for past vegetation diversity reconstructions, based on "corrected/transformed" pollen data (Fredh et al., 2012; Marquer et al., 2014).

Recently only few studies were realized comparing pollen diversity in modern samples with contemporaneous vegetation or landscape diversity (e.g. Meltsov et al., 2011; Meltsov et al., 2013; Goring et al., 2013), with different results. Whereas Meltsov et al. (2013) show a positive correlation between palynological richness to floristic richness and the importance of openland, Goring et al. (2013) show no relationship between pollen and vegetation diversity. Studies comparing floristic and palynological richness are limited by the availability of detailed vegetation data or assessment of species diversity across small scaled landscape units, covering a large area (Meltsov et al., 2011; Meltsov et al., 2013; Goring et al., 2013).

\subsection{Aims and objects of the thesis}

Studies that focused on the understanding of pollen and vegetation relationships have revealed many aspects and lead to the developed of models capturing pollen production, dispersal and deposition. However, so far not all factors concerning the pollen-vegetation relationship have been understood. Many questions concerning the theory of pollen analysis remain open. This thesis therefore aims to increase our understanding of the pollen-vegetation relationship which has implications for our ability obtaining quantitative vegetation reconstructions.

\section{Pollen productivity estimates}

Variations of PPEs between studies are explained by e.g. different climatic conditions and soil types (e.g. Broström et al., 2008). However, PPE calculations are based on different types of datasets (e.g. Soepboer et al., 2007; Mazier et al., 2008; Poska et al., 2011). The information potential of aerial photographs or satellite images of vegetation is restricted to the canopy layer and limited by the flowering age of trees. Vegetation documentation in the field is further hampered due to difficulties in determining the ages of trees and forest stands and their ability to produce pollen. Further, if PPEs change through time due to climatic variations (Broström et al., 2008) a large number of PPE calculations within different climate settings are helpful as they can provide an understanding of the influencing factor(s). This enriches the quality of data for past vegetation reconstructions and interpretations. In accordance with the above statements this thesis aims:

- To estimate the RSAP for small to medium sized lakes in Brandenburg, northeast Germany.

- To calculate PPEs for the major taxa in the study area.

- To compare PPEs from Brandenburg with results from other studies and discuss differences between the studies and their possible underlying reasons.

- To reveal the effect of flowering age and forest structure on PPE variations. 


\section{Pollen accumulation rates and absolute pollen productivity estimates}

First calculations for absolute pollen productivities (aPPE) were realized for three taxa (Pinus, Picea and Betula), based on PARs in Tauber traps in the northern border of Finland and the Arctic Circle (Sugita et al., 2010b). However, little is known about how PARs from lake sediments are related to the plant abundance around a site. Although a linear relationship between PAR and vegetation abundance is assumed this has never been shown for PARs obtained from sediments. The only study that compares PARs from lake sediments with vegetation data shows no linear relationship (Davis et al., 1973). This was explained by insufficient vegetation data (Davis et al., 1973). The bias of sediment focussing and lake internal deposition processes were discussed as further reasons (Davis, 2000). Since the first attempt in 1973 (Davis et al., 1973), no studies were conducted to reveal which factor has limited the relationship. Therefore, PARs from 16 modern lake sediments were compared with lake surrounding tree biomass in high spatial resolution and temporally way with the aim:

- To reveal the extent of comparability of PARs from different lake sediments and to which degree lake internal processes might limit the comparison.

- To reveal how the biomass of local and regional vegetation is reflected by PARs in lake sediments.

- To evaluate existing DWPA models and to reveal how they capture the aspects of pollen dispersal and deposition in lakes.

- To calculate aPPEs for the most abundant tree taxa in Brandenburg and compare them with aPPE values from Scandinavia.

\section{Pollen diversity}

Diversity is a measurement to describe the landscape. Recently only few studies focuses on understanding the pollen-vegetation-diversity relationship. Few theoretical studies describe the biases influencing and reducing pollen diversity (Birks and Line, 1992; Odgaard, 1999; Giesecke et al., 2014) and discuss possible indices which can be applied on pollen data, giving insights into real vegetation diversity (Birks and Line, 1992; Giesecke et al., 2014). However, only two studies compare modern pollen diversity with the diversity of the vegetation, with contradicting results (Meltsov et al., 2013; Goring et al., 2013). In both cases, the studies were limited due to the lack of detailed vegetation mapping for a large area.

For the federal state of Brandenburg a high resolution biotope map was used to reveal how pollen diversity provides information about landscape structure. Therefore biotopes were assumed to reflect aspects of diversity, because different biotopes contain different species. Further, detailed forest inventory data contain information about the abundance of most of the tree species in Brandenburg that can be used for diversity estimates of tree species. 
For this approach surface samples from 50 lakes in Brandenburg (Northeast Germany) were used to compare diversity of pollen with a high resolution biotope map and detailed forest inventory data and aims:

- To reveal how landscape diversity is reflected in the distribution of pollen types in the sample.

- To discover the importance of diversity, evenness and richness in different pollen based indices.

- To prove that only wind pollinated taxa provide information on landscape diversity.

- To test whether the extent the production/dispersal bias for pollen based diversity indicators can be reduced by the REVEALS adjustment.

\subsection{Study area}

The federal state Brandenburg in the eastern part of northeast Germany was chosen because of the large number of lakes that are surrounded by different forest types for which detailed forest inventory data and further vegetation information are available (e.g. Datenspeicherwald II).

\subsubsection{Geomorphology}

Brandenburg extends over an area of about 30,000 km² (Landesamt für Bergbau, Geologie und Rohstoffe Brandenburg, 2010) and was shaped by several glaciations (Böse, 2004). It can be divided into the young moraine area in the north and the old moraine area in the south. During the last glacial maximum of the Weichselean, the Scandinavian ice sheet ran through Brandenburg in a NW to SE direction. The ice shield reaches its maximum extent during the Brandenburger Stadium at 2220,000 years B.P., documented by the southern ice margin (Böse, 2004). The landscape of the northern area is therefore characterized by a series of ground and terminal moraines and outwash plains (Fig. 1.1) with different soil substrates (Liedtke and Marcinek, 2002) and a large number of lakes. Whereas the moraines are characterised by boulder clays/tills, outwash plains consists of sands and gravel material. The average thickness of quaternary sediments is about 100-200 m and but can reach a thickness of partly more than $500 \mathrm{~m}$. In general, the depth of quaternary sediments becomes shallower in a southern direction with an increasing pre-quaternary substrate (Landesamt für Bergbau, Geologie und Rohstoffe Brandenburg, 2010; Böse, 2004). However, because of lower temperatures and the relative thin organic layer in larger parts in Brandenburg, the soils are limited in their use for agriculture and are therefore used for forestry (Liedtke and Marschner, 2003). 


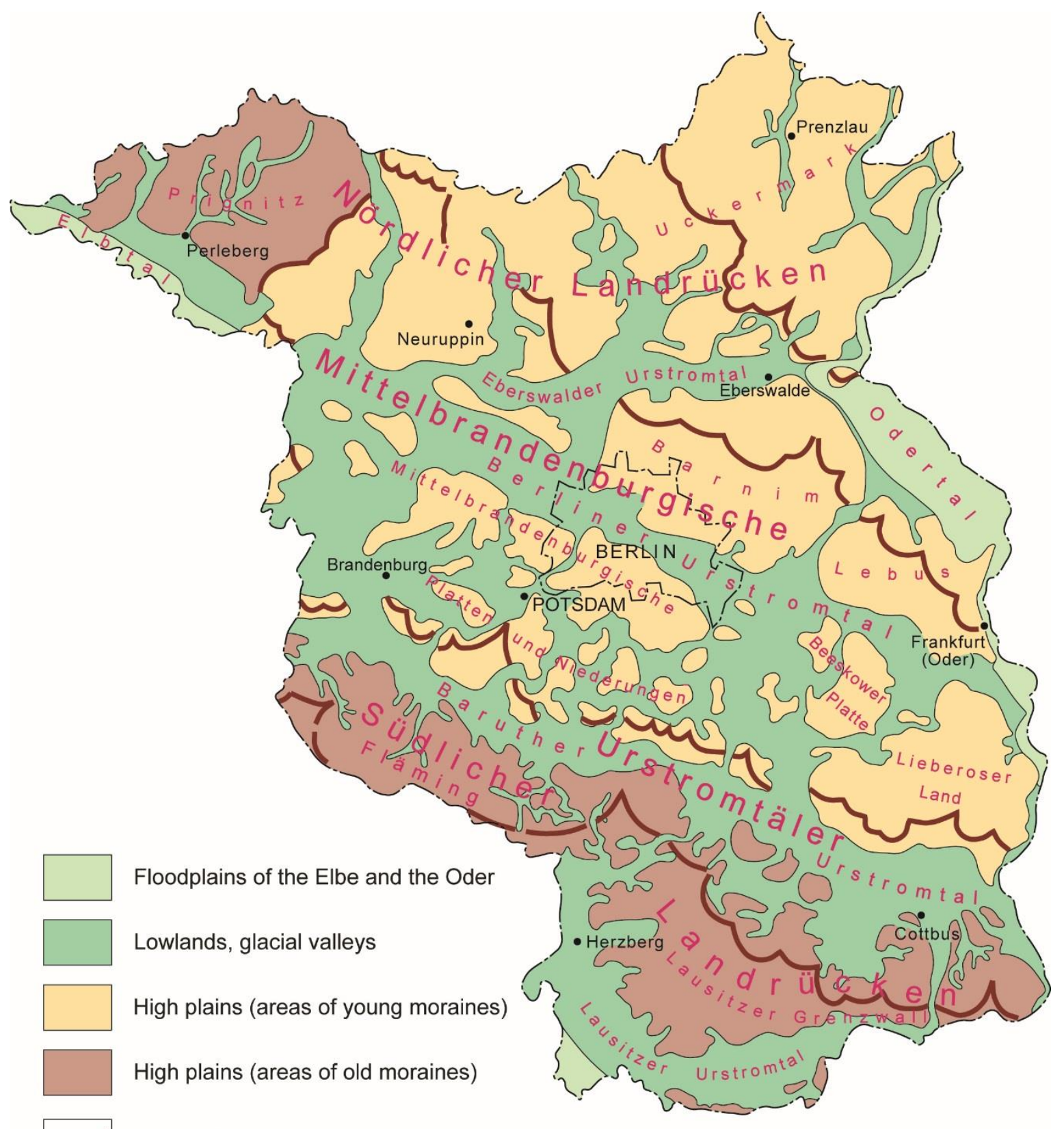

Terminal moraines, ice marings

Fig. 1.1 Geomorphology of Brandenburg (Landesamt für Bergbau, Geologie und Rohstoffe Brandenburg, 2010). Reproduced by the kind permission of the Landesamt für Bergbau, Geologie und Rohstoffe Brandenburg. The legend is translated.

\subsubsection{Climate}

Brandenburg is influenced by sub-maritime climate in the northeast and continental climate in the south and east (Endlicher and Hendl, 2003) and subjected to the west drift zone of the middle latitudes. Observations in the northern part of Brandenburg show that wind velocities vary between 4-4.5 m/s in the northern part and lower wind velocities of about 3.5-4 m/s in the southern part. In both cases the main wind directions are west and southwest (Bürger, 2003). For the years 1971-2000 the annual mean temperature in Brandenburg was measured with $9.0^{\circ} \mathrm{C}$. During this time span the 
annual mean precipitation was in average $553.3 \mathrm{~mm} / \mathrm{a}$ and the sunshine duration was measured with 1647.09 h/a (Deutscher Wetterdienst, 2014).

\subsubsection{Vegetation}

$37 \%$ of Brandenburg (1.09 million ha) is covered by forest. The most abundant tree species, Pinus, constitutes $70 \%$ and mixed forests about $11 \%$ (Engel, 2010). The potential natural vegetation is connected to soil substrates and climate in Brandenburg. According to this, common Fagus would cover the plains and terminal moraines in the northern part of Brandenburg. Despite human influence on forest stands the largest beech forest today occurs in the north, whereas pine forests are more dominant on outwash plains in the south (Böse, 2004). The agriculturally used area covers about $45 \%$ (1.32 million ha) and consists of $78.3 \%$ arable land and $21.3 \%$ pastures (MLUV, 2009).

\subsection{Material and Methods}

\subsubsection{Fieldwork}

Pollen composition in lake sediments is influenced by lake internal depositional environment, which is therefore an important factor that needs to be considered for studies focusing on the pollenvegetation relationship. The variability of internal deposition is reduced by a standardized sampling design, choosing similar types of lakes of the same size. For this thesis, lakes were chosen with simple basin without an inflow and/or outflow. Lakes that are deeper in proportion to their size were preferred to avoid high sediment redeposition. In most cases the sediment cores were taken from the deepest part of the lake basin. The selected lakes are located within different types of vegetation, covering areas of different tree abundance and composition, which is important to obtain an as broad as possible pollen spectrum.

Before fieldwork topographical maps, aerial photographs and satellite images were used for the selection of potential lakes. The suitability of the lake regarding its depth and sediment were assessed in the field. 50 short cores (Fig. 1.2) were taken from 49 small to medium sized lakes ranging between 0.5 and 32 ha and one large lake of about 780 ha (Table 1.1).

The sampling was realized during three field campaigns in spring and summer 2009. The short cores were obtained using a HON-Kajak sediment corer (Renberg, 1991) with a $10 \mathrm{~cm}$ diameter. In the field the cores were sampled at $1 \mathrm{~cm}$ intervals, with the first sample beginning at the sediment water interface (in cases where the interface was diffuse, the sample was taken shortly above it). Until processing in the lab, the samples were stored in small plastic bags at $4^{\circ} \mathrm{C}$. 


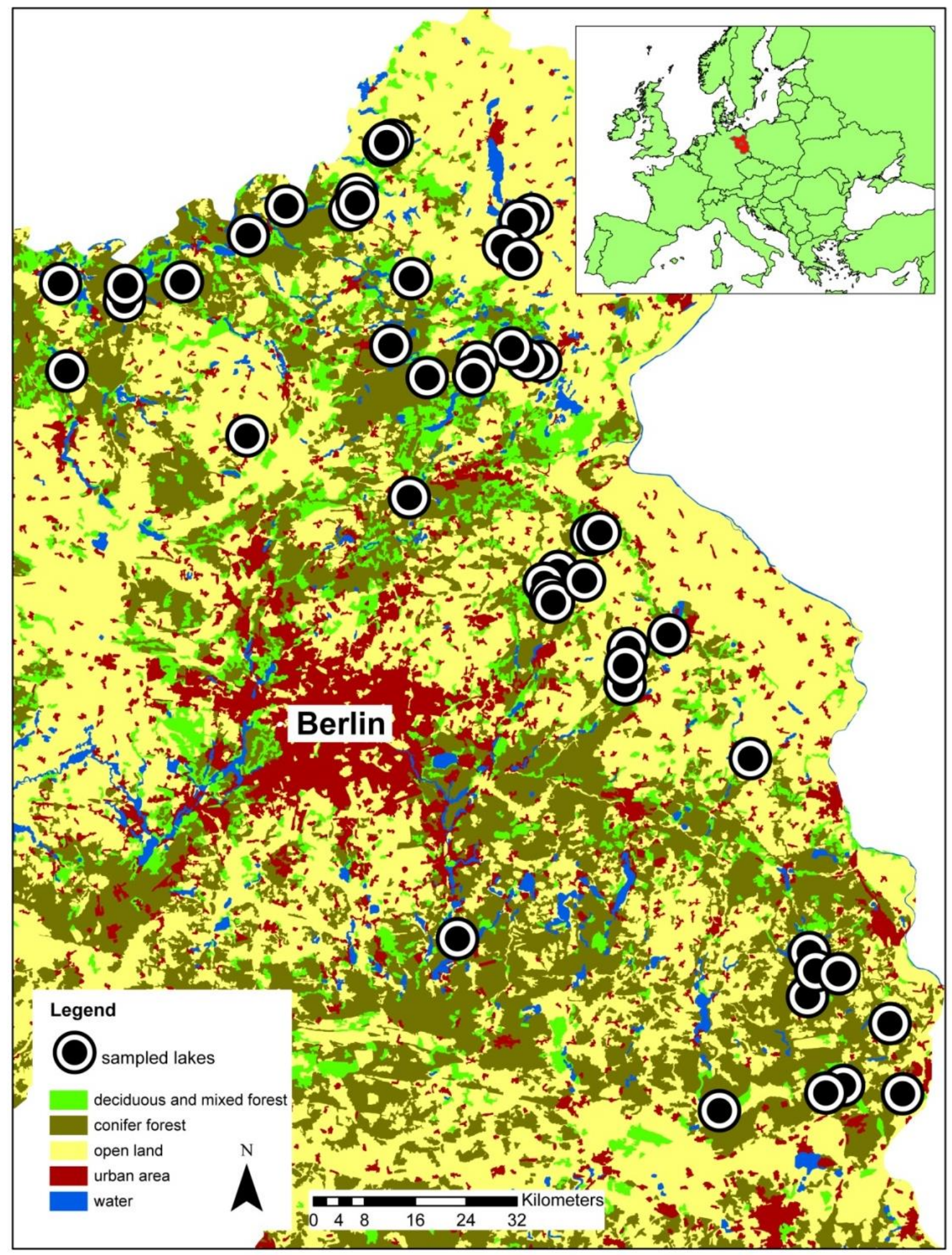

Fig. 1.2 Vegetation map of Brandenburg, based on CORINE Land Cover 2000 (Umweltbundesamt, DLR-DFD, 2004) with the location of the analyzed lakes. Inset: map of Europe. 
Table 1.1 Characteristics of the sampled lakes

\begin{tabular}{|c|c|c|c|c|c|c|}
\hline No & Name & $\begin{array}{l}\text { Latitude } \\
\text { (decima }\end{array}$ & $\begin{array}{l}\text { Longitude } \\
\text { srees) }\end{array}$ & Size (ha) & Radius (m) & Depth (m) \\
\hline 1 & Steinsee & 53.3184 & 13.6226 & 6.7 & 146 & 3.5 \\
\hline 2 & Petznicksee & 53.3155 & 13.6093 & 13.1 & 204 & 7.3 \\
\hline 3 & KleinerPetznicksee & 53.3114 & 13.6018 & 5.1 & 127 & 2 \\
\hline 4 & Hausseebruch & 53.2452 & 13.5306 & 3 & 98 & 10.1 \\
\hline 5 & Tiefer See & 53.2352 & 13.3631 & 17.2 & 234 & 33.7 \\
\hline 6 & TieferClöwen & 53.2333 & 13.5311 & 8.5 & 165 & 10.3 \\
\hline 7 & Poviestsee & 53.2239 & 13.5124 & 22 & 265 & 11.7 \\
\hline 8 & KleinerRathsburgsee & 53.2006 & 13.9394 & 3.2 & 101 & 6.6 \\
\hline 9 & KleinerLychensee* & 53.1964 & 13.2704 & 8.5 & 165 & 13.7 \\
\hline 10 & Bugsee* & 53.1930 & 13.9100 & 1.5 & 69 & 6 \\
\hline 11 & KleinerTrinsee & 53.1580 & 13.8674 & 1.1 & 59 & 5.6 \\
\hline 12 & KleinerZermittensee & 53.1440 & 12.8227 & 5.8 & 136 & 7.3 \\
\hline 13 & Aalgastsee* & 53.1391 & 13.9050 & 0.8 & 51 & 3.3 \\
\hline 14 & Weißesee & 53.1368 & 13.1089 & 5.8 & 136 & 8.2 \\
\hline 15 & Glabatzsee* & 53.1361 & 12.9745 & 2 & 80 & 7.3 \\
\hline 16 & Temnitzsee & 53.1217 & 13.6462 & 9.9 & 178 & 6.7 \\
\hline 17 & Plötzensee & 53.1148 & 12.9704 & 5.7 & 135 & 8.8 \\
\hline 18 & KleinerGollinsee & 53.0289 & 13.5882 & 3.2 & 101 & 3.3 \\
\hline 19 & Teufelssee* & 53.0200 & 12.8263 & 4.8 & 124 & 12 \\
\hline 20 & Heiliger See* & 53.0156 & 13.8720 & 9.1 & 170 & 10.8 \\
\hline 21 & Dovinsee* & 52.9980 & 13.7881 & 20.8 & 257 & 7 \\
\hline 22 & Schwarzersee* & 52.9940 & 13.9030 & 3.3 & 103 & 4.7 \\
\hline 23 & KleinerPlunzsee & 52.9927 & 13.9359 & 2.8 & 94 & 3.8 \\
\hline 24 & RunderKöllnsee & 52.9806 & 13.6685 & 2.7 & 93 & 3.9 \\
\hline 25 & Grimnitzsee* & 52.9787 & 13.7770 & 782 & 1578 & 6.2 \\
\hline 26 & Papensee* & 52.9140 & 13.2390 & 5.9 & 137 & 8.3 \\
\hline 27 & Buckowsee & 52.8132 & 13.6087 & 13.8 & 210 & 8.8 \\
\hline 28 & Schiebelsee* & 52.7457 & 14.0463 & 0.5 & 40 & 4.1 \\
\hline 29 & SonnenburgerFenn & 52.7446 & 14.0419 & 2.3 & 86 & 3.5 \\
\hline 30 & Baasee** & 52.7433 & 14.0258 & 2.2 & 84 & 3.6 \\
\hline 31 & Röthsee & 52.6949 & 13.9429 & 3.3 & 103 & 2.7 \\
\hline 32 & Modderpfuhl* & 52.6796 & 13.9084 & 1.7 & 74 & 3.8 \\
\hline 33 & Sternebecker See & 52.6793 & 14.0025 & 7.7 & 157 & 10.8 \\
\hline 34 & Piechesee** & 52.6596 & 13.9211 & 4.5 & 120 & 3 \\
\hline 35 & Blumenthalsee & 52.6517 & 13.9272 & 8.4 & 164 & 4.2 \\
\hline 36 & Staffsee & 52.5944 & 14.1890 & 9.6 & 175 & 3.8 \\
\hline 37 & KleinerTornowsee & 52.5795 & 14.0930 & 3.8 & 110 & 10 \\
\hline 38 & Schwarzer See & 52.5554 & 14.0835 & 7.1 & 150 & 4.3 \\
\hline 39 & Kesselsee* & 52.5292 & 14.0796 & 2.7 & 93 & 7.8 \\
\hline 40 & Kessel See & 52.4121 & 14.3562 & 3.5 & 106 & 1.2 \\
\hline 41 & Karbuschsee & 52.1867 & 13.6543 & 12.2 & 197 & 17.5 \\
\hline 42 & KleinerTreppelsee* & 52.1326 & 14.4585 & 5.4 & 131 & 4.5 \\
\hline
\end{tabular}




\begin{tabular}{|c|c|c|c|c|c|c|}
\hline \multicolumn{7}{|c|}{ (decimal degrees) } \\
\hline 43 & Ziskensee* & 52.1060 & 14.4699 & 2.6 & 91 & 4.4 \\
\hline 44 & Klautzkesee & 52.0997 & 14.5223 & 6.4 & 143 & 1.8 \\
\hline 45 & Rähdensee & 52.0707 & 14.4465 & 11.8 & 194 & 6.3 \\
\hline 46 & Buchwaldsee & 52.0239 & 14.6300 & 1.9 & 78 & 2.3 \\
\hline 47 & Kleinsee & 51.9420 & 14.5101 & 14 & 211 & 2 \\
\hline 48 & Großsee* & 51.9330 & 14.4719 & 31.7 & 318 & 8.3 \\
\hline 49 & Deulowitzer See & 51.9238 & 14.6467 & 13.9 & 210 & 4 \\
\hline 50 & Teersee & 51.9193 & 14.2263 & 8 & 160 & 3.7 \\
\hline
\end{tabular}

\subsubsection{Dating}

Out of the sampling collection of 50 lakes 18 short cores were chosen for ${ }^{210} \mathrm{~Pb}$ dating (Table 1.1). In the lab of the Department of Landscape Ecology at the University at Göttingen subsamples of the 18 short cores were dried at $105{ }^{\circ} \mathrm{C}$ in a drying oven and the water content of the subsamples was determined (see chapter 3). The prepared samples were analysed for ${ }^{210} \mathrm{~Pb},{ }^{226} \mathrm{Ra},{ }^{137} \mathrm{Cs}$ and ${ }^{241} \mathrm{Am}$ by direct gamma assay using an Ortec HPGe GMXseries coaxial low background intrinsic germanium detector (Appleby et al., 1986, Appleby et al., 1992) at the Environmental Radioactivity Research Centre at the University of Liverpool.

The ages of the sediments were inferred mainly based on the CRS-model, assuming a constant rate of supply of fallout ${ }^{210} \mathrm{~Pb}$ (Appleby and Oldfield, 1978). Age-depth models were tested and if necessary adjusted where well-defined peaks in the ${ }^{137} \mathrm{Cs}$ activity were present that could be linked to nuclear weapon tests in 1963 and/or the Chernobyl accident in 1986 (Appleby, 2001). In some cases the 1963 peak in ${ }^{137} \mathrm{Cs}$ activity was additionally confirmed by ${ }^{241} \mathrm{Am}$ increase (Appleby et al., 1991) (dating report see Appendix I). In two cases, the lakes Heiliger See and Teufelssee, laminations were observed and counted in the field. In the case of Teufelssee they aided in the selection of the agedepth model assuming the laminations to be annual (chapter 3).

\subsubsection{Pollen analysis}

For PPE calculations and to explore the way pollen diversity is correlated to landscape patterns and diversity, surface samples from the lake collection were taken and prepared for palynological analysis. In the lab $1 \mathrm{~cm}^{3}$ material was taken from the uppermost sample of each short core using a $1 \mathrm{ml}$ syringe. In single cases where the short cores had a diffuse sediment-water interface and samples contain a very low pollen concentration, the second sample of the short core was also subsampled and prepared for palynological analysis. Following the general procedure described by Bennett and Willis (2001), without sieving and using a 2 min acetolysis, the sediment subsamples were processed for pollen analysis. The pollen were coloured using safranine (detailed protocol in 
Appendix II). Afterwards the sample residues were mounted in glycerol and counted under a light microscope (Zeiss, Axiostar Plus) at 400x magnification, and cereals were identified at 1,000x magnification. The pollen types were identified using the keys of Beug (2004) and Moore et al. (1991), and the reference collection of the Department of Palynology and Climate Dynamics, GeorgAugust University, Göttingen. A minimum of 1,000 terrestrial pollen grains were counted for each surface sample. The pollen sum is defined as the sum of all terrestrial pollen grains (e.g. chapter 2 ). Further, samples used for the calculation of pollen accumulation rates and absolute pollen productivity estimates were processed in a similar way as the surface samples. Here, consecutive subsamples from the 16 dated short cores were selected from the youngest sediment and depth corresponding to ages around 1993, based on information of the age-depth models (see also chapter 3). Before proceeding, Lycopodium spore tablets were added to determine the pollen concentration (Stockmarr, 1971). For each sample a minimum of 500 terrestrial pollen grains as well as a minimum of 100 Lycopodium spores were counted. Inter-annual variability in pollen and sediment accumulation should be averaged out by bioturbation. Furthermore, PARs based on the pollen concentration from 2 to 4 samples were calculated to reduce a potential variability. The pollen concentration for the samples was multiplied by the sedimentation rate for these samples based on the age-depth-model.

\subsubsection{Vegetation data}

To understand the pollen-vegetation relationship, detailed information about vegetation cover and composition are required for the period covered by the obtained pollen data. Therefore, two different types of vegetation data were used: Detailed forest inventory data from the Datenspeicher Wald 2 and high resolution biotope map for the state Brandenburg.

In the 1930s a detailed inventory of forests in the eastern part of Germany was started and intensified in the 1960s and 70s. Forest inventories have been continued and continually updated. Forest inventory data have been collected and digitized in a forest inventory database and data are available since 1993. This type of data possesses a standardized format in the database "Datenspeicher Wald" (DSW2; http://www.dsw2.de/index.html) which is maintained by the states of Brandenburg, Mecklenburg-Vorpommern and Thuringia. The part of the recent data used here covers most of the forest inventory data for Brandenburg and adjacent parts of MecklenburgVorpommern. For some parts of the immediate study area data were supplemented with information from the federal agency "Bundesanstalt für Immobilienaufgaben" (chapter 3), which provide similar forest inventory data. The forest inventory database contains detailed information about tree species, cover, age and height, as well as data of forest structure e.g. superstructure, rejuvenation and understory. However, about one third of the forested areas are owned by the 
public and also information about the standing volume (SV (or biomass)) for 2009 is available. Forest inventory data were not available for military areas, roadside trees, trees in towns and villages as well as wooded areas $<0.01$ ha.

To extract measures of landscape diversity and cover of non-forested areas and vegetation types, a high resolution biotope and land-use map was used (CIR-Biotop- und Landnutzungstypenkartierung download: http://www.mugv.brandenburg.de/cms/detail.php/bb2.c.515599.de, version from 2009, accessed 1 December 2010). The map has been constructed in 1991-1996 and was updated annually.

\subsubsection{Data handling for PPE calculations}

\section{Vegetation}

To reveal how PPEs are affected by forest structure and flowering age, different datasets were generated based on the forest inventory data (chapter 2). Whereas aerial and satellite images consider information like the bird's-eye view, the forest inventory database yields information on the total ground cover of individual species (Fig. 1.3). To consider both aspects, the forest layers were classified into two stories, canopy and understory. Further, datasets that consider all trees as well as those that contain only trees that have reached their flowering age were created (see also chapter 2). Threshold values for the flowering age of the different trees were chosen based on information from literature (Table 1.2).

However, the biotope and land-use mapping project (CIR-Biotop- and Landnutzungstypenkartierungdownload:http://ww w.mugv.brandenburg.de/cms/detail.php/bb2.c.

515599.de, 2009 version, accessed 1 December 2010) was used to derive information about the cover on different types of non-forested vegetation. The biotope map was reclassified and
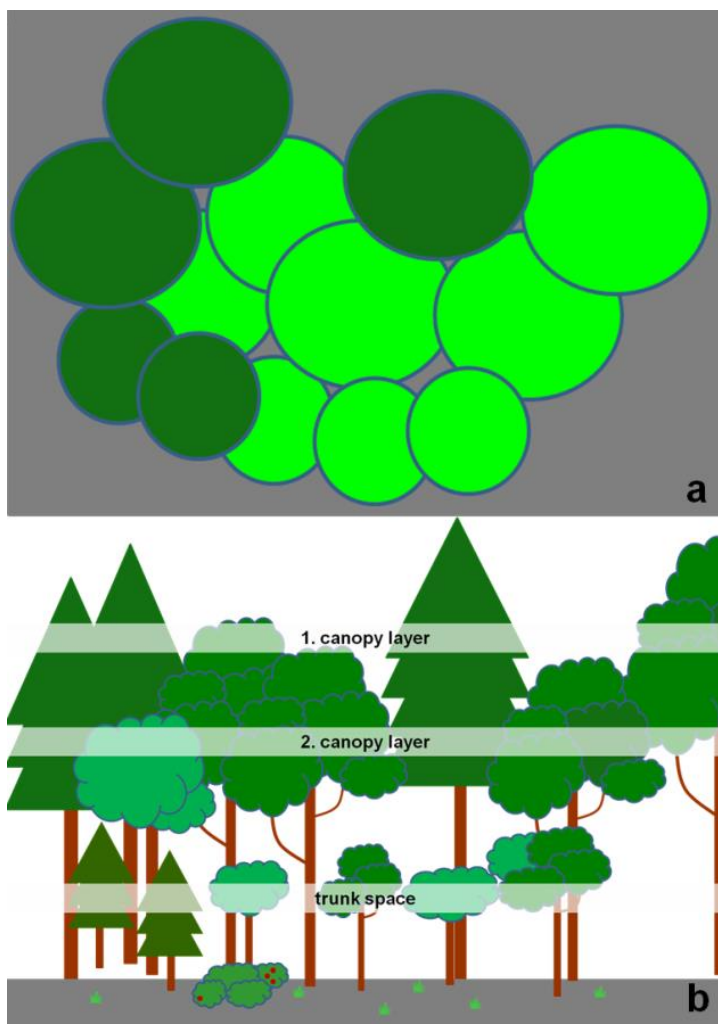

Fig. 1.3 a Example of a forest canopy from above, which is the basis for estimates of tree abundance from aerial photographs and satellite images; b a simplification of canopy layers as recognized in the forest inventory data illustrating the classification in canopy and understory that was for the PPE calculations (see also chapter 2 ).

generalized. The resulting units were used to represent unique combinations of taxa and considered in the PPE calculations. The pattern of arable fields was determined as a mixture of crops regarding to information of yield for the year 2009 (MLUV 2009), assuming that the cultivation of the different 
crops in Brandenburg is evenly distributed. The spatial data of tree and crops were combined and handled in ArcGIS 9 (ESRI) and Excel (Microsoft), and the vegetation cover data within radii between $250 \mathrm{~m}$ and $15 \mathrm{~km}$ around each sampling site were extracted for the four different datasets:

1. All forest inventory data are included (allFID).

2. Forest data are included if the flowering age of the different trees and shrubs is reached (allFIDage).

3. Only data from the canopy layer are included, while information on understory trees is excluded (canopyFID).

4. Only data from the canopy layer are included, and only if the flowering age of the different taxa is reached (canopyFIDage).

Table 1.2 Pollen fall speed of 16 taxa and flowering age considered for the tree taxa

\begin{tabular}{lllr}
\hline pollen taxa & $\begin{array}{l}\text { fall speed } \\
(\mathrm{m} \mathrm{sec}-1)\end{array}$ & tree taxa & $\begin{array}{r}\text { flowering } \\
\text { age }\end{array}$ \\
\hline Alnus & $0.021^{\mathrm{a}}$ & Alnus glutinosa & $10^{\mathrm{d}}$ \\
Betula & $0.022^{\mathrm{a}}$ & Betula pendula & $10^{\mathrm{d}}$ \\
Carpinus & $0.042^{\mathrm{a}}$ & Carpinus betulus & $30^{\mathrm{d}}$ \\
Fagus & $0.057^{\mathrm{b}}$ & Fagus sylvatica & $50^{\mathrm{d}}$ \\
Fraxinus & $0.022^{\mathrm{a}}$ & Fraxinus excelsior & $30^{\mathrm{d}}$ \\
Larix (and Pseudotsuga) & $0.126^{\mathrm{a}}$ & Larix & $10^{\mathrm{e}}$ \\
Picea & $0.056^{\mathrm{a}}$ & Picea & $40^{\mathrm{a}}$ \\
Pinus & $0.031^{\mathrm{a}}$ & Pinus & $20^{\mathrm{a}}$ \\
Populus & $0.025^{\mathrm{a}}$ & Populus alba & $20^{\mathrm{d}}$ \\
Quercus & $0.035^{\mathrm{a}}$ & Pseudotsuga & $30^{\mathrm{a}}$ \\
Tilia & $0.032^{\mathrm{a}}$ & Quercus robur & $30^{\mathrm{d}}$ \\
Avena-type & $0.078^{\mathrm{c}}$ & Tilia cordata & $20^{\mathrm{e}}$ \\
Hordeum-type & $0.06^{*}$ & & \\
Secale & $0.06^{\mathrm{b}}$ & & \\
Triticum-type & $0.078^{\mathrm{c}}$ & & \\
wild herbs & $0.03425^{*}$ & & \\
\hline
\end{tabular}

a)Eisenhut (1961); b) Gregory (1973); c) Cerialia in Soepboer et al. 2007; d)Schütt et al. (2006);

e) Haller and Fickler (1955); ${ }^{\text {f)} R i s p e n s ~(2003) ~ a n d ~ g) S t i n g l w a g n e r ~ e t ~ a l . ~(2005) . ~ * E s t i m a t e d ~ f a l l ~}$

speed (chapter 2).

\section{ERV analysis}

The pollen percentages from the surface samples were compared with the different generated vegetation information sets. The vegetation information of each dataset was extracted for the first $\mathrm{km}$ in $250 \mathrm{~m}$-wide rings and in one-km wide rings for the distances of 1 to $15 \mathrm{~km}$, seen from the centre of the lake. The compiled vegetation data were used for the distance-weighting. One test set with $200 \mathrm{~m}$ rings over the first $3 \mathrm{~km}$ was realized, to evaluate the influence of ring-width on the results of the distance-weighting (chapter 2). The Program ERV-Analysis 1.2.3 (Sugita unpublished) was used for calculating PPEs and the RSAP. The Ring Source model (Sugita et al., 1999) was used to distance-weight the vegetation data and was applied in each of the three different ERV submodels 
(Parsons and Prentice, 1981; Prentice and Parsons, 1983; Sugita 1994). The wind velocity was set 3 $\mathrm{m} / \mathrm{sec}$ and fall speeds of pollen were taken from the literature or estimated (Table 1.2). The radii of the lakes were fixed to an average radius of $140 \mathrm{~m}$ (Nielsen and Sugita, 2005; Soepboer et al., 2007). Pinus was set as a reference taxon, because it is abundant in the vegetation as well in the pollen samples from all sites and represents mainly the single native species, Pinus sylvestris. Preliminary analysis, based on the full dataset demonstrates that model performance was improved when reducing the samples to a subset of 39 lakes and omitting lakes that exceeded a cover of Fagus trees of 5 ha within a radius of $250 \mathrm{~m}$ from the centre of the lake. It was aimed to calculate PPEs for 16 taxa (Table 1.2), at which one is a group of taxa. This group is named as "wild herbs" and contains the pollen taxa of the uncultivated terrestrial herbs, e.g. Plantago lanceolata, Rumex acetosa, $R$. acetosella, Chenopodiaceae and Poaceae. Poaceae is the most abundant taxon in this group. The fall speed of the group of the wild herbs was determined based on the mean fall speed of the most frequent taxa in this group (chapter 2).

\subsubsection{Data handling for PAR and aPPE calculations}

\section{Vegetation}

For the comparison of PARs in lake sediments to absolute vegetation abundance, above ground biomass (standing volume abbreviated as SV) of trees was chosen as a measure for vegetation data, based on information of the forest inventory database (chapter 3). As mentioned above, for almost one third of the area information on SV for 2009 was directly available. However, for the other two thirds, which are mostly privately owned as well as for the forest inventory data from 1993, it was necessary to estimate the SV. To realize this purpose, the relationships between tree ages and the SV were estimated based on a yield table (Schober, 1975). Where more than one growth rate classification was available, the second yield power was used. Yield tables are restricted to taxa of silvicultural interest. In this manner, the relationship between age and SV for Fraxinus, was also applied for the SV for Tilia cordata and UImus. The growing function for Carpinus was based on a study from Lockow and Lockow (2009). Further, calculation of SV was restricted to trees which have reached their flowering age, as only these can potentially be reflected in the pollen assemblage (Hicks, 2006; Matthias et al., 2012). However, information about the relationship between SV and age is generally only available after the trees have reached a certain age. In few cases the age for which SV data were available was higher than the age when the tree starts flowering. In these cases the dissimilarity between the age of flowering and the start of the yield table was small and the latter was used as threshold value (Table 1.3; chapter 3 ). 
Table 1.3 Pollen fall speed and threshold age of the tree taxa

\begin{tabular}{llll} 
Taxa & Threshold age & Choosen cartegory & Fall speed (m sec-1) \\
\hline Alnus & $20^{\mathrm{b}, \mathrm{a}}$ & YT/FA & $0.021^{\mathrm{h}}$ \\
Betula & $30^{\mathrm{a}}$ & YT & $0.022^{\mathrm{h}}$ \\
Carpinus & $30^{\mathrm{c}, \mathrm{b}}$ & YT/FA & $0.042^{\mathrm{h}}$ \\
Fagus & $50^{\mathrm{b}}$ & $\mathrm{FA}$ & $0.057^{\mathrm{i}}$ \\
Fraxinus & $30^{\mathrm{b}}$ & FA & $0.022^{\mathrm{h}}$ \\
Larix & $20^{\mathrm{a}}$ & YT & $0.126^{\mathrm{h}}$ \\
Picea & $40^{\mathrm{d}}$ & FA & $0.056^{\mathrm{h}}$ \\
Pinus & $25^{\mathrm{a}, \mathrm{d}, \mathrm{e}}$ & YT/FA & $0.031^{\mathrm{h}}$ \\
Pseudotsuga & $30^{\mathrm{f}}$ & FA & $5 e e$ Larix $^{\mathrm{h}}$ \\
Quercus & $30^{\mathrm{b}}$ & FA & $0.035^{\mathrm{h}}$ \\
Tilia & $20^{\mathrm{g}}$ & FA & $0.032^{\mathrm{i}}$ \\
Ulmus & $40^{\mathrm{b}}$ & FA & $0.032^{\mathrm{i}}$
\end{tabular}

a)Schober (1975); b) Schütt et al. (2006); c)Lockow and Lockow (2009); d)Rispens (2003); e) Schröck et al. (1949); f)Stingelwagner et al. (2005) g)Haller and Fickler (1955); h)Eisenhut; (1961); i) Gregory (1973). YT=Yield table; FA=flowering age (chapter 3).

\section{Compilation of vegetation data PAR}

ArcGis 10.1 (ESRI) was used to obtain information about the SV for the single taxa that surround the sampled lakes, considering the shape of the sampled lakes. For gathering detailed information of each sample site, vegetation data were extracted in two different ways (Fig. 1.4):

1) SV of the tree taxa within a radius of $15 \mathrm{~km}$ starting from the sampling point were extracted in rings of increasing radii. Close to a lake small rings (with $25 \mathrm{~m}$ in width) were chosen which increased in size with increasing distance from the lake (up to $1 \mathrm{~km}$ at a distance of $5 \mathrm{~km}$ ).

2) SV of the tree taxa were extracted within buffers surrounding the lake shore up to a distance of $15 \mathrm{~km}$. In this case also the width of the buffers were smaller near the lake shore and increased with increasing distance, similar to the chosen ring distances.

The latter procedure was initiated because of the fact that in most cases lakes are not perfectly round shaped. Due to this, vegetation near the distant lake shore may already be strongly downweighted in elongated lakes, while the pollen could be mixed in the basin and contribute to a similar ratio to that from plants growing near a more proximal lake shore. Values of the SVs obtained in increasing circles or buffers around the sampled lakes were compared to PARs from the lake sediments in two ways (chapter 3):

1) Directly as SV and as SV/ha reducing the influence of distant trees through down weighting. 
2) With distance-weighted vegetation using:

a. The Prentice-Sugita model (DWPAps). In this case mean vegetation abundance at increasing distances, lake size and wind speed (set to $3 \mathrm{~m} / \mathrm{s}$ ), as well as the fall speed of the pollen considered (Sugita, 1993; Sugita et al., 1999). The pollen transport for the different taxa is implemented in this model.

b. Values of SV obtained in increasing buffers surrounding the lake shore were down weighted by dividing the SV/ha with the mean distance to the lake shore plus the average radius of the lake (DWPA $A_{\text {Buffer }}$ ). This simple distance-weighting approach considers no species-specific differences in the dispersal of pollen.

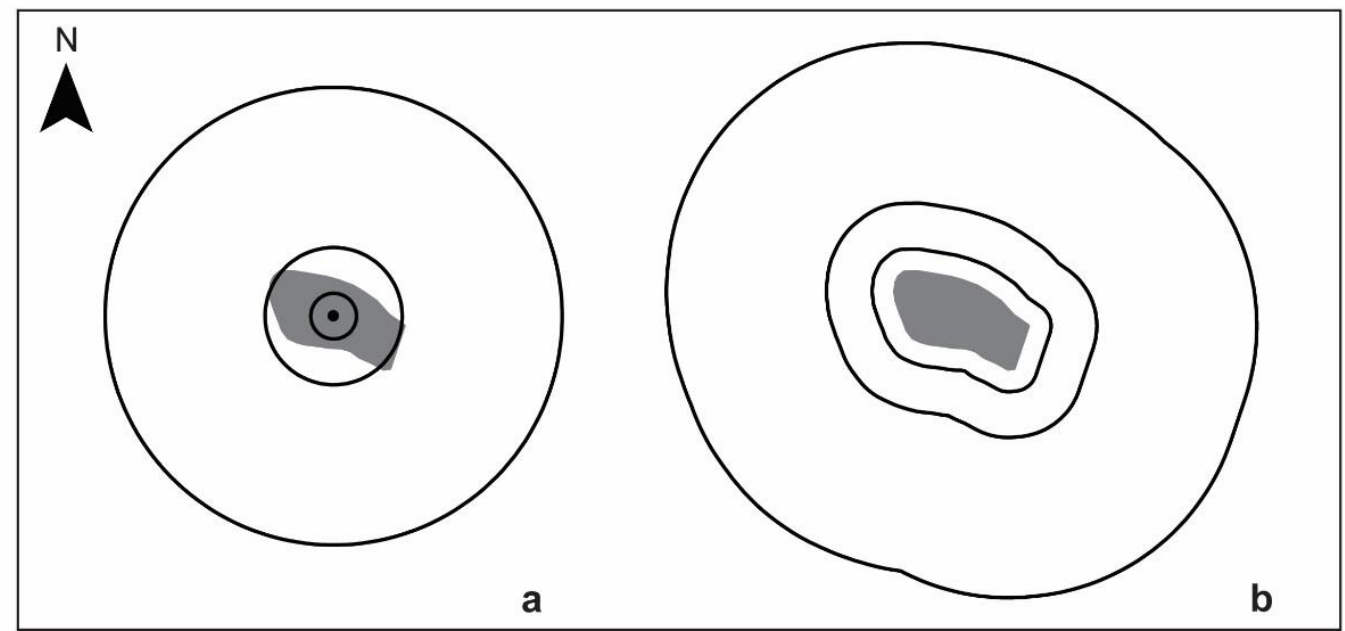

Fig. 1.4 Vegetation extraction schema. a) Illustrates how the vegetation data were extracted using circles starting from the centre of the lake. b) Shows the vegetation extraction within buffers starting from the lake shore. The major differences exist for the closed vegetation, e.g. in a) only vegetation from the northeast and from the southwest will be considered in the first circle. In b) the whole vegetation surrounding the lake shore is considered in the first buffer (chapter 3 ).

\subsubsection{Data handling of pollen and landscape diversity}

\section{Vegetation}

The different landscape variables, e.g. number of polygons or number of different polygons, were obtained for the different distances surrounding the lakeshore, ranging between $0.1 \mathrm{~km}$ and seven km. Data were extracted using the program ArcGIS 10.1 (ESRI).

Abundances of the single tree taxa were taken from the forest inventory data in the same way as it was realized for the dataset that was used for PPE calculations and consider all trees that have reached their flowering age. For the distance-weighting, the mean vegetation abundance was weighted by the mean distances of the circles starting from the centre of the lake (chapter 4). 


\section{REVEALS}

For reducing the bias of pollen production and deposition, the REVEALS model was applied on the pollen data (e.g. Marquer et al., 2014). The analysis was realized using REVEALS.v4.5. (Sugita unpublished) with the Prentice-Sugita dispersal model which is appropriate for lakes (Sugita et al., 1999). The vegetation region was set to seven $\mathrm{km}$ and is the RSAP, which was already estimated in the connection to the PPE calculation for most of these sites in Brandenburg. Information about the fall speed individual pollen types was obtained from literature (Eisenhut, 1961; Gregory, 1973; Dyakowska, 1936; Sugita et al., 1999) or calculated using Stockes Law (Gregory, 1973) for taxa without available information about fall speed. PPEs were taken from the literature (Sugita et al., 1999; Broström et al., 2004, Soepboer et al., 2007; Matthias et al., 2012) and Pinus was set as a reference taxon. In cases were no PPEs were available approximate values based on the mode of pollen production and dispersal were assigned (see chapter 4; Appendix S2.). Information on the pollination mode was taken from the literature (BiolFlor http://www2.ufz.de/biolflor/index.jsp; Jäger, 2011; Raven et al., 2000; Willemstein, 1987). Information about the general pollination strategy of the genus or family was used for species without available data. Considering this information, the obtained taxa were divided in three different groups. A) wind pollinated taxa (PPE set to 0.4); B) wind and insect pollinated taxa (PPE set to 0.2 ) and C) insect pollinated taxa (PPE set to 0.1). The calculated PPEs for the Cerealia-types vary widely between the studies (Broström et al., 2004, Soepboer et al., 2007; Matthias et al., 2012) and, as they are often self-pollinated, were set as insect pollinated taxa (Biolflor http://www2.ufz.de/biolflor/index.jsp), with the exception of the Secale-type, which was set to wind and insect pollinated taxa. The pollen counts were transformed by the calculated abundance, with the aim to obtain unbiased pollen counts as if all taxa would have the same pollen production as the reference taxon (here Pinus). For this approach, the original pollen count of the reference taxon was multiplied with abundance of the taxon adjusted in REVEALS, with the aim to calculate the "corrected" pollen count. This result was divided by the REVEALS-adjusted abundance of Pinus.

\section{Diversity indices: Shannon-index, rarefaction and rang-order-abundance}

For measuring diversity, the Shannon-Index was chosen, because it is one of the most popular and often used indexes for estimating diversity (Hill, 1973; Tuomisto, 2012). The most indices consider both, abundance information and the number of taxa, and pollen data are biased by the pollen production and dispersal. Therefore, only the number of taxa per sample (palynological richness) is generally used as a diversity measure based on pollen data (Birks and Line, 1992). However, the number of different pollen types encountered per sample is influenced by the total number of 
counted grains (Rull, 1987). The rarefaction analysis is therefore used to calculate palynological richness for a standardized pollen count of all samples (Birks and Line, 1992). This approach was realized using sample based rarefaction based on the lowest count, to obtain the maximal palynological richness which is possible for the whole dataset $\left(E\left(T_{\max }\right)\right)$. Further, for comparisons of palynological richness between the datasets it should be stated that a standard high pollen sum and a count of 500 seems convenient $\left(E\left(T_{500}\right)\right)$ and was hence calculated. Palynological richness expressed in a low pollen sum was suggested to represent aspects of evenness in the pollen sample (Odgaard, 2008; Giesecke et al., 2012). To assess results following this idea, rarefaction analysis was also conducted to numbers between 2 and 30. Further, an evaluation of the rank-order-abundance might also provide information about aspects of sample evenness (Giesecke et al., 2012; Giesecke et al., 2014). The inverted slope of the rank order abundance was therefore computed with a sample based threshold of $1 \%$ (Giesecke et al., 2014), which refered to "SLOPE $1 \%$ " within this study. The vegan package (version 2.0-9, Oksanen, 2013) and the R program (version 3.0.1) were used for calculating rarefaction analysis as well as the rang-order-abundance. All three indices were calculated for the four different pollen data sets:

1. The dataset that includes all original pollen counts.

2. The dataset that includes only wind pollinated taxa from the original pollen count.

3. The dataset that includes all pollen counts transformed in the REVEALS program.

4. And the dataset that includes only wind pollinated taxa that are transformed in the REVEALS program.

The Shannon-Index was calculated for the most important tree pollen taxa of species that are included in the forest inventory database and both results were compared. The Shannon-Index was further also applied to the dataset of the tree pollen counts transformed in the REVEALS program (see chapter 4).

\section{Pollen diversity and landscape structure}

Results of the indices that are based on the pollen data were compared to the single landscape variables at different distances from the lake shore (chapter 4). For the comparison the following variables were used: the number of biotopes, the number of different biotopes, the cover of the nonforested area and the ratio between lake perimeter and lake area. The importance of the combination of these variables was assessed with a multiple linear regression models using the Akaike Information Criterion (AIC) in a stepwise algorithm, which is implemented in the MASS package (version 7.3-29, Venables and Ripley, 2002) with both, forward and backward selection. Therefore, landscape variables were chosen for the distance that shows the strongest relationship in a simple regression model. 
One lake (Sonnenburger Fenn) was omitted from comparisons with the landscape variables, because the pollen sample was strongly influenced by adjacent gardens that were indicated by the detection of a high number of exotic pollen types.

\subsection{Outline and contents of the chapters}

The objectives of this thesis were developed in three separate manuscripts that were prepared for publishing in international scientific journals (peer-review) and used for a cumulative dissertation. Within the following chapters 2-4 the manuscripts are presented in the way they were submitted or already published in journals. The supplementary provides further information and discussion that has not been published or submitted to a journal and outcomes are connected to the third chapter. Chapter 5 summarizes and discusses results and outcomes of the whole investigation. The paragraphs below provide a brief summary for the single chapters.

Chapter 2 (published as Matthias et al., 2012) presents relative pollen productivity rates of the major taxa and the RSAP for small and medium sized lakes in Brandenburg. The effects of flowering age and forest structure on PPEs for the different taxa are obtained and discussed. Furthermore, calculated PPEs and the RSAP are compared with results from different studies and variances are explained by different character of landscape and vegetation patterns.

Chapter 3 (published as Matthias and Giesecke, 2014) focuses on the relationship between PARs from lake sediments and absolute vegetation cover (standing volume) for the single tree taxa. While comparing PARs with SV, different dispersal models are considered and their ability to capture best the pollen source is discussed. Further, the obtained PARs from small to medium sized lakes in Brandenburg are compared with PARs from previous studies and the results are discussed.

Supplementary to chapter $\mathbf{3}$ provides absolute pollen productivities estimates for the major tree taxa in Brandenburg. The calculations are based on the relationship between PARs and SV from small to medium sized lakes that are also used in the analysis from chapter 3. The aPPEs are compared with aPPEs from Finland and differences in the results are discussed. The calculated values from Brandenburg are set in relation to Pinus and the results are compared with PPEs calculated with the ERV submodel 3 (chapter 2) and variations are discussed.

Chapter 4 (published as Matthias et al., 2015) investigates the relationship between pollen diversity and landscape diversity patterns. Different indices were applied on pollen data and values were compared with different landscape factors, e.g. number of biotopes and number of different 
biotopes. Further subsets are created to test whether that only wind pollinated taxa provides insights into landscape variations. Additionally, pollen data are corrected with the REVEALS reducing the bias in pollen production and dispersal. The results of the datasets are presented and discussed and further approaches in interpreting pollen diversity, evenness and richness are provided.

Chapter 5 represents a comprehensive synthesis and discussion considering the major outcomes of the three manuscripts and the supplementary material. Finally an outlook for future research that is required to further understand pollen theory for quantitative vegetation reconstructions is proposed.

\subsection{References}

Abraham, V. \& Kozáková, R. (2012): Relative pollen productivity estimates in the modern agricultural landscape of Central Bohemia (Czech Republic). Review of Palaeobotany and Palynology, 179: 1-12.

Andersen, S.T. (1970): The relative pollen productivity and pollen representation of north European trees, and correction factors for tree pollen spectra determined by surface pollen analyses from forests. Determinated by Surface Pollen Analyses from Forests. Danmarks geologiske unders $\varnothing$ gelse. Raekke 2, 96, 1-99.

Andersen, S.T. (1974): Wind Conditions and Pollen Deposition in a mixed Deciduous Forest. I. Wind Conditions and Pollen Dispersal. Grana, 14: 57-63.

Appleby, P.G. \& Oldfield, F. (1978): The calculation of $210 \mathrm{~Pb}$ dates assuming a constant rate of supply of unsupported ${ }^{210} \mathrm{~Pb}$ to the sediment. Catena, 5: 1-8.

Appleby, P.G., Nolan, P.J., Gifford, D.W., Godfrey, M.J., Oldfield, F., Anderson, N.J. \& Battarbee, R.W. (1986): ${ }^{210} \mathrm{~Pb}$ dating by low background gamma counting. Hydrobiologia, 141: 21-27.

Appleby, P.G., Richardson, N. \& Nolan, P.J. (1991): ${ }^{241}$ Am dating of lake sediments. Hydrobiologia, 214: 35-42.

Appleby, P.G., Richardson, N. \& Nolan, P.J. (1992): Self-absorption corrections for well type germanium detectors. Nuclear Instruments and Methods in Physics Research Section B: Beam Interactions with Materials and Atoms, 7: 228-233.

Appleby, P.G. (2001): Chronostratigraphic techniques in recent sediments. In: Last, W.M., Smol, J.P. (Eds.), Tracking Environmental Change Using Lake Sediments, Basin Analysis, Coring, and Chronological Techniques, vol. 1. Kluwer Academic, pp. 171-203.

Beaudoin, A.B. \& Reasoner, M.A. (1992): Evaluation of differential pollen deposition and pollen focusing from three Holocene intervals in sediments from Lake O'Hara, Yoho National Park, British Columbia, Canada: intra-lake variability in pollen percentages, concentrations and influx. Review of Palaeobotany and Palynology, 75: 103-131.

Bennett, K.D. \& Willis, K.J. (2001): Pollen. In: Smol, J.P., Birks, H.J.B., Last, W.M. (Eds.), Tracking Environmental Change Using Lake Sediments, Terrestrial, Algal and Siliceous Indicators, vol. 3. Kluwer Academic Publishers, Dordrecht, pp. 5-32.

Beug, H.-J. (2004): Leitfaden der Pollenbestimmung. Verlag Dr. Friedrich Pfeil, München.

BiolFlor (2013): Eine Datenbank mit biologisch-ökologischen Merkmalen der Flora von Deutschland. Eine Kooperation von Umweltforschungszentrum Leipzig-Halle $\mathrm{GmbH}$ und Bundesamt für Naturschutz. Bundesamt für Naturschutz. http://www2.ufz.de/biolflor/index.jsp

Birks, H.J.B. \& Line, J.M. (1992): The use of rarefaction analysis for estimating palynological richness from Quaternary pollen-analytical data. The Holocene, 2: 1-10.

Bonny, A.P. (1976): Recruitment of pollen to the seston and sediment of some Lake District lakes. Journal of Ecology, 64: 859-887. 
Bonny, A.P. (1978): The effect of pollen recruitment processes on pollen distribution over the sediment surface of a small lake in Cumbria. Journal of Ecology, 66: 385-416.

Bonny, A.P. (1980): Seasonal and Annual Variation Over 5 Years in Contemporary Airborne Pollen Trapped at a Cumbrian Lake. The Journal of Ecology, 68: 421-441.

Böse, M. (2004): Naturraum und Ressourcen: Berlin und Brandenburg im Überblick. In: Exkursionsführer. Berlin + Brandenburg zwischen Kiez, Metropole und ländlicher Peripherie. Räumliche Entwicklung seit 1989/90. Wieckert, R. \& Ellger, C. (Hrsg.). Gesellschaft für Erdkunde zu Berlin, Berlin.

Bradshaw, R.H.W. \& Webb III, T. (1985): Relationships between contemporary pollen and vegetation data from Winsconsin and Michigan, USA. Ecology, 66: 721-737.

Broström, A., Sugita, S. \& Gaillard, M.-J. (2004): Pollen productivity estimates for reconstruction of past vegetation cover in the cultural landscape of southern Sweden. The Holocene, 14: 371384.

Broström, A., Nielsen, B., Gaillard, M.-J., Hjelle, K.L., Mazier, F., Binney, H., Bunting, M.J., Fyfe, R., Meltsov, V., Poska, A., Räsänen, S., Soepboer, W., Von Stedingk, H., Suutari, H. \& Sugita, S. (2008): Pollen productivity estimates of key European plant taxa for quantitative reconstruction of past vegetation: a review. Vegetation History and Archaeobotany, 17: 461478.

Bunting, M.J., Armitage, R., Binney, H.A. \& Waller, M. (2005): Estimates of "relative pollen productivity" and "relevant source area of pollen" for major tree taxa in two Norfolk (UK) woodlands. The Holocene, 15: 459-465.

Bürger, M. (2003): Bodennahe Windverhältnisse und windrelevante Reliefstrukturen. In: Nationalatlas Bundesrepublik Deutschland. Klima, Pflanzen- und Tierwelt. Leibniz-Institut für Länderkunde (Hrsg.). Bd. 3. Spektrum Akademischer Verlag Heidelberg, Berlin.

Calcote, R. (1995): Pollen Source Area and Pollen Productivity: Evidence from Forest Hollows. Journal of Ecology, 83: 591-602.

Colombaroli, D. \& Tinner, W. (2013): Determining the long-term changes in biodiversity and provisioning services along a transect from Central Europe to the Mediterranean. The Holocene, 23: 1625-1634.

Colombaroli, D., Beckmann, M., van der Knaap, W.O., Curdy, P. \& Tinner, W. (2013): Changes in biodiversity and vegetation composition in the central Swiss Alps during the transition from pristine forest to first farming. Diversity and Distributions, 19: 157-170.

Cui, Q.-Y., Gaillard, M.-J., Lemdahl, G., Sugita, S., Greisman, A., Jacobson, G.L. \& Olsson, F. (2013): The role of tree composition in Holocene fire history of the hemiboreal and southern boreal zones of southern Sweden, as revealed by the application of the Landscape Reconstruction Algorithm: Implications for biodiversity and climate-change issues. The Holocene, 23: 17471763.

Davis, M.B. (1963): On the theory of pollen analysis. American Journal of Science, 261: 897-912.

Davis, M.B. \& Deevey, E.S. (1964): Pollen Accumulation Rates: Estimates from Late-Glacial Sediment of Rogers Lake. Science, 145: 1293-1295.

Davis, M.B. (1967a): Pollen accumulation rates at Roger Lake, Connecticut during late and postglacial time. Review of Palaeobotany and Palynology, 2: 219-230.

Davis, M.B. (1967b): Pollen deposition in lakes as measured by sediment traps. Geological Society of America Bulletin, 78: 849-58.

Davis, M.B. (1973): Redeposition of pollen grains in lake sediment. Limnology and Oceanography, 18: 44-52.

Davis, M.B. \& Burbaker, L.B. (1973): Differential sedimentation of pollen grains in lakes. Limnology and Oceanography, 18: 635-646.

Davis, M.B., Brubaker, L.B. \& Webb, T. (1973): Calibration of absolute pollen influx. In: Birks, H.J.B., West, R.G. (Eds.), Quaternary Plant Ecology. Blackwell Scientific Publications, Oxford, pp. 925. 
Davis, M.B., Moeller, R.E. \& Ford, J. (1984): Sediment focusing and pollen influx. In: Haworth, E.Y., Lund, J.W.G. (Eds.), Lake Sediments and Environmental History. Univ. Leicester Press, Leicester UK, pp. 261-293.

Davis, M.B. (2000): Palynology after Y2K - understanding the source area of pollen in sediments. Annual Review of Earth and Planetary Sciences, 28: 1-18.

Dawson, T.P., Jackson, S.T., House, J.I., Prentice, I.C. \& Mace, G.M. (2011): Beyond Predictions: Biodiversity Conservation in a Changing Climate. Science, 332: 53-58.

Deutscher Wetterdienst (2014): Wetter und Klima aus einer Hand. Bundesministerium für Verkehr und digitale Infrastruktur. http://www.dwd.de/bvbw/appmanager/bvbw/dwdwwwDesktop? nfpb=true\& pageLabel= dwdwww klima umwelt klimadaten deutschland\&T82002gsbDocumentPath=Navigation\% 2FOeffentlichkeit\%2FKlima Umwelt\%2FKlimadaten\%2Fkldaten kostenfrei\%2Fdaten geb ietsmittel node.html\%3F nnn\%3Dtrue. (Access, 27 May, 2014).

Dyakowska, J. (1936): Research on the rapidity of the falling down of pollen of some trees. Bulletin international de l'Academie polonaise des sciences et des lettres, Classe des Sciences mathematiques et naturelles. Serie B, Sciences naturelles III, 155-69.

Endlicher, W. \& Hendl, M. (2003): Klimaspektrum zwischen Zugspitze und Rügen. In: Nationalatlas Bundesrepublik Deutschland. Klima, Pflanzen- und Tierwelt. Leibniz-Institut für Länderkunde (Hrsg.). Bd. 3. Spektrum Akademischer Verlag Heidelberg, Berlin.

Engel, J. (2010): Brandenburg - Kiefernland in Wandel. MILAktuell 2, 29-30.

Eisenhut, G. (1961): Untersuchung über die Morphologie und Ökologie der Pollenkörner heimischer und fremdländischer Waldbäume. Parey, Hamburg.

Fagerlind, F. (1952): The real signification of pollen diagrams. Botaniska Notiser, 185-224.

Fredh, D., Broström, A., Zillén, L., Mazier, F., Rundgren, M. \& Lageås, P. (2012): Floristic diversity in the transition from traditional to modern land-use in southern Sweden A.D. 1800-2008. Vegetation History and Archaeobotany, 21: 439-452.

Giesecke, T. \& Fontana, S.L. (2008): Revisiting pollen accumulation rates from Swedish lake sediments. The Holocene, 18: 293-305.

Giesecke, T., Fontana, S.L., van der Knaap, W.O., Pardoe, H.S. \& Pidek, I.A. (2010): From early pollen trapping experiments to the Pollen Monitoring Programme. Vegetation History and Archaeobotany, 19: 247-258.

Giesecke, T., Wolters, S., Jahns, S. \& Brande, A. (2012): Exploring Holocene Changes in Palynological Richness in Northern Europe - Did Postglacial Immigration Matter? PLoS ONE, 7: 1-11.

Giesecke, T., Ammann, B. \& Brande, A. (2014): Palynological richness and evenness - insights from the taxa accumulation curve. Vegetation History and Archaeobotany, 23: 217-228.

Goring, S., Lacourse T., Pellatt, M.G. \& Mathewes, R.W. (2013): Pollen assemblage richness does not reflect regional plant species richness: a cautionary tale. Journal of Ecology, 101: 1137-1145.

Gregory, P.H. (1973): The microbiology of the atmosphere. Leonard Hill, Aylesbury.

Haller, K.E. \& Fickler, H.-H. (1955): Waldbäume, Sträucher und Zwergholzgewächse. Winter, Heidelberg.

Hellmann, S., Gaillard, M.-J., Broström, A. \& Sugita, S. (2008): The REVEALS model, a new tool to estimate past regional plant abundance from pollen data in large lakes: validation in southern Sweden. Journal of Quaternary Science, 23: 21-42.

Hicks, S. (1992): Modern pollen deposition and its use in interpreting the occupation history of the island Hailuoto, Finland. Vegetation History and Archaeobotany, 1: 75-86.

Hicks, S., Tinsley, H., Huusko, A., Jensen, C., Hattestrand, M., Gerasimides, A. \& Kvavadze, E. (2001): Some comments on spatial variation in arboreal pollen deposition: first records from the Pollen Monitoring Programme (PMP). Review of Palaeobotany and Palynology, 117: 183-194.

Hicks, S., (2001): The use of annual arboreal pollen deposition values for delimiting tree-lines in the landscape and exploring models of pollen dispersal. Review of Palaeobotany and Palynology, 117, 1-29. 
Hicks, S. (2006): When no pollen does not mean no trees. Vegetation History and Archaeobotany, 15: 253-261.

Hill, M.O. (1973): Diversity and evenness: a unifying notation and its consequences. Ecology, 54: 427432.

Hjelle, K.L. (1998): Herb pollen representation in surface moss samples from mown meadows and pastures in western Norway. Vegetation History and Archaeobotany, 7: 79-96.

Hjelle, K.L. \& Sugita, S. (2012): Estimating pollen productivity and relevant source area of pollen using lake sediments in Norway: How does lake size variation affect the estimates? The Holocene, 22: 313-324.

Jacobson, G.L. \& Bradshaw, R.H.W. (1981): The selection of sites for paleovegetational studies. Quaternary Research, 16: 80-96.

Jackson, S.T. (1990): Pollen Source Area and Representation in Small Lakes of the Northeastern United States. Review of Palaeobotany and Palynology, 63: 53-76.

Jäger, E.J. (2011): Rothmaler. Excursionsflora von Deutschland. Gefäßpflanzen: Grundband. 20th edn. Spektrum Akademischer Verlag, Heidelberg.

Janssen, C.R. (1966): Recent pollen spectra from the deciduous and coniferous-deciduous forests of northeastern Minnesota: A study in pollen dispersal. Ecology, 47: 804-825.

Jantz, N., Homeier, J. \& Behling, H. (2014): Representativeness of tree diversity in the modern pollen rain of Andean montane forests. Journal of Vegetation Science, 25: 481-490.

Landesamt für Bergbau, Geologie und Rohstoffe Brandenburg (2010): Atlas zur Geologie von Brandenburg. 4. aktualisierte Auflage, Cottbus.

Libby, W.F. (1955): Radiocarbon Dating. University of Chicago Press, Chicago 175p.

Liedtke, H. \& Marcinek, J., (2002): Physische Geographie Deutschlands. Klett-Perthes, Gotha, Stuttgart.

Liedtke, H. \& Marschner, B. (2003): Bodengüte der landwirtschaftlichen Nutzflächen. In: Nationalatlas Bundesrepublik Deutschland. Relief, Boden- und Wasser. Leibniz-Institut für Länderkunde (Hrsg.). Bd. 2. Spektrum Akademischer Verlag Heidelberg, Berlin.

Likens, G.E. \& Davis, M.B. (1975): Post-glacial History of Mirror Lake and its Watershed in New Hampshire: an Initial Report. In: Mitteilungen Internationale Vereinigung für Theoretische und Angewandte Limnologie, 19, pp. 982-993.

Lockow, K.-W. \& Lockow, J. (2009): Die Hainbuche im nordostdeutschen Tiefland - Wuchsverhalten und Bewirtschaftungshinweise. In: Eberswalder Forstliche Schriftenreihe, Band 41.

Marquer, L., Gaillard, M.J., Sugita, S., Trondman, A.-K., Mazier, F., Nielsen, A.B., Fyfe, R.M., Odgaard, B.V., Aleniusg, T., Birks, H.J.B., Bjune, A.E., Christiansen, J., Dodsonk, J., Edwards, K.J., Giesecke, T., Herzschuh, U., Kangur, M., Lorenz, S., Poska, A., Schult, M. \& Seppä, H. (2014): Holocene changes in vegetation composition in northern Europe: why pollen-based quantitative reconstruction matters. Quaternary Sciences Reviews, 90: 199-216.

Matthias, I., Nielsen, A.B. \& Giesecke, T. (2012): Evaluating the effect of flowering age and forest structure on pollen productivity estimates. Vegetation History and Archaeobotany, 21: 471484.

Matthias, I. \& Giesecke, T. (2014): Insights into pollen source area, transport and deposition from modern pollen accumulation rates in lake sediments. Quaternary Science Reviews, 87: 12-23.

Matthias, I., Semmler, M.S.S. \& Giesecke, T. (2015): Pollen diversity captures landscape structure and diversity. Journal of Ecology, DOI: 10.1111/1365-2745.12404.

Mazaris, A.D., Kallimanis, A.S., Tzanopoulos, J., Sgardelis, S.P. \& Pantis, J.D. (2010): Can we predict the number of plant species from the richness of a few common genera, families or orders? Journal of Applied Ecology, 47: 662-670.

Mazier, F., Brostöm, A., Gaillard, M.J., Sugita, S., Vittoz, P. \& Buttler, A. (2008): Pollen productivity estimates and relevant source area of pollen for selected plant taxa in a pasture woodland landscape of the Jura mountains (Switzerland). Vegetation History and Archaeobotany, 17: 479-495. 
Meltsov, V., Poska, A., Odgaard, B.V., Sammul, M. \& Kull, T. (2011): Palynological richness and pollen sample evenness in relation to local floristic diversity in southern Estonia. Review of Palaeobotany and Palynology, 166: 344-351.

Meltsov, V., Poska, A., Reitlau, T., Sammul, M. \& Kull, T. (2013): The role of landscape structure in determining palynological and floristic richness. Vegetation History and Archaeobotany, 22: 39-49.

MLUV (2009): Agrarbericht 2009 zur Land- und Ernährungswirtschaft des Landes Brandenburg. Ministerium für Ländliche Entwicklung, Umwelt und Verbraucherschutz des Landes Brandenburg (MLUV). Landesamt für Verbraucherschutz, Landwirtschaft und Flurneuordnung. $\quad$ http://www.mil.brandenburg.de/sixcms/media.php/4055/ Agrarbericht_2009.pdf (accessed 27.02.12.).

Moore, P.D., Webb, J.A. \& Collinson, M.E. (1991): Pollen Analysis. Blackwell Scientific, Oxford.

Nielsen, A.B. (2003): Pollen-based quantitative estimation of land cover-relationships between pollen sedimentation in lakes and land cover as seen on historical maps in Denmark A.D. 1800. Doctoral thesis, University of Copenhagen.

Nielsen, A.B. \& Sugita, S. (2005): Estimating relevant source area of pollen for small Danish lakes around AD 1800. Holocene, 15: 1006-1020.

Odgaard, B.V. (1993): Wind-determined sediment distribution and Holocene sediment yield in a small, Danish, kettle lake. Journal of Paleolimnology, 8: 3-13.

Odgaard, B.V. (1994) The Holocene vegetation history of northern West Jutland, Denmark. Opera Botanica, 123: 1-171.

Odgaard, B.V. (1999): Fossil pollen as a record of past biodiversity. Journal of Biogeography, 26: 7-17.

Odgaard, B.V. (2007): Reconstructing past biodiversity development. In: Elias SA (Ed.), Encyclopaedia of Quaternary Science. Elsevier, pp 2508-2514.

Odgaard, B.V. (2008): Does pollen type diversity reflect vegetation diversity? Terra Nostra 2008/2: 209.

Oksanen, J. (2013): Vegan: ecological diversity. Id: diversity-vegan. Rnw 2597 2013-08-28 08:56:55Z jarioksa processed with vegan 2.0-9 in R Under development (unstable) (2013-09-25 r63985) on September 25, 2013.

Parsons, R.W. \& Prentice, I.C. (1981): Statistical approaches to R-values and pollen-vegetation relationship. Review of Palaeobotany and Palynology, 32: 127-152.

Pennington, W. (1973): Absolute pollen frequencies in the sediments of lakes of different morphometry. In: Birks, H.J.B. \& West, R.G. (Eds.), Quaternary Plant Ecology, $14^{\text {th }}$ Symposium of the British Ecological Society. Blackwell Scientific Publications, Oxford.

Poska, A., Saarse, L. \& Veski, S. (2004): Reflections of pre- and early-agrarian human impact in the pollen diagrams of Estonia. Palaeogeography, Palaeoclimatology, Palaeoecology, 209: 37-50.

Poska, A., Meltsov, V., Sugita, S. \& Vassiljev, J. (2011): Relative pollen productivity estimates of major anemophilous taxa and relevant source area of pollen in a cultural landscape of the hemiboreal forest zone (Estonia). Review of Palaeobotany and Palynolnology, 167: 30-39.

Prentice, I.C. \& Parsons, R.W. (1983): Maximum likelihood linear calibration of pollen spectra in terms of forest composition. Biometrics, 39: 1051-1057.

Prentice, I.C. (1985): Pollen Representation, Source Area, and Basin Size: Toward a Unified Theory of Pollen Analysis. Quaternary Research, 23: 76-86.

Prentice, C. (1988): Records of vegetation in time and space: the principles of pollen analysis. In Vegetation history, Springer Netherlands, pp. 17-42.

Raven, P.H., Evert, R.F. \& Eichhorn S.E. (2000): Biologie der Pflanzen. 3th edn.Walter de Gruyter, Berlin, New York.

Raynor, G.S., Hayes, V. \& Ogden, E.C. (1974): Particulate dispersion into and within a forest. Meteorology, 7: 429-456.

Räsänen, S., Suutari, H. \& Nielsen, A.B. (2007): A step further towards quantitative reconstruction of past vegetation in Fennoscandian boreal forests: Pollen productivity estimates for six dominant taxa. Review of Palaeobotany and Palynology, 146: 208-220. 
Renberg, I. (1991): The HON-Kajak sediment corer. Journal of Paleolimnology, 6: 167-170.

Rispens, J.A. (2003): Der Nadelbaumtypus - Schritte zu einem imaginativen Baumverständnis. Elemente der Naturwissenschaft, 79: 51-77.

Rull, V. (1987): A note on pollen counting in palaeoecology. Pollen et Spores, 29: 471-480.

Schober, R. (1975): Ertragstafeln wichtiger Baumarten bei verschiedener Durchforstung. Sauerländer, Frankfurt a. M.

Schröck, O. (1949): Die Vererbung der Frühblüte der Kiefer. Der Züchter, 19: 247-254.

Schütt, P., Weisgerber, H., Schuck, H.-J., Lang, U., Stimm, B. \& Roloff, A. (2006): Enzyklopädie der Laubbäume. Nikol, Hamburg.

Schwartz, M. W. (1989): Predicting tree frequencies from pollen frequency: an attempt to validate the R value method. New Phytologist, 112: 129-143.

Seppä, H. \& Hicks, S. (2006): Integration of modern and past pollen accumulation rate (PAR) records across the arctic tree-line: a method for more precise vegetation reconstructions. Quaternary Science Reviews, 25: 1501-1516.

Seppä, H., Alenius, T., Muukkonen, P., Giesecke, T., Miller, P.A. \& Ojala, A.E.K. (2009): Calibrated pollen accumulation rates as a basis for quantitative tree biomass reconstructions. The Holocene, 19: 209-220.

Smith, B. \& Wilson, J.N. (1996): A consumer's guide to evenness indices. Oikos, 76: 70-82.

Soepboer, W., Sugita, S., Lotter, A.F., Van Leuwen, J.F.N. \& Van der Knaap, W.O. (2007): Pollen productivity estimates for quantitative reconstruction of vegetation cover on the Swiss Plateau. The Holocene, 17: 1-13.

Stinglwagner, G., Haseder, I. \& Erlbeck, R. (2005): Das Kosmos Wald- und Forstlexikon. Kosmos, Stuttgart.

Stockmarr, J. (1971): Tablets with spores used in absolute pollen analysis. Pollen et Spores, 13: 615621.

Sugita, S. (1993): A model of pollen source area for an entire lake surface. Quaternary Research, 39: 239-244.

Sugita, S. (1994): Pollen representation of vegetation in quaternary sediments: theory and method in patchy vegetation. Journal of Ecology, 82: 881-897.

Sugita, S., Gaillard, M.J. \& Broström, A. (1999): Landscape openness and pollen records: A simulation approach. The Holocene, 9, 409-421.

Sugita, S. (2007a): Theory of quantitative reconstruction of vegetation I: pollen from large sites REVEALS regional vegetation composition. The Holocene, 17: 229-241.

Sugita, S. (2007b): Theory of quantitative reconstruction of vegetation II: all you need is LOVE. The Holocene, 17:2 43-257.

Sugita, S., Parshall, T., Calcote, R. \& Walker, K. (2010a): Testing the Landscape Reconstruction Algorithm for spatially explicit reconstruction of vegetation in northern Michigan and Wisconsin. Quaternary Research, 74: 289-300.

Sugita, S., Hicks, S. \& Sormunen, H., (2010b): Absolute pollen productivity and pollen-vegetation relationships in northern Finland. Journal of Quaternary Science, 25: 724-736.

Sutton, O.G. (1953): Micrometeorology: a study of physical processes in the lowest layers of the Earth's atmosphere. New York: McGraw-Hill Book Conpany, Inc.

Tauber, H. (1965): Differential pollen dispersion and the interpretation of pollen diagrams. Danmarks Geologiske Undersogelse, 89: 1-69.

Tauber, H. (1977): Investigations of aerial pollen transport in a forested area. Dansk Botanisk Arkiv, 32: 1-221.

Theuerkauf, M., Kuparinen, M. \& H. Joosten (2013): Pollen productivity estimates strongly depend on assumed pollen dispersal. The Holocene, 23: 14-24.

Thomas, C.D., Cameron, A., Green, R.E., Bakkenes, M., Beaumont, L.J., Collingham, Y.C., Erasmus, B.F.N., de Siqueira, M.F., Grainger, A., Hannah, L., Hughes, L., Huntley, B., van Jaarsveld, A.S., Midgley, G.F., Miles, L., Ortega-Huerta, M.A., Peterson, A.T., Phillips, O.L. \& Williams, S.E. (2004): Extinction risk from climate change. Nature, 427: 145-148. 
Thuiller, W., Lavorel, S., Araujo, M.B., Sykes, M.T. \& Prentice, I.C. (2005): Climate change threats to plant diversity in Europe. PNAS, 102: 8245-8250.

Tinner, W., Hubschmid, P., Wehrli, M., Ammann, B. \& Conedera, M. (1999): Long term forest fire ecology and dynamics in southern Switzerland. Journal of Ecology, 87: 273-289.

Tuomisto, H. (2012): An updated consumer's guide to evenness and related indices. Oikos, 121: $1203-1218$.

Umweltbundesamt \& DLR-DFD (2004): CORINE Land Cover 2000. Daten zur Bodenbedeckung Deutschland. http://www.corine.dfd.dlr.de.

Venables, W.N. \& Ripley, B.D. (2002): Modern Applied Statistics with S. Fourth Edition. Springer, New York.

Von Post, L. (1918): Skogsträdspollen i sydsvenskatorfmosslagerföljder. In: Forhandlingerved de 16. Skandinaviske Naturforskeresmøte 1916, pp. 433-465.

Von Stedingk, H., Fyfe, R. \& Allard, A. (2008): Pollen productivity estimates from the forest-tundra ecotone in west-central Sweden: implications for vegetation reconstruction at the limits of the boreal forest. The Holocene 18: 323-332.

Welten, M. (1944): Pollenanalytische, stratigraphische und geochronologische Untersuchungen aus dem Faulenseemoos bei Spiez. Veröffentlichungen Geobotanisches Institut Rübel, 21: 1-201.

Weng, C., Hooghiemstra, H. \& Duivenvoorden, J.F. (2006): Challenges in estimating past plant diversity from fossil pollen data: statistical assessment, problems, and possible solutions. Biodiversity Research, 12: 310-318.

Willemstein, S.C. (1987): An Evolutionary Basis for Pollination Ecology. Leiden botanical series Vol. 10. E. J. Brill, Leiden.

Willis, K.J., Bailey, R.M., Bhagwat, S.A. \& Birks, H.J.B. (2010): Biodiversity baselines, thresholds and resilience: testing predictions and assumptions using palaeoecological data. Trends in Ecology and Evolution, 25: 583-591. 


\section{Chapter 2}

\section{Evaluating the effect of flowering age and forest structure on pollen productivity estimates}

Isabelle Matthias ${ }^{1}$, Anne Birgitte Nielsen ${ }^{1} \&$ Thomas Giesecke $^{1}$

${ }^{1}$ Department of Palynology and Climate Dynamics, Albrecht-von-Haller Institute for Plant Sciences, University of Göttingen, 37073 Göttingen, Germany

Vegetation History and Archaeobotany (2012) 21:471-484

DOI 10.1007/s00334-012-0373-z

(C) Springer 


\begin{abstract}
Pollen productivity estimates (PPEs) are indispensable prerequisites for quantitative vegetation reconstructions. Estimates from different European regions show a large variability and it is uncertain whether this reflects regional differences in climate and soil or is brought about by different assessments of vegetation abundance. Forests represent a particular problem as they consist of several layers of vegetation and many tree species only start producing pollen after they have attained ages of several decades. Here we used detailed forest inventory data from north-eastern Germany to investigate the effect of flowering age and understory trees on PPEs. Pollen counts were obtained from 49 small to medium sized lakes chosen to represent the different forest types in the region. Surface samples from lakes within a closed forest of Fagus yielded disproportionate amounts of Fagus pollen, increasing its PPE and the variability of all other estimates. These samples were removed from further analysis but indicate a high trunk-space component that is not considered in the Prentice-Sugita pollen dispersal and deposition model. Results of the restricted dataset show important differences in PPEs based on the consideration of flowering age and understory position. The effect is largest for slow growing and/or late flowering trees like Fagus and Carpinus while it is minimal for species that flower early in their development like Betula and Alnus. The large relevant source area of pollen (RSAP) of $7 \mathrm{~km}$ obtained in this study is consistent with the landscape structure of the region.
\end{abstract}

Keywords: Germany, Relevant source area of pollen, Pollen productivity estimates, Forest structure, Flowering age, Surface samples

\title{
2.1 Introduction
}

It is an old dream of quaternary palynologists to translate pollen diagrams into quantitative representations of past plant abundance (Davis 2000). This is especially important where pollen analytical results are used by neighboring disciplines like archeology (Gaillard 2007) and vegetation or climate modeling (Miller et al. 2008; Gaillard et al. 2010). Also the influence of land use and abiotic factors on regional vegetation patterns can only be evaluated if it is possible to reduce the effect of differential pollen production and dispersal in vegetation reconstructions (Nielsen et al. 2012). Studies investigating the pollen vegetation relationship have been conducted for several decades and the concept of finding factors for correcting pollen proportions to reflect the vegetation abundance goes back to Davis (1963). However, the non-linearity between pollen and vegetation proportions hampered the application of simple correction factors. The development of the extended R-value (ERV) model was intended to correct for the nonlinearity, and allow the estimation of the relative 
pollen productivity of different species (Parsons and Prentice 1981; Prentice and Parsons 1983). This approach was combined with knowledge from studies on pollen transport (e.g. Tauber 1965) to develop numerical models that separate the two species-specific components: pollen production and pollen dispersal (Prentice 1985; Sugita 1993, 1994). Using these models, the dispersal and deposition of pollen can be simulated based on the different fall speed of differently shaped pollen types, which can be estimated or measured directly (Eisenhut 1961), provided estimates of relative pollen productivity are available. Over the last decade, continued theoretical development has led to a conceptual framework that realizes the longstanding dream of quantitative vegetation reconstructions (Sugita 2007a, b; Gaillard et al. 2008). Together with the development of userfriendly computer programs (Sugita 2007a, b; Bunting and Middleton 2005), this has given the impulse for many palynologists to work towards quantitative reconstructions. As mentioned before, pollen productivity estimates (PPEs) are a very important component of these models, but estimating the relative (or absolute) production of pollen of different plant species remains a challenge, as many different factors influence the results (Broström et al. 2008). Moreover, each study addressing the pollen-vegetation relationship to obtain PPEs provides new information to test the models and theoretical concepts of pollen transport and deposition, highlighting potential factors influencing the calculation of PPEs and adding confidence to future reconstructions. Recently a number of these studies have been carried out in Europe: e.g. Norway (Hjelle 1998), Sweden (Sugita et al. 1999; Broström et al. 2004; Von Stedingk et al. 2008), Denmark (Nielsen 2004), England (Bunting et al. 2005), Finland (Räsänen et al. 2007), Estonia (Poska et al. 2011), northern Germany (Theuerkauf et al. 2012), and the Czech Republic (Abraham and Kozáková 2012) as well as for the Swiss Jura (Mazier et al. 2008) and the Swiss Plateau (Soepboer et al. 2007). Initial comparisons of different regional studies revealed large differences in estimated PPEs, which may be due to real differences in pollen production, brought about by regionally different climate or soils, but could also stem from methodological differences (Broström et al. 2008). The influence of vegetation survey methods on PPEs have been shown on the small scale for heathland vegetation in Norway (Bunting and Hjelle 2010), but have so far not been investigated for different assessments of forest vegetation on a landscape scale.

Forests are multi-layered and trees require a number of years of growth before they start to produce flowers and shed pollen. While the former factor will influence the assessment of vegetation cover, the latter affects the vegetation-pollen relationship directly. For example, a 15-year-old plantation of Pinus will hardly be the source of much Pinus pollen, while it will appear like a dense forest on an aerial photograph or satellite image. Even when a vegetation survey is conducted on the ground, it is difficult to decide whether or not a Fagus tree has reached flowering age. 
The forest inventory data in north-eastern Germany are exceptionally detailed and thus permit the assessment of the influence of flowering age and canopy structure on PPEs. Moreover, as the data are available in digitized formats there is little limitation to the area that can be used in the analysis.

The aim of this study is: (i) to contribute to the emerging dataset on regional relative PPEs with a focus on tree species; (ii) to examine what influence flowering age and understory position have on PPEs of the major tree species.

\subsection{Material and methods}

\subsubsection{Study area}

For this study we have chosen the state of Brandenburg in the eastern part of Germany, because it

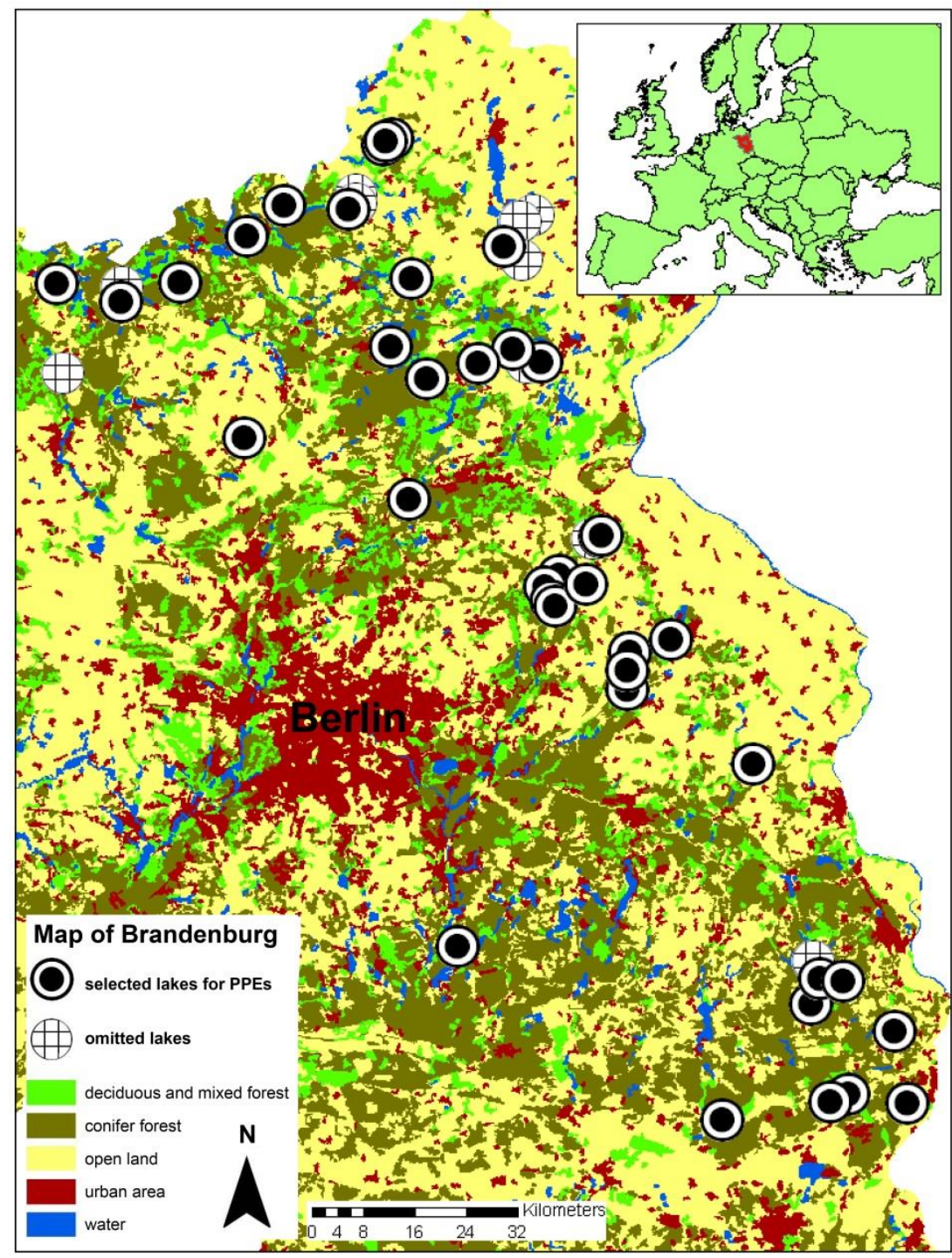

Fig. 2.1 Vegetation map of Brandenburg, based on CORINE Land Cover 2000 (Umweltbundesamt, DLR-DFD 2004) with the study sites. Inset: map of Europe showing the state of Brandenburg, where the study area is situated has a large number of lakes and different forest types (Fig. 2.1) for which detailed inventory data are available. The maximum limit of the Scandinavian ice sheet runs through Brandenburg in a NW to SE direction and this study was confined to the glaciated part with abundant lakes. The area is characterized by series of ground and terminal moraines and outwash plains with different soil substrates (Liedtke and Marcinek 2002). Climatically, Brandenburg is situated between the oceanic climate of Western Europe and the continental climate further east. Precipitation ranges between 450 and 720 $\mathrm{mm}$, with the driest areas in

the southeast (Linke et al. 2010). The state of Brandenburg has a forest cover of $37 \%$ (1.09 million 
ha) of which pine forests constitute $70 \%$ and mixed forests about $11 \%$ (Engel 2010). The agriculturally used area represents $45 \%$ (1.32 million ha) consisting of $78.3 \%$ arable land and $21.3 \%$ pastures (MLUV 2009).

\subsubsection{Sample collection and preparation}

The depositional environment has an influence on the pollen composition (Giesecke and Fontana 2008; Pardoe et al. 2010) and when studying the pollen-vegetation relationship it is therefore important to standardize the size and type of sampling site as much as possible to reduce this variability. We aimed at sampling small lakes with a single, simple basin with as small a peat margin as possible and without permanent inflow. Lakes that were deeper in proportion to the lake size were preferred, to avoid lakes with a high sediment redeposition (Giesecke and Fontana 2008). The estimation of pollen productivity requires samples from sites situated within different vegetation types so that abundance gradients for different taxa can be obtained. In order to achieve this, the constraint of uniform lake size had to be relaxed. Potential lakes were selected from topographical maps, aerial and satellite photographs and their suitability was assessed in the field. In this way a total of 49 lakes ranging between 0.5 and 32 ha were selected and sampled (Table 2.1).

Sampling was carried out during the spring and summer of 2009 using a HON-Kajak sediment corer (Renberg 1991) with a $10 \mathrm{~cm}$ diameter. The short cores obtained were sampled in the field at $1 \mathrm{~cm}$ intervals beginning at the sediment water interface (or shortly above it where the interface was diffuse). Samples were stored in small plastic bags at $4{ }^{\circ} \mathrm{C}$ until processing.

In the lab a subsample of $1 \mathrm{~cm}^{3}$ was taken from the uppermost sample of each short core using a syringe. In a few cases from cores with a diffuse sediment-water interface this sample yielded a very low pollen concentration and here the second sample in the short core was also subsampled and processed. The subsamples were processed for pollen analysis following the general procedure described by Bennett and Willis (2001), without sieving and using a 2 min acetolysis. The sample residues were mounted in glycerol and counted at 400x magnification, while cereals were identified at 1,000x magnification. The pollen was identified using the keys of Beug (2004) and Moore et al. (1991), and the reference collection of the Department of Palynology and Climate Dynamics, Göttingen University. A minimum of 1,000 terrestrial pollen grains were counted in each sample. The pollen sum is defined as the sum of all terrestrial pollen grains. 
Table 2.1 Characteristics of the study sites

\begin{tabular}{|c|c|c|c|c|c|c|}
\hline \multirow[t]{2}{*}{ No } & \multirow[t]{2}{*}{ Name } & \multirow{2}{*}{$\begin{array}{r}\text { Latitude } \\
\text { (decimal degrees) }\end{array}$} & \multirow{2}{*}{$\begin{array}{l}\text { Longitude } \\
\text { (decimal degrees) }\end{array}$} & \multirow[t]{2}{*}{ Size (ha) } & \multirow[t]{2}{*}{ Radius (m) } & \multirow[t]{2}{*}{ Depth $(\mathrm{m})$} \\
\hline & & & & & & \\
\hline 1 & Steinsee & 53.31843 & 13.6226 & 6.7 & 146 & 3.5 \\
\hline 2 & Petznicksee & 53.31551 & 13.6093 & 13.1 & 204 & 7.3 \\
\hline 3 & Kleiner Petznicksee & 53.31142 & 13.6018 & 5.1 & 127 & 2 \\
\hline 4 & ${ }^{*}$ Hausseebruch & 53.24517 & 13.5306 & 3 & 98 & 10.1 \\
\hline 5 & Tiefer See & 53.23517 & 13.3631 & 17.2 & 234 & 33.7 \\
\hline 6 & *Tiefer Clöwen & 53.23330 & 13.5311 & 8.5 & 165 & 10.3 \\
\hline 7 & Poviestsee & 53.22387 & 13.5124 & 22 & 265 & 11.7 \\
\hline 8 & *Kleiner Rathsburgsee & 53.20058 & 13.9394 & 3.2 & 101 & 6.6 \\
\hline 9 & Kleiner Lychensee & 53.19640 & 13.2704 & 8.5 & 165 & 13.7 \\
\hline 10 & *Bugsee & 53.19298 & 13.9100 & 1.5 & 69 & 6 \\
\hline 11 & Kleiner Trinsee & 53.15804 & 13.8674 & 1.1 & 59 & 5.6 \\
\hline 12 & Kleiner Zermittensee & 53.14401 & 12.8227 & 5.8 & 136 & 7.3 \\
\hline 13 & ${ }^{*}$ Aalgastsee & 53.13914 & 13.9050 & 0.8 & 51 & 3.3 \\
\hline 14 & Weißesee & 53.13679 & 13.1089 & 5.8 & 136 & 8.2 \\
\hline 15 & ${ }^{*}$ Glabatzsee & 53.13607 & 12.9745 & 2 & 80 & 7.3 \\
\hline 16 & Temnitzsee & 53.12171 & 13.6462 & 9.9 & 178 & 6.7 \\
\hline 17 & Plötzensee & 53.11484 & 12.9704 & 5.7 & 135 & 8.8 \\
\hline 18 & Kleiner Gollinsee & 53.02887 & 13.5882 & 3.2 & 101 & 3.3 \\
\hline 19 & ${ }^{*}$ Teufelssee & 53.01995 & 12.8263 & 4.8 & 124 & 12 \\
\hline 20 & Heiliger See & 53.01560 & 13.8720 & 9.1 & 170 & 10.8 \\
\hline 21 & Dovinsee & 52.99795 & 13.7881 & 20.8 & 257 & 7 \\
\hline 22 & *Schwarzersee & 52.99400 & 13.9030 & 3.3 & 103 & 4.7 \\
\hline 23 & Kleiner Plunzsee & 52.99271 & 13.9359 & 2.8 & 94 & 3.8 \\
\hline 24 & Runder Köllnsee & 52.98064 & 13.6685 & 2.7 & 93 & 3.9 \\
\hline 25 & Papensee & 52.91403 & 13.2390 & 5.9 & 137 & 8.3 \\
\hline 26 & Buckowsee & 52.81319 & 13.6087 & 13.8 & 210 & 8.8 \\
\hline 27 & Schiebelsee & 52.74569 & 14.0463 & 0.5 & 40 & 4.1 \\
\hline 28 & Sonnenburger Fenn & 52.74459 & 14.0419 & 2.3 & 86 & 3.5 \\
\hline 29 & *Baasee & 52.74333 & 14.0258 & 2.2 & 84 & 3.6 \\
\hline 30 & Röthsee & 52.69485 & 13.9429 & 3.3 & 103 & 2.7 \\
\hline 31 & Modderpfuhl & 52.67960 & 13.9084 & 1.7 & 74 & 3.8 \\
\hline 32 & Sternebecker See & 52.67933 & 14.0025 & 7.7 & 157 & 10.8 \\
\hline 33 & Piechesee & 52.65964 & 13.9211 & 4.5 & 120 & 3 \\
\hline 34 & Blumenthalsee & 52.65168 & 13.9272 & 8.4 & 164 & 4.2 \\
\hline 35 & Staffsee & 52.59436 & 14.1890 & 9.6 & 175 & 3.8 \\
\hline 36 & Kleiner Tornowsee & 52.57950 & 14.0930 & 3.8 & 110 & 10 \\
\hline 37 & Schwarzer See & 52.55541 & 14.0835 & 7.1 & 150 & 4.3 \\
\hline 38 & Kesselsee & 52.52920 & 14.0796 & 2.7 & 93 & 7.8 \\
\hline 39 & Kessel See & 52.41206 & 14.3562 & 3.5 & 106 & 1.2 \\
\hline 40 & Karbuschsee & 52.18666 & 13.6543 & 12.2 & 197 & 17.5 \\
\hline 41 & *Kleiner Treppelsee & 52.13257 & 14.4585 & 5.4 & 131 & 4.5 \\
\hline 42 & Ziskensee & 52.10599 & 14.4699 & 2.6 & 91 & 4.4 \\
\hline 43 & Klautzkesee & 52.09969 & 14.5223 & 6.4 & 143 & 1.8 \\
\hline
\end{tabular}




\begin{tabular}{|c|c|c|c|c|c|c|}
\hline No & Name & Latitude & Longitude & Size (ha) & Radius (m) & Depth (m) \\
\hline 44 & Rähdensee & 52.07074 & 14.4465 & 11.8 & 194 & 6.3 \\
\hline 45 & Buchwaldsee & 52.02388 & 14.6300 & 1.9 & 78 & 2.3 \\
\hline 46 & Kleinsee & 51.94195 & 14.5101 & 14 & 211 & 2 \\
\hline 47 & Großsee & 51.93298 & 14.4719 & 31.7 & 318 & 8.3 \\
\hline 48 & Deulowitzer See & 51.92377 & 14.6467 & 13.9 & 210 & 4 \\
\hline 49 & Teersee & 51.91930 & 14.2263 & 8 & 160 & 3.7 \\
\hline
\end{tabular}

* Lakes with more than 5 ha Fagus within a radius of $250 \mathrm{~m}$ from the lake centre, omitted from the restricted dataset

\subsubsection{Vegetation data}

Detailed inventories of East German forests started before the 1940s and intensified during the 1960s and 70s. Much of this information has been continually updated and later digitized and collected in forest inventory databases. The states of Brandenburg, Mecklenburg-Vorpommern and Thuringia have collected this information with a standardized format in the database "Datenspeicher

Wald"' (DSW2;http://www.dsw2.de/index.html).

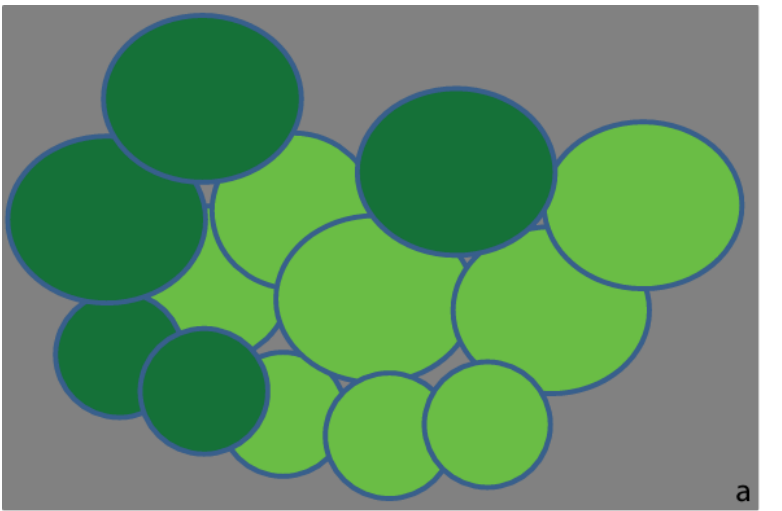

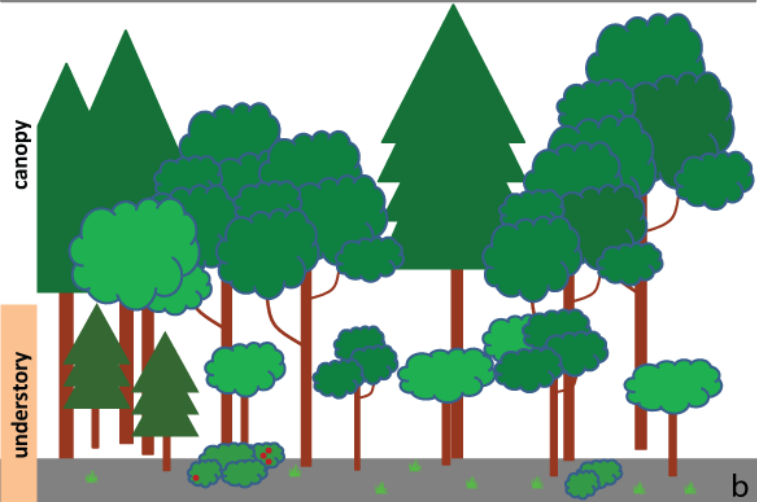

Fig. 2.2 a Example of a forest canopy from above, which is the basis for estimates of tree abundance from aerial photographs and satellite images; $\mathbf{b}$ a simplification of canopy layers as recognized in the forest inventory data illustrating the classification in canopy and understory that was used here
Most of the forest inventory data for Brandenburg and adjacent parts of Mecklenburg-Vorpommern may be obtained from this database. However, large parts of the forest in Brandenburg are owned by the German Federation and partly administered by a federal agency "Bundesanstalt für Immobilienaufgaben", who provided the same type of forest inventory data for the immediate study area. For each forest stand, the inventory data contain information on the absolute tree cover, age, and wood volume as well as forest structure differentiated into several layers e.g. superstructure, rejuvenation, understory. These layers were classified into two stories, canopy, and understory. Unlike a bird's-eye view, as obtained from aerial and satellite images the database yields information on the total ground cover of individual species (Fig. 2.2). Information about the cover on different types of nonforested vegetation was derived from the biotope and land-use mapping project (CIR-Biotop- und Landnutzungstypenkartierung download: http://www.mugv.brandenburg.de/cms/detail.php/bb2.c.515599.de, 2009 version, accessed 1 
December 2010). This map was constructed in 1991-1996 and is updated annually. The map was reclassified and generalized so that the resulting units would represent unique combinations of plants that were considered in the PPE calculations. The area of arable fields was assigned to a mixture of crops according to information of yield for the year 2009 (MLUV 2009), assuming an even distribution of cultivation of the different crops in Brandenburg.

All spatial data were combined and handled in ArcGIS 9 (ESRI) and Excel (Microsoft), and the vegetation cover data within a radius of $15 \mathrm{~km}$ around each sampling site was extracted in four different ways:

1. All forest inventory data were included (allFID).

2. Forest data were included if the flowering age of the different trees and shrubs had been reached (allFIDage).

3. Only data from the canopy layer were included, while information on understory trees was excluded (canopyFID).

4. Only data from the canopy layer were included, and only if the flowering age of the different taxa was reached (canopyFIDage). The information on the flowering age for the trees was obtained from the literature (Table 2.2).

\subsubsection{ERV analysis}

The four different sets of assembled vegetation information for a radius of $15 \mathrm{~km}$ around the lakes were compared to pollen percentages in the surface samples. For distance weighting, vegetation data was compiled in $250 \mathrm{~m}$-wide rings for the first $\mathrm{km}$ and one $\mathrm{km}$-wide rings from 1 to $15 \mathrm{~km}$ distance from the center of the lake. To evaluate the effect of ring width on the results we compiled one test set with $200 \mathrm{~m}$ rings over the first $3 \mathrm{~km}$. Calculations of PPEs and the relevant source area of pollen (RSAP) were conducted using the Program ERV-Analysis 1.2.3 (Sugita unpublished). Each of the three different ERV submodels (Prentice and Parsons 1983; Sugita 1994) were applied using the Ring Source model (Sugita et al. 1999) to distance-weight the vegetation data. Wind speed was set to $3 \mathrm{~m} / \mathrm{sec}$ and pollen fall speeds were taken from the literature or estimated (Table 2.2). Lake radii were set to an average radius of $140 \mathrm{~m}$ (Nielsen and Sugita 2005; Soepboer et al. 2007). We used Pinus as a reference taxon as it is abundant in the vegetation and pollen samples from all sites and represents mainly the single native species, Pinus sylvestris. Initial analysis of the full dataset showed that model performance was improved by reducing the samples to a subset of 39 lakes, omitting lakes where Fagus exceeded a cover of 5 ha within a radius of $250 \mathrm{~m}$ from the center of the lake.

We calculated PPEs for 16 taxa (Table 2.2), of which one is a group of taxa. This group is labeled "wild herbs" and consists of the uncultivated terrestrial herb pollen, including e.g. Poaceae, Plantago lanceolata, Rumex acetosa, R. acetosella, and Chenopodiaceae, with Poaceae being the most 
abundant. The fall speed for the wild herbs was estimated, using the fall speed of the most frequent taxa in this group.

Table 2.2 Pollen fall speed of 16 taxa and the flowering age considered for the tree taxa

\begin{tabular}{|c|c|c|c|c|}
\hline pollen taxa & $\begin{array}{l}\text { fall speed } \\
\text { (m sec-1) }\end{array}$ & tree taxa & $\begin{array}{r}\text { flowering } \\
\text { age }\end{array}$ & \\
\hline Alnus & $0.021^{\mathrm{a}}$ & Alnus glutinosa & $10^{d}$ & Eisenhut (1961) \\
\hline Betula & $0.022^{\mathrm{a}}$ & Betula pendula & $10^{d}$ & b Gregorv (1973) \\
\hline Carpinus & $0.042^{\mathrm{a}}$ & Carpinus betulus & $30^{d}$ & \\
\hline Fagus & $0.057^{b}$ & Fagus sylvatica & $50^{d}$ & ${ }^{c}$ Cerealia in Soepboer et al. \\
\hline Fraxinus & $0.022^{\mathrm{a}}$ & Fraxinus excelsior & $30^{d}$ & 2007 \\
\hline Larix (and Pseudotsuga) & $0.126^{\mathrm{a}}$ & Larix & $10^{\mathrm{e}}$ & ${ }^{d}$ Schütt et al (2006) \\
\hline Picea & $0.056^{\mathrm{a}}$ & Picea & $40^{f}$ & \\
\hline Pinus & $0.031^{\mathrm{a}}$ & Pinus & $20^{f \& g^{* *}}$ & Haller and Fickler (1955) \\
\hline Populus & $0.025^{a}$ & Populus alba & $20^{d}$ & ${ }^{f}$ Rispens (2003) \\
\hline Quercus & $0.035^{\mathrm{a}}$ & Pseudotsuga & $30^{\text {h }}$ & \\
\hline Tilia & $0.032^{\mathrm{a}}$ & Quercus robur & $30^{d}$ & Schröck (1949) \\
\hline Avena-type & $0.078^{c}$ & Tilia cordata & $20^{e}$ & ${ }^{\mathrm{h}}$ Stinglwagner et al. (2005) \\
\hline Hordeum-type & $0.06^{*}$ & & & * Estimated fall speed, $* *$ \\
\hline Secale & $0.06^{b}$ & & & average value \\
\hline Triticum-type & $0.078^{c}$ & & & \\
\hline wild herbs & $0.03425^{*}$ & & & \\
\hline
\end{tabular}

\subsection{Results}

All of the lakes sampled are surrounded by at least some trees and most are adjacent to or within closed canopy forest, as this is where most detailed vegetation information is available. This close proximity of the lakes to forested land explains the high tree pollen proportions of up to $95 \%$ in the surface samples. It is noteworthy that the amount of tree pollen is above $75 \%$ in all samples, even though the overall tree cover in the state of Brandenburg is only $37 \%$. The pollen diagram (Fig. 2.3) presents all 49 sampled lakes along a north-south gradient, illustrating the regional distribution limit of Fagus. Regardless of the extra-local abundance of Fagus in the region, lakes where the tree dominates the shore of the lake were found to stand out in their abundance of Fagus pollen (Fig. 2.4) and were therefore omitted from further analysis. The restricted dataset contains a good dispersion of pollen abundance for the following taxa: Alnus (4-37\%), Betula (6-24\%), Fagus (0.2-12\%), Pinus (17-58 \%), Quercus (3-19\%), and the wild herbs (3-18\%). Although a maximum of $19 \%$ Carpinus pollen is represented in one sample, the pollen type is restricted to few samples. Also pollen of Fraxinus (0-4\%), Populus (0-1\%), and Tilia cordata (0-2\%) only occurs in a small number of samples, while Picea (0-4 \%) as well as the cereal pollen types occur in many samples with low abundances. 


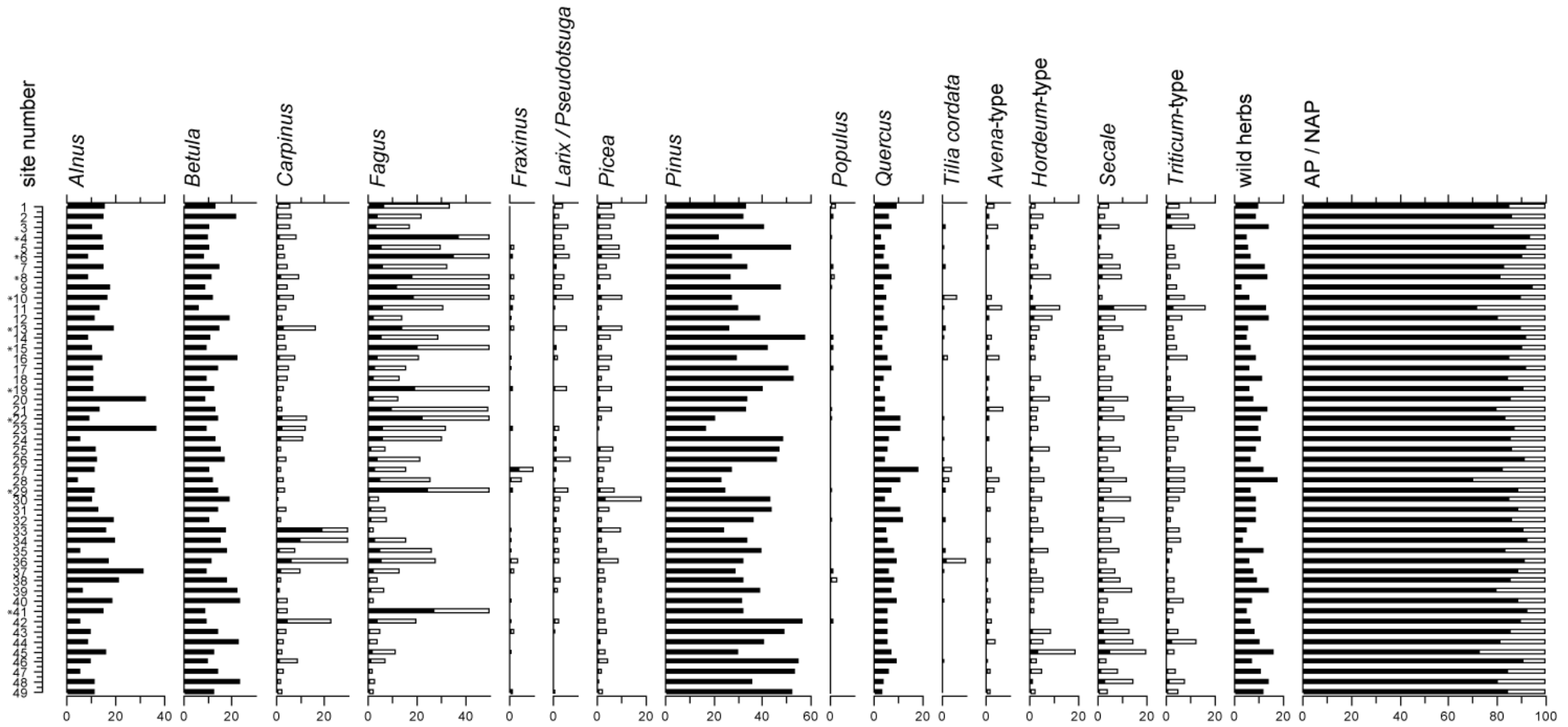

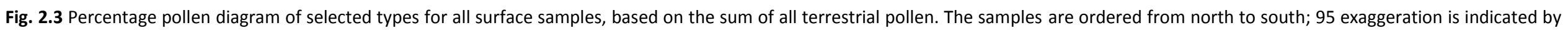
hollow bars. Asterisks mark the omitted lakes 


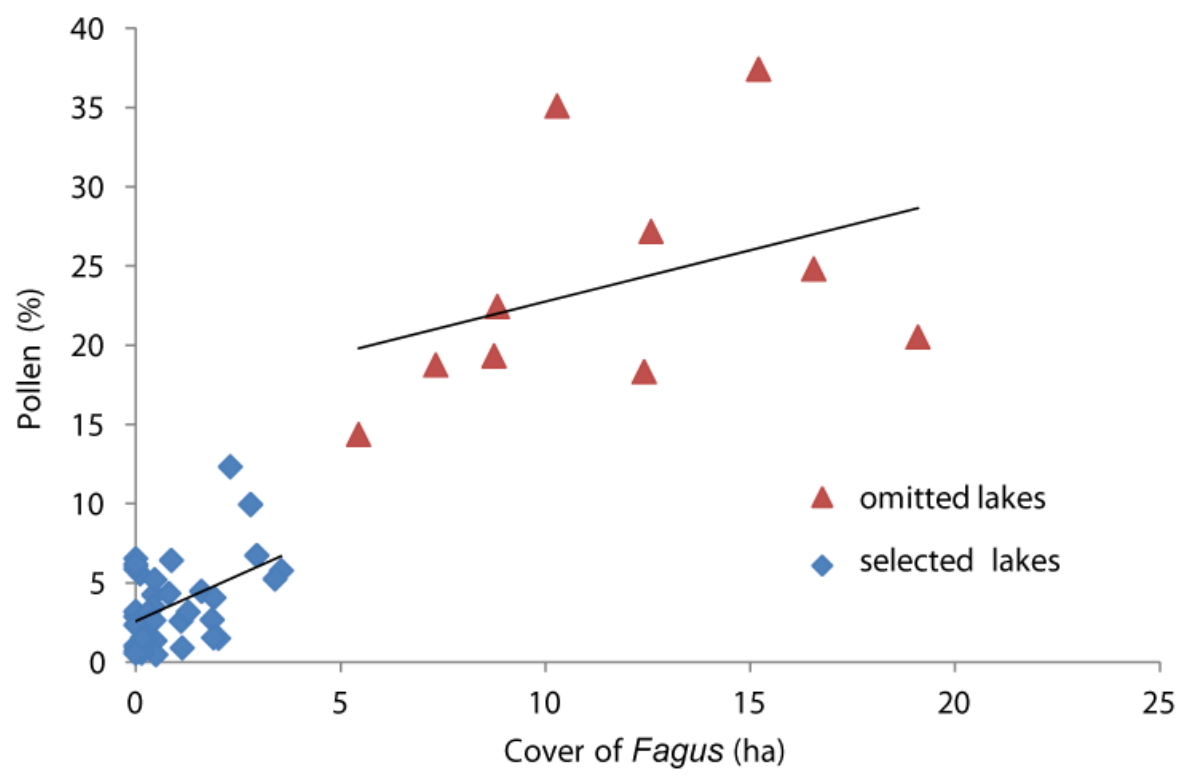

Fig. 2.4 Scatter-plot of the cover of Fagus trees (ha) within a radius of $250 \mathrm{~m}$ from the lake center vs. the percentage of Fagus pollen in the surface samples of all study sites. Trend-lines are linear regressions for the two sets. Lakes within closed Fagus forests yielded disproportionately higher amounts of Fagus pollen and were therefore excluded from further analysis

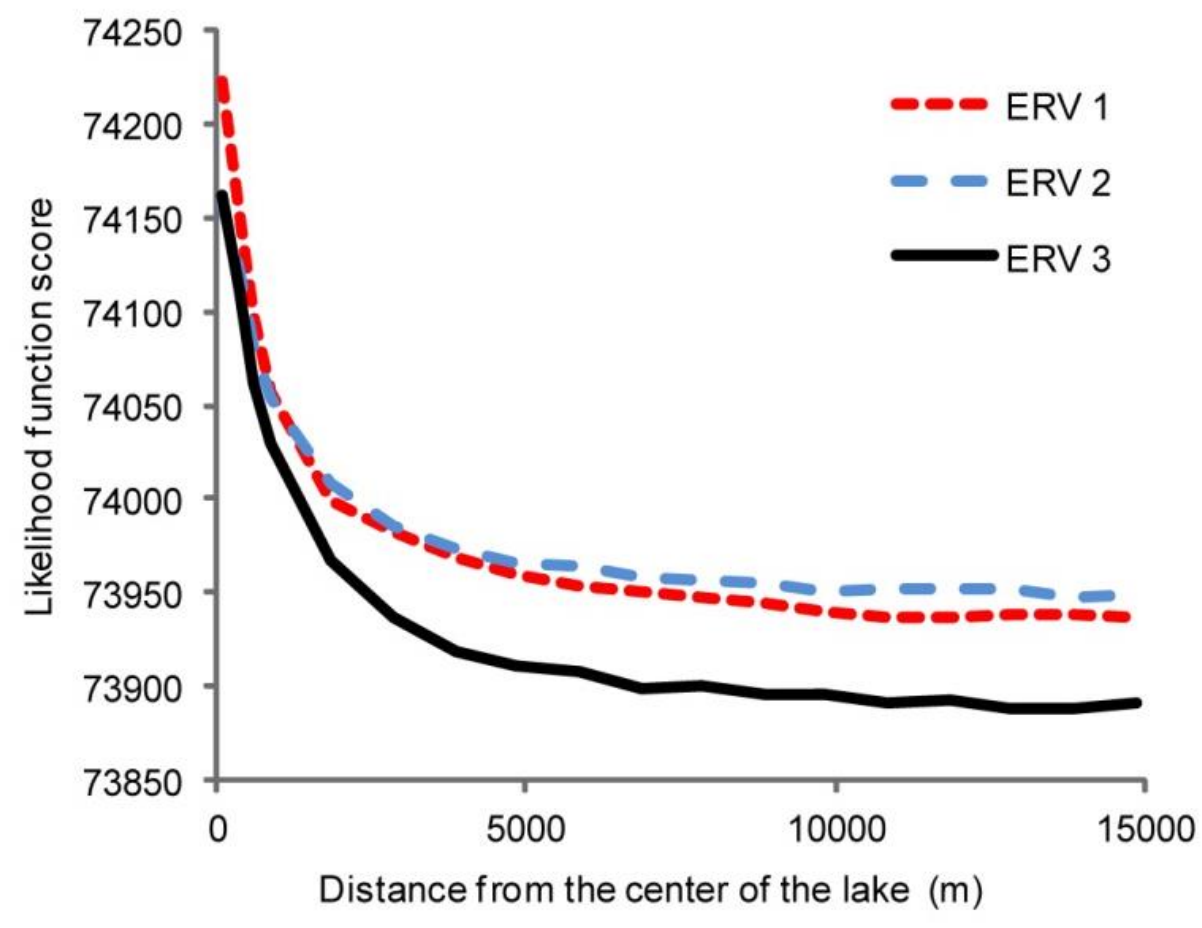

Fig. 2.5 Likelihood function scores for the ERV submodels 1, 2 and 3, based on the restricted dataset of 39 lakes with an assumed radius of $140 \mathrm{~m}$, considering all trees that have reached their respective flowering age (allFIDage) 


\subsubsection{RSAP}

For all three ERV submodels, likelihood function scores decrease to a distance of $7 \mathrm{~km}$ from the center of the lakes (Fig. 2.5). Scores for submodel 3 show a small dip at this distance, while submodels 1 and 2 have reached the asymptote at this point. While Fig. 2.5 is based on the inclusion of all trees that have reached their flowering age, the results for the different datasets yield similar trends indicating the RSAP at $7 \mathrm{~km}$ from the centers of the lakes. We tested if this result for the RSAP was influenced by compiling the vegetation data over $1 \mathrm{~km}$ wide rings, but did not find narrower rings to have any influence on the result.

\subsubsection{Pollen-vegetation relationships}

Scatter-plots depicting the ERV-model adjusted pollen-vegetation relationships (Fig. 2.6) give some indication of the reliability of calculated PPEs. The patterns of points around the regression line differ little between the four sets of forest inventory data and therefore only the results based on the dataset allFIDage are shown for the three ERV submodels. As with the likelihood function scores, the patterns are most similar between ERV submodels 1 and 2. The patterns differ most between the three submodels for the wild herbs with a particularly poor fit for model 3 , whereas Pinus shows the best fit with this submodel. Most of the more abundant tree species have long gradients and positive relationships between pollen and vegetation data. The trend is especially clear for the reference taxon Pinus, but also Alnus, Carpinus, Fraxinus, Larix/Pseudotsuga, and Quercus show similarly good fits for all ERV sub-models. The pollen-vegetation relationship for Carpinus and Fraxinus is captured by few samples while the trend for Tilia cordata is dominated by the elevated pollen and plant abundance at a single lake. The pollen-vegetation relationship is weak for Betula, Picea, and Populus and poor for most cereals and wild herbs.

\subsubsection{Vegetation cover}

When sampling the lakes, the vegetation immediately around each lake was noted in the field and for random sites later compared with the information from the forest inventory data. There was a good agreement, often down to small patches or groups of trees. In effect considering only those trees that have reached flowering age, or that occur in the canopy, means reducing the amount of vegetation cover. This is shown in Table 2.3 for tree species within $7 \mathrm{~km}$ around the lakes (the RSAP). Pinus dominates the area around the sampled lakes with an average cover of about $30 \%$ (Table 2.3), but with a high variability between the different lakes, as indicated by a standard deviation (s.d.) of more than $50 \%$. Pinus cover is little affected by omitting trees below average flowering age or those occurring in the understory. The next most abundant trees are Fagus and Quercus, covering on average 6 and $4 \%$ of the RSAP, respectively. Their abundance is much affected by omitting trees 


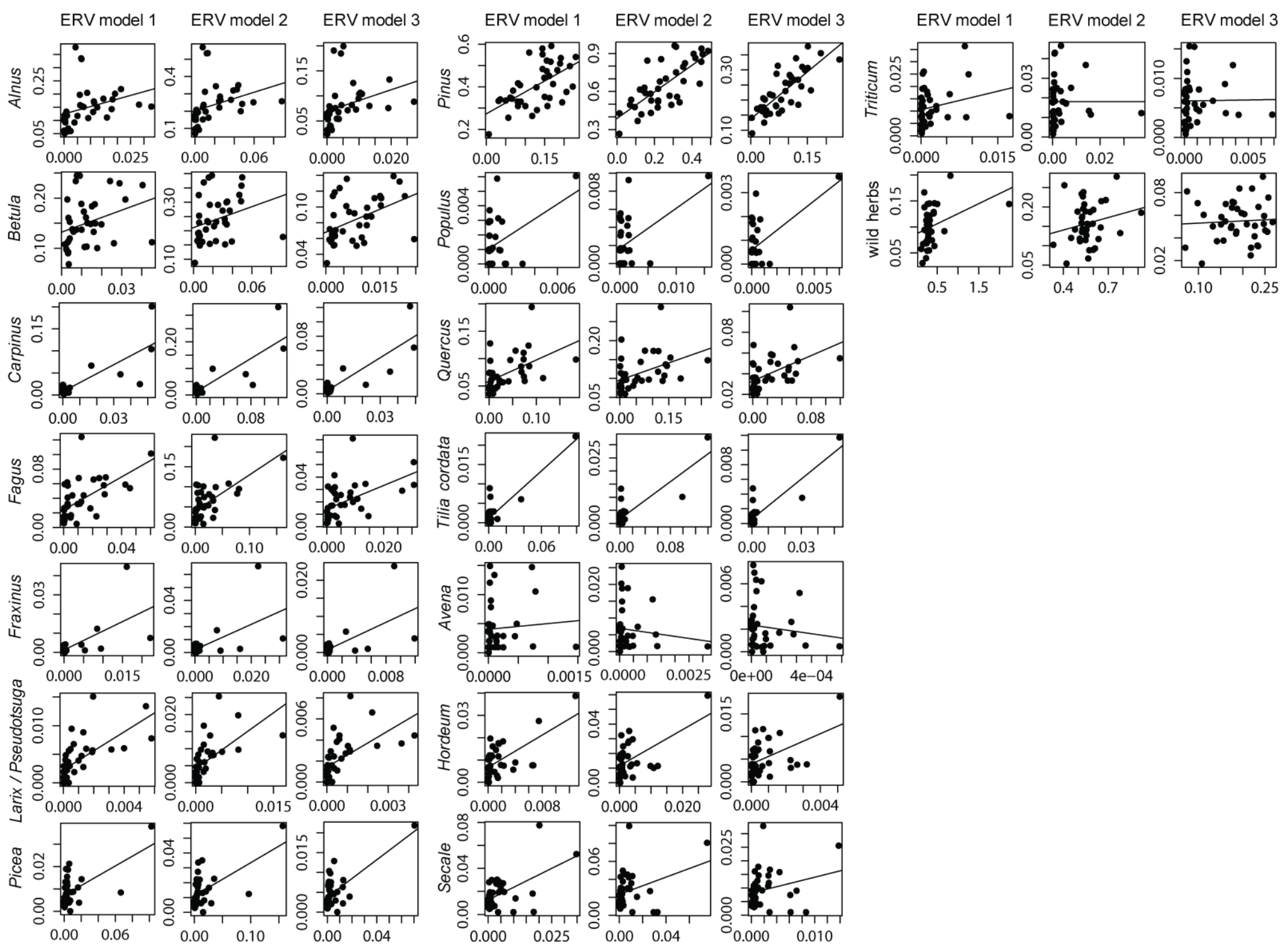

Fig. 2.6 Scatter-plots of pollen ( $y$-axis) and vegetation ( $x$-axis) data of the 16 selected taxa within the RSAP, based on the dataset considering only trees where the flowering age had been reached (allFIDage). ERV 1 adjusted vegetation proportion vs. pollen proportion. ERV 2 vegetation proportion vs. adjusted pollen proportion. ERV 3 relative pollen loading vs. absolute vegetation 
below flowering age and Fagus is especially reduced when removing the understory trees. Betula, Picea, and Larix/Pseudotsuga have average abundances of about $2 \%$. While none of these constraints greatly affected Betula, the constraint of flowering age reduces the abundance of Picea and, to a lesser extent, Larix/Pseudotsuga. Alnus, which is often found the shore of the sampled lakes only reaches an average cover of $0.9 \%$ and age or canopy structure, have almost no influence. Carpinus, Fraxinus, Populus, and Tilia cordata occur on average with less than $1 \%$ cover and the removal of their understory occurrences reduces the abundance of Carpinus and T. cordata by half, while Populus is not affected at all.

Table 2.3 Average cover and s.d. (\%) of the tree taxa within the RSAP

\begin{tabular}{lrrrr}
\hline & $\begin{array}{r}\text { allFID } \\
\text { cover +/- s.d. }\end{array}$ & $\begin{array}{r}\text { allFIDage } \\
\text { cover +/- s.d. }\end{array}$ & $\begin{array}{r}\text { canopyFID } \\
\text { cover +/-s.d. }\end{array}$ & $\begin{array}{r}\text { canopyFIDage } \\
\text { cover +/-s.d. }\end{array}$ \\
\hline Alnus & $0.85+/-0.71$ & $0.85+/-0.71$ & $0.84+/-0.71$ & $0.83+/-0.69$ \\
Betula & $2.07+/-1.11$ & $2.05+/-1.10$ & $1.92+/-1.00$ & $1.89+/-0.99$ \\
Carpinus & $0.74+/-0.91$ & $0.64+/-0.89$ & $0.34+/-0.53$ & $0.33+/-0.53$ \\
Fagus & $6.36+/-5.61$ & $4.23+/-4.34$ & $2.77+/-2.75$ & $2.55+/-2.55$ \\
Fraxinus & $0.13+/-0.14$ & $0.10+/-0.13$ & $0.10+/-0.12$ & $0.09+/-0.11$ \\
Larix and Pseudotsuga & $2.21+/-1.31$ & $1.84+/-1.19$ & $1.98+/-1.24$ & $1.77+/-1.17$ \\
Picea & $2.32+/-1.79$ & $1.55+/-1.22$ & $1.89+/-1.47$ & $1.26+/-1.04$ \\
Pinus & $33.61+/-17.79$ & $32.43+/-16.87$ & $33.08+/-17.25$ & $32.04+/-16.57$ \\
Populus & $0.18+/-0.17$ & $0.17+/-0.17$ & $0.18+/-0.17$ & $0.17+/-0.17$ \\
Quercus & $4.36+/-2.76$ & $3.01+/-2.08$ & $2.89+/-1.93$ & $2.49+/-1.84$ \\
Tilia cordata & $0.39+/-0.27$ & $0.25+/-0.27$ & $0.16+/-0.15$ & $0.14+/-0.15$ \\
\hline
\end{tabular}

\subsubsection{Reference taxon and the representation of herb pollen}

As calculation of absolute PPEs on a landscape scale is difficult and requires pollen accumulation rates (Sugita et al. 2010), PPEs are commonly estimated relative to a reference taxon, which needs to be present in the pollen count and vegetation of all samples. A common choice is Poaceae (Broström et al. 2008) as it occurs almost everywhere. Here forest lakes were targeted and the cover of herbaceous vegetation on the forest floor was not assessed. Consequently, vegetation information on Poaceae is incomplete, and probably particularly biased near the lakes. Poaceae was therefore not chosen as a reference taxon and not calculated separately (but combined with the other wild herbs in an attempt to minimize this bias). The scatter-plots in Fig. 2.6 show a poor fit for herbaceous pollen which may reflect the sampling design, where lakes seldom border non-forested areas. As the commonest tree in the study region, Pinus fulfilled all requirements of a reference taxon including a good fit between vegetation and pollen data. 
Table 2.4 Pollen productivity estimates ( \pm s.d.); calculated with the lake dispersal model (PrenticeSugita-model: Sugita et al. 1999), wind speed of $3 \mathrm{~m} / \mathrm{s}$ and Pinus as reference taxon

\begin{tabular}{|c|c|c|c|c|c|}
\hline Taxon & $\begin{array}{r}\text { ERV } \\
\text { submodel }\end{array}$ & $\begin{array}{r}\text { allFID } \\
\text { PPE +/-s.d. }\end{array}$ & $\begin{array}{l}\text { allFIDage } \\
\text { PPE +/-s.d. }\end{array}$ & $\begin{array}{l}\text { canopyFID } \\
\text { PPE +/-s.d. }\end{array}$ & $\begin{array}{l}\text { canopyFIDag } \\
\text { e PPE +/- s.d. }\end{array}$ \\
\hline \multirow[t]{3}{*}{ Alnus } & ERV 1 & $4.55+/-2.29$ & $3.83+/-1.19$ & $4.75+/-0.99$ & $4.78+/-0.83$ \\
\hline & ERV 2 & $2.64+/-0.26$ & $2.25+/-0.23$ & $2.65+/-0.17$ & $2.5+/-0.25$ \\
\hline & ERV 3 & $2.69+/-0.31$ & $2.74+/-0.22$ & $3.42+/-0.27$ & $2.73+/-0.29$ \\
\hline \multirow[t]{3}{*}{ Betula } & ERV 1 & $2.34+/-1.78$ & $1.56+/-1.08$ & $2.17+/-0.75$ & $1.9+/-0.73$ \\
\hline & ERV 2 & $1.62+/-0.61$ & $1.4+/-0.59$ & $1.26+/-0.58$ & $1.72+/-0.43$ \\
\hline & ERV 3 & $2.35+/-0.31$ & $1.7+/-0.34$ & $2.37+/-0.34$ & $2.24+/-0.3$ \\
\hline \multirow[t]{3}{*}{ Carpinus } & ERV 1 & $1.94+/-0.16$ & $1.89+/-0.17$ & $3.14+/-0.24$ & $3.46+/-0.31$ \\
\hline & ERV 2 & $1.75+/-0.07$ & $1.52+/-0.07$ & $2.5+/-0.11$ & $2.61+/-0.1$ \\
\hline & ERV 3 & $1.56+/-0.03$ & $1.67+/-0.09$ & $3.2+/-0.11$ & $2.94+/-0.13$ \\
\hline \multirow[t]{3}{*}{ Fagus } & ERV 1 & $1.08+/-0.08$ & $1.33+/-0.12$ & $1.8+/-0.19$ & $1.91+/-0.23$ \\
\hline & ERV 2 & $0.93+/-0.04$ & $1.01+/-0.04$ & $1.64+/-0.06$ & $1.39+/-0.1$ \\
\hline & ERV 3 & $1.07+/-0.05$ & $1.03+/-0.08$ & $1.67+/-0.15$ & $1.76+/-0.11$ \\
\hline \multirow[t]{3}{*}{ Fraxinus } & ERV 1 & $0.7+/-0.09$ & $1.05+/-0.17$ & $0.72+/-0.1$ & $1.33+/-0.24$ \\
\hline & ERV 2 & $0.73+/-0.09$ & $1.25+/-0.13$ & $0.84+/-0.09$ & $1.16+/-0.14$ \\
\hline & ERV 3 & $0.81+/-0.1$ & $1.19+/-0.12$ & $0.96+/-0.11$ & $1.34+/-0.15$ \\
\hline \multirow[t]{3}{*}{ Larix and Pseudotsuga } & ERV 1 & $1.24+/-0.26$ & $1.49+/-0.3$ & $1.3+/-0.27$ & $1.71+/-0.3$ \\
\hline & ERV 2 & $1.89+/-0.29$ & $2.04+/-0.29$ & $1.41+/-0.28$ & $1.89+/-0.31$ \\
\hline & ERV 3 & $2.62+/-0.35$ & $1.55+/-0.32$ & $1.89+/-0.35$ & $1.74+/-0.34$ \\
\hline \multirow[t]{3}{*}{ Picea } & ERV 1 & $0.18+/-0.02$ & $0.27+/-0.07$ & $0.16+/-0.03$ & $0.24+/-0.04$ \\
\hline & ERV 2 & $0.15+/-0.04$ & $0.24+/-0.04$ & $0.2+/-0.04$ & $0.22+/-0.04$ \\
\hline & ERV 3 & $0.2+/-0.04$ & $0.28+/-0.05$ & $0.22+/-0.04$ & $0.23+/-0.04$ \\
\hline \multirow[t]{3}{*}{ Populus } & ERV 1 & $0.88+/-0.34$ & $0.61+/-0.27$ & $0.84+/-0.35$ & $0.98+/-0.42$ \\
\hline & ERV 2 & $0.51+/-0.23$ & $0.47+/-0.22$ & $0.47+/-0.22$ & $0.55+/-0.26$ \\
\hline & ERV 3 & $0.39+/-0.19$ & $0.47+/-0.22$ & $0.52+/-0.24$ & $0.42+/-0.21$ \\
\hline \multirow{3}{*}{ Quercus } & ERV 1 & $0.28+/-0.07$ & $0.4+/-0.06$ & $0.45+/-0.03$ & $0.41+/-0.04$ \\
\hline & ERV 2 & $0.32+/-0.05$ & $0.36+/-0.03$ & $0.34+/-0.05$ & $0.33+/-0.05$ \\
\hline & ERV 3 & $0.38+/-0.04$ & $0.38+/-0.03$ & $0.44+/-0.05$ & $0.39+/-0.05$ \\
\hline \multirow[t]{3}{*}{ Tilia Cordata } & ERV 1 & $0.21+/-0.05$ & $0.2+/-0.06$ & $0.28+/-0.04$ & $0.28+/-0.05$ \\
\hline & ERV 2 & $0.18+/-0.03$ & $0.22+/-0.04$ & $0.22+/-0.04$ & $0.26+/-0.04$ \\
\hline & ERV 3 & $0.22+/-0.04$ & $0.26+/-0.04$ & $0.26+/-0.05$ & $0.28+/-0.05$ \\
\hline \multirow[t]{3}{*}{ Avena-type } & ERV 1 & $2.38+/-2.03$ & $0.24+/-1.35$ & $2.03+/-2.18$ & $2.17+/-2.66$ \\
\hline & ERV 2 & $0.01+/-1.42$ & $0.002+/-1.36$ & $0.04+/-1.47$ & $0.01+/-1.48$ \\
\hline & ERV 3 & $0.004+/-2$ & $0.01+/-1.89$ & $0.02+/-2.14$ & $0.07+/-2.05$ \\
\hline \multirow[t]{3}{*}{ Hordeum-type } & ERV 1 & $1.87+/-0.33$ & $1.51+/-0.31$ & $1.63+/-0.33$ & $2.18+/-0.48$ \\
\hline & ERV 2 & $1.16+/-0.25$ & $1.13+/-0.23$ & $1.11+/-0.24$ & $1.17+/-0.25$ \\
\hline & ERV 3 & $2+/-0.4$ & $1.59+/-0.34$ & $1.95+/-0.41$ & $1.78+/-0.38$ \\
\hline \multirow[t]{3}{*}{ Secale } & ERV 1 & $1.1+/-0.15$ & $1.22+/-0.2$ & $1.22+/-0.19$ & $1.17+/-0.21$ \\
\hline & ERV 2 & $0.57+/-0.12$ & $0.38+/-0.1$ & $0.41+/-0.11$ & $0.56+/-0.12$ \\
\hline & ERV 3 & $0.47+/-0.17$ & $0.72+/-0.17$ & $0.81+/-0.2$ & $0.82+/-0.19$ \\
\hline \multirow[t]{3}{*}{ Triticum-type } & ERV 1 & $0.72+/-0.24$ & $0.78+/-0.26$ & $0.85+/-0.29$ & $0.8+/-0.31$ \\
\hline & ERV 2 & $0.08+/-0.18$ & $0.11+/-0.17$ & $0.09+/-0.18$ & $0.19+/-0.2$ \\
\hline & ERV 3 & $0.13+/-0.27$ & $0.08+/-0.26$ & $0.23+/-0.31$ & $0.23+/-0.29$ \\
\hline \multirow[t]{3}{*}{ wild herbs } & ERV 1 & $0.05+/-0.01$ & $0.04+/-0.01$ & $0.05+/-0.003$ & $0.04+/-0.004$ \\
\hline & ERV 2 & $0.14+/-0.01$ & $0.12+/-0.01$ & $0.1+/-0.01$ & $0.13+/-0.01$ \\
\hline & ERV 3 & $0.01+/-0.01$ & $0.01+/-0.01$ & $0.01+/-0.01$ & $0+/-0.01$ \\
\hline
\end{tabular}




\subsubsection{PPEs}

Taxa that show good fits in the scatter-plots (Fig. 2.6) also yield similar PPEs in the different ERV submodels (Table 2.4). The PPEs were taken at the RSAP $(7 \mathrm{~km})$ and datasets with differently assessed tree-cover abundance vary especially for Alnus, Populus and all non-arboreal based on flowering age and forest structure affect the PPEs pollen types between different submodels. The four datasets with differently assessed tree-cover abundance based on flowering age and forest structure affect the PPEs in different directions. Most strongly affected is Carpinus, where the relationship is determined by a few sites at which the tree often occurs in the understory. Similarly, Fagus shows different values depending on the inclusion of understory trees, while for Quercus a large difference is only seen for ERV submodel 1. PPEs for Carpinus, Fagus, and Quercus increase as their cover abundances are reduced, which is to be expected as fewer trees account for the same proportion of pollen. As the reduction in cover abundance is least for Alnus and Betula in the different datasets, their relative abundance increases slightly and there is a decreasing trend in the calculated PPEs for most ERV submodels when understory and/or young trees are excluded. For some species the direction of change varies between ERV submodels. For example Larix/Pseudotsuga PPEs decrease in submodel 3 and for Populus in submodels 1 and 2.

\subsection{Discussion}

\subsubsection{Flowering age and forest structure}

The results show that flowering age and forest structures have a marked influence on the calculation of PPEs for some taxa. The autecology of the different tree species is modulating this effect in different ways and, based on the forest inventory data from Brandenburg, we can identify three different groups. Betula and Alnus are fast growing and reach their flowering age quickly. Thus, consideration of flowering age and understory have little influence on the estimates of their abundance, while their relative PPEs may be affected due to the reduction in effective abundance of other species. A second group consists of fast growing trees that are rarely found in the understory, while their flowering age may directly affect the pollen-vegetation relationship. In this dataset, examples of this type are Fraxinus and Picea. For the third group, mainly Fagus and Carpinus, the abundance in the understory has a larger effect than the flowering age on the pollen-vegetation relationship. These different ways in which the autecology of the tree species influences their pollenvegetation relationship would also play a role in the natural woodlands of the past that we are aiming to reconstruct. However, nearly all European forests today are heavily managed and naturally occurring age structures are likely to be skewed towards younger non-flowering trees. The harvesting age of trees is often the time when they have started to produce ample pollen and thus the strong 
pollen producers are removed from the forest. Thus present tree plantations and woodlands may not be good analogies for the past, and it would be preferable to estimate relative pollen productivity from flowering trees only. Regional differences in the age structure of woodlands are a potential reason for differences in PPEs between regions in previous studies, e.g. those compared by Broström et al. (2008). However, omitting trees based on their flowering age is also not without problems, as trees start to flower at different ages depending on biotic and abiotic conditions (Schütt et al. 2006). Most trees will not go from not flowering to abundant pollen production in a single year, but rather gradually increase the amount of pollen produced with age. It is also likely that a free-standing tree produces more pollen than one that grows within a dense stand (Aaby 1994). This effect of increased pollen production with forest openings has so far not been quantified, but, if important, it would greatly hamper our ability to reconstruct small openings in the forest using pollen data.

The occurrence of species in different stories in the canopy (e.g. superstructure, matured forest) is easy to assess in the field, but is difficult, if not impossible, to gauge from remote sensing. Tree abundance for PPEs has been estimated in a number of different ways: field estimates of basal area (e.g. Jackson and Kearsley 1998), cover of individual plants, considering different forest layers and leading to values above 100 \% (e.g. Soepboer et al. 2007), canopy cover as seen for one forest layer (e.g. Mazier et al. 2008) based on land-cover classifications in combination with field surveys and forest inventory, land-cover classification, and combinations with field surveys (e.g. Poska et al. 2011), remote sensing forest inventory data (Räsänen et al. 2007) or detailed forest inventory data (Theuerkauf et al. 2012 and present study).

Based on different assessments of heathland vegetation cover in western Norway, Bunting and Hjelle (2010) have shown that the way in which vegetation data are collected influences the PPEs and RSAP. We do not find differences in the RSAP, but show that PPEs are markedly influenced by the inclusion or exclusion of understory trees.

Considering the understory trees also has theoretical implications for the modeling of pollen dispersal. Tauber (1967) argued that the pollen carried to the lake through the trunk space is a significant component of the total pollen deposited at the site. However, this trunk space component is not considered in the dispersal models used here (Prentice 1985, 1988; Sugita 1993, 1994). In the present study, we omitted 10 lakes from the analysis that were situated in closed-canopy forest dominated by Fagus. The inclusion of this subset resulted in inflated PPEs for Fagus and less stable results for other taxa, indicating that the local abundance of Fagus around the lakes was not adequately considered in the model. The reason may be the dispersal model used in the ERVprogram (Theuerkauf et al. 2012) and the large trunk space component of Fagus pollen in these situations. Sjögren et al. (2010) address the problem of the large trunk space component by dividing the pollen source area into different components and applying different dispersal functions. This 
approach seems rather ad hoc, as it is difficult to determine the contribution of the different components. However, this method can potentially accommodate a large trunk-space component (Filipova-Marinova et al. 2010). Pollen from understory trees may not contribute to above-canopy pollen transport in the same way as canopy trees, but it should be important in the trunk-space component (Tauber 1965). In this sense, the abundance of trees in the understory could be important near a site, while it may have little influence several hundred meters away from the site. Thus it could be meaningful to include the understory trees within a short distance around the site and exclude them from vegetation data further afield.

\subsubsection{RSAP}

The obtained RSAP of $7 \mathrm{~km}$ is rather large in comparison with similar analysis based on lakes of similar size, where RSAP values of 0.8-2 km were obtained (Nielsen and Sugita 2005; Soepboer et al. 2007; Hjelle and Sugita 2012; Poska et al. 2011). Poska et al. (2011) showed that vegetation classification can influence the RSAP for lakes, as was shown for moss polsters and heath vegetation by Bunting and Hjelle (2010). We did not find this effect using the different datasets with regards to flowering age and understory trees being omitted. The reason may be that the configuration of vegetation units remained the same in all situations and the omission of trees generally only affected their abundance rather than their presence. Hjelle and Sugita (2012) found that the distribution of lake-sizes could also influence the RSAP. The restricted dataset has a lake-size distribution nearing a normal distribution, which is slightly right skewed. The full dataset has a lake size distribution with a stronger skew to the right but yields a similar RSAP. It is most likely that the result is in fact due to the distribution of vegetation types and forest species in the study area, which is a well-known factor controlling the size of the RSAP (Sugita et al. 1999; Bunting et al. 2004; Nielsen and Sugita 2005; Hellman et al. 2009). Soil substrate, and therefore nutrient and water availability in north-east Germany are linked to the glacial geomorphology of the area. The Quaternary geology of the region consists of glacial sediments several hundred meters thick, including sands, clays and tills. The extensive outwash plains often only support Pinus trees and are rarely used for agriculture, while much of the nutrient-rich till plains are cleared for agricultural purposes. Nutrient-rich soils also developed on terminal moraines that are too steep for agriculture and are often covered by Fagusdominated forests. These three geomorphological units dominate the landscape structure and vegetation-type patch size. They may occur in their pure form over tens of kilometres or mix with other geomorphological features creating smaller-scaled vegetation patterns.

The lakes in Switzerland from which Soepboer et al. (2007) obtained an RSAP of 800 m were often surrounded by a belt of trees, and woodland patches in the surroundings have diameters of several hundred meters. The size of woodland patches in Estonia range from a few hundred meters to 
several kilometers and Poska et al. (2011) find a RSAP of 1,500-2,000 m. In Brandenburg extensive forests (which often stretch over more than $20 \mathrm{~km}$ ) alternate with extensive agricultural areas. Thus, extrapolation from the woodland patch-size versus RSAP in Switzerland and Estonia to the size of forest patches in Brandenburg may explain the large RSAP obtained. This example shows the dependency of RSAP on the patch size (Bunting et al. 2004; Hellman et al. 2009) for the selected lakes and indicates large effective patch size for the region investigated here.

\subsubsection{PPES}

While the RSAP is markedly different from earlier studies the obtained relative PPEs agree with values obtained elsewhere (Fig. 2.7). The strong point of the analysis presented here is the forest inventory data, which are spatially and taxonomically precise. On the other hand the vegetation information extracted from the biotope map of Brandenburg is spatially precise but taxonomically vague. Agricultural lands are vast and, although we did use information on the proportion of different crops, we could not account for geographic differences between predominantly cereal and root crops, which exist in the area. Areas dominated by herbaceous vegetation were often distant from the sampling points so that long gradients could not be obtained, hampering the computation of PPEs. Our confidence in the obtained PPEs is high for arboreal pollen types, and for this reason we selected an arboreal taxon, Pinus, as the reference taxon. We choose to report PPEs for herbaceous species as these differ widely between different study designs. The results presented here are based on a landscape perspective similar to the study by Poska et al. (2011) and may help evaluating published results or to design new studies. Our results indicate that the PPEs for Avena and Triticumtype are lower than for Secale and Hordeum-type, which could have implications for reconstructions of past cultural landscapes, although the exact values reported here have large uncertainties, as seen for example by the large differences between ERV submodels.

Our estimates for Alnus agree well with studies based on lakes (Poska et al. 2011), while studies using moss samples tend to produce much lower values (Southern Sweden, Broström et al. 2004; Central Bohemia, Abraham and Kozáková 2012). This may again be a result of the trunk-space component, which is generally not considered in the pollen dispersal model. Alnus is often found on the lake shore where a large amount of pollen may be carried in the trunk-space, or simply drop into the lake, while moss samples from upland vegetation are generally distant from this tree species and thus collect Alnus pollen that is transported by the wind above the canopy. The good agreement for the PPE of Betula relative to Pinus between studies is encouraging, especially as Betula is often mixed in with other trees or occurs near the lake shore and it is thus difficult to estimate its abundance. 


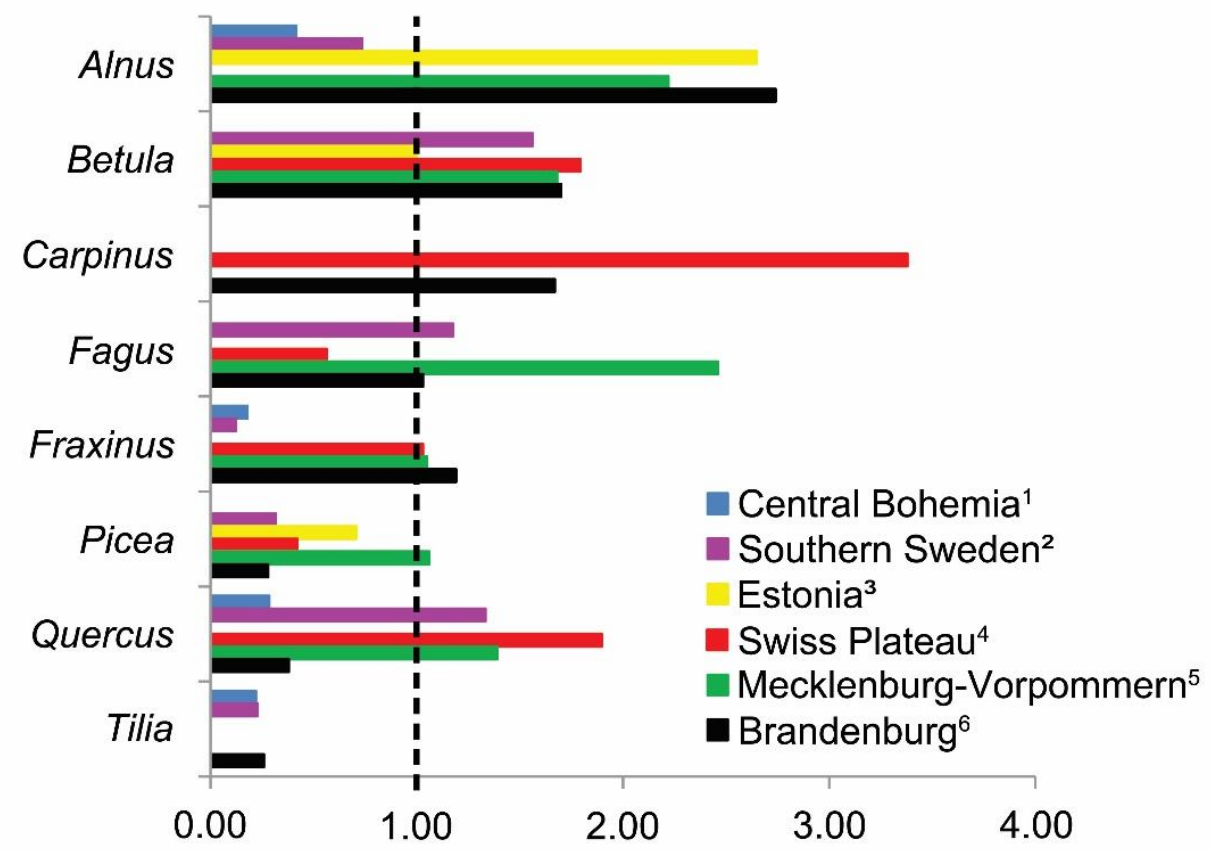

Fig. 2.7 PPEs for various taxa from different studies. The PPEs from Brandenburg are based on ERV 3 and on the dataset allFIDage. The PPEs from Sweden and Central Bohemia were calculated from moss polsters, the remaining studies were based on lake samples. All results were rescaled to assign a PPE of 1 (the dashed line) to the reference taxon Pinus. The comparison is based on original studies: 1 Abraham and Kozáková (2012); 2 Sugita et al. (1999) and Broström et al. (2004); 3 Poska et al. (2011); 4 Soepboer et al. (2007); 5 Theuerkauf et al. (2012); 6 this paper. PPE values of studies 2-4 were taken from the overview by Broström et al. (2008)

Few studies have obtained a PPE for Carpinus and our result agrees with Soepboer et al. (2007) in that its relative pollen production is higher than Pinus, although the relative amount differs greatly between the two studies. This may in part be due to the high uncertainty in the PPE for Pinus obtained for Switzerland (Soepboer et al. 2007). Our results show that the PPE of Carpinus depends strongly on whether understory trees are included in the vegetation estimate (Table 2.4), a factor which was not or only partly considered in several previous studies. More studies have estimated the PPE for Fagus with varying results. As discussed earlier, we suppose that the trunk-space transport of Fagus pollen may have a strong influence at sites within Fagus-dominated forest. This may contribute to the high PPE estimated by Theuerkauf et al. (2012) for the area just north of this study (calculated by the ERVv1.2.3. software). The value obtained here compares well with that estimated in southern Sweden, where, as in Brandenburg, both Pinus and Fagus are abundant forest trees. Also the PPE for Picea compares well to the estimate from southern Sweden, although the Picea trees in Brandenburg are planted and the distribution considered natural is situated just to the south of the study area. Larix and Pseudotsuga are planted widely in Brandenburg and were thus considered in the analysis. As the two trees cannot be differentiated by their pollen type, the PPE is difficult to interpret.

The values obtained for Quercus are surprisingly low and similar values have only been obtained 
from Central Bohemia (Abraham and Kozáková 2012). The dataset has a good spread of Quercus tree and pollen abundance, which gives us confidence in the results. In recent years many areas of Quercus trees in Brandenburg have been severely damaged by insects (particularly the moth Thaumetopoea processionea) and/or the fungus Microsphaera alphitoides (Möller et al. 2010) which can completely defoliate the tree, influencing its resource allocation and potentially reducing if not stopping the production of pollen. Also the age structure of Quercus in Brandenburg is skewed towards younger trees which may not produce the same amount of pollen as an abundance of older trees. While these factors would explain a somewhat lower PPE, the difference compared to the estimates from Switzerland is about threefold and thus difficult to explain by these factors alone.

The PPE for Tilia cordata compares well with the value for Tilia estimated in Southern Sweden (Sugita et al. 1999). Tilia cordata is the more abundant species in our dataset, while T. platyphyllos is also present. ERV model runs combining both pollen types and trees yield similar PPEs and thus we suggest that the value presented here may be appropriate for both species. However, T. platyphyllos is rare in the region and we thus restricted the final analysis to $T$. cordata.

It is desirable that the relationship between pollen and vegetation should be as good as possible for the reference taxon, because all the calculated PPEs depend on this taxon. We propose to use PPEs from ERV submodel 3 for vegetation reconstruction, because Pinus shows the best fit. Submodel 3 also produced lower likelihood function scores than the other submodels (Fig. 2.5), indicating a generally better fit to the data across all taxa. Based on the insights gained when working with the data, we recommend the further usage of the results from ERV submodel 3, based on the inclusion of all flowering trees, i.e. considering the effect of flowering age.

\subsection{Conclusion}

Both forest structure and flowering age have strong effects on the calculation of PPEs for most tree species, which should be considered when estimating PPEs or reconstructing vegetation. Forest structure is more important for slow growing trees like Fagus and Carpinus, while flowering age is most important for fast growing trees like Fraxinus and Picea, where flowering age is reached late. Based on this dataset, these effects may cause variations in PPEs in the order of up to $100 \%$ for trees that are slow growing and/or reach their flowering age late. Larger differences in PPEs between regions will most likely have different reasons, as will differences observed for trees that reach their flowering age early.

Trees growing at or near the lake shore contribute a large amount of pollen to the lake through the trunk-space component of pollen transport. This component is generally not considered when estimating PPEs, but could have a large effect and may thus be another factor explaining the differences between studies. 
The large RSAP of $7 \mathrm{~km}$ is consistent with the landscape structure consisting of large units shaped by ice-marginal processes during the last glaciation. The resulting differences in soil substrates and geomorphology are reflected in different land use today, and it would also have supported different forest types in the past.

This study adds to the growing dataset of PPEs for Europe and thus improves our ability to reconstruct past vegetation cover.

\section{Acknowledgements}

We thank Ralf Köhler from the Landesumweltamt in Brandenburg for the authorization to do our fieldwork as well as Sabine Busch from Landesbetrieb Forst Brandenburg (LFB). We would like to thank Martin Theuerkauf for support in handling of the forest inventory data and long and good discussions. We thank Shinya Sugita for providing us with the unpublished software ERV-Analysis 1.2.3 and a critical discussion of the results. We also thank Jörg Christiansen for technical support. We thank the forest authorities of Brandenburg and Mecklenburg-Vorpommern for providing us with the forest data, particularly Konrad Müller from LFB, Potsdam. We also like to thank Simon Connor and an anonymous referee for helpful comments upon an earlier draft of this manuscript. This study was funded by the German Research Foundation (DFG, GI 732/1-1).

\subsection{References}

Aaby B (1994) NAP percentages as an expression of cleared areas. Paläoklimaforschung 12:13-27 Abraham V, Kozáková R (2012) Relative pollen productivity estimates in the modern agricultural landscape of Central Bohemia (Czech Republic). Rev Palaeobot Palynol 179:1-12

Bennett KD, Willis KJ (2001) Pollen. In: Smol JP, Birks HJB, Last WM (eds) Tracking environmental change using lake sediments, vol 3., Terrestrial, algal and siliceous indicators. Kluwer, Dordrecht, pp 5-32

Beug H-J (2004) Leitfaden der Pollenbestimmung. Pfeil, München

Broström A, Sugita S, Gaillard MJ (2004) Pollen productivity estimates for reconstruction of past vegetation cover in the cultural landscape of southern Sweden. Holocene 14:371-384

Broström A, Nielsen B, Gaillard M-J, Hjelle K, Mazier F, Binney H, Bunting MJ, Fyfe R, Meltsov V, Poska A, Räsänen S, Soepboer W, Von Stedingk H, Suutari H, Sugita S (2008) Pollen productivity estimates of key European plant taxa for quantitative reconstruction of past vegetation: a review. Veget Hist Archaeobot 17:461-478

Bunting MJ, Hjelle KL (2010) Effect of vegetation data collection strategies on estimates of relevant source area of pollen (RSAP) and relative pollen productivity estimates (relative PPE) for nonarboreal taxa. Veget Hist Archaeobot 19:365-374

Bunting MJ, Middleton R (2005) Modelling pollen dispersal and deposition using HUMPOL software, including simulating wind-roses and irregular lakes. Rev Palaeobot Palynol 134:185-196

Bunting MJ, Gaillard M-J, Sugita S, Middleton R, Broström A (2004) Vegetation structure and pollen source area. Holocene 14: 651-660

Bunting MJ, Armitage R, Binney HA, Waller M (2005) Estimates of "relative pollen productivity" and "relevant source area of pollen" for major tree taxa in two Norfolk (UK) woodlands. Holocene 15:459-465 
Davis MB (1963) On the theory of pollen analysis. Am J Sci 261: 897-912

Davis MB (2000) Palynology after Y2K-understanding the source area of pollen in sediments. Ann Rev Earth Planet Sci 28:1-18

Eisenhut G (1961) Untersuchung über die Morphologie und O "kologie der Pollenkörner heimischer und fremdländischer Waldbäume. Parey, Hamburg

Engel J (2010) Brandenburg-Kiefernland in Wandel. MILAktuell 2:29-30

Filipova-Marinova MV, Kvavadze EV, Connor SE, Sjögren P (2010) Estimating absolute pollen productivity for some European tertiary-relict taxa. Veget Hist Archaeobot 19:351-364

Gaillard MJ (2007) Pollen methods and studies-archaeological applications. In: Elias SA (ed) Encyclopedia of quaternary science, vol 3. Elsevier, Amsterdam, pp 2575-2595

Gaillard M-J, Sugita S, Bunting MJ, Middleton R, Broström A, Caseldine C, Giesecke T, Hellman SEV, Hicks S, Hjelle K, Langdon C, Nielsen AB, Poska A, Von Stedingk H, Veski S, POLLANDCAL Members (2008) The use of modelling and simulation approach in reconstructing past landscapes from fossil pollen data: a review and results from the POLLANDCAL network. Veget Hist Archaeobot 17:419-443

Gaillard M-J, Sugita S, Mazier F, Trondman A-K, Broström A, Hickler T, Kaplan JO, Kjellström E, Kokfelt $U$, Kuneš $P$, Lemmen C, Miller P, Olofsson J, Poska A, Rundgren $M$, Smith B, Strandberg G, Fyfe R, Nielsen AB, Alenius T, Balakauskas L, Barnekow L, Birks HJB, Bjune A, Björkman L, Giesecke $T$, Hjelle KL, Kalnina L, Kangur M, van der Knaap WO, Koff $T$, Lagerås $P$, Latałowa $M$, Leydet M, Lechterbeck J, Lindbladh M, Odgaard BV, Peglar S, Segerström U, Von Stedingk H, Seppä H (2010) Holocene land-cover reconstructions for studies on land cover-climate feedbacks. Clim Past 6:483-499

Giesecke T, Fontana SL (2008) Revisiting pollen accumulation rates from Swedish lake sediments. Holocene 18:293-305

Gregory PH (1973) The microbiology of the atmosphere. Leonard Hill, Aylesbury

Haller KE, Fickler H-H (1955) Waldbäume, Sträucher und Zwergholzgewächse. Winter, Heidelberg

Hellman S, Gaillard M-J, Bunting MJ, Mazier F (2009) Estimating the relevant source area of pollen in the past cultural landscapes of southern Sweden-a forward modelling approach. Rev Palaeobot Palynol 153:259-271

Hjelle KL (1998) Herb pollen representation in surface moss samples from mown meadows and pastures in western Norway. Veget Hist Archaeobot 7:79-96

Hjelle KL, Sugita S (2012) Estimating pollen productivity and relevant source area of pollen using lake sediments in Norway: how does lake size variation affect the estimates? Holocene 22:313324

Jackson ST, Kearsley JB (1998) Quantitative representation of local forest composition in forest-floor pollen assemblages. J Ecol 86:474-490

Liedtke H, Marcinek J (2002) Physische Geographie Deutschlands. Klett-Perthes, Gotha

Linke C, Grimmert S, Hartmann I, Reinhardt K (2010) Auswertung regionaler Klimamodelle für das Land Brandenburg. Fachbeiträge des Landesumweltamtes Heft Nr. 113. http://www. mugv.brandenburg.de/cms/media.php/lbm1.a.2334.de/i_fb113. pdf. Accessed 27 February 2012

Mazier F, Brostöm A, Gaillard MJ, Sugita S, Vittoz P, Buttler A (2008) Pollen productivity estimates and relevant source area of pollen for selected plant taxa in a pasture woodland landscape of the Jura Mountains (Switzerland). Veget Hist Archaeobot 17: 479-495

Miller PA, Giesecke T, Hickler T, Bradshaw RHW, Smith B, Seppä H, Valdes PJ, Sykes MT (2008) Exploring climatic and biotic controls on Holocene vegetation change in Fennoscandia. J Ecol 96:247-259

MLUV (2009) Agrarbericht 2009 zur Land-und Ernährungswirtschaft des Landes Brandenburg. Ministerium fürLändliche Entwicklung, Umwelt und Verbraucherschutz des Landes Brandenburg (MLUV). Landesamt für Verbraucherschutz, Landwirtschaft und Flurneuordnung. $\quad$ http://www.mil.brandenburg.de/ sixcms/media.php/4055/Agrarbericht_2009.pdf. Accessed 27 February 2012 
Möller K, Heydeck P, Hielscher K, Engelmann A, Wenk M, Schulz P-M, Dahms C, Born B, Dietz H, Braunschweig A (2010) Waldschutzbericht 2010. Jahresbericht der Hauptstelle für Waldschutz. Landeskompetenzzentrum Forst Eberswalde. http://forst.brandenburg.de/sixcms/media.php/4055/ws2010.pdf. Accessed 07 March 2012

Moore PD, Webb JA, Collinson ME (1991) Pollen analysis. Blackwell Scientific, Oxford

Nielsen AB (2004) Modelling pollen sedimentation in Danish lakes at c. A.D. 1800: an attempt to validate the POLLSCAPE model. J Biogeogr 31:1693-1709

Nielsen AB, Sugita S (2005) Estimating relevant source area of pollen for small Danish lakes around $A D$ 1800. Holocene 15: 1006-1020

Nielsen AB, Giesecke T, Theuerkauf M, Feeser I, Behre K-E, Beug H-J, Chen S-H, Christiansen J, Dörfler W, Endtmann E, Jahns S, De Klerk P, Kühl N, Latałowa M, Odgaard BV, Rasmussen $P$, Stockholm JR, Voigt R, Wiethold J, Wolters S (2012) Quantitative reconstructions of changes in regional openness in north-central Europe reveal new insights into old questions. Quat Sci Rev 47:131-149

Pardoe HS, Giesecke T, Van der Knaap WO, Svitavska-Svobodova H, Kvavadze EV, Panajiotidis S, Gerasimidis A, Pidek IA, Zimny M, Swieta-Musznicka J, Latalowa M, Noryskiewicz AM, Bozilova E, Tonkov S, Filipova-Marinova MV, Van Leeuwen JFN, Kalnina L (2010) Comparing pollen spectra from modified Tauber traps and moss samples: examples from a selection of woodlands across Europe. Veget Hist Archaeobot 19:271-283

Parsons RW, Prentice IC (1981) Statistical approaches to R-values and pollen-vegetation relationship. Rev Palaeobot Palynol 32: 127-152

Poska A, Meltsov V, Sugita S, Vassiljev J (2011) Relative pollen productivity estimates of major anemophilous taxa and relevant source area of pollen in a cultural landscape of the hemiboreal forest zone (Estonia). Rev Palaeobot Palynol 167:30-39

Prentice IC (1985) Pollen representation, source area, and basin size: toward a unified theory of pollen analysis. Quat Res 23:76-86

Prentice IC (1988) Records of vegetation in time and space: the principles of pollen analysis. In: Huntley B, Webb TIII (eds) Vegetation history. Kluwer, Dordrecht, pp 17-42

Prentice IC, Parsons RW (1983) Maximum likelihood linear calibration of pollen spectra in terms of forest composition. Biometrics 39:1051-1057

Räsänen S, Suutari H, Nielsen AB (2007) A step further towards quantitative reconstruction of past vegetation in Fennoscandian boreal forests: pollen productivity estimates for six dominant taxa. Rev Palaeobot Palynol 146:208-220

Renberg I (1991) The HON-Kajak sediment corer. J Paleolimnol 6: 167-170

Rispens JA (2003) Der Nadelbaumtypus-Schritte zu einem imaginativen Baumverständnis. Elemente der Naturwissenschaft 79: 51-77

Schröck O (1949) Die Vererbung der Frühblüte der Kiefer. Der Züchter 19:247-254

Schütt P, Weisgerber H, Schuck H-J, Lang U, Stimm B, Roloff A (2006) Enzyklopädie der Laubbäume. Nikol, Hamburg

Sjögren P, Connor SE, Van der Knaap WO (2010) The development of composite pollen-dispersal functions for estimating absolute pollen productivity in the Swiss Alps. Veget Hist Archaeobot 19:341-349

Soepboer W, Sugita S, Lotter AF, Van Leuwen JFN, Van der Knaap WO (2007) Pollen productivity estimates for quantitative reconstruction of vegetation cover on the Swiss Plateau. Holocene $17: 1-13$

Stinglwagner G, Haseder I, Erlbeck R (2005) Das Kosmos Wald-und Forstlexikon. Kosmos, Stuttgart

Sugita $S$ (1993) A model of pollen source area for an entire lake surface. Quat Res 39:239-244

Sugita S (1994) Pollen representation of vegetation in quaternary sediments: theory and method in patchy vegetation. J Ecol 82: 881-897

Sugita S (2007a) Theory of quantitative reconstruction of vegetation I: pollen from large sites REVEALS regional vegetation composition. Holocene 17:229-241

Sugita S (2007b) Theory of quantitative reconstruction of vegetation II: all you need is LOVE. 
Holocene 17:243-257 Sugita S, Gaillard MJ, Broström A (1999) Landscape openness and pollen records: a simulation approach. Holocene 9:409-421

Sugita S, Hicks S, Sormunen H (2010) Absolute pollen productivity and pollen-vegetation relationships in northern Finland. J Quat Sci 25:724-736

Tauber H (1965) Differential pollen dispersion and the interpretation of pollen diagrams. Danmarks Geologiske Undersøgelse. II Række 89:1-69

Tauber H (1967) Investigations of the mode of pollen transfer in forested areas. Rev Palaeobot Palynol 3:277-286

Theuerkauf M, Kuparinen A, Joosten H (2012) Pollen productivity estimates strongly depend on assumed pollen dispersal. Holocene. doi:10.1177/0959683612450194

Umweltbundesamt, DLR-DFD (2004) CORINE Land Cover 2000. Daten zur Bodenbedeckung Deutschland. http://www.corine. dfd.dlr.de

Von Stedingk H, Fyfe R, Allard A (2008) Pollen productivity estimates from the forest-tundra ecotone in west-central Sweden: implications for vegetation reconstruction at the limits of the boreal forest. Holocene 18:323-332 


\section{Chapter 3}

\section{Insights into pollen source area, transport and deposition from modern pollen accumulation rates in lake sediments}

Isabelle Matthias ${ }^{1} \&$ Thomas Giesecke ${ }^{1}$

${ }^{1}$ Department of Palynology and Climate Dynamics, Albrecht-von-Haller Institute for Plant Sciences, University of Göttingen, 37073 Göttingen, Germany 


\section{Abstract}

Pollen accumulation rates (PAR) from late Quaternary deposits can provide direct estimates of past plant abundance. They are influenced by lake internal processes and therefore rarely used in between site comparisons, although few studies from Fennoscandia have applied them successfully. This study aims to explore how PARs from selected lakes from Northeast Germany reflect differences in plant abundance as a step towards quantitative vegetation reconstructions from PARs.

Short sediment cores were collected from 18 lakes of which 16 could be dated by ${ }^{210} \mathrm{~Pb}$. PARs were estimated for the youngest sediment, representing approximately two years before sampling in 2009, and samples dated to around 1993. Forest inventory data for the two time slices were obtained for $15 \mathrm{~km}$ around the sites and standing volume (SV) was estimated as a measure of above ground biomass. PARs were compared to the total SV within increasing areas around the lakes, as well as to distance-weighted SV using the Prentice/Sugita model of pollen dispersal and deposition. Both assessments of the vegetation data yielded strong linear relationships with PARs already over distances of tens of metres to a few kilometres documenting the importance of the local vegetation. This indicates the importance of the often neglected trunk space component of pollen transport for small lakes. Results from the small number of large lakes suggest that these sites receive a larger absolute input of pollen from regional sources. These observations indicate that small lakes may be somewhat sheltered from pollen transported above the canopy.

We demonstrate that PARs of the major tree taxa obtained from lake sediments are linear related to the lake surrounding biomass. This confirms that PAR can be used to infer past changes in plant biomass, although absolute pollen deposition may also be determined by net primary productivity of the biomass.

Keywords: Sedimentation rate, Pollen accumulation rate (PAR), Quantitative vegetation reconstruction, Source area of pollen, Northeast Germany

\subsection{Introduction}

Pollen grains preserved in sediments represent a record of past changes in terrestrial plant abundance that is still unrivalled in its completeness and potential time-resolution on Quaternary time scales. Pollen composition from any given site encompasses a distance weighted integral over the vegetation cover surrounding that site, and it is essential to decompose this signal into its discrete components and estimate the vegetation cover quantitatively (e.g. Sugita, 1994; Gaillard et al., 2008). These quantitative estimates of past vegetation are increasingly important for the understanding of processes and interactions with neighbouring disciplines, for instance to assess land 
cover climate feed backs (Gaillard et al., 2010), understand past soil erosion (e.g. Enters et al., 2008), evaluate the performance of dynamic vegetation models (e.g. Miller et al., 2008), and also to understand the landscape context of archaeological monuments (e.g. Caseldine et al., 2008).

However, understanding the source area of pollen and converting pollen analytical results into estimates of plant cover or biomass is not a simple task and palynologists have been striving to achieve it since the introduction of modern pollen analysis at the 16th convention of Scandinavian naturalists in Oslo in 1916 (Von Post, 1918; Davis, 2000). Although the discussion during that meeting initially steered experiments monitoring absolute pollen deposition (Hicks et al., 2001; Giesecke et al., 2010a), later efforts to gain understanding of the spatial extent represented by a pollen diagram were based on pollen percentage data (e.g. Janssen, 1966; Jacobson and Bradshaw, 1981). Evaluations of the goodness of fit in scatter plots of plant abundance versus pollen percentages showed that different pollen types gave best fits with the vegetation abundance in different distances around the sampling site (Bradshaw and Webb, 1985; Prentice et al., 1987; Jackson, 1990). These observations could be explained by the different fall speed of pollen types (Eisenhut, 1961) and reproduced in numerical models (Prentice, 1985; Sugita, 1993). Observations (Bradshaw and Webb, 1985), conceptual (Tauber, 1965) and numerical models (Prentice, 1985) indicate that basin size has a strong influence on the proportion of pollen coming from local or regional sources. However, the proposed mechanisms differ between Tauber's (1965) conceptual model considering different components of pollen transport and Prentice's (1985) numerical model simulating only above canopy flow. Refinements of the numerical model, further observations and considerations led to the development of the relevant source area of pollen (Sugita, 1994), describing the area around a site for which the vegetation pattern is different from the regional average. The size of this area is determined by the patchiness of the vegetation, which in turn may be determined by the patchiness of soil types or geomorphology and thus varies between hundreds of metres to several kilometres (e.g. Nielsen and Sugita, 2005; Soepboer et al., 2007; Matthias et al., 2012).

Since the beginning of pollen analysis, the absolute amount of pollen deposition per unit area and time was an important concept, and found application in hay fever and pollination research (Giesecke et al., 2010a). To apply it in vegetation reconstruction it is necessary to determine the rate of sediment accumulation. This was already realized by Welten (1944), who produced the first pollen accumulation rate (PAR) diagram from the Lateglacial section of the annually laminated sediments of Faulenseemoos (Switzerland), revealing new insights into vegetation history. Since the 1950's, radiocarbon dating has been providing means to obtain average sedimentation rates also from sediments that are not annually laminated, and Davis and Deevey (1964) made first use of this possibility to estimate rates of pollen accumulation. They also focused on the Lateglacial vegetation history, where pollen accumulation rates give insight into vegetation cover and change more 
accurately than possible with pollen percentages that cannot portray landscape-wide changes in pollen production due to the closure effect. As it was realized that lake internal processes may alter sediment accumulation rates (Lehman, 1975; Likens and Davis, 1975; Davis et al., 1984), this measure was neglected as a means of quantitative reconstruction of past plant abundance. Nevertheless, pollen accumulation rates remained in use to describe the reduction in tree density across the northern tree-line in Fennoscandia (Hicks, 2001), and investigated lakes in this region yielded pollen accumulation rates that are comparable to each other as well as to pollen monitoring results (Hyvärinen, 1976). Thus it was possible to use the modern understanding of absolute pollen deposition in relation to the tree line to reconstruct past environments with respect to the presence and absence of trees in northernmost Finland (Seppä and Hicks, 2006). Also further south in the boreal forest of Fennoscandia, Giesecke and Fontana (2008) could show that the species-specific accumulation rates of pollen in small lakes are comparable between sites and with pollen traps. Thus, PAR rather than percentages could be used directly to study the dynamics of the vegetation change during the expansion of Picea abies in boreal forests of Fennoscandia (Seppä et al., 2009). Nevertheless, this application of PAR could only circumvent the interdependence problem of percentage pollen data, but did not provide estimates of how many trees per unit area surrounding the sites were replaced by Picea abies. In order to achieve this it is necessary to calibrate speciesspecific PAR against some measure of tree biomass (Seppä et al., 2009) and obtain estimates of absolute pollen production (Sugita et al., 2010).

Most of these recent successful insights into e and applications of PARs come from Fennoscandia, where sedimentation rates are generally low with a high inorganic proportion. It is possible that effects of lake internal processes affecting PAR are more pronounced in more productive lakes where a sediment matrix of mainly organic particles is more easily resuspended. The only comprehensive study on modern PAR in lakes was carried out by Davis et al. in 1973, at the time when this method was initially developed. This study was based on short cores from 29 lakes from Michigan varying between 1 and 314 ha. Davis et al. (1973) used the rise of Ambrosia pollen for dating and estimated the overall pollen accumulation for the 70-100 years between the time marker and the year of sampling and compared the values against tree diameter at breast height per hectare as an average over $1500 \mathrm{~km}^{2}$ around each site. Although general trends were visible between tree abundance and PAR, regression analysis gave no significant results, which is easily explained by the many uncertainties involved. In particular the comparison of the average basal area within more than 20 $\mathrm{km}$ around the site estimated in 1966 with the average pollen accumulation over as much as 100 years may at best yield a general trend, while Davis et al. (1973) in particular blame lake internal processes. However, this type of analysis is important not only to gain a better understanding of PAR, but also to test current theoretical models of pollen transport and deposition. 
The aim of the present study is therefore to compare PARs from modern lake sediments with tree biomass around these lakes in a spatially and temporally precise way, to answer two main questions: Is PAR from selected highly productive lakes comparable between lakes, or will lake internal processes obscure such comparisons?

How is the local and regional abundance of trees reflected by PAR in lakes and can this be explained by current models of pollen dispersal and deposition?

\subsection{Study area}

The landscape of north eastern Germany was shaped by Quaternary glaciations. During the Last Glacial, the maximum limit of the last Scandinavian ice sheet ran through Brandenburg in a NW to SE direction. The landscape to the northeast of this line is therefore covered by a series of ground and terminal moraines and outwash plains with different soil substrates (Liedtke and Marcinek, 2002).

These soil substrates determine the different forest types found in this region, and together with abundant lakes situated in different vegetation types, provide an ideal setting for this investigation (Fig. 3.1).

Climatically Brandenburg is situated between the oceanic climate of Western Europe and the continental climate further east. Precipitation ranges between 450 and $720 \mathrm{~mm}$, with the driest areas in the southeast (Linke et al., 2010). Brandenburg is one of the most forest covered states in Germany with a forest cover of $37 \%$ (1.09 million ha) of which the most abundant tree, pine, constitute $70 \%$, and mixed forests about $11 \%$ (Engel, 2010). The agriculturally used area represents 45\% (1.32 million ha) consisting of $78.3 \%$ arable land and 21.3\% pastures (MLUV, 2009).

\subsection{Material and methods}

\subsubsection{Sample collection and preparation}

We aimed at sampling small lakes with a single, simple basin without permanent inflow and outflow. Lakes that were deep in proportion to their area were preferred, to avoid lakes with a high sediment redeposition (Giesecke and Fontana, 2008). In most cases, the sediment core was taken in the deepest part of the lake. We aimed to sample lakes from different forest types, which required relaxing constraints on uniform lake size. Potential lakes were selected from topographical maps, aerial and satellite photographs and the suitability was assessed in the field. In this way a total of 49 small to medium sized lakes ranging between 0.5 and 32 ha were sampled (Matthias et al., 2012). Further, one large lake, Grimnitzsee, with about 780 ha was sampled to explore the influence of lake size. Out of this collection, 18 cores were chosen for ${ }^{210} \mathrm{~Pb}$ dating (Table 3.1).

Sampling was carried out during summer 2009 using a HON-Kajak sediment corer (Renberg, 1991) 
with a $10 \mathrm{~cm}$ diameter. The short cores obtained were sampled in the field at $1 \mathrm{~cm}$ intervals beginning at the sediment water interface (or shortly above it where the interface was diffuse). Samples were stored in small plastic bags at $4{ }^{\circ} \mathrm{C}$ until processing.

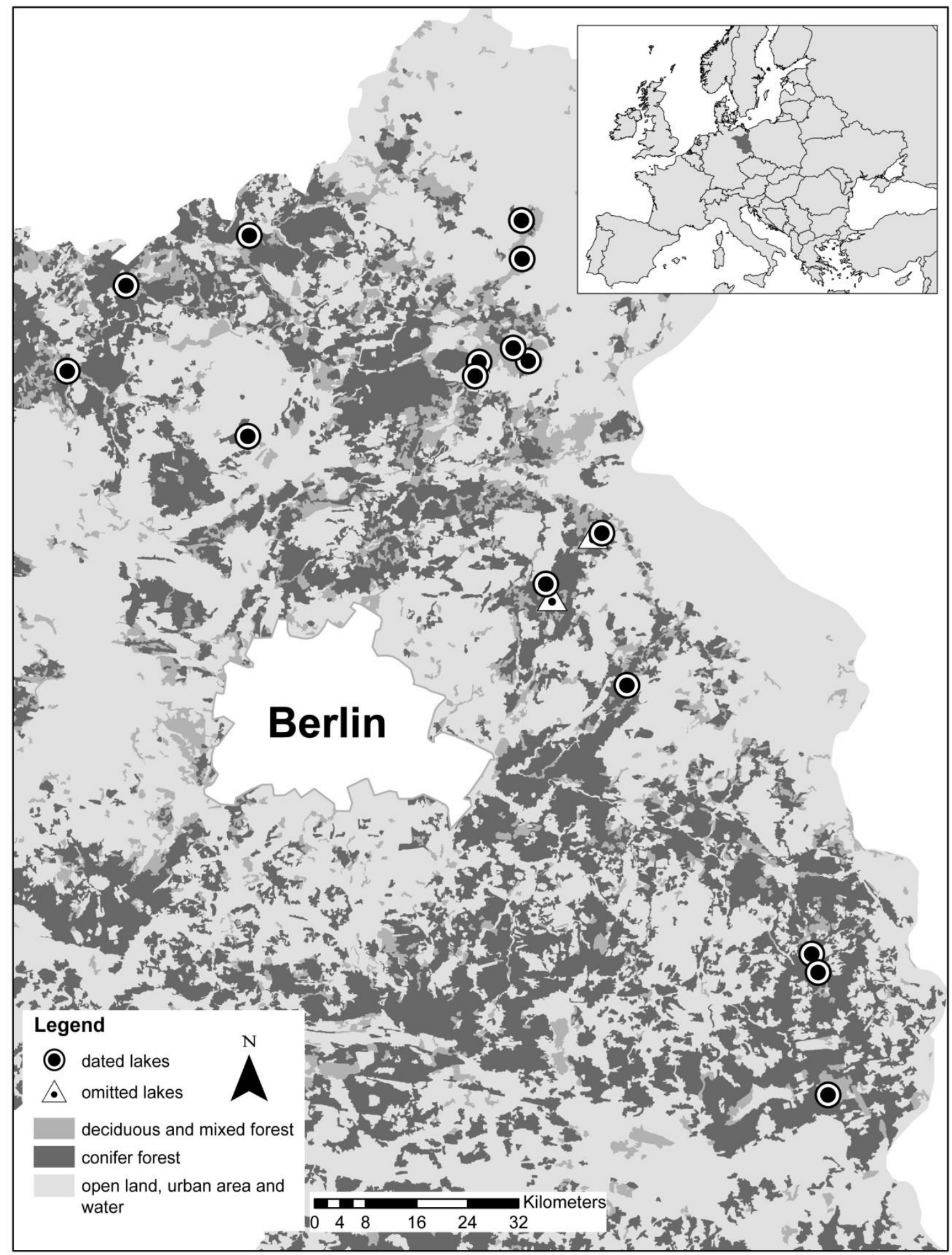

Fig. 3.1 Vegetation map of Brandenburg, based on CORINE Land Cover 2000 (Umweltbundesamt, DLR-DFD, 2004) with the location of the analysed lakes. Inset: map of Europe showing the state of Brandenburg, where the study area is situated. 
Table 3.1 Characteristics of the studied lakes and average sediment accumulation over the last 10 and 50 years

\begin{tabular}{|c|c|c|c|c|c|c|c|c|c|}
\hline No & Name & $\begin{array}{c}\text { Latitude } \\
\text { (decimal } \\
\text { degrees) }\end{array}$ & $\begin{array}{c}\text { Longitude } \\
\text { (decimal } \\
\text { degrees) }\end{array}$ & Size (ha) & Radius (m) & Perimeter $(\mathrm{m})$ & $\begin{array}{r}\text { Depth at sampling } \\
\text { point }(\mathrm{m})\end{array}$ & $\begin{array}{l}\text { Sedimentation }(\mathrm{cm}) \\
\text { in } 50 \text { years }\end{array}$ & $\begin{array}{l}\text { Sedimentation }(\mathrm{cm}) \\
\text { in } 10 \text { years }\end{array}$ \\
\hline 1 & Schiebelsee & 52.74570 & 14.04643 & 0.5 & 40 & 250 & 4.1 & 32 & 12 \\
\hline 2 & Aalgastsee & 53.13919 & 13.90501 & 0.8 & 51 & 340 & 3.3 & 22.5 & 4 \\
\hline 3 & Bugsee & 53.19288 & 13.90977 & 1.5 & 69 & 540 & 6 & 24.5 & 6 \\
\hline 4 & Modderpfuhl & 52.67974 & 13.90877 & 1.7 & 74 & 530 & 3.8 & 15.5 & 6 \\
\hline 5 & Glabatzsee & 53.13616 & 12.97426 & 2 & 80 & 720 & 7.3 & 19 & 5.5 \\
\hline 6 & Ziskensee & 52.10605 & 14.47010 & 2.6 & 91 & 640 & 4.4 & 21 & 7 \\
\hline 7 & Kesselsee & 52.52914 & 14.08000 & 2.7 & 93 & 690 & 7.8 & 25.5 & 9 \\
\hline 8 & Schwarzersee & 52.99397 & 13.90280 & 3.3 & 103 & 750 & 4.7 & 20 & 7 \\
\hline 9 & Teufelssee & 53.01992 & 12.82700 & 4.8 & 124 & 880 & 12 & 10 & 2.5 \\
\hline 10 & Kleiner Treppelsee & 52.13258 & 14.45817 & 5.4 & 131 & 940 & 4.5 & 22 & 6 \\
\hline 11 & Papensee & 52.91453 & 13.23900 & 5.9 & 137 & 960 & 8.3 & 23 & 8 \\
\hline 12 & Kleiner Lychensee & 53.19616 & 13.27013 & 8.5 & 165 & 1110 & 13.7 & 20 & 5 \\
\hline 13 & Heiliger See & 53.01571 & 13.87216 & 9.1 & 170 & 1300 & 10.8 & 20.5 & 5 \\
\hline 14 & Dovinsee & 52.99774 & 13.78780 & 20.8 & 257 & 1800 & 7 & 20.5 & 7 \\
\hline 15 & Großsee & 51.93299 & 14.47030 & 31.7 & 318 & 2620 & 8.3 & 20.5 & 6.5 \\
\hline 16 & Grimnitzsee & 52.97867 & 13.77721 & 782 & 1578 & 12140 & 6.2 & 24.5 & 7 \\
\hline 17 & Baasee & 52.74333 & 14.0262 & 2.2 & 84 & 910 & 3.6 & & \\
\hline 18 & Piechesee & 52.65964 & 13.9211 & 4.5 & 120 & 1240 & 3 & & \\
\hline
\end{tabular}




\subsubsection{Dating}

Subsamples of every short core were dried at $105^{\circ} \mathrm{C}$ and the water content of every subsample was determined. The prepared samples were analysed for ${ }^{210} \mathrm{~Pb},{ }^{226} \mathrm{Ra},{ }^{137} \mathrm{Cs}$ and ${ }^{241} \mathrm{Am}$ by direct gamma assay using an Ortec HPGe GMXseries coaxial low background intrinsic germanium detector (Appleby et al., 1986, 1992) by the Environmental Radioactivity Research Centre at the University of Liverpool (P.G. Appleby and G.T. Piliposyan, personal communication). Sediment ages were inferred mainly based on the CRS model, which assumes a constant rate of supply of fallout ${ }^{210} \mathrm{~Pb}$ (Appleby and Oldfield, 1978). Age-depth models were checked and if necessary adjusted where well-defined peaks in the ${ }^{137} \mathrm{Cs}$ activity were present that could be linked to nuclear weapon tests in 1963 and/or the Chernobyl accident in 1986 (Appleby, 2001). In some cases the 1963 peak in ${ }^{137}$ Cs activity was confirmed by ${ }^{241} \mathrm{Am}$ (Appleby et al., 1991). Two lakes, Heiliger See and Teufelssee, showed laminations that were counted in the field and in the case of Teufelssee assisted in the selection of the age-depth model assuming the laminations to be annual.

\subsubsection{Pollen analysis}

Based on the age-depth model of the dated cores, consecutive subsamples were selected from the youngest sediment and depth corresponding to ages around 1993. In the lab $1 \mathrm{~cm}^{3}$ material was taken using a syringe. Before proceeding, Lycopodium spore tablets were added to determine the pollen concentration (Stockmarr, 1971). The subsamples were processed for pollen analysis following the general procedure described by Bennett and Willis (2001), without sieving and using a 2 min acetolysis. The sample residues were mounted in glycerol and counted at $400 x$ magnification. The pollen was identified using the keys of Beug (2004) and Moore et al. (1991), and the reference collection of the Department of Palynology and Climate Dynamics, Göttingen University. A minimum of 500 terrestrial pollen grains as well as a minimum of 100 Lycopodium spores was counted in each sample. Although bioturbation should average out inter-annual variability in pollen and sediment accumulation, we calculated PAR based on the pollen concentration from 2 to 4 samples to further reduce this variability. The pollen concentration over consecutive samples was multiplied by the sedimentation rate for these samples derived from the age-depth model.

\subsubsection{Forest inventory data}

We choose the above ground biomass (standing volume abbreviated as SV) of trees as the absolute unit of vegetation abundance to compare to PAR in lake sediments. The states of Brandenburg, Mecklenburg-Vorpommern and Thuringia possess a detailed forest inventory database, "Datenspeicher Wald" (DSW2;http://www.dsw2.de/index.html). This database contains detailed 
information about tree species, cover and age as well as forest structure. Data for some areas were supplemented with information from a federal agency "Bundesanstalt für Immobilienaufgaben", who administer similar types of forest inventory data. Almost one third of the forest is owned publically and here information on SV for 2009 was directly available. For the private forest from 2009 as well as the forest inventory data from 1993 it was necessary to estimate the SV. For this purpose, relationships between age and the SV were derived using a yield table (Schober, 1975). If there was a classification for the growth rate, thinning and the second yield power were used. Yield tables are not available for taxa without silvicultural interest. Here we applied the age to SV relationship based on Fraxinus, to estimate the SV for Tilia cordata and UImus. The function for Carpinus was based on a study from Lockow and Lockow (2009).

The calculation of SV was restricted to trees which have reached their flowering age, because only those trees can be potentially reflected in the pollen assemblage (Hicks, 2006; Matthias et al., 2012). The SV to age relationship is generally only available after the trees have reached a certain age and in a few cases this age was older than the age when the tree starts flowering. In these cases the difference in the age of flowering and the start of the yield table was small and the latter was therefore used as a threshold (Table 3.2). Forest inventory data from 1993 were not available for all studied lakes, reducing the dataset for analysis. Furthermore, forest inventory data do not consider military areas, roadside trees, trees in towns and villages as well as wooded areas $<0.01$ ha.

Table 3.2 Pollen fall speed and threshold age of the tree taxa

\begin{tabular}{llll}
\hline Taxa & Threshold age & Choosen cartegory & Fall speed $\left(\mathbf{m ~ s e c}^{-1}\right)$ \\
\hline Alnus & $20^{\mathrm{b}, \mathrm{a}}$ & $\mathrm{YT} / \mathrm{FA}$ & $0.021^{\mathrm{h}}$ \\
Betula & $30^{\mathrm{a}}$ & $\mathrm{YT}$ & $0.022^{\mathrm{h}}$ \\
Carpinus & $30^{\mathrm{c}, \mathrm{b}}$ & $\mathrm{YT} / \mathrm{FA}$ & $0.042^{\mathrm{h}}$ \\
Fagus & $50^{\mathrm{b}}$ & $\mathrm{FA}$ & $0.057^{\mathrm{i}}$ \\
Fraxinus & $30^{\mathrm{b}}$ & $\mathrm{FA}$ & $0.022^{\mathrm{h}}$ \\
Larix & $20^{\mathrm{a}}$ & $\mathrm{YT}$ & $0.126^{\mathrm{h}}$ \\
Picea & $40^{\mathrm{d}}$ & $\mathrm{FA}$ & $0.056^{\mathrm{h}}$ \\
Pinus & $25^{\mathrm{a}, \mathrm{d}, \mathrm{e}}$ & $\mathrm{YT} / \mathrm{FA}$ & $0.031^{\mathrm{h}}$ \\
Pseudotsuga & $30^{\mathrm{f}}$ & $\mathrm{FA}$ & $5 \mathrm{Larix}$ \\
Quercus & $30^{\mathrm{b}}$ & $\mathrm{FA}$ & $0.035^{\mathrm{h}}$ \\
Tilia & $20^{\mathrm{g}}$ & $\mathrm{FA}$ & $0.032^{\mathrm{i}}$ \\
Ulmus & $40^{\mathrm{b}}$ & FA & $0.032^{\mathrm{i}}$
\end{tabular}

YT=Yield table; FA=flowering age.

aSchober (1975). bSchütt et al. (2006). ' Lockow and Lockow (2009). dRispens (2003). eSchröck et al. (1949).

fStingelwagner et al. (2005). gHaller and Fickler (1955). ' 'Eisenhut; (1961). 'Gregory (1973). 


\subsubsection{Compilation of vegetation data}

The above described information on SV, as well as the shape of the sampled lakes and the position of the sample was compiled in ArcGIS (ESRI). To obtain detailed information on the vegetation near the sample site vegetation data were extracted in two different ways (Fig. 3.2). First, SV for the mayor wind-pollinated tree species within a radius of $15 \mathrm{~km}$ from the sampling point was extracted in rings of increasing radii. Small rings $(25 \mathrm{~m})$ were chosen close to a lake and with increasing diameters farther away from the lake (up to $1 \mathrm{~km}$ at a distance of $5 \mathrm{~km}$ ). Second, vegetation within buffer surrounding the lake shore, was extracted up to a distance of $15 \mathrm{~km}$. Similar to the chosen ring distances, also here the buffer widths were smaller near the lake and increased with distance from it. This procedure was motivated by the fact that lakes are often not perfectly round shaped. Thus, in elongated lakes the vegetation near the distant lake shore may already be strongly down-weighted, while the pollen may be mixed in the lake and contribute to a similar proportion as that from vegetation near a more proximal shore.

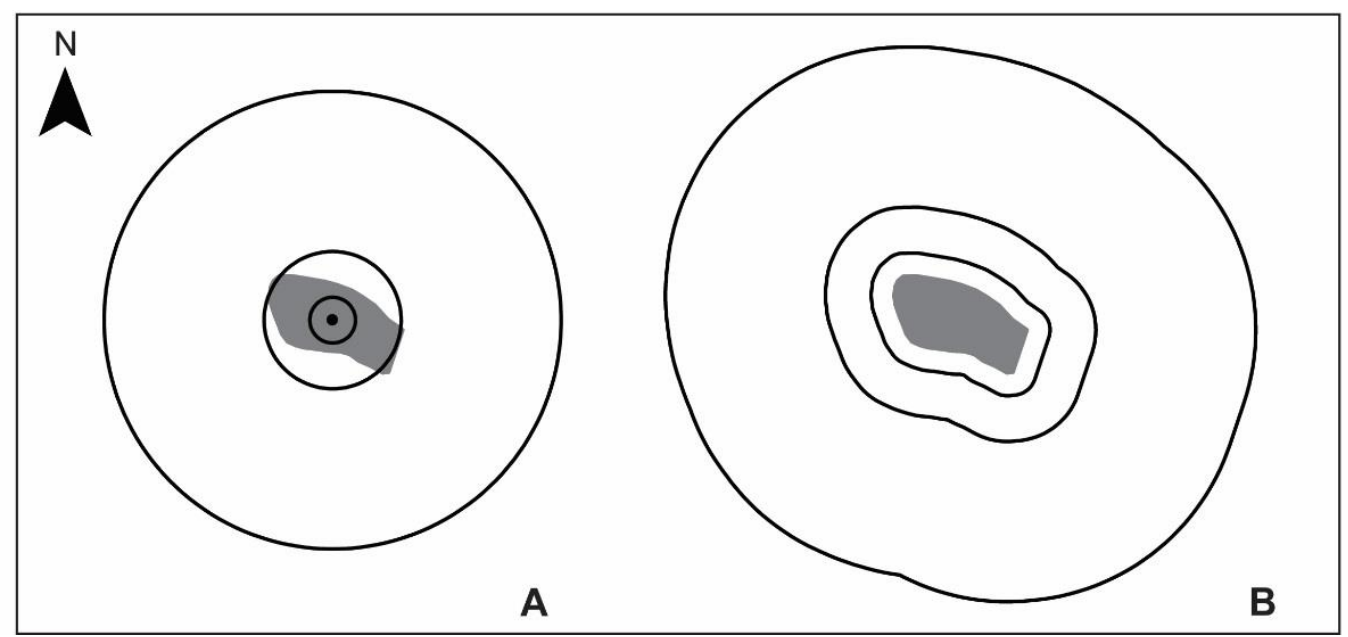

Fig. 3.2 Vegetation extraction schema. A) Illustrates how the vegetation data were extracted using circles starting from the centre of the lake. B) Shows the vegetation extraction within buffers starting from the lake shore. The major differences exist for the close vegetation, e.g. in A) only vegetation from the northeast and from the southwest will be considered in the first circle. In B) the whole vegetation surrounding the lake shore is considered in the first buffer.

The resulting SV in increasing circles or buffers around the lakes was compared to PAR from the lakes in two ways: directly as SV and as SV per hectare reducing the influence of distant trees through down weighting. Vegetation data extracted in concentric rings was distance-weighted using the Prentice-Sugita model (DWPAPs) described in Sugita et al. (1999). The DWPAps considers mean vegetation abundance at increasing distances, basin size and wind speed, as well as the fall speed of the pollen (Sugita, 1993; Sugita et al., 1999). The wind speed was set to $3 \mathrm{~m} / \mathrm{s}$. Thus, the pollen transport for the different taxa is implemented in the model. Vegetation data extracted in increasing 
buffers around the lakes was down weighted by dividing the SV per hectare by the mean distance to the lake shore plus the average lake radius (DWPA $A_{\text {Buffer }}$ ). For this simple distance-weighting approach, no species specific differences in pollen dispersal are considered.

\subsection{Results}

\subsubsection{Dating}

Out of the 18 selected lakes, short cores of 16 lakes could be dated by ${ }^{210} \mathrm{~Pb}$. Many cores show a distinct ${ }^{137} \mathrm{Cs}$ peak or strong increase in ${ }^{137} \mathrm{Cs}$ activity, which is related to the maximum fallout due to the peak in nuclear weapon testing in 1963 and could be further ascertained for some cores by the ${ }^{241} \mathrm{Am}$ peak. A second distinct peak or rise in ${ }^{137} \mathrm{Cs}$ activity is visible in some cores, marking the Chernobyl accident in 1986. Both signals provided a further constraint for the development of agedepth models. Well defined ${ }^{137}$ Cs peaks occur in the records of Heiligen See, Kleiner Lychensee, Bugsee and Aalgastsee. Dating failed on sediments from two small and elongated lakes surrounded by relatively steep slopes. They show no stratigraphic ${ }^{210} \mathrm{~Pb}$ decay and neither an increase in ${ }^{137} \mathrm{Cs}$ activity. Most of the dated lakes are characterized by a higher sedimentation rate in the upper part (Table 3.1). Sedimentation rates between the lakes vary widely, with $3-12 \mathrm{~cm}$ for the last 10 years and $10-32 \mathrm{~cm}$ for last 50 years, respectively. The sedimentation rates do not correspond to the size of the lakes.

\subsubsection{PAR}

Based on the ${ }^{210} \mathrm{~Pb}$ age-depth models, PARs were obtained for two time slices about 1993 and 2009 (Fig. 3.3) and can be divided into three groups of wind-pollinated tree taxa. A first group includes taxa with trees abundant in the vegetation and corresponding pollen types abundant in lake sediments. The second group encompasses less abundant taxa and the third group contains rare taxa.

The group of the abundant tree taxa contains Pinus, Fagus, Quercus, Betula and Alnus, which are reflected with high PARs in all samples. In most samples the PAR values are larger than 1000 grains $\mathrm{cm}^{-2} \mathrm{a}^{-1}$, and in particular the PARs for Pinus, the most abundant tree, exceed 10,000 grains $\mathrm{cm}^{-2} \mathrm{a}^{-1}$ and reach up to more than 30,000 grains $\mathrm{cm}^{-2} \mathrm{a}^{-1}$. Although high PARs of Alnus occurred in all samples, the parent tree $A$. glutinosa is abundant at waterlogged sites at the lakeshore, which are often not well represented in the forest inventory data. Therefore, no connection between Alnus PAR and SV could be found and the taxon was removed from further analysis. For all other abundant taxa PAR yielded strong relationships with SV. 


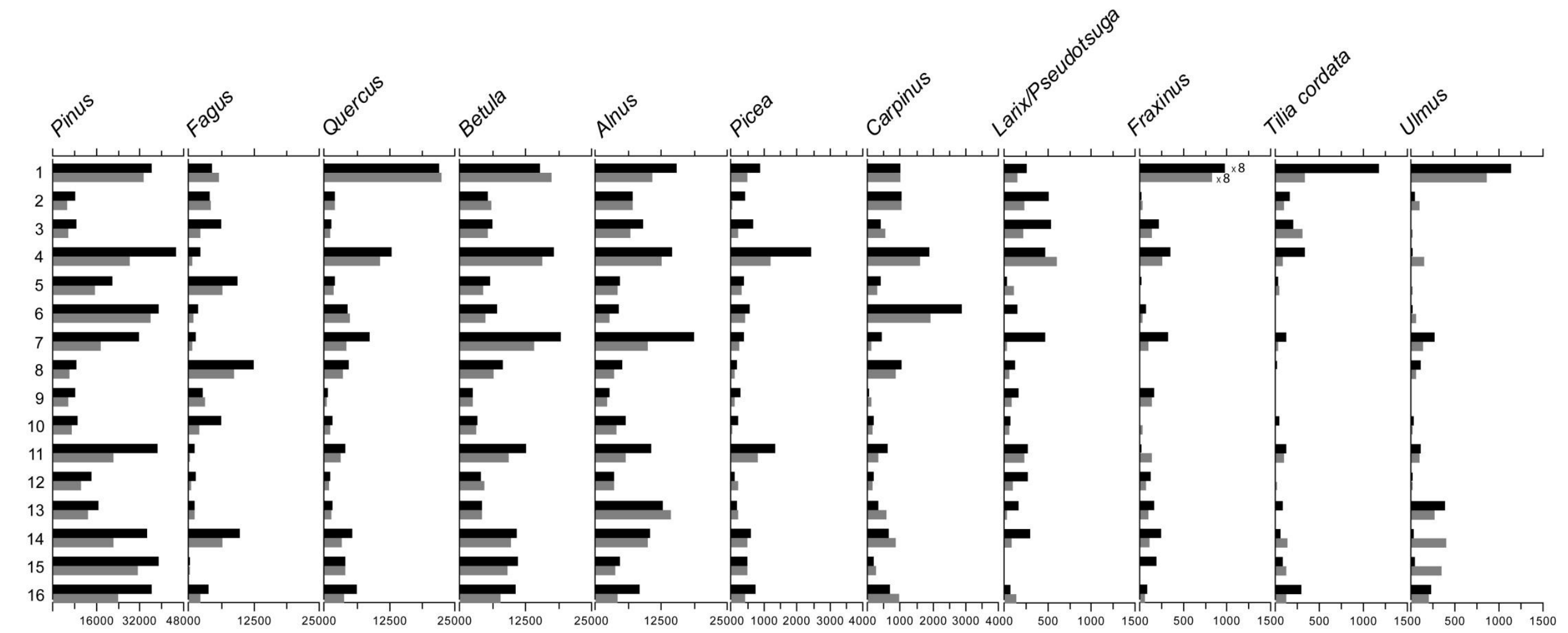

Fig. 3.3 Pollen accumulation rate (grains $\mathrm{cm}^{-2} \mathrm{a}^{-1}$ ) diagram for the most important wind-pollinated tree taxa in Brandenburg. The samples are ordered by lake size with the smallest on the top. Black bars show the values in the uppermost sediment assigned to the year 2009, grey bars represent values from sediment dated to around 1993. 
The group of less abundant taxa contains Picea, Carpinus and Larix/Pseudotsuga. Picea and Carpinus trees are reflected in most samples with PARs of less than 1000 grains $\mathrm{cm}^{-2} \mathrm{a}^{-1}$ (Fig. 3.3) and these estimates are often based on small counts. However, at a few sites PARs of Carpinus with 1000 grains $\mathrm{cm}^{-2} \mathrm{a}^{-1}$ or more are observed, and this taxon could be included in further comparisons. Although pollen from Larix/Pseudotsuga is present in almost all samples and highest values reach about 450 grains $\mathrm{cm}^{-2} \mathrm{a}^{-1}$, the counts are generally too small to be used in further analysis.

The group of the rare taxa contains Fraxinus, Tilia cordata and UImus. These taxa are absent in many samples or represented by single occurrences and low counts. Solely in the smallest lake of the collection (Schiebelsee), very high PAR with about 7850 grains $\mathrm{cm}^{-2} \mathrm{a}^{-1}$ in 2009, and 6700 grains $\mathrm{cm}^{-2}$ $\mathrm{a}^{-1}$ in 1993 was observed for Fraxinus. This lake is surrounded by a belt of Fraxinus trees, which is included in the forest inventory data for 2009. Relatively high PAR of Fraxinus (150-230 grains cm $\mathrm{cm}^{-2}$ $\left.{ }^{1}\right)$ was also observed in the lake Bugsee. This lake is only surrounded by few Fraxinus trees but contains in a distance of ca $300 \mathrm{~m}$ from the lakeshore more Fraxinus SV than Schiebelsee.

While Tilia cordata is often planted along roads and in villages, the tree is scarce in the forest. Also Ulmus was too rare to attempt comparisons between pollen and tree abundance.

\subsubsection{Comparison of PAR to non-weighted vegetation data}

It is generally assumed that a tree near the shore of the lake contributes more to the pollen deposition in the lake than one further away from it (e.g. Davis, 2000), which is the reason for distance-weighting of the vegetation in such comparisons. However, here we aim to explore how far out from the lake the increasing SV of individual species can explain the amount of pollen deposited in the lake. This comparison is made both by assessing the vegetation in increasing circles from the centre of the lake (Fig. 3.4a) and in buffers of increasing size from the shore of the lake (Fig. 3.4b).

In both cases, results show good agreement between SV and PAR already within tens- to hundreds of metres from the sampling point or lake shore. However, the three lakes with an area of more than 10 ha have no vegetation within $150 \mathrm{~m}$ from the centre of the lake and were therefore excluded from all regressions (Fig. 3.5) for comparability. Schiebelsee, the smallest lake in the dataset, formed an outlier in most scatter plots with unexpectedly high PARs per SV. Regressions between SV in increasing circles or buffers and PAR are presented for the remaining 12 sites. Coefficients of determination $\left(R^{2}\right)$ in such a small dataset are susceptible to outliers. Therefore scatter plots were visually examined, confirming that high $\mathrm{R}^{2}$ values were not caused by outliers.

The trends of $R^{2}$ values with distance (Fig. 3.5) are different for the five species, with curves reaching optima at different distances, while the patterns are similar for the two methods of compiling the vegetation around the lakes in circles or buffers. For some species the curves indicate several optima, although the values generally decrease at $4 \mathrm{~km}$ distance from the lake. Similar trends and peaks can 
be observed for the dataset for 1993. However, here the vegetation data are not as fine-scaled, obscuring some of the patterns at close distance and the dataset is a further 3 lakes smaller giving more weight to individual sites.

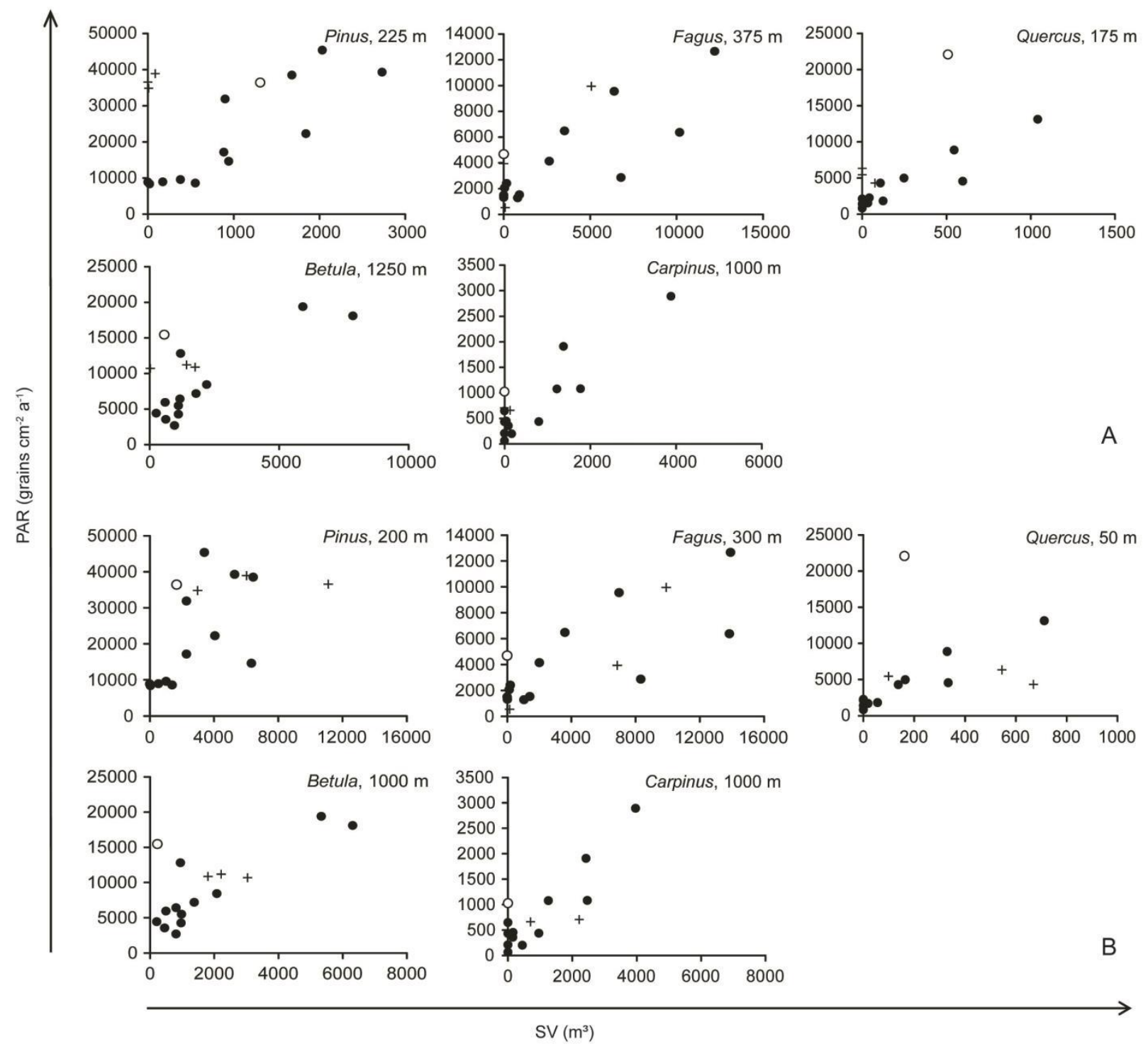

Fig. 3.4 Scatter plots for SV versus PAR for 2009. A) Scatter from the data within circles seen from the centre of the lake; B) results from the buffer surrounding the lakeshore. Distance was chosen for highest $R^{2}$ with low influence of individual sites. Lakes $>10$ ha (cross), lakes $<10->0.5$ ha (black dots) and one lake $\sim 0.5$ ha (hollow dot).

Of the five taxa, Pinus is the only that shows a distinctly higher coefficient of determination when the vegetation data were extracted in circles. The trend in $\mathrm{R}^{2}$ values for Pinus is unimodal with a peak of above 0.7 at around $200 \mathrm{~m}$ for the 2009 and the 1993 data and the extraction in circles. The trend is similar when the vegetation data were extracted in buffers, and the highest values were reached in a distance of $300 \mathrm{~m}$. Also Carpinus shows a clear unimodal curve with a peak around $1000 \mathrm{~m}$ for all datasets. Quercus shows particularly good fits for small rings or buffers and has mainly unimodal 
trends for the 2009 data. For the buffers, the best fit is observed at only $50 \mathrm{~m}$ while the rings show best agreement at $175 \mathrm{~m}$. With fewer sites the 1993 data maintain the best fit at small distances but show an additional peak around $600 \mathrm{~m}$ and also good agreement at large distances.

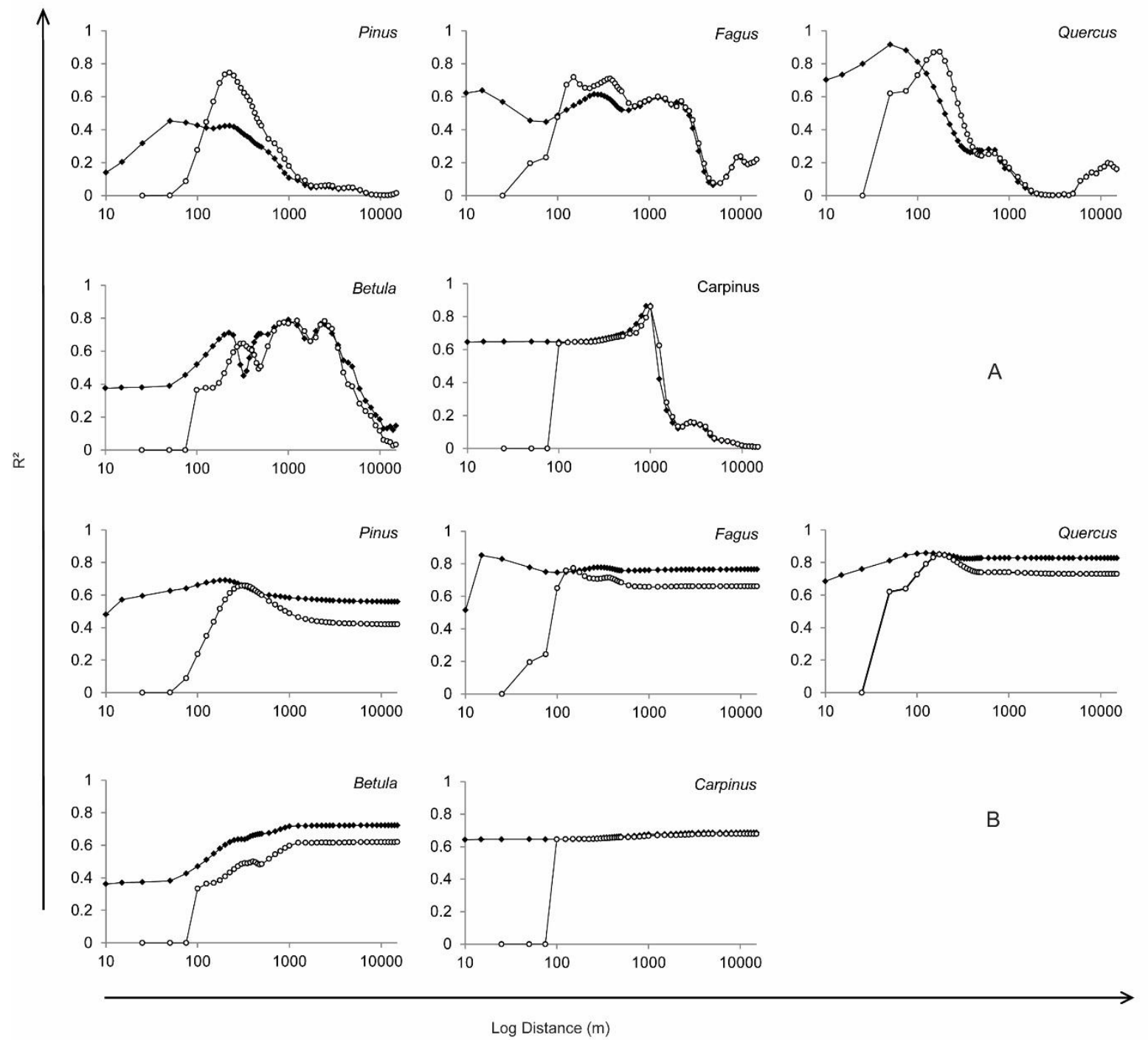

Fig. 3.5 $\mathrm{R}^{2}$ for regressions between SV and PAR A) Values from the raw vegetation and B) values from the DWPA. Diamond shows data for the vegetation in buffer surrounding the lakeshore and DWPABuffer. Hollow circles show values for vegetation extracted starting from centre of the lake and DWPAPs. The $R^{2}$-values based on lakes $<10->0.5$ ha.

The other two species show more complex patterns. The $\mathrm{R}^{2}$ values for Fagus are above 0.5 for a range of distances and only drop after $3 \mathrm{~km}$. Sites dominated by Fagus within the first few hundred metres are also Fagus dominated within a few kilometres around the lake. The 2009 set shows a clear peak at a distance around $300 \mathrm{~m}$, while the 1993 set shows a robust trend at $2.5 \mathrm{~km}$. The trends for Betula are controlled by two sites in all datasets with highest Betula PAR and highest SV at a range of distances. For the 2009 dataset the trend is most robust at distances around $1000 \mathrm{~m}$.

This comparison of absolute SV versus PAR allows exploring the importance of local vegetation in examples. The two lakes Schwarzer See and Heiliger See are only $3 \mathrm{~km}$ apart, but while the former 
had the highest PAR for Fagus $\left(12,600\right.$ grains $\left.\mathrm{cm}^{-2} \mathrm{a}^{-1}\right)$, the latter yielded average low values (1300 grains $\mathrm{cm}^{-2} \mathrm{a}^{-1}$ ). Within a radius of $3.5 \mathrm{~km}$ both lakes have about the same amount of Fagus SV, while within $300 \mathrm{~m}$ the difference in SV is about tenfold, like the PAR. The importance of the regional plant abundance becomes clear when adding the lake Kleiner Treppelsee to this comparison. This lake is situated in the southern part of the study region, were Fagus is generally scarce, while the lake itself is situated within a Fagus stand of limited extent. Within $300 \mathrm{~m}$ the SV of Fagus is the same for Schwarzer See and Kleiner Treppelsee, while PAR for Kleiner Treppelsee is only half compared to that for Schwarzer See. This indicates that, while local plant abundance has much explanatory power, a large proportion of pollen is coming from the vegetation beyond a few hundred metres from the lake shore.

\subsubsection{Distance-weighted plant abundance}

The comparison of PAR versus distance-weighted plant abundance for the five tree taxa yields linear trends for both weighting methods and time slices (Fig. 3.6). The two different distance weighting methods have only a small effect on the pattern and fit to a linear relationship. However, they yield different estimates of distance-weighted plant abundance which influence the relationship to PAR in absolute terms. For all five taxa $\mathrm{R}^{2}$ values reach constant high levels after $1 \mathrm{~km}$. The trends for Pinus, Fagus and Quercus show slightly higher coefficients of determination for shorter distances before the values stabilize. Maximum $\mathrm{R}^{2}$ values occur within 200-300 m and 100-200 m for Pinus and Quercus, respectively. For Fagus the weighted average abundance in buffers around the sites shows the highest $R^{2}$ value already at $15 \mathrm{~m}$ from the shore, but this fit is determined by a group of four sites with high values, and a secondary small peak at $300 \mathrm{~m}$ is based on a better spread of points. The trends for Carpinus and Betula are determined by high vegetation and PAR values at one and two sites (Fig. 3.6). The site with high Carpinus PAR is situated within a Carpinus rich forest, with the tree reaching the shore of the lake. In contrast, vegetation data in a radius of $1 \mathrm{~km}$ is needed to explain the two sites with high Betula PARs. The fit of the data to a linear relationship varies between the two time periods, with Pinus and Fagus having better fits in the 1993 dataset. The coefficients of determination are similarly good for the distance-weighted average SV and the best fits of the absolute SV within a given distance from the lake, while the trends in the scatter plots are often clearer in the latter assessment.

It is reassuring that linear regressions on the data from both time slices show similar slopes, usually with higher values for the set from 2009. This is particularly clear for Pinus, where the increase in PAR from 1993 to 2009 is also prominent in the pollen diagram (Fig. 3.3). While this may be partly due to uncertainties in the assessment of sediment accumulation for the very recent sediments, this trend can be explained by a regional increase in the SV of Pinus from 1993 to 2009 documented by forest 
inventory data. Thus the higher $y$-intercept of the linear model for the 2009 data may indicate an increased regional release of Pinus pollen.

When including the smallest and the three larger lakes in this analysis, results yield distinctly lower coefficients of determination indicating that variable lake size is not being well accounted for in the distance down weighting of vegetation. In particular for Pinus, the three large lakes yielded higher PAR per distance-weighted SV compared to the trend for the remaining lakes.

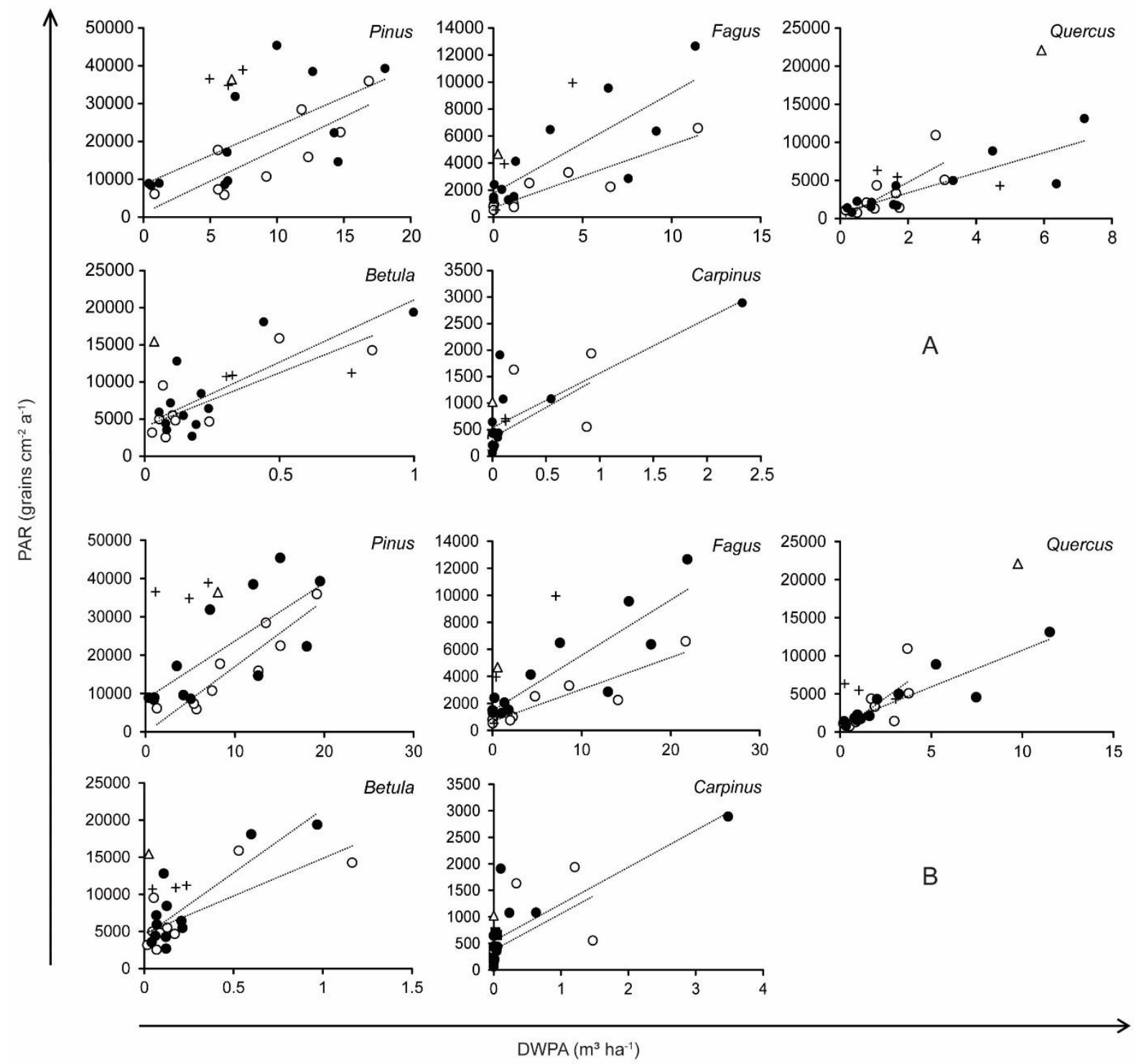

Fig. 3.6 A) Scatter plots of DWPAPs versus PAR within a distance of $10 \mathrm{~km}$ from the centre of the lake. B) Scatter plots of

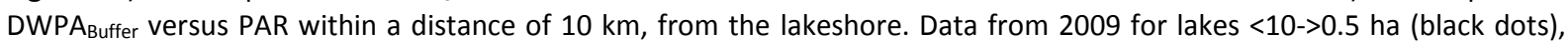
lakes $>10$ ha (cross), one lake $\sim 0.5$ ha (triangle) and data from 1993 (hollow dots). Trend-line based on lakes $<10->0.5$ ha. 


\subsection{Discussion}

\subsubsection{Confidence in PAR from lake sediments}

The comparison between contemporary PAR and standing tree volume relies heavily on the ability to accurately obtain sedimentation rates for the recent sedimentation in lakes. This is particularly challenging for the upper unconsolidated part of the sediment. We were able to include a comparison using somewhat older and more consolidated sediments to check the results obtained from the most recent sediments. To reduce the effect of inter-annual pollen production (Hicks et al., 2001; Nielsen et al., 2010) and sediment accumulation, several slices of sediment were combined to obtain average values. Moreover, in the case of Heiligen See we were able to evaluate the obtained ages and derived PAR from the lead dated core. The bottom water in the deepest part of the lake is oxygen free and the laminations observed for the recent sediment were interpreted to be annual. Based on this assumption, PARs were estimated from an additional core, which matched those obtained from the lead dated core.

The obtained PARs for individual taxa are generally higher than values reported from pollen traps within the Pollen Monitoring Program (Hicks et al., 2001; Giesecke et al., 2010a). For example, results of Tauber-type traps show highest average PAR of 2500 grains $\mathrm{cm}^{-2} \mathrm{a}^{-1}$ for traps from a Fagus dominated forest (Pidek et al., 2010). Whereas Fagus PAR from lakes reported here often exceed 5000 grains $\mathrm{cm}^{-2} \mathrm{a}^{-1}$ and up to more than 12,000 grains $\mathrm{cm}^{-2} \mathrm{a}^{-1}$, at a lake where a nearly pure Fagus forest is surrounding the lake.

These high PARs could be explained by sediment focussing, the process of differential sediment deposition and resuspension of sediments from shallower parts and their deposition in the deeper part of the basin (e.g. Lehman, 1975; Likens and Davis, 1975; Davis et al., 1984). These processes could deliver more sediment to the centre of the lake, from where we obtained the cores for this investigation, which would increase the amount of pollen deposited per unit sediment surface per year. With only one core per lake, we were unable to assess this effect directly. However, it is unlikely that these processes work on all investigated lakes with the same magnitude, as they would be influenced by basin morphometry. A correlation between lake size or depth and particularly high PARs is not present in the here presented data. Redeposition of sediment may occur in most lakes and could explain the lack in the attenuation of the ${ }^{137} \mathrm{Cs}$ profiles for some lakes. However, well defined fallout peaks of ${ }^{137} \mathrm{Cs}$ in the records from four lakes suggest little or no redeposition, and PARs for these sites clearly support the trends in tree SV versus PAR. Moreover, a generally good agreement between vegetation and pollen data for major tree species in both time slices indicates that lake internal processes had at most a small effect on obtained PARs. Recent studies investigating PARs from modern sediments in similar types of lakes in Scandinavia neither encountered strong 
influences of redeposition or focussing on PARs (Seppä and Hicks, 2006; Giesecke and Fontana, 2008). Contrary examples however do exist (e.g. Davis et al., 1984; Odgaard, 1993).

Unfortunately there are no studies monitoring the pollen deposition in Tauber-type traps in the study region, which could be used for comparisons. However, PARs for Fagus of 10,000 grains cm$^{-2} \mathrm{a}^{-1}$ were reported from a pollen monitoring study from Draved Forest, Denmark, were the Tauber traps are placed under the canopy (Andersen, 1974; Nielsen et al., 2010). A high resolution study from the mire Barschpfuhl (Van der Linden et al., 2008) shows values that are comparable with similar sized lakes few km away (Aalgastsee and Heiliger See). Thus the here reported values, although generally high, seem to represent the modern PARs in the region of northeast Germany, with negligible effects of lake internal processes. Still it would be desirable to compare the here presented results to pollen monitoring data from gravity traps in the region.

\subsubsection{Landscape pattern}

The different morphology of pollen types determines differences in fall speed (e.g. Eisenhut, 1961), and thus the fraction of pollen that stays airborne with increasing distance from the tree (Prentice, 1988). Therefore, one would expect to find that the distance at which plant abundance best explains pollen loading at a site differs between taxa, and this has been documented for percentage pollen data (Prentice et al., 1987; Jackson, 1990). The here presented results show that the SV already within tens to few hundred metres from the lake shore can explain between site differences in PAR for Pinus, Fagus and Quercus. For these taxa comparisons between PAR and distance-weighted tree abundance show that the goodness of fit is not improving with distance after the first few hundred metres, and even worsening somewhat.

The goodness of fit in a short distance from the lake is determined by a single site and two sites in the case of Carpinus and Betula, respectively. Good correspondences are found for Carpinus, Betula and Fagus in distances of 1-2.5 km, which may be caused by the landscape structure. The large geomorphological structures created by the last ice age have been identified in a previous, pollen percentage based study (Matthias et al., 2012) to affect the vegetation pollen relationship. In the study area forests are generally restricted to extensive outwash plains, which are dominated by Pinus occasionally accompanied by Quercus and to smaller patches of terminal moraines dominated by Fagus, sometimes with an admixture of Carpinus and Betula. Particularly in the case of Fagus there is a strong correlation between the SV in $200 \mathrm{~m}$ and $2 \mathrm{~km}$ around all but two sites.

Comparisons between the distance-weighted tree abundance and PAR yield similarly high coefficients of determination compared to the best fits for the raw SV. Also the patterns in the scatter plots are similar between the two assessments of vegetation, indicating that the distanceweighted tree abundance is strongly determined by the abundance of trees within the first few 
hundred metres. The strong landscape pattern in the abundance of different trees may support the relationship, without improving it.

\subsubsection{The importance of local vegetation and the trunk-space component}

Pollen monitoring experiments have shown that PAR for a given tree species is several times higher under its canopy or close to it compared to open areas away from the edge of a stand of that species (Bonny, 1980; Hicks, 2001; Tinsley, 2001). While lakes represent open areas in the forest, trees often grow right up to the edge of lakes and even extend branches over the water. All lakes in this study were bordered by trees, for at least part of the shore, and most were fully surrounded by mature trees. Tauber (1965) speculated that a small lake with a diameter of $100-200 \mathrm{~m}$ would receive $80 \%$ of its pollen from the trunk space component. In a subsequent experiment, Tauber (1967) showed that refloation of pollen after the flowering season may account for as much as $50 \%$ of the total deposition of pollen from species with local presence. As pollen or entire anthers may directly fall into the lake from overhanging trees the gravity component (Jacobson and Bradshaw, 1981) needs to be added to the consideration, although in this context it may be considered part of the trunk space. The importance of the trunk space component would explain the high explanatory power of the local tree abundance for the between site variation in PAR, as well as the lack of strong between species differences in the radius of the best fit. It may also explain the high PAR values for Fraxinus and Quercus at the smallest lake, Schiebelsee. The 0.5 ha lake is surrounded by a belt of Fraxinus trees, with a Quercus dominated stand next to it. The strong determination of the local vegetation was also suspected in an earlier, pollen percentage based study that included the lakes from this investigation (Matthias et al., 2012), and where lakes surrounded by dense Fagus stands formed a distinct group. Local vegetation dynamics determining patterns in PARs can also be seen in an example from a small lake in central Sweden, where the exponential increase in Picea bud-scales was parallelled by the increase in Picea PAR (Giesecke, 2005). As bud scales don't disperse far, this suggests that also the PAR signal was generated by trees in the immediate vicinity of the lake.

Thus the here presented data support Tauber's (1965) speculation that pollen transport through trunk space is the major source of pollen delivered to small lakes in a forest. However, this component is ignored in numerical models of pollen deposition (Prentice, 1985; Sugita et al., 1999).

\subsubsection{Extra-local pollen and large lakes}

While the local tree SV is a good predictor for the PARs at the investigated sites, it does not account for all pollen deposited in the lakes. The site Kleiner Treppelsee is a good example to illustrate this. The Fagus stand in the immediate surroundings of the lake is similar in age and structure to that around Schwarzer See, and both have the highest SV within $300 \mathrm{~m}$ from the lake (Fig. 3.4b). However 
the PAR for Fagus in Schwarzer See is twice the value in Kleiner Treppelsee, as the latter is situated in the south of the study region where Fagus is rare. Considering the SV within $1.25 \mathrm{~km}$ reduces the relative amount of Fagus at Kleiner Treppelsee sufficient to bring it onto the regression line. This indicates that perhaps as much as half of the pollen at Schwarzer See comes from an area beyond $300 \mathrm{~m}$ from the shore. It is also interesting to note that the distance-weighting of the SV cannot account for the difference in extra-local SV between the two sites (Fig. 3.6).

With increasing radius of a circle the circumference increases slower than the area. As the shorelines of lakes are undulating this relationship may not be as strong in nature, but also here the length of the shoreline will in general not increase with the same amount as the area of a lake with increasing radius. Therefore larger lakes should receive a smaller contribution from the trunk-space component and thereby have lower rates of pollen accumulation. Numerical models of pollen dispersal (e.g. Prentice, 1985; Sugita et al., 1999) strongly down weight distant vegetation and as no terrestrial pollen is produced on lakes, these models predict decreasing pollen accumulation with increasing lake size. However, the here presented data do not support this concept. The three larger lakes have generally higher taxon specific PAR per SV around the lakes (Figs. 3.4b and 3.6). In particular for the case of Pinus all three lakes yield higher than expected PAR values (Fig. 3.6). It should also be noted that the PAR values for Pinus and Betula are similar for all tree larger lakes. Specific examples are again found for Fagus. Lake Glabatzsee with its size of 2 ha and Dovinsee with 20 ha have the same average SV of Fagus per hectare over a range of distances around the lakes, and Fagus PAR is slightly larger at the larger lake. Even for the 782 ha Grimnitzsee, Fagus PAR are higher than predicted when using average SV of Fagus in buffers around $1 \mathrm{~km}$ as the predictor and using all studied lakes in a linear regression model. Although the observations from the three large lakes point in the same direction, they may be caused by lake internal processes. Also the small number of large lakes does not permit drawing firm conclusions. The PAR estimates reported by Davis et al. (1973) show a positive trend with lake size for lakes smaller than 100 ha, while the four larger lakes do not follow this trend. If large lakes receive proportionally less pollen from the local vegetation they need to have an additional source of pollen from the regional vegetation. Tauber $(1965,1967)$ suggested that small lakes only receive a proportionally small fraction of pollen transported above the canopy, as pollen from above the canopy may pass over a small lake faster than would be required for gravity or eddy diffusion to reach the lake surface. Monitoring experiments by Rempe (1937) showed that the highest amount of Fagus pollen collected on impact sampler occurred in $150 \mathrm{~m}$ from the edge of a closed stand, which is supporting Tauber's (1965) theory. Large lakes with a long wind fetch would thus receive an absolute higher amount of pollen from the canopy component. The different relative proportion of the trunk space and the above canopy component could for the here presented data balance each other out, and this combination is in accordance with the observations. 
Comparing PARs from pollen traps Sjögren et al. (2010) suggested that the combination of numerical dispersal functions would reflect the trunk space and the above canopy component separately. Such a combination may be the way forward to disentangle these two modes of pollen transport. However, it will be challenging to determine their proportional importance at sites of different size and shape. The current dispersal models give too little weight to the trunk space component but also to the amount of pollen from regional sources.

\subsubsection{Are PARs a good indicator of biomass?}

The ultimate aim of studying the vegetation pollen relationships is their application to pollen based reconstructions of the past in order to facilitate communication with neighbouring disciplines. In particular, data-model comparisons require that a common unit of plant abundance can be compared (e.g. Miller et al., 2008) and aboveground biomass (SV) would be a useful variable.

Within this study aboveground biomass can explain a large proportion of between site variance in the PAR for common forest trees. Using pollen monitoring results from Tauber-type traps in northern Finland good agreement could be shown for PAR and SV for Pinus and Picea, while the relationship was weak for Betula, the third common species (Sugita et al., 2010). Regional plant abundance was shown to correspond well to average PAR from pollen traps at tree-line situations in Switzerland (Sjögren et al., 2008) and average Fagus PAR could be explained by the regional abundance of Fagus (Pidek et al., 2010). Thus it seems as if PARs are a good indicator for biomass, while obtaining reliable estimates for the past is limited to particular site conditions (e.g. Giesecke and Fontana, 2008).

Nevertheless, the here reported absolute values are rather high compared to estimates from the pollen monitoring network using Tauber-type traps (Giesecke et al., 2010b). Already the average values for Fagus, across all lakes in this study, of 4400 grains $\mathrm{cm}^{-2} \mathrm{a}^{-1}$ are within the upper range of reported values from pollen traps (Pidek et al., 2010) the highest value of 12,700 grains cm${ }^{-2} \mathrm{a}^{-1}$ is only similar to Tauber traps placed under the canopy in a small forest in Denmark (Andersen, 1974; Nielsen et al., 2010). Comparing PAR for Pinus yields a more extreme picture. For this tree the average values from this study are 25,000 grains $\mathrm{cm}^{-2} \mathrm{a}^{-1}$, while in northern Finland highest average trap values of 6000 grains $\mathrm{cm}^{-2} \mathrm{a}^{-1}$ come from within forest stands of Pinus. Average Holocene values from 3 small lakes in central Sweden range between 3000 and 6000 grains $\mathrm{cm}^{-2} \mathrm{a}^{-1}$ (Giesecke and Fontana, 2008). However, Theuerkauf and Joosten (2012) estimate values around $14,000 \mathrm{grains} \mathrm{cm}^{-2}$ $a^{-1}$ for the Allerød period for sites in Brandenburg (within this study area). Pollen monitoring studies using Tauber-type traps are unfortunately not available from the study area. Available data from Poland (e.g. Poska and Pidek, 2010) do not show similar average values indicating that perhaps the deposition in lakes is different from traps and/or that the regional dominance of the tree in Brandenburg has an effect. 
Pollen monitoring experiments have shown that the amount of pollen produced varies between years and this variation can be explained to a large extent by weather conditions of the previous year (Hicks, 2006; Huusko and Hicks, 2009; Nielsen et al., 2010; Van der Knaap et al., 2010). In particular near the tree-line the same parameter, July temperature, determines annual pollen production, tree growth and abundance as well as the forest limit (Huusko and Hicks, 2009; Mazier et al., 2012). It is striking that already the Pinus PAR estimated from sites in Brandenburg for the Allerød period (Theuerkauf and Joosten, 2012) is higher than the Holocene estimates from central Sweden (Giesecke and Fontana, 2008). However, the sandy soils in Brandenburg were during the Allerød period, as well as today, dominated by Pinus and an increase in the average from 14,000 to 25,000 grains $\mathrm{cm}^{-2} \mathrm{a}^{-1}$ does not seem too much considering higher productivity under the warmer climate at present. Nevertheless, this interpretation would imply that PAR is dependent on net primary production of the standing biomass.

\subsection{Conclusions}

In this study we could demonstrate, that PARs of the major tree taxa observed from lake sediments are linearly related to the lake surrounding biomass. Lake internal processes are potentially important as indicated by the failure of dating 2 out of 18 lakes using ${ }^{210} \mathrm{~Pb}$. However, we interpret these processes to have little effect on the PAR from the remaining 16 lakes. The results show that PAR from as single lake core contains a strong representation of the amount of pollen released by the vegetation surrounding the site, and can thus be used as an indicator for absolute plant abundance, and compared between sites. However, long-term averages in PARs may not only reflect plant abundance but also regional differences in net primary productivity.

The plant abundance within a few hundred metres around the lakes explains a high proportion of between site variations in PARs, indicating that the trunk space component of pollen transport is of major importance. Data from three large lakes suggest that larger lakes receive an absolute higher amount of pollen from regional sources. These observations support Tauber's (1965) conceptual model of pollen transport and deposition, while they do not comply with the processes reflected in the numerical Prentice/Sugita models. Nevertheless, this family of models does describe the overall pattern reasonably well. More complex models are desirable to resolve the differentiated importance of local and regional pollen loading. This study shows that vegetation dynamics within few hundred metres of the lake shore are well documented in the PAR of small to medium sized lakes. 


\section{Acknowledgements}

We thank Anne Birgitte Nielsen for assisting us in the field and Martin Theuerkauf, Lars Schmidt and Malte Semmler for their support and/or suggestions concerning the handling of the forest inventory data. We thank the department of landscape ecology, particularly Jürgen Grotheer, for giving us permission to use their lab. We thank the forest authorities of Brandenburg for providing us with the forest data, particularly Konrad Müller from LFB, Potsdam. We are grateful to Shinya Sugita for providing a DWPA-Calculator and for further fruitful discussion and suggestions for handling DWPA. This study was funded by the German Research Foundation (DFG, GI 732/1-1).

\subsection{References}

Andersen, S.Th, 1974. Wind conditions and pollen deposition in a mixed deciduous forest. II. Seasonal and annual pollen deposition 1967-1972. Grana 14, 64-77.

Appleby, P.G., Oldfield, F., 1978. The calculation of $210 \mathrm{~Pb}$ dates assuming a constant rate of supply of unsupported ${ }^{210} \mathrm{~Pb}$ to the sediment. Catena $5,1-8$.

Appleby, P.G., Nolan, P.J., Gifford, D.W., Godfrey, M.J., Oldfield, F., Anderson, N.J., Battarbee, R.W., 1986. ${ }^{210} \mathrm{~Pb}$ dating by low background gamma counting. Hydrobiologia 141, 21-27.

Appleby, P.G., Richardson, N., Nolan, P.J., 1991. 241Am dating of lake sediments. Hydrobiologia 214, 35-42.

Appleby, P.G., Richardson, N., Nolan, P.J., 1992. Self-absorption corrections for well-type germaniun detectors. Nucl. Instr. Meth. Phys. Res. Sec. B. Beam Interact. Mater. Atoms 71, 228-233.

Appleby, P.G., 2001. Chronostratigraphic techniques in recent sediments. In: Last, W.M., Smol, J.P. (Eds.), Tracking Environmental Change Using Lake Sediments, Basin Analysis, Coring, and Chronological Techniques, vol. 1. Kluwer Academic, pp. 171-203.

Bennett, K.D., Willis, K.J., 2001. Pollen. In: Smol, J.P., Birks, H.J.B., Last, W.M. (Eds.), Tracking Environmental Change Using Lake Sediments, Terrestrial, Algal and Siliceous Indicators, vol.

3. Kluwer Academic Publishers, Dordrecht, pp. 5-32.

Beug, H.-J., 2004. Leitfaden der Pollenbestimmung. Verlag Dr. Friedrich Pfeil, München.

Bonny, A.P., 1980. Seasonal and annual variation over 5 Years in contemporary airborne pollen trapped at a Cumbrian Lake. J. Ecol. 68, 421-441.

Bradshaw, R.H.W., Webb III, T., 1985. Relationships between contemporary pollen and vegetation data from Winsconsin and Michigan, USA. Ecology 66, 721-737.

Caseldine, C., Fyfe, R., Hjelle, K.L., 2008. Pollen modeling, palaeoecology and archaeology: virtualization and/or visualisation of the past? Veg. Hist. Archaeobot. 17, 543-549.

Davis, M.B., Deevey, E.S., 1964. Pollen accumulation rates: estimates from Late-Glacial sediment Rogers Lake. Science 145, 1293-1295.

Davis, M.B., Brubaker, L.B., Webb, T., 1973. Calibration of absolute pollen influx. In: Birks, H.J.B., West, R.G. (Eds.), Quaternary Plant Ecology. Blackwell Scientific Publications, Oxford, pp. 925.

Davis, M.B., Moeller, R.E., Ford, J., 1984. Sediment focusing and pollen influx. In: Haworth, E.Y., Lund, J.W.G. (Eds.), Lake Sediments and Environmental History. Univ. Leicester Press, Leicester UK, pp. 261-293.

Davis, M.B., 2000. Palynology after Y2K e understanding the source area of pollen in sediments. Ann. Rev. Earth Planet. Sci. 28, 1-18.

Eisenhut, G., 1961. Untersuchungen über die Morphologie und Ökologie der Pollenkörner heimischer und fremdländischer Waldbäume. Paul Parey, Hamburg.

Engel, J., 2010. Brandenburg e Kiefernland in Wandel. MILAktuell 2, 29-30. 
Enters, D., Dörfler, W., Zolitschka, B., 2008. Historical soil erosion and land-use change during the last two millennia recorded in lake sediments of Frickenhauser See, northern Bavaria, central Germany. Holocene 18, 243-254.

Gaillard, M.-J., Sugita, S., Bunting, J., Dearing, J., Bittmann, F., 2008. Human impact on terrestrial ecosystems, pollen calibration and quantitative reconstruction of past land-cover. Veg. Hist. Archaeobot. 17, 415-418.

Gaillard, M.-J., Sugita, S., Mazier, F., Trondman, A.-K., Broström, A., Hickler, T., Kaplan, J.O., Kjellström, E., Kokfelt, U., Kunes, P., Lemmen, C., Miller, P., Olofsson, J., Poska, A., Rundgren, M., Smith, B., Strandberg, G., Fyfe, R., Nielsen, A.B., Alenius, T., Balakauskas, L., Barnekov, L., Birks, H.J.B., Bjune, A., Bjorkman, L., Giesecke, T., Hjelle, K., Kalnina, L., Kangur, M., van der Knaap, W.O., Koff, T., Lageras, P., Latalowa, M., Leydet, M., Lechterbeck, J., Lindbladh, M., Odgaard, B., Peglar, S., Segerstrom, U., von Stedingk, H., Seppä, H., 2010. Holocene landcover reconstructions for studies on land cover-climate feedbacks. Clim. Past 6, 483-499.

Giesecke, T., 2005. Moving front or population expansion: how did Picea abies (L.) Karst. become frequent in central Sweden? Quat. Sci. Rev. 24, 2495-2509.

Giesecke, T., Fontana, S.L., 2008. Revisiting pollen accumulation rates from Swedish lake sediments. Holocene 18, 293-305.

Giesecke, T., Fontana, S.L., van der Knaap, W.O., Pardoe, H.S., Pidek, I.A., 2010a. From early pollen trapping experiments to the Pollen Monitoring Programme. Veg. Hist. Archaeobot. 19, 247258.

Giesecke, T., van der, K., W., O., Bittmann, F., 2010b. Towards quantitative palynology: using pollen accumulation rates and models of pollen dispersal. Veg. Hist. Archaeobot. 19, 243-245.

Gregory, P.H., 1973. The Microbiology of the Atmosphere. Leonard Hill, Aylesbury.

Haller, K.E., Fickler, H.-H., 1955. Waldbäume, Sträucher und Zwergholzgewächse. Winter, Heidelberg.

Hicks, S., 2001. The use of annual arboreal pollen deposition values for delimiting tree-lines in the landscape and exploring models of pollen dispersal. Rev. Palaeobot. Palynol. 117, 1-29.

Hicks, S., Tinsley, H., Huusko, A., Jensen, C., Hattestrand, M., Gerasimides, A., Kvavadze, E., 2001. Some comments on spatial variation in arboreal pollen deposition: first records from the Pollen Monitoring Programme (PMP). Rev. Palaeobot. Palynol. 117, 183-194.

Hicks, S., 2006. When no pollen does not mean no trees. Veg. Hist. Archaeobot. 15, 253-261.

Huusko, A., Hicks, S., 2009. Conifer pollen abundance provides a proxy for summer temperature: evidence from the latitudinal forest limit in Finland. J. Quat. Sci. 24, 522-528.

Hyvärinen, H., 1976. Flandrian pollen deposition rates and tree-line history in northern Fennoscandia. Boreas 5, 163-175.

Jacobson, G.L., Bradshaw, R.H.W., 1981. The selection of sites for paleovegetational studies. Quat. Res. 16, 80-96.

Jackson, S.T., 1990. Pollen source area and representation in small lakes of the northeastern United States. Rev. Palaeobot. Palynol. 63, 53-76.

Janssen, C.R., 1966. Recent pollen spectra from the deciduous and Coniferous-deciduous forests of northeastern. Ecology 47, 804-825.

Lehman, J.T., 1975. Reconstructing the rate of accumulation of lake sediment: the effect of sediment focusing. Quat. Res. 5, 541-550.

Liedtke, H., Marcinek, J., 2002. Physische Geographie Deutschlands. Klett-Perthes, Gotha, Stuttgart.

Linke, C., Grimmert, S., Hartmann, I., Reinhardt, K., 2010. Auswertung regionaler Klimamodelle für das Land Brandenburg. In: Fachbeiträge des Landesumweltamtes Heft Nr. 113. http://www.mugv.brandenburg.de/cms/media. php/lbm1.a.2334.de/i_fb113.pdf (accessed 27.02.12.).

Likens, G.E., Davis, M.B., 1975. Post-glacial History of Mirror Lake and its Watershed in New Hampshire: an Initial Report. In: Mitteilungen Internationale Vereinigung für Theoretische und Angewandte Limnologie 19, pp. 982-993.

Lockow, K.-W., Lockow, J., 2009. Die Hainbuche im nordostdeutschen Tiefland - Wuchsverhalten und Bewirtschaftungshinweise. In: Eberswalder Forstliche Schriftenreihe, Band 41. 
Matthias, I., Nielsen, A.B., Giesecke, T., 2012. Evaluating the effect of flowering age and forest structure on pollen productivity estimates. Veg. Hist. Archaeobot. 21, 471-484.

Mazier, F., Nielsen, A.B., Broström, A., Sugita, S., Hicks, S., 2012. Signals of tree volume and temperature in a high-resolution record of pollen accumulation rates in northern Finland. J. Quat. Sci. 27, 564-574.

Miller, P.A., Giesecke, T., Hickler, T., Bradshaw, R.H.W., Smith, B., Seppä, H., Valdes, P.J., Sykes, M.T., 2008. Exploring climatic and biotic controls on Holocene vegetation change in Fennoscandia. J. Ecol. 96, 247-259.

MLUV, 2009. Agrarbericht 2009 zur Land- und Ernährungswirtschaft des Landes Brandenburg. Ministerium für Ländliche Entwicklung, Umwelt und Verbraucherschutz des Landes Brandenburg (MLUV). Landesamt für Verbraucherschutz, Landwirtschaft und Flurneuordnung. http://www.mil.brandenburg.de/sixcms/media.php/4055/ Agrarbericht_2009.pdf (accessed 27.02.12.).

Moore, P.D., Webb, J.A., Collinson, M.E., 1991. Pollen Analysis. Blackwell Scientific, Oxford.

Nielsen, A.B., Sugita, S., 2005. Estimating relevant source area of pollen for small Danish lakes around AD 1800. Holocene 15, 1006-1020.

Nielsen, A.B., Moller, P.F., Giesecke, T., Stavngaard, B., Fontana, S.L., Bradshaw, R.H.W., 2010. The effect of climate conditions on inter-annual flowering variability monitored by pollen traps below the canopy in Draved Forest, Denmark. Veg. Hist. Archaeobot. 19, 309-323.

Odgaard, B.V., 1993. Wind-determined sediment distribution and Holocene sediment yield in a small, Danish, kettle lake. J. Paleolimnol. 8, 3-13.

Pidek, I.A., Svitavska-Svobodova, H., van der Knaap, W.O., Noryskiewicz, A.M., Filbrandt-Czaja, A., Noryskiewicz, B., Latalowa, M., Zimny, M., Swieta-Musznicka, J., Bozilova, E., Tonkov, S., Filipova-Marinova, M., Poska, A., Giesecke, T., Gikov, A., 2010. Variation in annual pollen accumulation rates of Fagus along a N-S transect in Europe based on pollen traps. Veg. Hist. Archaeobot. 19, 259-270.

Poska, A., Pidek, I.A., 2010. Pollen dispersal and deposition characteristics of Abies alba, Fagus sylvatica and Pinus sylvestris, Roztocze region (SE Poland). Veg. Hist. Archaeobot. 19, 91-101.

Prentice, I.C., 1985. Pollen representation, source area, and basin size: toward a unified theory of pollen analysis. Quat. Res. 23, 76-86.

Prentice, I.C., Berglund, B.E., Olsson, T., 1987. Quantitative forest-composition sensing characteristics of pollen samples from Swedish lakes. Boreas 16, 43-54.

Prentice, C., 1988. Records of vegetation in time and space: the principles of pollen analysis. In: Vegetation History. Springer, Netherlands, pp. 17-42.

Rempe, H., 1937. Untersuchungen über die Verbreitung des Blütenstaubes durch die Luftströmungen. Planta 27, 93e147.

Renberg, I., 1991. The HON-Kajak sediment corer. J. Paleolimnol. 6, 167-170.

Rispens, J.A., 2003. Der Nadelbaumtypus - Schritte zu einem imaginativen Baumverständnis. Elemente der Naturwissenschaft 79, 51-77.

Schober, R., 1975. Ertragstafeln wichtiger Baumarten bei verschiedener Durchforstung. Sauerländer, Frankfurt a. M.

Schütt, P., Weisgerber, H., Schuck, H.-J., Lang, U., Stimm, B., Roloff, A., 2006. Enzyklopädie der Laubbäume. Nikol, Hamburg.

Schröck, O., 1949. Die Vererbung der Frühblüte der Kiefer. Der Züchter 19, $247 e 254$.

Seppä, H., Hicks, S., 2006. Integration of modern and past pollen accumulation rate (PAR) records across the arctic tree-line: a method for more precise vegetation reconstructions. Quat. Sci. Rev. 25, 1501-1516.

Seppä, H., Alenius, T., Muukkonen, P., Giesecke, T., Miller, P.A., Ojala, A.E.K., 2009. Calibrated pollen accumulation rates as a basis for quantitative tree biomass reconstructions. Holocene 19, 209-220.

Sjögren, P., Van der Knaap, W.O., Kaplan, J.O., van Leeuwen, J.F., Ammann, B., 2008. A pilot study on pollen representation of mountain valley vegetation in the central Alps. Rev. Palaeobot. 
Palynol. 149, 208-218.

Sjögren, P., Connor, S.E., van der Knaap, W.O., 2010. The development of composite pollen-dispersal functions for estimating absolute pollen productivity in the Swiss Alps. Veg. Hist. Archaeobot. 19, 341-349.

Soepboer, W., Sugita, S., Lotter, A.F., Van Leuwen, J.F.N., Van der Knaap, W.O., 2007. Pollen productivity estimates for quantitative reconstruction of vegetation cover on the Swiss Plateau. Holocene 17, 1-13.

Stinglwagner, G., Haseder, I., Erlbeck, R., 2005. Das Kosmos Wald- und Forstlexikon. Kosmos, Stuttgart.

Stockmarr, J., 1971. Tablets with spores used in absolute pollen analysis. Pollen Spores 13, 615-621.

Sugita, S., 1993. A model of pollen source area for an entire lake surface. Quat. Res. 39, 239-244.

Sugita, S., 1994. Pollen representation of vegetation in quaternary sediments: theory and method in patchy vegetation. J. Ecol. 82, 881-897.

Sugita, S., Gaillard, M.J., Broström, A., 1999. Landscape openness and pollen records: a simulation approach. Holocene 9, 409-421.

Sugita, S., Hicks, S., Sormunen, H., 2010. Absolute pollen productivity and pollen-vegetation relationships in northern Finland. J. Quat. Sci. 25, 724-736.

Tauber, H., 1965. Differential pollen dispersion and the interpretation of pollen diagrams. Danmarks Geologiske Undersogelse 89, 1-69.

Tauber, H., 1967. Investigations of the mode of pollen transfer in forested areas. Rev. Palaeobot. Palynol. 3, 277-286.

Theuerkauf, M., Joosten, H., 2012. Younger Dryas cold stage vegetation patterns of central Europe e climate, soil and relief controls. Boreas 41, 391-407.

Tinsley, H., 2001. Modern pollen deposition in traps on a transect across an anthropogenic tree-line on Exmoor, southwest England: a note summarising the first three years of data. Rev. Palaeobot. Palynol. 117, 153-158.

Umweltbundesamt, DLR-DFD, 2004. CORINE Land Cover 2000. Daten zur Bodenbedeckung Deutschland. http://www.corine.dfd.dlr.de.

Van der Knaap, W.O., van Leeuwen, J.F.N., Svitavska-Svobodova, H., Pidek, I.A., Kvavadze, E., Chichinadze, M., Giesecke, T., Kaszewski, B.M., Oberli, F., Kalnina, L., Pardoe, H.S., Tinner, W., Ammann, B., 2010. Annual pollen traps reveal the complexity of climatic control on pollen productivity in Europe and the Caucasus. Veg. Hist. Archaeobot. 19, 285-307.

Van der Linden, M., Vickery, E., Charman, D.J., Broekens, P., van Geel, B., 2008. Vegetation history and human impact during the last 300 years recorded in a German peat deposit. Rev. Palaeobot. Palynol. 152, 158-175.

Von Post, L., 1918. Skogsträdspollen i sydsvenska torfmosslagerföljder. In: Forhandlinger ved de 16. Skandinaviske Naturforskeresmøte 1916, pp. 433-465.

Welten, M., 1944. Pollenanalytische, stratigraphische und geochronologische Untersuchungen aus dem Faulenseemoos bei Spiez. In: Veröffentlichungen Geobotanisches Institut Rübel 21, pp. 1-201. 


\section{Supplementary material:}

\section{Absolute pollen productivity estimates}

\section{Motivation}

Relative pollen productivity estimates (PPE) are a necessary prerequisite for quantitative vegetation reconstruction (see chapter 2). However, where pollen accumulation rates (PAR) and the biomass data for the single tree taxa are available, absolute and independent values may be obtained. Until now, only one study was realised calculating absolute pollen productivity estimates (aPPE) (Sugita et al., 2010). The obtained aPPEs are based on PAR from Tauber traps and the aboveground biomass (Sugita et al., 2010). However, no study was conducted that provides aPPEs from lake sediments. The interest using PAR from lake sediments was limited because of possible biases of lake internal processes, in particular different accumulation rates within the basin (e.g. Lehman, 1975; Likens and Davis, 1975; Davis et al., 1984). However, motivated by the observation of Giesecke and Fontana (2008), where PARs from lake sediments were similar to PARs in Tauber traps as well as the strong correlation between PAR and the standing volume/aboveground biomass (SV) for the most important tree taxa in the previous chapter, this supplementary focusses on aPPEs from lake sediments.

\section{Method}

In this small chapter further information to the second manuscript (chapter 3 ) is added, while detailed information on material and methods is provided in the second manuscript (chapter 3 ). In the previous chapter pollen accumulation rate (PAR) for the years 2009 and 1993 were obtained from lakes ranging $<10$ and $>0.5$ ha and compared with the SV for the main tree taxa at different distances. The PARs were compared with the distance-weighted SV within a distance of $10 \mathrm{~km}$ from the lake. For the distance-weighted plant abundance (DWPA), two different weightings were used. First, the Prentice/Sugita model (DWPAps) (Sugita et al., 1999) and second, a simple weighting of dividing the SV within a buffer by the mean distance to the lake (DWPA $A_{\text {Buffer }}$ ). The comparisons demonstrate a strong linear relationship between PAR and the SV for the abundant wind-pollinated tree taxa (see results in chapter 3). The values for the aPPE represent the slope of the regression of PAR versus SV for the single taxa that are presented in the scatter plots (Fig. 3.6). The aPPE describe the pollen production of $10^{8}$ pollen grains per distance weighted $\mathrm{m}^{3} \mathrm{a}^{-1}$. 


\section{Results}

aPPEs were obtained and presented for the five taxa: Pinus, Fagus, Quercus, Betula and Carpinus for the years 2009 and 1993 (Table 1). The aPPE values for Pinus, which is the most abundant taxon in Brandenburg, is about 1,600 in 1993 and 2009 for the vegetation weightings, DWPAps and DWPA $A_{\text {Buffer }}$ respectively. The smallest aPPE values are obtained for Fagus, ranging between 450 and 750 for the

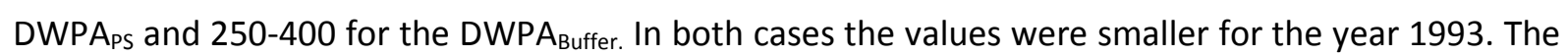
aPPEs for Quercus are in a similar range as the ones for Pinus, but with higher values in 1993 for the

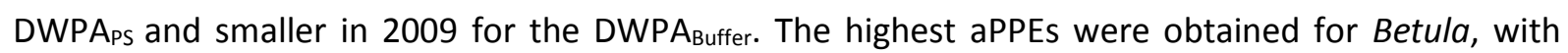
aPPE values about ten times higher than the ones calculated for Pinus (Table 1; Fig. 1). The aPPE for Betula, obtained for both DWPAs are higher for 2009 than for 1993, the smallest value is reached in 1993 for the DWPA $A_{\text {Buffer. }}$ Carpinus is shown to be a moderate pollen producer, with an aPPE of about 1,000 in both time slice based on the DWPAPs and about a quarter smaller for the DWPA Buffer. In particular for the 1993 data aPPE values based on the DWPA $A_{\text {Buffer }}$ are smaller and the largest differences in aPPE between the DWPA models were obtained for Fagus and Carpinus whereas they were smallest for Pinus.

Table 1 Presents aPPEs* and the $y$-intercept (background loading) coming from beyond $10 \mathrm{~km}$ radius for the major tree taxa in Brandenburg. Pollen productivity and the background loading are given as $10^{8}$ pollen grains per distance weighted $\mathrm{m}^{3} \mathrm{a}^{-1}$.

\begin{tabular}{lrrrr}
\hline & \multicolumn{2}{c}{ DWPAPS } & \multicolumn{2}{c}{ DWPA $_{\text {Buffer }}$} \\
& 2009 & 1993 & 2009 & 1993 \\
\hline Pinus aPPE & 1,550 & 1,700 & 1,500 & 1,750 \\
Pinus intercept & 8,650 & 1,050 & 8,500 & 350 \\
Fagus aPPE & 750 & 450 & 400 & 250 \\
Fagus intercept & 1,800 & 700 & 1,450 & 700 \\
Quercus aPPE & 1,300 & 2,400 & 950 & 1,750 \\
Quercus intercept & 800 & -50 & 1,100 & 200 \\
Betula aPPE & 16,800 & 14,450 & 17,100 & 10,150 \\
Betula intercept & 4,250 & 4,000 & 4,350 & 4,700 \\
Carpinus aPPE & 1,050 & 1,150 & 700 & 700 \\
Carpinus intercept & 550 & 350 & 550 & 400 \\
\hline *rounded values & \multicolumn{4}{c}{}
\end{tabular}

A comparison between the different aPPE values relative to Pinus and the calculated PPE from chapter 2 is shown in Fig. 1. The calculation of aPPEs for Betula shows a value about five times as high as in the PPE calculation. In both cases Betula is the highest pollen producer. Values for Quercus 
are much smaller in the PPE calculations than in the aPPE. In contrary to Betula and Quercus, the values of Carpinus and Fagus are in comparison much higher than the relative values.

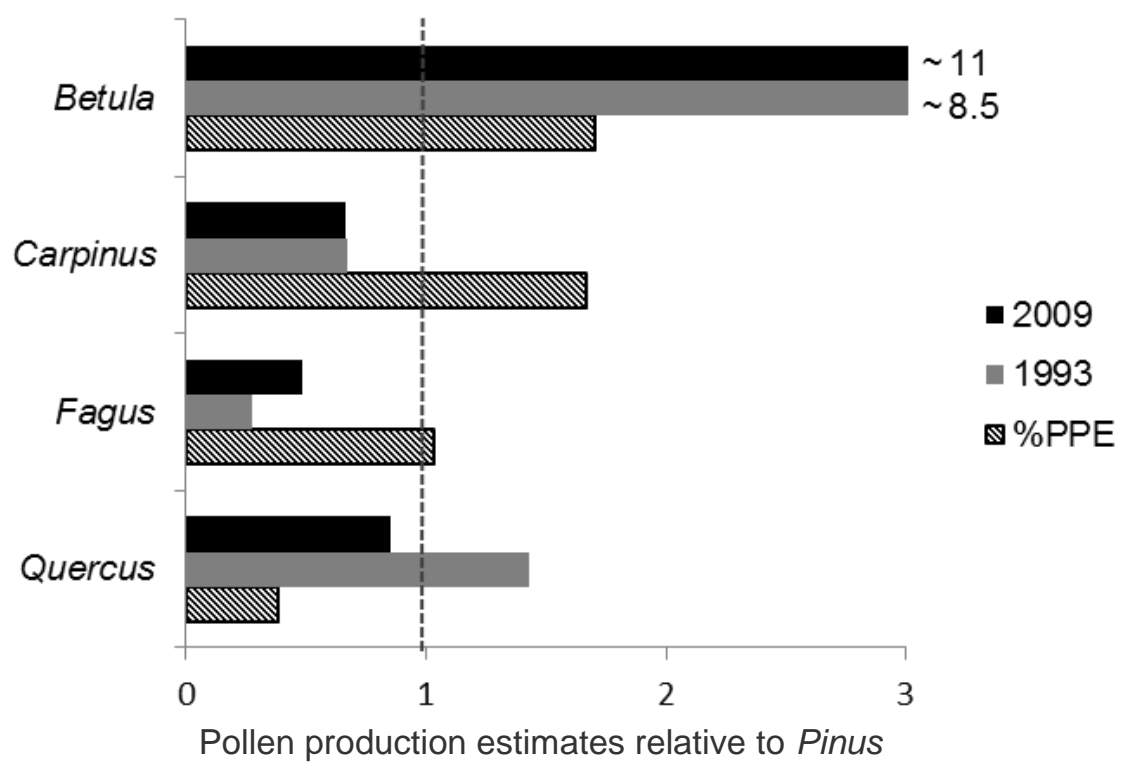

Fig. 1 Illustrates the obtained aPPE based on the DWPAps in relation to Pinus as well PPEs (in the figure as \% PPE) calculated in chapter 3 and based on the dataset that considers all trees that have reached their flowering age. The dashed line marks the value of the reference taxon.

\section{Brief discussion}

\section{Differences in aPPEs between 1993 and 2009 and the DWPA}

Differences of aPPEs for Fagus and Carpinus between the DWPA-models may due to the different provision of the pollen fall speed. Measurements of pollen fall speed have demonstrated variations between the taxa (Eisenhut, 1961; Gregory, 1973) and in particular the fall speed of Fagus and Carpinus differs widely from that of Pinus. This component is considered in the DWPAps (Sugita et al., 1999) but not captured in the DWPA $A_{\text {Buffer }}$. The good dispersal efficiency of small pollen e.g. Betula (e.g. Sugita, 1993) might reduce the importance of strong distance weighting of these taxa and result in small differences between the different DWPA-models.

The information from forest inventory data base show for many sites an increase in the SV from 1993 to 2009, in particular for Pinus. Also in most cases the aPPEs increase from 1993 to 2009. However, the scatter plots in chapter 3 (Fig. 3.6) demonstrates that the slope of the regression of PAR versus SV is same between the years and suggests that PAR or aPPEs increases linear with the SV. The increasing aPPEs might be due to the increasing age of trees, which start to produce small amounts of pollen when young and pollen production increases with increasing age (Jalkanen, pers. comm., cited in Hicks, 2006). However, in the case of Quercus the values for aPPE decrease. This might be explained by the fact that in recent years many areas of Quercus stands in Brandenburg have been partly damaged by insects (particularly the moth Thaumetopoe aprocessionea) and/or the fungus 
Microsphaera alphitoides (Möller et al., 2010). Such attacks can result in complete defoliation of the tree, influencing its resource allocation and potentially reducing if not stopping its pollen production.

\section{Differences between aPPEs and PPEs}

Reasons for differences between PPE values and aPPEs may be due to the different vegetation data used. Vegetation cover in percentage values was used for the PPE calculations, and absolute data (SV) were considered for aPPEs calculations. Data available from the forest inventory database for the public forests demonstrate that $100 \%$ cover can be achieved by different stocking levels. Thus the cover abundance of individual tree species around different sites may not be linearly related to their SV. Consequently, comparing the pollen data with the vegetation as cover or as SV may result in different ratios between pollen and vegetation.

\section{Comparison of aPPEs with a previous study}

Recently only one study was realized calculating aPPEs based on PAR from Tauber traps in nortern Finland (Sugita et al., 2010). When comparing the obtained aPPE for the tree taxa (Pinus, Picea and Betula), the aPPE values are much higher in Brandenburg. Values for Pinus are about ten times higher in Brandenburg than in the study by Sugita et al. (2010). One reason might be the use of different aboveground biomass data, for the Brandenburg region the yield table from Schober (1975) and Lockow and Lockow (2009) were used to estimate the SV, which may provide differed volumes for the trees than was calculated for Finland. Another reason for the higher pollen production in Brandenburg might be found in differences between PAR from Tauber traps and lake sediments. Previous studies concerned with PAR from lake sediments reveal the effect of a sediment focusing, which describes higher accumulation rates in the deeper parts of the lake (e.g. Lehman, 1975; Likens and Davis, 1975; Davis et al., 1984). Comparisons between PAR from lake sediments and Tauber traps have shown only little differences (Giesecke and Fontana, 2008). However, results from the pollen monitoring programme have revealed that the variation in pollen production through the years is influenced by different weather conditions of the previous year (Hicks, 2006; Huusko and Hicks, 2009; Nielsen et al., 2010; Van der Knaap et al., 2010). Furthermore, a comparison of PAR values for the Allerød period (Theuerkauf and Joosten, 2012) shows differences between the regions, with lower values matching current observation for Scandinavia (Giesecke and Fontana, 2008). Considering these observations, higher aPPE values might be explained by a higher net primary production of the standing biomass in Central Europe. 


\section{References}

Davis, M.B., Moeller, R.E. \& Ford, J. (1984): Sediment focusing and pollen influx. In: Haworth E.Y., Lund, J.W.G. (Eds.), Lake Sediments and Environmental History. Univ. Leicester Press, Leicester UK, pp. 261-293.

Eisenhut, G. (1961): Untersuchung über die Morphologie und Ökologie der Pollenkörner heimischer und fremdländischer Waldbäume. Parey, Hamburg.

Giesecke, T. \& Fontana, S.L. (2008): Revisiting pollen accumulation rates from Swedish lake sediments. Holocene, 18: 293-305.

Gregory, P.H. (1973): The microbiology of the atmosphere. Leonard Hill, Aylesbury.

Hicks, S. (2006): When no pollen does not mean no trees. Vegetation History and Archaeobotany, 15:253-261.

Huusko, A. \& Hicks, S. (2009): Conifer pollen abundance provides a proxy for summer temperature: evidence from the latitudinal forest limit in Finland. Journal of Quaternary Science, 24: 522528.

Lehman, J.T. (1975): Reconstructing the rate of accumulation of lake sediment: the effect of sediment focusing. Quaternary Research, 5: 541-550.

Likens, G.E. \& Davis, M.B. (1975): Post-glacial history of Mirror Lake and its watershed in New Hampshire: an initial report. Mitteilungen Internationale Vereinigung für Theoretische und Angewandte Limnologie, 19: 982-993.

Lockow, K.-W. \& Lockow, J. (2009): Die Hainbuche im nordostdeutschen Tiefland - Wuchsverhalten und Bewirtschaftungshinweise. In: Eberswalder Forstliche Schriftenreihe, Band 41.

Möller, K., Heydeck, P., Hielscher, K., Engelmann, A., Wenk, M., Schulz, P.-M., Dahms, C., Born, B., Dietz, H. \& Braunschweig, A. (2010): Waldschutzbericht 2010. Jahresbericht der Hauptstelle für Waldschutz. Landeskompetenzzentrum Forst Eberswalde. http://forst.brandenburg.de/sixcms/media.php/4055/ws2010.pdf (Accessed 07 March 2012)

Nielsen, A.B., Moller, P.F., Giesecke, T., Stavngaard, B., Fontana, S.L. \& Bradshaw, R.H.W. (2010): The effect of climate conditions on inter-annual flowering variability monitored by pollen traps below the canopy in Draved Forest, Denmark. Vegetation History and Archaeobotany, 19: 309-323.

Schober, R. (1975): Ertragstafeln wichtiger Baumarten bei verschiedener Durchforstung. Sauerländer, Frankfurt a. M.

Sugita, S. (1993): A model of pollen source area for an entire lake surface. Quaternary Research, 39: 239-244.

Sugita, S. (1994): Pollen representation of vegetation in quaternary sediments: theory and method in patchy vegetation. Journal of Ecology, 82: 881-897.

Sugita, S., Gaillard, M.J. \& Broström, A. (1999): Landscape openness and pollen records: a simulation approach. The Holocene 9: 409-421.

Sugita, S., Hicks, S. \& Sormunen, H. (2010): Absolute pollen productivity and pollen-vegetation relationships in northern Finland. Journal of Quaternary Science, 25:724-736.

Theuerkauf, M. \& Joosten, H. (2012): Younger Dryas cold stage vegetation patterns of central Europe - climate, soil and relief controls. Boreas 41, 391-407.

Van der Knaap, W.O., van Leeuwen, J.F.N., Svitavska-Svobodova, H., Pidek, I.A., Kvavadze, E., Chichinadze, M., Giesecke, T., Kaszewski, B.M., Oberli, F., Kalnina, L., Pardoe, H.S., Tinner, W. \& Ammann, B. (2010): Annual pollen traps reveal the complexity of climatic control on pollen productivity in Europe and the Caucasus. Vegetation History and Archaeobotany, 19: 285307. 


\section{Chapter 4}

\section{Pollen diversity captures landscape structure and diversity}

Isabelle Matthias ${ }^{1}$, Malte S.S. Semmler ${ }^{1} \&$ Thomas Giesecke $^{1}$

${ }^{1}$ Department of Palynology and Climate Dynamics, Albrecht-von-Haller Institute for Plant Sciences, University of Göttingen, 37073 Göttingen, Germany

Journal of Ecology

DOI: $10.1111 / 1365-2745.12404$

(C) John Wiley \& Sons, Inc. 


\section{Summary}

1. Past changes in plant and landscape diversity can be evaluated through pollen analysis, however, pollen-based diversity indexes are potentially biased by differential pollen production and deposition. Studies examining the relationship between pollen and landscape diversity are therefore needed. The aim of this study was to evaluate how different pollen-based indexes capture aspects of landscape diversity.

2. Pollen counts were obtained from surface samples of 50 small- to medium-sized lakes in Brandenburg (north-east Germany) and compiled into two sets, with one containing all pollen counts from terrestrial plants and the second restricted to wind-pollinated taxa. Both sets were adjusted for the pollen production/dispersal bias using the REVEALS model. A high-resolution biotope map was used to extract the density of total biotopes and different biotopes per area as parameters describing landscape diversity. In addition, tree species diversity was obtained from forest inventory data.

3. The Shannon index and the number of taxa in a sample of 10 pollen grains are highly correlated and provide a useful measure of pollen type diversity which corresponds best to landscape diversity within one $\mathrm{km}$ of the lake and the proportion of non-forested area within seven $\mathrm{km}$. Adjustments of the pollen production/dispersal bias only slightly improve the relationships between pollen diversity and landscape diversity for the restricted data set as well as for the forest inventory data and corresponding pollen types.

4. Using rarefaction analysis, we propose the following convention: pollen type diversity is represented by the number of types in a small sample (low count e.g. 10), pollen type richness is the number of types in a large sample (high count e.g. 500), and pollen sample evenness is characterized by the ratio of the two.

5. Synthesis. Pollen type diversity is a robust index that captures vegetation structure and landscape diversity. It is ideally suited for between site comparisons as it does not require high pollen counts. In concert with pollen type richness and evenness, it helps evaluating the effect of climate change and human land use on vegetation structure on long timescales.

Key-words: diversity, evenness, landscape structure, north-east Germany, palaeoecology and landuse history, palynological richness, pollen, rarefaction analysis, REVEALS, Shannon index

\subsection{Introduction}

Ecosystem functioning, stability and productivity have been shown to be influenced by species diversity on short timescales and for dynamic ecosystems such as grasslands (Tilman, Lehman \& Thompson 1997; Loreau et al. 2001; Ives \& Carpenter 2007). The importance of diversity for 
ecosystem functioning on longer timescales and more resilient systems like forests is more difficult to assess, and pollen analysis is in principle an apt tool in such an investigation. However, the application of pollen-based diversity indexes is biased by three factors: the lack of taxonomic precision, species-specific differences in pollen production and dispersal, and the lack of a fixed source area (Giesecke, Ammann \& Brande 2014). Nevertheless, pollen analytical results document that the number of different pollen types per sample varies through time (Odgaard 1994; Berglund et al. 2008a; Giesecke et al. 2012; Colombaroli et al. 2013). These variations in the number of pollen types in standard high counts (palynological richness) have been shown to be indicative of landscape changes (Birks \& Line 1992). For example, increases in palynological richness are connected with early human land use in the naturally forested landscapes of central and northern Europe (Poska, Saarse \& Veski 2004; Colombaroli \& Tinner 2013). High palynological richness could also be linked to inferred intermediate values of landscape disturbance (Odgaard 1994; Colombaroli \& Tinner 2013). In species poor floras, palynological richness might be converted to floristic richness (Odgaard 1994), while higher taxonomic levels may be sufficient in species rich situations (Mazaris et al. 2010). In tropical forests with a high richness of plant families, the family level may be adequate to evaluate diversity based on pollen (Jantz, Homeier \& Behling 2014). Thus, taxonomic precision might not to be the limiting factor for pollen-based diversity studies.

Species-specific differences in pollen production and dispersal cause different relative species abundances in the vegetation vs. the pollen sample. The general expression of pollen analytical results as percentages means that when one taxon declines others will increase by the same overall proportion while their true abundances in the vegetation may not have changed. For this reason, diversity indexes such as the Shannon index are rarely applied to pollen data and palynological richness has become the standard measure (Birks \& Line 1992). However, differential pollen production also affects the probability of detecting new pollen taxa in a given count and thus palynological richness (Weng, Hooghiemstra \& Duivenvoorden 2006; Giesecke, Ammann \& Brande 2014). Moreover, palynological richness is calculated for widely varying pollen counts in different investigations, ranging for example between counts of 200 (Colombaroli \& Tinner 2013) and 2000 (Berglund et al. 2008a). Odgaard (2001) suggested that vegetation diversity may be well reflected by pollen sample evenness. The choice of measures for evenness is wide (Smith \& Wilson 1996; Tuomisto 2012), and all indexes are influenced by the pollen production/dispersal problem. One index with relatively large independence from other measures can be extracted from Whittaker plots, as the inverse slope of the log abundance on the rank of abundance (Smith \& Wilson 1996). This index can be visually examined and flexibly applied by restricting it to the abundance distribution of taxa exceeding a set threshold in the sample, which makes it interesting for pollen data (Giesecke, Ammann \& Brande 2014). 
Reducing the effect of differential pollen production and dispersal is a long-standing goal among palynologists (Davis 2000). Progress has been made over the last two decades with a large number of investigations studying the pollen vegetation relationship and applying models of pollen dispersal and deposition (e.g. Gaillard et al. 2008). As a result of these developments, relative pollen productivity estimates (PPE) are available for several European regions (Broström et al. 2008) and together with numerical models yield vegetation proportions from pollen data (Sugita 2007a,b; Sugita et al. 2010). By reducing the production/dispersal bias through the application of the REVEALS model (Sugita 2007a), the full range of diversity indexes should be applicable to pollen data and the first studies using this approach have been published (Fredh et al. 2012; Marquer et al. 2014; Reitalu et al. in press).

The aim of this study was to explore which pollen-based diversity indexes are useful for reconstructing changes in past vegetation diversity. Using modern and fossil pollen data from northeast Germany, we will focus on the following questions:

1. How is the landscape diversity reflected by the distribution of pollen types in the sample?

2. Which diversity and evenness measures provide useful information for pollen data?

3. Will reducing the pollen production bias with the REVEALS model improve the relationship between pollen-based diversity indicators and landscape diversity?

4. How does a reduction to wind-pollinated taxa influence assessments of pollen diversity?

\subsection{Materials and methods}

\subsubsection{Study area and sampling}

In north-eastern Germany, the last glaciation has created a landscape with a large density of lakes and a mosaic of soil substrates (Liedtke \& Marcinek 2002), ideally suited for this study. We focussed this investigation on the northern and eastern parts of the state of Brandenburg which has a large proportion of forest cover (37\%, 1.09 million ha) that is dominated by pine (70\%) particularly on poor sandy soils (Engel 2010). The study region is situated between the oceanic climate of Western Europe and the continental climate further east. The precipitation ranges between 450 and $720 \mathrm{~mm}$, with the driest areas in the south-east (Linke et al. 2010).

During spring and summer of 2009, we sampled 50 lakes (Fig. 4.1) with a single, simple basin without permanent inflow (Matthias, Nielsen \& Giesecke 2012). Most lakes are small to medium in size (0.5 to 32 ha, with one lake of 780 ha; Appendix S1 in Supporting Information) and situated within woodlands, while some border fields and meadows. The sediment was sampled in the deepest part of the lake using a HON-Kajak sediment corer (Renberg 1991), and the short cores were subsampled in the field. In this study, we use material from the first centimetre, which was combined with the 
second centimeter where the material in the sediment water interface was highly unconsolidated. In a subset of 16 lakes, this first sample corresponds to the accumulation of sediment during the previous one to three years (Matthias \& Giesecke 2014) and thus approximately coincides in time with the information on the vegetation.

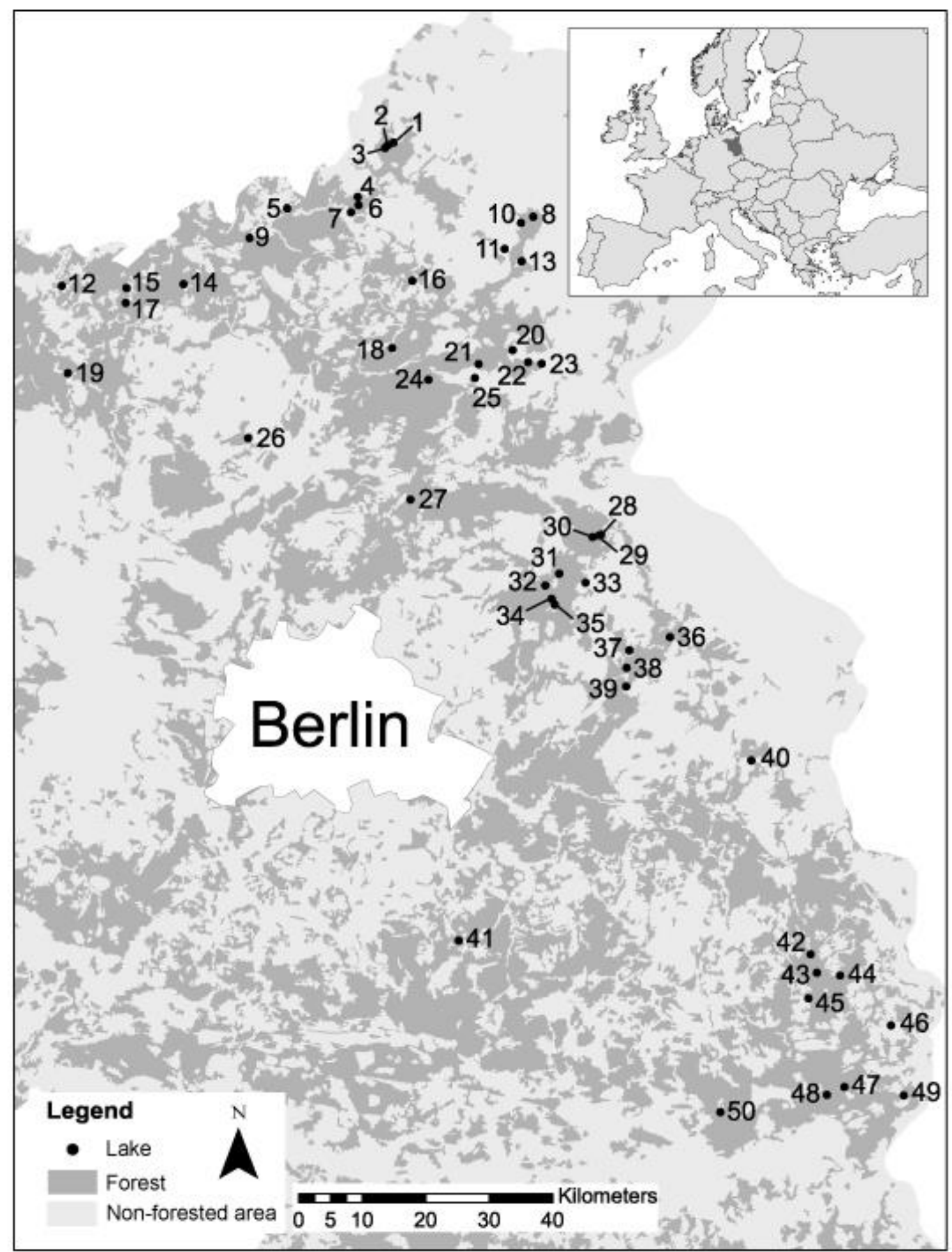

Fig. 4.1 Distribution study sites in relation to forested area in the German state of Brandenburg. Site names and geographical positions of the lakes are provided in Appendix S1. The distribution of forest cover is based on CORINE Land Cover 2000 (Umweltbundesamt \& DLR-DFD 2004). 
Sample preparation followed Bennett \& Willis (2001), using hydrofluoric acid, without sieving and a 2 min acetolysis. The sample residues were mounted in glycerol and counted at $400 x$ magnification. Identification was aided by the reference collection of the Department as well as keys, following the classification of Beug (2004). All samples were counted to a minimum pollen sum of 950 terrestrial pollen grains. Pollen from aquatic plants and spores were excluded from the pollen sum and analysis.

\subsubsection{Vegetation data sources}

Biotopes and land use were mapped in the state of Brandenburg in the years 1991-1996, and this annually updated map is freely available as a shape file (CIR-Biotop- und Landnutzungstypenkartierung 2009, http://www.mugv.brandenburg.de/cms/detail.php/bb2.c.515599.de, downloaded 1 December 2010). Using ArcGIS 10.1 (ESRI), we extracted the number of distinct polygons (biotopes), the absolute number of biotopes and the non-forested area within different distances from the lake shore to a maximum of $7 \mathrm{~km}$. Biotopes that describe water surfaces as well as floating leaf communities were excluded from the analysis. Lake area and perimeter were obtained from digitized topographic maps.

The composition of tree species around the lakes was obtained from the tree inventory data bases 'Datenspeicher Wald' (DSW2; http://www.dsw2.de/index.html) and a federal agency, 'Bundesanstalt für Immobilienaufgaben' (Matthias, Nielsen \& Giesecke 2012). Forest inventory data were not available for military areas, roadside trees, trees in urban areas and woodlands $<0.01$ ha. Tree abundance around the lakes was extracted for the different distances from the centre of the lake (Matthias, Nielsen \& Giesecke 2012). The mean tree abundance was distance weighted by the mean distances of the circles from the centre of the lake. The Shannon index was calculated based on the resulting weighted species abundance and compared to the Shannon index on the REVEALS transformed pollen counts of tree pollen.

\subsubsection{Data analysis}

\section{REVEALS}

The REVEALS model was applied to reduce the production/dispersal bias of the pollen data (Marquer et al. 2014). We used REVEALS v4.5 (S. Sugita personal communication) with the Prentice-Sugita dispersal model for lakes (Sugita, Gaillard \& Broström 1999). Vegetation proportions were reconstructed for an area of $7 \mathrm{~km}$ (Fig. 4.2), which is a spatial scale relevant to the pollen data in this region (Matthias, Nielsen \& Giesecke 2012). Fall speed for the single pollen types was taken from the literature (Dyakowska 1936; Eisenhut 1961; Gregory 1973; Sugita, Gaillard \& Broström 1999) and calculated using Stokes's Law (Gregory 1973). Pollen productivity estimates (PPEs) were applied from 


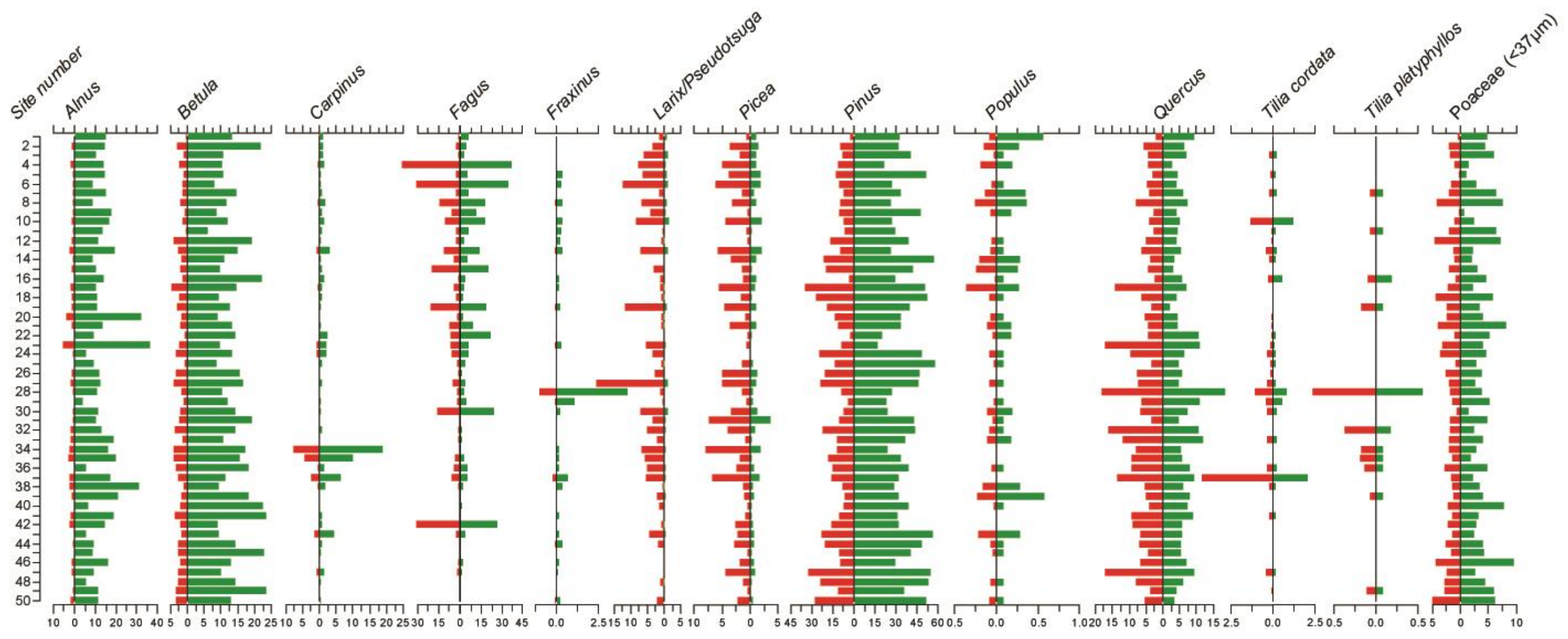

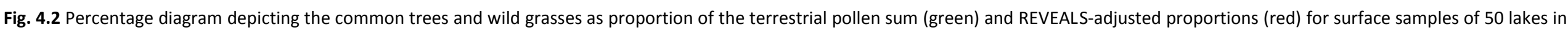
Brandenburg ordered from north to south. Site numbers correspond to locations in Fig. 4.1, and names and geographical positions of the lakes are provided in Appendix S1. 
the literature (Sugita, Gaillard \& Broström 1999; Broström, Sugita \& Gaillard 2004; Soepboer et al. 2007; Matthias, Nielsen \& Giesecke 2012) recalculated with Pinus as a reference taxon. Approximate values based on the mode of pollen dispersal were assigned to species where PPEs were not available (see Appendix S2). The pollination mode was obtained from data bases and literature (Willemstein 1987; Raven, Evert \& Eichhorn 2000; Jäger 2011; BiolFlor 2013). Taxa were divided in three groups: wind pollinated taxa (PPE set to 0.4), wind and insect pollinated taxa (PPE set to 0.2) and insect pollinated taxa (PPE set to 0.1). PPE for Cerealia vary widely in the literature (Broström, Sugita \& Gaillard 2004; Soepboer et al. 2007; Matthias, Nielsen \& Giesecke 2012) and were therefore handled as insect pollinated taxa, as they are often self-pollinated (BiolFlor 2013). Only Secale was set to wind and insect pollinated. The estimated vegetation proportions were used to adjust the pollen counts to be able to use the same kind of indexes as with the original data.

\subsubsection{Diversity indexes}

A large number of indexes have been developed to evaluate diversity and evenness in ecology and most are strongly related to each other (Hill 1973). In a preliminary analysis, we tested the performance of different indexes and selected the Shannon index $\mathrm{H}^{\prime}$ as a diversity measure and the slope of the inverted rank-order abundance (henceforth SLOPE) with a threshold of $1 \%$ for taxon inclusion as an evenness measure (Giesecke, Ammann \& Brande 2014). Initial analysis included the Simpson index, which behaved similar to the Shannon index, however, with slightly lower correlations to the vegetation data and was therefore not pursued further. Palynological richness, the number of pollen types per sample, depends on the number of grains counted, and samplebased rarefaction is therefore applied to obtain palynological richness for standardized high pollen counts (Birks \& Line 1992). This measure compares to the richness in the ecological sense, which is understood as the number of elements at a particular assessment level. In particular for small samples, the number of taxa $(S)$ depends on the relative abundances of taxa within the sample (Hurlbert 1971). Odgaard (2008) observed in a study of modern samples in Denmark that the number of pollen types in a small sample was correlated with the evenness of that sample as calculated by Pielou's evenness $\mathrm{J}=\mathrm{H}^{\prime} / \log (\mathrm{S})$ and found the strongest correlation for a pollen count of 10 grains. We conducted a similar comparison of sample-based rarefaction to different pollen counts and compared them to the above diversity and evenness indexes (Fig. 4.3). The Shannon index $H^{\prime}$ and rarefaction to a base of 10 were found to be closely correlated, and the Shannon index was therefore not used as a separate index. Since the Shannon index is the varying parameter in Pielou's evenness, the correlations found by Odgaard (2008) support the robustness of this correlation, only that here we argue it to reflect diversity rather than evenness. The SLOPE ${ }_{1 \%}$ index describes additional variance 
and was retained as an index as well as rarefaction to a base of 10, 500 and the highest possible sum, which is the lowest count in any one sample per data set and differs between them. Rarefaction analysis was conducted using the vegan package, version 2.0-9 (Oksanen et al. 2013) and the R program, version 3.0.1 (R Core Team 2013). All indices were calculated for different pollen data sets: the original pollen counts, only wind-pollinated taxa, as well as for the pollen data-transformed using the REVEALS program.

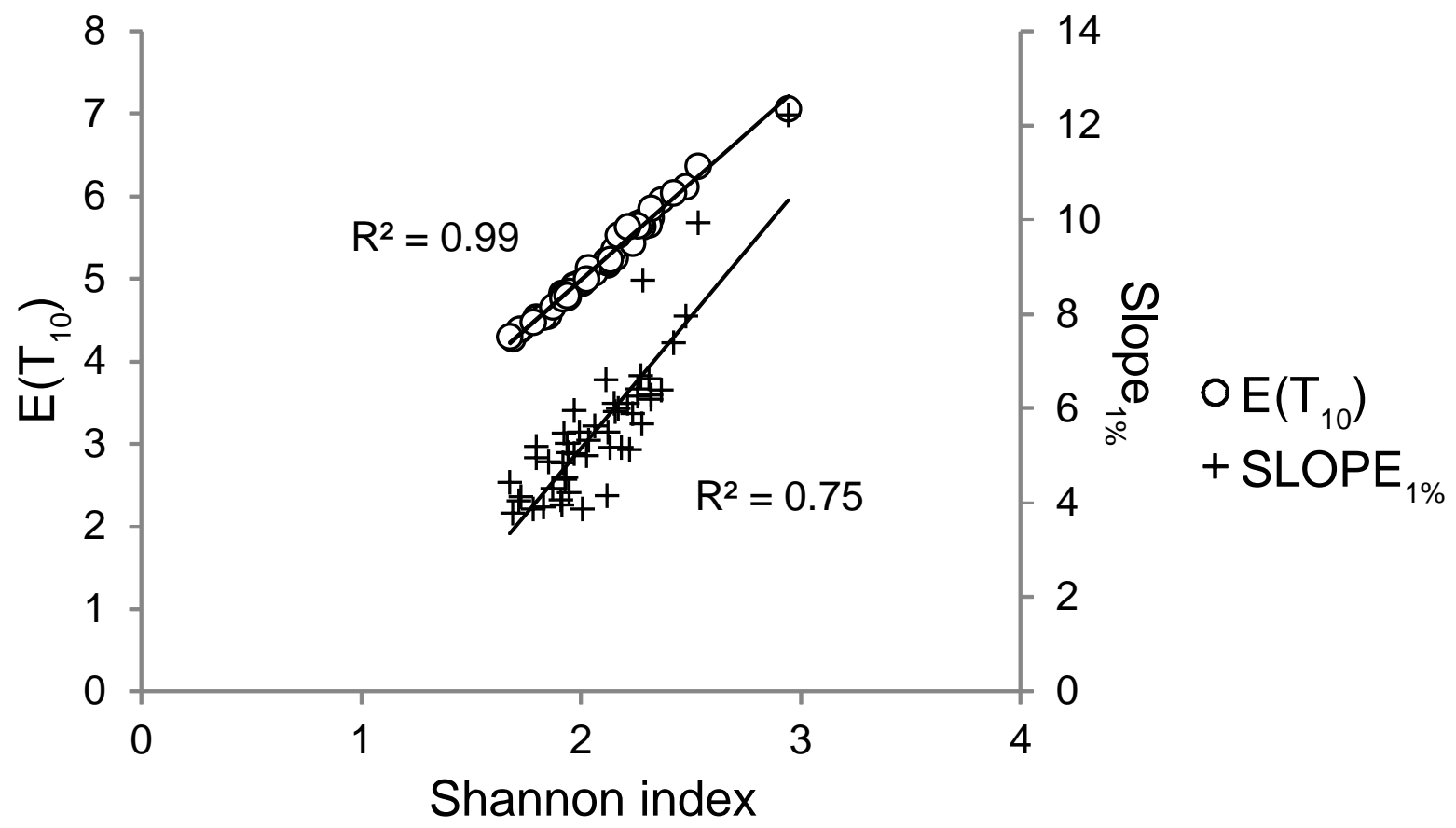

Fig. 4.3 Comparison of Shannon index with the number of taxa in a sample of 10 (sample-based rarefaction to $10\left(E\left(T_{10}\right)\right.$ ) and the inverted slope of the rank-order abundance $\left(\mathrm{SLOPE}_{1 \%}\right)$ for the unconstraint pollen proportions.

Pollen-based indexes were compared to the total number of biotopes per area, the number of distinct biotopes and the proportion of the non-forested area for different distances from the lake shore as well as to the ratio between lake perimeter and lake area. The importance of combinations of these variables was assessed in multiple linear regression models and evaluated with the Akaike information criterion (AIC) in a stepwise algorithm as implemented in the MASS package (version 7.329, Venables \& Ripley 2002) with both, forward and backward selection. Landscape variables were used for the distance that gave the best fit in a simple regression model.

The lake Sonnenburger Fenn was excluded from comparisons with the landscape factors, because the pollen assemblage was strongly affected by neighbouring gardens as indicated by the encounter of a high richness of rare pollen types. 


\subsection{Results}

\subsubsection{Pollen data}

In total, 118 different terrestrial pollen types could be distinguished, though most were single occurrences. The number of different taxa varies for single samples between 29 and 64, with a mean of about 36 pollen types. The pollen diagram (Fig. 4.2) shows the most frequent tree taxa and the non-cereal Poaceae. After correcting for the production/dispersal bias using REVEALS, abundances shift mainly according to the trend in PPEs (Matthias, Nielsen \& Giesecke 2012). Abundances of Fagus and Populus remain similar in the REVEALS adjustments, while the values of Larix/Pseudotsuga increase strongly due to the high fall speed. Abundances of Poaceae decrease in the REVEALS adjustment, which is due to the strong increase of the Cerealia types that have low PPEs and high fall speeds.

\subsubsection{Pollen diversity and landscape structure}

Based on the original pollen counts, rarefaction to small numbers $\left(E\left(T_{2-30}\right)\right)$ correlates to vegetation patchiness and openness. Highest correlations were found for rarefaction results between 8 and 20 with a maximum at $10\left(E\left(T_{10}\right)\right)$. These values capture the same information as the Shannon index, indicated by an $R^{2}$ above 0.9 between $E\left(T_{10}\right)$ and the Shannon index (Fig. 4.3). The results summarized in Table 4.1 demonstrate that rarefaction to $10\left(E\left(T_{10}\right)\right)$ is the best pollen-based indicator capturing the variability of landscape parameters. Rarefaction analysis to higher numbers shows in general lower correlation to the landscape factors. The adjustment of the production/dispersal bias using REVEALS did in general not yield higher correlations than the original count data.

Comparisons between $\mathrm{E}\left(\mathrm{T}_{10}\right)$ and the number of biotopes as well as the number of different biotopes show that the amount of explained variance decreases with increasing distance beyond one km (Fig. 4.4). In contrast, the relationship to the non-forested area increases with increasing distance, with the highest explanation of variance at a distance of 5-7 km (Fig. 4.4). Although the best $R^{2}$ values are relatively low (0.2-0.3), the scatter plots (Fig. 4.4) show clear trends. The number of biotopes and the number of different biotopes are correlated, but each parameter contains some unique information. Site differences in the lake perimeter/area ratio explain up to $25 \%$ variance in $E\left(T_{10}\right)$. The strongest, although negative relationship occurs between the abundance of Pinus within the seven $\mathrm{km}$ and $E\left(T_{10}\right)$ with a correlation of 0.7 (Table 4.1). Results from the rarefaction analysis to higher counts show similar trends with distance from the lake as found for $E\left(T_{10}\right)$. Relationships are poor between rarefaction to high counts and the lake perimeter/area ratio as well as for Pinus cover. The SLOPE ${ }_{1 \%}$ index shows similar results compared to those obtained with $E\left(T_{10}\right)$, with a different distance trend for the non-forested area, where it shows stronger correlations for smaller and weaker for larger 
Table 4.1 Correlation coefficients between landscape parameters and pollen diversity indexes based on all terrestrial taxa, wind-pollinated taxa, and REVEALS adjustments of these

\begin{tabular}{|l|l|l|l|l|l|l|l|l|}
\hline & $E\left(T_{10}\right)$ & $E\left(T_{10}\right)$ & $E\left(T_{500}\right)$ & $E\left(T_{500}\right)$ & $E\left(T_{\max }\right)$ & $E\left(T_{\max }\right)$ & $S_{2}$ SPE $_{1 \%}$ & SLOPE $_{1 \%}$ \\
\hline Dataset: all taxa & Original count & REVEALS & Original count & REVEALS & Original count & REVEALS & Original count & REVEALS \\
\hline Number of biotopes $(1 \mathrm{~km})$ & $0.47^{* * *}$ & -0.13 & $0.34^{*}$ & 0.06 & $0.25+$ & -0.09 & $0.41^{* *}$ & -0.09 \\
\hline Number of diff. biotopes $(1 \mathrm{~km})$ & $0.54^{* * *}$ & -0.15 & $0.24+$ & -0.08 & 0.14 & 0.14 & $0.48^{* * *}$ & -0.13 \\
\hline Non-forested area $(7 \mathrm{~km})$ & $0.57^{* * *}$ & -0.09 & $0.46^{* * *}$ & 0.07 & $0.42^{* *}$ & $0.38^{* *}$ & $0.43^{* *}$ & 0.02 \\
\hline Lake perimeter/size & $0.50^{* * *}$ & $0.33^{*}$ & 0.07 & 0.09 & -0.06 & -0.09 & $0.34^{* *}$ & $0.35^{*}$ \\
\hline Pinus $(7 \mathrm{~km})$ & $-0.69^{* * *}$ & 0.07 & $-0.42^{* *}$ & -0.03 & $-0.35^{*}$ & $-0.32^{*}$ & $-0.56^{* * *}$ & -0.01 \\
\hline Dataset: wind pollinated taxa & & & & & & & & \\
\hline Number of biotopes $(1 \mathrm{~km})$ & $0.40^{* *}$ & $0.40^{* *}$ & 0.05 & 0.02 & -0.04 & -0.09 & $0.33^{*}$ & $0.43^{* *}$ \\
\hline Number of diff. biotopes $(1 \mathrm{~km})$ & $0.55^{* * *}$ & $0.42^{* *}$ & 0.11 & -0.06 & 0.01 & -0.04 & $0.50^{* * *}$ & $0.32^{*}$ \\
\hline Non-forested area $(7 \mathrm{~km})$ & $0.55^{* * *}$ & $0.56^{* * *}$ & $0.45^{* * *}$ & $0.30^{*}$ & $0.36^{* *}$ & $0.28^{*}$ & $0.44^{* *}$ & $0.59^{* * *}$ \\
\hline Lake perimeter/size & $0.50^{* * *}$ & 0.12 & 0.05 & -0.04 & -0.03 & -0.08 & $0.37^{* *}$ & 0.02 \\
\hline Pinus (7 km) & $-0.70^{* * *}$ & $-0.64^{* * *}$ & $-0.40^{* *}$ & $-0.25+$ & $-0.30^{*}$ & $-0.21+$ & $-0.61^{* * *}$ & $-0.55^{* * *}$ \\
\hline
\end{tabular}

Highly significant correlations are indicated by grey shading.

P-value: ${ }^{\prime * * *}<0.0011^{\prime * * \prime}<0.01 i^{\prime * \prime}<0.05 ;^{\prime}+{ }^{\prime}<0.1$ 
distances. Using a higher threshold for the inclusion of taxa in the calculation of the SLOPE index (e.g. $5 \%)$ did not improve correspondence to the landscape variables.

\subsubsection{Comparisons of restricted and adjusted pollen data}

Indexes based on REVEALS adjusted counts considering all taxa show weak or no relationships to landscape indexes (Table 4.1). The best correlation (0.38) is found for the proportion of non-forested area within seven $\mathrm{km}$ and rarefaction to the highest possible number $\left(\mathrm{E}\left(\mathrm{T}_{\max }\right)\right)$ (Table 4.1). Restricting the data to the 31 wind-pollinated taxa improved correlations for REVEALS adjusted indexes. However, the restricted data set without adjustments yields similarly high correlations as obtained for the full data set. REVEALS adjustments only markedly improved the correlation between SLOPE ${ }_{1 \%}$ and landscape openness within seven $\mathrm{km}$ from 0.44 to 0.59 (Table 4.1 ). This is also the only case where the correlation for $\mathrm{SLOPE}_{1 \%}$ is higher than for $\mathrm{E}\left(\mathrm{T}_{10}\right)$.

To further test the performance of REVEALS adjustments for pollen-based diversity studies, we used the forest inventory data to calculate the Shannon index on distance weighted tree abundance within seven $\mathrm{km}$ of each lake. The comparison between the Shannon index on tree abundance and the Shannon index on pollen counts restricted to the same taxa yielded a $R^{2}$-value of 0.4 (Fig. 4.5). The REVEALS adjustment of the pollen data improves this relationship minimally, raising the $R^{2}$ value to 0.42 .

\subsubsection{Multiple linear regression}

The results from all pollen data sets show that the number of the non-forested areas within seven $\mathrm{km}$ and biotopes in one $\mathrm{km}$ are important landscape parameters influencing pollen diversity (Table 4.2). In combination with the lake perimeter/area ratio, these parameters explain the highest amount of variance for $E\left(T_{10}\right)$ of the untransformed data sets. The combination of number of biotopes and non-forested area explains $39 \%$ of the variance in $E\left(T_{10}\right)$, and only the addition of the lake perimeter/area ratio brings the final model to explain $59 \%$ variance for the original count data. $\mathrm{SLOPE}_{1 \%}$ yields a high $\mathrm{R}^{2}$ value (0.39) with the number of biotopes in one $\mathrm{km}$ and the non-forested area within seven $\mathrm{km}$ as explanatory variables for the REVEALS adjusted data set (Table 4.2). 

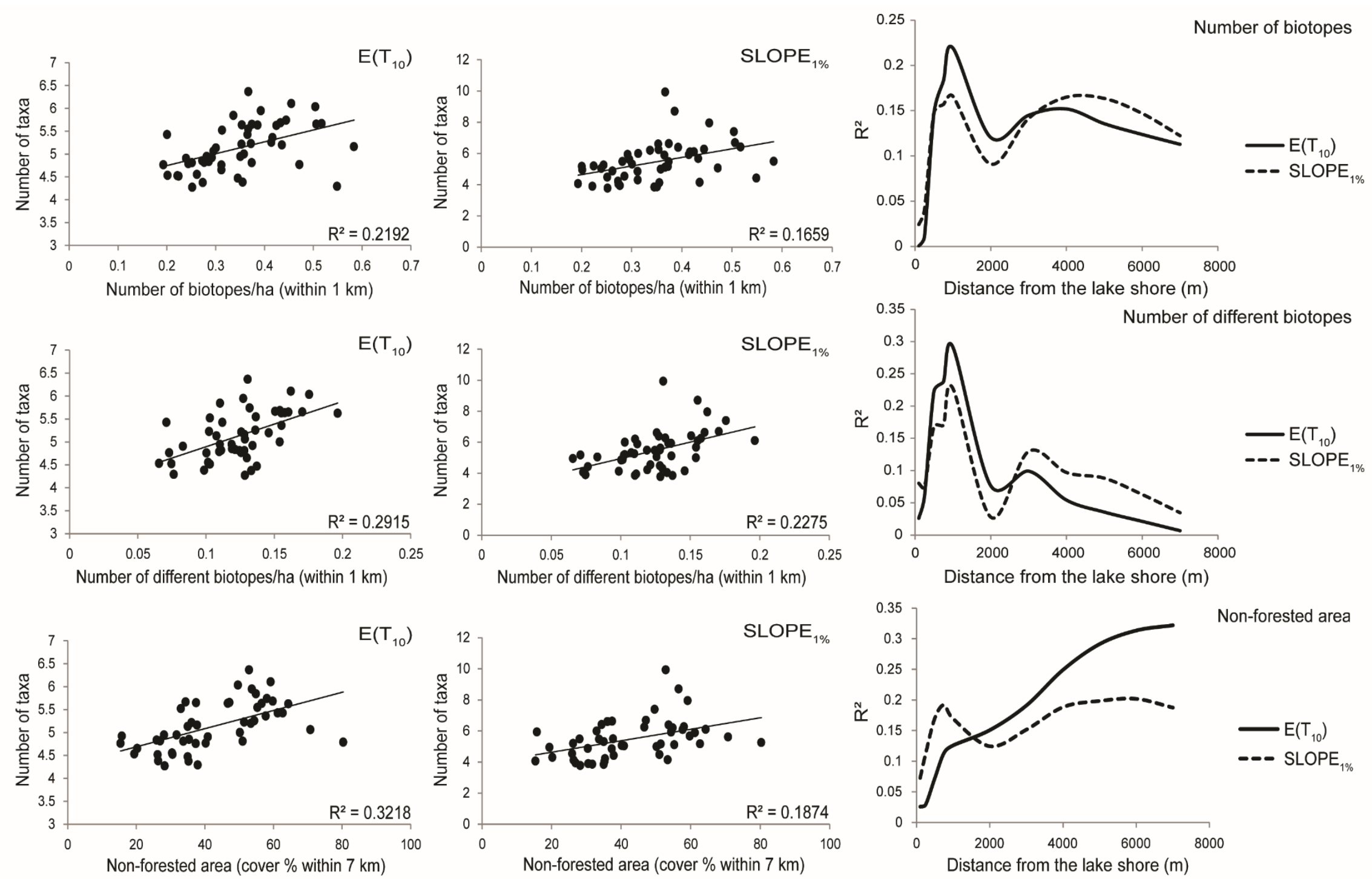

Fig. 4.4 Scatter plots for the best correlations between the number of taxa in a sample of $10\left(E\left(T_{10}\right)\right)$ and inverted slope of the rank-order abundance (SLOPE $\left.E_{1 \%}\right)$ based on all terrestrial pollen, with the total number of biotopes per hectare, number of different biotopes per hectare and proportion of non-forested area. Right hand panels depict the changes of $R^{2}$ with distance from the lake. 
Table 4.2 Performance of multiple regression models combining landscape parameters as predictors for pollen diversity and richness indicators

\begin{tabular}{|c|c|c|c|c|c|}
\hline \multicolumn{6}{|l|}{ Original counts } \\
\hline Dataset: all taxa & $\begin{array}{l}\text { Non-forested } \\
\text { area }(7 \mathrm{~km})\end{array}$ & $\begin{array}{l}\text { Number of } \\
\text { biotopes }(1 \mathrm{~km})\end{array}$ & $\begin{array}{l}\text { Number of diff. } \\
\text { biotopes }(1 \mathrm{~km})\end{array}$ & $\begin{array}{l}\text { Lake } \\
\text { perimeter/size }\end{array}$ & adjusted $\mathrm{R}^{2}$ \\
\hline$E\left(T_{10}\right)$ & $\mathrm{FM} * *$ & $\mathrm{FM} * * *$ & & $\mathrm{FM} * * *$ & 0.5968 \\
\hline$E\left(T_{500}\right)$ & $\mathrm{FM} * *$ & FM & & & 0.2271 \\
\hline$E\left(T_{\max }\right)$ & $\mathrm{FM} * *$ & & & & 0.1585 \\
\hline SLOPE $_{1 \%}$ & $\mathrm{FM}+$ & $\mathrm{FM} * *$ & & FM $*$ & 0.3262 \\
\hline \multicolumn{6}{|l|}{$\begin{array}{l}\text { Dataset: wind } \\
\text { pollinated taxa }\end{array}$} \\
\hline$E\left(T_{10}\right)$ & $\mathrm{FM} * *$ & $\mathrm{FM}+$ & FM & $\mathrm{FM} * * *$ & 0.5417 \\
\hline$E\left(T_{500}\right)$ & $\mathrm{FM}^{* *}$ & & & & 0.1843 \\
\hline$E\left(T_{\max }\right)$ & FM * & & & & 0.1145 \\
\hline SLOPE $_{1 \%}$ & $\mathrm{FM}+$ & & $\mathrm{FM}^{* *}$ & $\mathrm{FM}+$ & 0.3298 \\
\hline \multicolumn{6}{|l|}{ REVEALS } \\
\hline \multicolumn{6}{|l|}{$\begin{array}{l}\text { Dataset: wind } \\
\text { pollinated taxa }\end{array}$} \\
\hline$E\left(T_{10}\right)$ & $\mathrm{FM}^{* * *}$ & $\mathrm{FM}^{*}$ & & & 0.3432 \\
\hline$E\left(T_{500}\right)$ & FM* $^{*}$ & & FM & & 0.08698 \\
\hline$E\left(T_{\max }\right)$ & $\mathrm{FM}^{* *}$ & FM & & FM & 0.09816 \\
\hline SLOPE $_{1 \%}$ & $\mathrm{FM}^{* * *}$ & $\mathrm{FM}^{*}$ & & & 0.391 \\
\hline
\end{tabular}

p-value: ${ }^{(* * * \prime}<0.001 ;^{(* * \prime}<0.01 ;^{\prime * \prime}<0.05 ;^{\prime}+{ }^{\prime}<0.1$

FM, Final model.

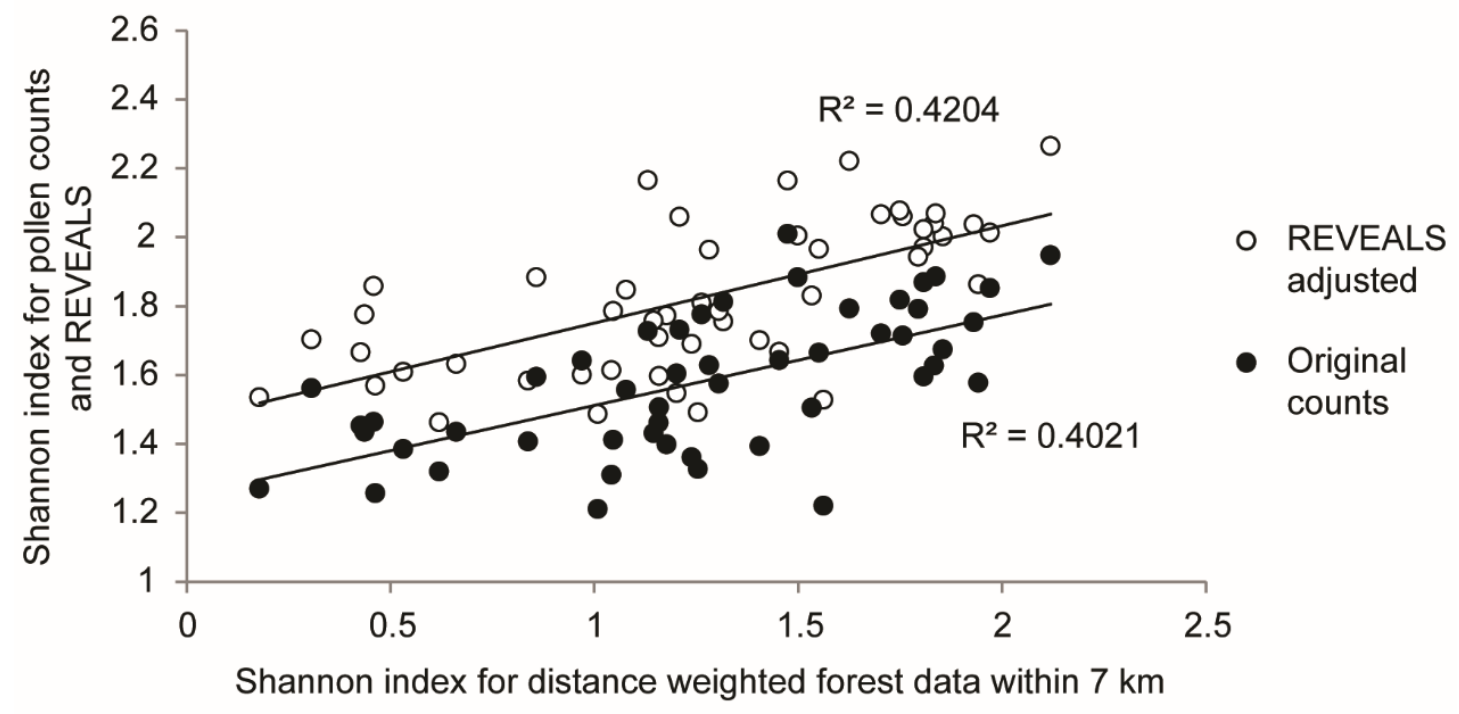

Fig. 4.5 Agreement of Shannon index calculated on distance weighted tree species abundance obtained from forest inventory data and the Shannon index of corresponding pollen percentages and their REVEALS adjustments. 


\subsection{Discussion}

The Shannon index and the number of pollen types in a theoretical count of $10\left(E\left(T_{10}\right)\right)$ describe nearly the same characteristics of the abundance distribution in the sample (Fig. 4.3, see also Odgaard 2008). Palynological richness or the number of pollen types in high pollen counts shows little correspondence to the Shannon index. Thus, in the following, we use rarefaction to the low count $E\left(T_{10}\right)$ to describe pollen diversity in addition to the common usage of palynological richness expressed for high pollen counts to refer to the richness aspect of the sample (Birks \& Line 1992).

\subsubsection{Openness}

The proportion of non-forested area is the strongest factor explaining differences in palynological diversity and richness (Fig. 4.4; Table 4.1). Agreement between the total proportion of herbaceous pollen, indicating open areas in a forested region and palynological richness, has been previously observed in fossil records (e.g. Seppä 1998; Poska, Saarse \& Veski 2004; Berglund, Persson \& Björkman 2008b) and demonstrated in a modern comparison similar to this study (Meltsov et al. 2013). The reason for this relationship may be a combination of factors: trees generally produce more pollen than herbs, and thus, the latter has a low probability to be detected in a tree dominated landscape (Odgaard 1999). Pollen originating from herbs below a forest canopy may be less likely to reach a lake compared to pollen emitted by herbs in a treeless situation, due to lower wind velocities within the trunk space and filtration of twigs and leafs (e.g. Anderson 1970; Raynor, Hayes \& Ogden 1974; Tauber 1977). The herbaceous flora in Europe is richer than the tree flora and even if the pollen types for many taxa cannot be separated beyond subfamily level, there are still more distinguishable herbaceous than arboreal pollen types. As humans started opening the central and northern European forests for agriculture around 6000 years ago, they increased the habitat for herbaceous taxa and thus increased floristic diversity on a landscape scale (e.g. Berglund et al. 2008a; Giesecke et al. 2012; Colombaroli et al. 2013).

The non-forested area within seven $\mathrm{km}$ from the lake is negatively correlated to the area covered by Pinus, which is the variable with the strongest correlation to pollen diversity. Pinus is the most important tree species in Brandenburg constituting about $70 \%$ of the forest cover (Engel 2010), and it occurs predominantly in monospecific plantations on nutrient poor sandy soils. Thus, the variable 'Pinus cover within seven $\mathrm{km}^{\prime}$ describes the proportion of large homogeneous floristically species poor pine forests which often occur on extensive outwash plains in the region. Like non-forested area, Pinus cover correlates with pollen richness, although not as strongly. Therefore, it may rather be the effect of a single pollen type dominating the pollen sample than the reduced floristic diversity in extensive pine plantations that leads to the strong correlation with pollen diversity. 


\subsubsection{Local vegetation and patchiness}

The number of different biotopes and in particular the total number of biotopes per area represents vegetation patchiness and landscape diversity. Within one $\mathrm{km}$ from the lake, this is correlated to pollen diversity (Fig. 4.4). It is difficult to relate the different biotopes to numbers of species they may harbour; however, it is fair to assume that the number of species increases with the number of different biotopes. As the transitions between biotopes are often characterized by higher richness (e.g. Beierkuhnlein 2007) also, the total number of biotopes per area may be related to species richness. Thus, it may be hypothesized that the good correlation between patchiness and pollen diversity for shorter distances is due to the higher probability of detecting pollen from taxa with low production, as well as from rare species. If this were true, there should be a correlation with pollen richness, which is not observed. Meltsov et al. (2013) compared pollen richness to patch diversity and found the correlation to increase beyond one $\mathrm{km}$ from the lake. However, the authors used a land cover map with coarser units so that patch diversity may be correlated to non-forested area. A comparison of absolute pollen deposition and plant abundance shows that the largest proportion of pollen is delivered from plants within a few hundred metres from the lake shore (Matthias \& Giesecke 2014). Consequently, pollen diversity captures the diversity aspect of abundant species as described by the two patchiness variables.

The strong correlation between lake shore length relative to size and pollen diversity (Table 4.1) seems to work in a similar way as the two patchiness parameters, while it is not correlated to either. A long curvy shoreline increases the probability that different tree and herb species occur near the shore, which leads to a strong representation of their pollen. However, there is no correlation between the lake perimeter/area ratio and pollen richness. This parameter holds some explanatory power for between site investigations. However, it should change little through time at most sites.

\subsubsection{Adjusting for pollination mode and production dispersal bias}

The abundant vegetation types in the study region are represented by wind-pollinated taxa. Therefore, reducing the data set to pollen types from wind-pollinated species yielded little difference for the correlation between landscape factors and pollen diversity. The REVEALS adjustment of the wind-pollinated taxa shows similar correlations to the landscape parameters as found for the uncorrected data set. For the non-forested area, the adjustment improved the correlation for the $\mathrm{SLOPE}_{1 \%}$ index, while reducing it for pollen richness. We expected to find a stronger effect of the REVEALS adjustment for the diversity indicators like $E\left(T_{10}\right)$ and its absence may be explained by the similar PPEs for the main tree species in the region. Most lakes are surrounded by forest so that also the large differences in pollen production between forested and non-forested area hardly come to 
bare. The REVEALS adjustments of the full data set resulted in poor correlations to landscape parameters compared to the untransformed data. This is mainly due to simplified pollen productivity estimates for many less common taxa. The introduced bias outweighs any potential improvements. We nevertheless attempted this correction, as in principle REVEALS adjustments could improve assessments of pollen richness by equalizing the detection probability between samples. Assessing richness from restricted data sets is problematic as the restricting constraint sets the limit for the highest richness. In the here presented case, richness was restricted to a maximum of 31 windpollinated taxa and this restriction alone reduced the correlation between pollen type richness and non-forested area. Thus, REVEALS adjustments does not improve assessments of pollen type richness, but may be beneficial for the application of diversity indicators.

\subsubsection{Diversity, richness and evenness}

We have shown pollen diversity to be a responsive measure capturing aspects of landscape diversity around a site, but it has rarely been used to describe past changes in vegetation structure. The pollen-based Shannon index and rarefaction to 10 show significant correlations to all landscape variables tested. Also, the $\mathrm{SLOPE}_{1 \%}$ index correlates with these parameters indicating that it represents diversity rather than evenness as assumed earlier (Giesecke, Ammann \& Brande 2014). All these diversity measures are potentially biased by species-specific differences in pollen production and dispersal (Birks \& Line 1992). Nevertheless, this study shows that the presumed bias due to production and dispersal may not inhibit a correspondence between landscape diversity around a site and pollen diversity in a surface sample. There may, however, be distortions in different settings, for example near tree lines in arctic and alpine settings (Seppä 1998), where the most abundant pollen types are potentially of long distance origin.

While we did not directly investigate the correspondence between floristic diversity near the lake and pollen type richness, the removed outlier does indicate that this component may be important. The removed lake was bordered by a garden and the pollen count yielded disproportionately high richness of rare pollen types. Land use resulting in increased floristic diversity such as gardens, orchards or villages was not differentiated in the analysis, which may explain the high variability in richness that cannot be explained by landscape parameters. The much smaller but more controlled data set from Estonia (Meltsov et al. 2011, 2013) shows a strong correlation of non-forested area with pollen richness, which also increases with distance. Human population density in Estonia is less than half of that in Brandenburg and the above described factors may therefore have a smaller effect. Nevertheless, both studies agree that pollen richness corresponds to land use and landscape diversity in a wider area around a site. 
Thus, pollen sample richness and diversity provide a description of different aspects of the abundance distribution of pollen types in the sample and relate to different aspects of landscape diversity. It seems therefore these indices can be used to explore the concept of evenness. Tuomisto (2012) argues that evenness may be obtained as the ratio of diversity and richness. This follows in principle Hill's (1973) suggestion that evenness can be defined as the ratio between the diversity numbers $\mathrm{N}$ of lower and higher order (e.g. $\mathrm{N}_{0} / \mathrm{N}_{1}$ ). Hills concept of diversity number of different order or the effective number of species at different sampling depths is conceptually similar to the rarefaction analysis to different sample size with the sample size or pollen count being inversely related to the order a in 'Hill's numbers'. It has been previously discussed that the reciprocal of Simpson's index $\left(\mathrm{N}_{2}\right)$ corresponds to rarefaction to a sample of 2 (Oksanen 2013). Here we demonstrate that the Shannon index or its exponential $\left(N_{1}\right)$ is closely correlated to the number of taxa in a sample of 10 and argue that rarefaction to a high count (e.g. counts of 500-1000 pollen grains) corresponds to richness $\left(\mathrm{N}_{0}\right)$. Following this, evenness can be obtained as the ratio between rarefaction to a low count (2-30) and a high count (500-1000). Testing this evenness index against the landscape factors, we see significant correlations with lake perimeter/size $(r=0.53, P<0.001)$ and number of different biotopes $(r=0.39, P<0.01)$ which is in line with the above discussion.

A post-glacial pollen diagram (Brande 1996) from the study region provides a convenient data set to explore the usefulness of these three indexes for fossil data (Fig. 4.6). In particular, during the Lateglacial and early Holocene, palynological richness changes little indicating a stable species pool, while the cooling during the Younger Dryas and the initial warming of the Holocene changed vegetation structure as indicated by strong changes in pollen diversity. The trough in diversity at the beginning of the Holocene marks a reduction in landscape diversity, as the Lateglacial parkland changes into a species poor birch and pine forest. Since diversity encompasses richness, the diversity and richness curves cannot show completely different trends, while their ratio depicts a different pattern. With the onset of agriculture, diversity increases slower than richness, resulting in a decline in evenness. This low evenness for samples describing enhanced human land use may be counter intuitive when thinking about the landscape, but it does describe the abundance distribution of pollen types in these samples, which are characterized by a large number of rare pollen types. Early human land use may have resulted in reducing the abundance of particular trees that were used for construction and enhancing the area for herbs, thus reducing pollen diversity while enhancing pollen richness. Here the rarefaction derived evenness helps detecting settlement phases as troughs in evenness. In the example of the Tegeler See diagram (Fig. 4.6), this is particularly visible for a settlement phase during the late Bronze Age between 3000 and 2500 years cal. BP. 


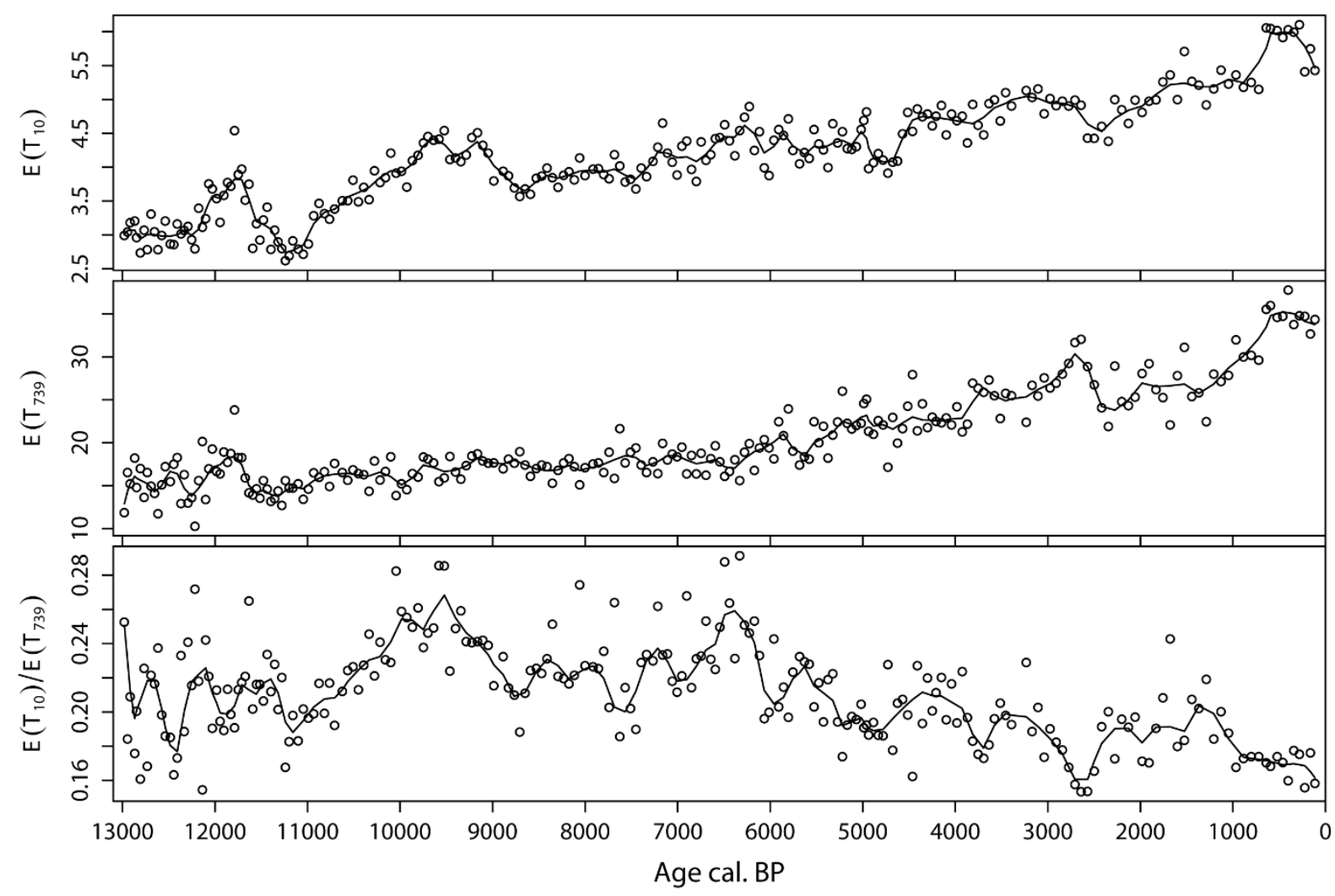

Fig. 4.6 Pollen type diversity $\left(E\left(T_{10}\right)\right)$, richness $\left(E\left(T_{739}\right)\right)$ and evenness $\left(E\left(T_{10}\right) / E\left(T_{739}\right)\right)$ for the terrestrial pollen types analysed in a post-glacial core from Tegeler See in north-west Berlin (Brande 1996).

\subsubsection{Perspectives and pitfalls}

Utilizing the abundance distributions of pollen types to make inferences about changes in landscape diversity is largely unexplored, while it holds potential for the understanding of long-term drivers for floristic and landscape diversity. Rarefaction to common high pollen counts has proven a convenient tool. The here suggested pollen diversity and evenness will not replace it, but add to it and help differentiate and evaluate changes in past vegetation structure and richness. The reduction in pollen production/dispersal bias seems most effective for diversity indexes. Additional modern comparisons are needed to understand what pollen diversity indexes correspond to in the flora and landscape around a site.

The study by Goring et al. (2013) illustrates potential problems when applying diversity indicators to large data bases. However, the lack of a relationship in their study between pollen and floristic richness in north-western North America can be explained. The study focusses on richness using counts of around 300 pollen grains. It includes sites from very different settings, ranging from small ponds to lakes with several $\mathrm{km}$ in diameter, lakes where farming activity is ongoing in the catchment, sites from predominantly forested regions and presumably also sites from naturally open, dry mountain valleys. In such, a mixed sample collection pollen type richness will mainly be influenced by 
local pollen production and show differences in local vegetation structure and diversity, such as landscape openness and land use, rather than differences in the regional species pool. Palynological richness may in principle reflect the size of the regional species pool; however, pollen counts higher than 300 may be necessary (Giesecke et al. 2012). Here surface samples may be combined in regional clusters to reduce local effects and obtain high sample sizes. Working with samples from data bases has the added problem of analysis from different investigators, which generally results in different taxonomic precision. To circumvent this, Goring et al. (2013) combined the taxa at higher taxonomic level, which leads to a loss of information. This strategy may be inevitable when aiming to work with all possible samples. However, different names may be used by different investigators that both achieved high taxonomic precession and here synonym tables may be better suited to harmonize such data sets. Databases store results from investigations with different purposes and while investigations aiming at general shifts in vegetation cover may not require high taxonomic precision, studies on early human land use will put more effort in pollen determination. Both types of data sets may be used for a range of analysis where they provide similar results, but this will not be the case with studies focussing on pollen type richness or evenness.

\subsection{Conclusion}

We show that pollen type diversity as measured by the Shannon index or rarefaction to a sample of 10 is a useful indicator that corresponds to different aspects of landscape diversity such as the richness of biotopes. In this study, pollen diversity was determined by the proportion of non-forested area within seven $\mathrm{km}$, vegetation patchiness within one $\mathrm{km}$ and the ratio of shore length to lake area. Pollen type richness (the number of types in a high count) was found to be little influenced by local vegetation patchiness and correlates best to the proportion of non-forested area within seven $\mathrm{km}$. Following ecological theory suggesting that evenness can be obtained as the ratio between diversity and richness, we propose that this variable can be assessed as the ratio between the number of species in a small and a large sample or the number of taxa in a low (10) vs. a high (500) pollen count as assessed by rarefaction analysis.

The pollen production/dispersal bias influences pollen-based diversity indicators. This bias may be reduced using models of pollen transport and deposition together with information on pollen productivity. Adjustments may only be robust for the most abundant and in particular windpollinated taxa. This is sufficient for diversity, but not for richness and evenness indexes. In central Europe, the reduction to only wind-pollinated taxa did not affect the pollen diversity index as most abundant pollen types come from wind-pollinated plants. This may hold true for many parts of the world but should be tested for different vegetation types. 
Thus, pollen type diversity seems to be a robust measure for between site comparisons. It is not restricted to pollen diagrams with high counts and therefore valuable for large scale comparisons. The example pollen data show that the index highlights climate driven shifts in vegetation structure and the evenness index may be useful detecting early human impact. In combination, the suggested set of indexes may yield new insight into pollen analytical results. Using rarefaction-based diversity, richness and evenness indexes are conceptually simple and may also prove useful in related fields.

\section{Acknowledgements}

We are grateful to Shinya Sugita for providing the REVEALS.v4.5. program and for further fruitful discussion and suggestions for handling the pollen data. We also like to thank the referees for helpful comments on an earlier draft of this manuscript. We thank Daniela Rorig for language editing. This study was funded by the German Research Foundation (DFG, GI 732/1-1).

\section{Data accessibility}

The biotope map is available from the official webpage of the state of Brandenburg (http://www.lugv.brandenburg.de/cms/detail.php/bb1.c.310483.de). Forest inventory data can be obtained from the forest administration 'Datenspeicher Wald' (DSW2; http://www.dsw2.de/index.html) and the federal agency "Bundesanstalt für Immobilienaufgaben" (http://www.bundesimmobilien.de/). The original pollen counts of the surface samples from all lakes are stored in Pangaea (data are available at http://doi.pangaea.de/10.1594/PANGAEA.844893).

\subsection{References}

Anderson, S.Th. (1970) The relative pollen productivity and pollen representation of North European trees, and correction factors for tree pollen spectra. Determined by surface pollen analyses from forests. Danmarks geologiske unders $\varnothing$ gelse. Raekke, 2, 96, 1-99.

Beierkuhnlein, C. (2007) Biogeographie. Die räumliche Organisation des Lebens in eine sich verändernden Welt. Verlag Eugen Ulmer, Stuttgart.

Bennett, K.D. \& Willis, K.J. (2001) Pollen. Tracking environmental change using lake sediments, Vol 3: Terrestrial, Algal and Siliceous Indicators (eds J.P. Smoll, H.J.B. Birks \& W.M. Last), pp. 5-32. Kluwer Academic Publishers, Dordrecht.

Berglund, B.E., Persson, T. \& Björkman, L. (2008b) Late Quaternary landscape and vegetation diversity in a North European perspective. Quaternary International, 184, 187-194.

Berglund, B.E., Gaillard, M.-J., Björkman, L. \& Persson, T. (2008a) Long-term changes in floristic diversity in southern Sweden: palynological richness, vegetation dynamics and land-use. Vegetation History and Archaeobotany, 17, 573-583.

Beug, H.-J. (2004) Leitfaden der Pollenbestimmung. Verlag Dr. Friedrich Pfeil, München.

BiolFlor (2013) Eine Datenbank mit biologisch-ökologischen Merkmalen der Flora von Deutschland. Eine Kooperation von Umweltforschungszentrum Leipzig-Halle $\mathrm{GmbH}$ und Bundesamt f€ur Naturschutz. Bundesamt für Naturschutz. http://www2.ufz.de/biolflor/index.jsp.

Birks, H.J.B. \& Line, J.M. (1992) The use of rarefaction analysis for estimating palynological richness from Quaternary pollen-analytical data. The Holocene, 2, 1-10. 
Brande, A. (1996) Berlin. Palaeoecological Events During the Last 15000 Years: Regional Syntheses of Palaeoecological Studies of Lakes and Mires in Europe (eds B.E. Berglund, H.J.B. Birks, M. Ralska-Jasiewiczowa \& H.E. Wright), pp. 518-523. John Wiley \& Sons, Chichester.

Broström, A., Sugita, S. \& Gaillard, M.J. (2004) Pollen productivity estimates for reconstruction of past vegetation cover in the cultural landscape of southern Sweden. The Holocene, 14, 371384.

Broström, A., Nielsen, B., Gaillard, M.-J., Hjelle, K.L., Mazier, F., Binney, H. et al. (2008) Pollen productivity estimates of key European plant taxa for quantitative reconstruction of past vegetation: a review. Vegetation History and Archaeobotany, 17, 461-478.

Colombaroli, D. \& Tinner, W. (2013) Determining the long-term changes in biodiversity and provisioning services along a transect from Central Europe to the Mediterranean. The Holocene, 23, 1625-1634.

Colombaroli, D., Beckmann, M., van der Knaap, W.O., Curdy, P. \& Tinner, W. (2013) Changes in biodiversity and vegetation composition in the central Swiss Alps during the transition from pristine forest to first farming. Diversity and Distributions, 19, 157-170.

Davis, M.B. (2000) Palynology after Y2K - understanding the source area of pollen in sediments. Annual Review of Earth and Planetary Sciences, 28, 1-18.

Dyakowska, J. (1936) Research on the rapidity of the falling down of pollen of some trees. Bulletin international de l'Academie polonaise des sciences et des lettres, Classe des Sciences mathematiques et naturelles. Serie B, Sciences naturelles, III, 155-169.

Eisenhut, G. (1961) Untersuchung über die Morphologie und Ökologie der Pollenkörner heimischer und fremdländischer Waldbäume. Paul Parey, Hamburg.

Engel, J. (2010) Brandenburg - Kiefernland in Wandel. MILAktuell, 2, 29-30.

Fredh, D., Broström, A., Zillén, L., Mazier, F., Rundgren, M. \& Lageras, P. (2012) Floristic diversity in the transition from traditional to modern land-use in southern Sweden A.D. 1800-2008. Vegetation History and Archaeobotany, 21, 439-452.

Gaillard, M.-J., Sugita, S., Bunting, M.J., Middleton, R., Broström, A., Caseldine, C. et al. (2008) The use of modelling and simulation approach in reconstructing past landscapes from fossil pollen data: a review and results from the POLLANDCAL network. Vegetation History and Archaeobotany, 17, 419-443.

Giesecke, T., Ammann, B. \& Brande, A. (2014) Palynological richness and evenness - insights from the taxa accumulation curve. Vegetation History and Archaeobotany, 23, 217-228.

Giesecke, T., Wolters, S., Jahns, S. \& Brande, A. (2012) Exploring Holocene changes in palynological richness in northern Europe - did postglacial immigration matters? PLOS ONE, 7, 1-12.

Goring, S., Lacourse, T., Pellatt, M.G. \& Mathewes, R.W. (2013) Pollen assemblage richness does not reflect regional plant species richness: a cautionary tale. Journal of Ecology, 101, 1137-1145.

Gregory, P.H. (1973) The Microbiology of the Atmosphere. Leonard Hill, Aylesbury.

Hill, M.O. (1973) Diversity and evenness: a unifying notation and its consequences. Ecology, 54, 427432.

Hurlbert, S.H. (1971) The nonconcept of species diversity: a critique and alternative parameters. Ecology, 52, 577-586.

Ives, A.R. \& Carpenter, S.R. (2007) Stability and diversity of ecosystems. Science, 317, 58-62.

Jäger, E.J. (2011) Rothmaler. Excursionsflora von Deutschland. Gefäßpflanzen: Grundband. Spektrum Akademischer Verlag, Heidelberg.

Jantz, N., Homeier, J. \& Behling, H. (2014) Representativeness of tree diversity in the modern pollen rain of Andean montane forests. Journal of Vegetation Science, 25, 481-490.

Liedtke, H. \& Marcinek, J. (2002) Physische Geographie Deutschlands. Klett-Perthes, Gotha, Stuttgart.

Linke, C., Grimmert, S., Hartmann, I. \& Reinhardt, K. (2010) Auswertung regionaler Klimamodelle für das Land Brandenburg. Fachbeitr€age des Landesumweltamtes Heft Nr. 113. http://www.mugv.brandenburg.de/cms/media.php/lbm1.a.2334.de/i_fb113.pdf (Accessed 27 February 2012). 
Loreau, M., Naeem, S., PInchausti, P., Bengtsson, J., Grime, J.P., Hector, A., Hooper, D.U., Huston, M.A., Raffaelli, D., Schmid, B., Tilman, D. \& Wardle, D.A. (2001) Biodiversity and ecosystem functioning: current knowledge and future challenges. Science, 294, 804-808.

Marquer, L., Gaillard, M.J., Sugita, S., Trondman, A.-K., Mazier, F., Nielsen, A.B. et al. (2014) Holocene changes in vegetation composition in northern Europe: why pollen-based quantitative reconstruction matters. Quaternary Sciences Reviews, 90, 199-216.

Matthias, I. \& Giesecke, T. (2014) Insights into pollen source area, transport and deposition from modern pollen accumulation rates in lake sediments. Quaternary Science Reviews, 87, 12-23.

Matthias, I., Nielsen, A.B. \& Giesecke, T. (2012) Evaluating the effect of flowering age and forest structure on pollen productivity estimates. Vegetation History and Archaeobotany, 21, 471484.

Mazaris, A.D., Kallimanis, A.S., Tzanopoulos, J., Sgardelis, S.P. \& Pantis, J.D. (2010) Can we predict the number of plant species from the richness of a few common genera, families or orders? Journal of Applied Ecology, 47, 662-670.

Meltsov, V., Poska, A., Odgaard, B.V., Sammul, M. \& Kull, T. (2011) Palynological richness and pollen sample evenness in relation to local floristic diversity in southern Estonia. Review of Palaeobotany and Palynology, 166, 344-351.

Meltsov, V., Poska, A., Reitlau, T., Sammul, M. \& Kull, T. (2013) The role of landscape structure in determining palynological and floristic richness. Vegetation History and Archaeobotany, 22, 39-49.

Odgaard, B.V. (1994) The Holocene vegetation history of northern West Jutland, Denmark. Opera Botanica, 123, 3-171.

Odgaard, B.V. (1999) Fossil pollen as a record of past biodiversity. Journal of Biogeography, 26, 7-17.

Odgaard, B.V. (2001) Palaeoecological perspectives on pattern and progress in plant diversity and distribution adjustments: a comment on recent developments. Diversity and Distributions, 7 , 197-201.

Odgaard, B.V. (2008) Does pollen type diversity reflect vegetation diversity? Terra Nostra, 2, 209.

Oksanen, J. (2013) Vignettes: ecological diversity. R: a language and environment for statistical computing. Vegan: Community Ecology Package. R package version 2.0-9. (eds J. Oksanen, F.G. Blanchet, R. Kindt, P. Legendre, P.R. Minchin, R.B. O'Hara, G.L. Simpson, P. Solymos, M.H.H. Stevens \& H. Wagner) http://CRAN.R-project.org/package=vegan.

Oksanen, J., Blanchet, F.G., Kindt, R., Legendre, P., Minchin, P.R., O'Hara, R.B., Simpson, G.L., Solymos, P., Stevens, M.H.H. \& Wagner, H. (2013) Vegan: Community Ecology Package. R package version 2.0-9. http://CRAN.R-project.org/package=vegan.

Poska, A., Saarse, L. \& Veski, S. (2004) Reflections of pre- and early-agrarian human impact in the pollen diagrams of Estonia. Palaeogeography, Palaeoclimatology, Palaeoecology, 209, 37-50.

R Core Team (2013) R: A Language and Environment for Statistical Computing. R Foundation for Statistical Computing, Vienna, Austria. URL http://www.R-project.org/.

Raven, P.H., Evert, R.F. \& Eichhorn, S.E. (2000) Biologie der Pflanzen. Walter de Gruyter, Berlin, New York.

Raynor, G.S., Hayes, J.V. \& Ogden, E.C. (1974) Particulate dispersion into and within a forest. Boundary-Layer Meteorology, 7, 429-456.

Reitalu, T., Gerhold, P., Poska, A., Pärtel, M., Väli, V. \& Veski, S. (in press) Novel insights into postglacial vegetation change: functional and phylogenetic diversity in pollen records. Journal of Vegetation Science. doi: 10.1111/jvs.12300.

Renberg, I. (1991) The HON-Kajak sediment corer. Journal of Paleolimnology, 6, 167-170.

Seppä, H. (1998) Postglacial trends in palynological richness in the northern Fennoscandian tree-line area and their ecological interpretation. The Holocene, 8, 43-53.

Smith, B. \& Wilson, J.N. (1996) A consumer's guide to evenness indices. Oikos, 76, 70-82.

Soepboer, W., Sugita, S., Lotter, A.F., Van Leuwen, J.F.N. \& Van der Knaap, W.O. (2007) Pollen productivity estimates for quantitative reconstruction of vegetation cover on the Swiss Plateau. The Holocene, 17, 1-13. 
Sugita, S. (2007a) Theory of quantitative reconstruction of vegetation I: pollen from large sites REVEALS regional vegetation composition. The Holocene, 17, 229-241.

Sugita, S. (2007b) Theory of quantitative reconstruction of vegetation II: all you need is LOVE. The Holocene, 17, 243-257.

Sugita, S., Gaillard, M.J. \& Broström, A. (1999) Landscape openness and pollen records: a simulation approach. The Holocene, 9, 409-421.

Sugita, S., Parshall, T., Calcote, R. \& Walker, K. (2010) Testing the Landscape Reconstruction Algorithm for spatially explicit reconstruction of vegetation in northern Michigan and Wisconsin. Quaternary Research, 74, 289-300.

Tauber, H. (1977) Investigations of aerial pollen transport in a forested area. Dansk Botanisk Arkiv, 3, 1-121.

Tilman, D., Lehman, D. \& Thompson, K. (1997) Plant diversity and ecosystem productivity: theoretical considerations. Proceedings of the National Academy of Sciences of the United States of America, 94, 1857-1861.

Tuomisto, H. (2012) An updated consumer's guide to evenness and related indices. Oikos, 121, 12031218.

Umweltbundesamt \& DLR-DFD (2004) CORINE Land Cover 2000. Daten zur Bodenbedeckung Deutschland. http://www.corine.dfd.dlr.de. Venables, W.N. \& Ripley, B.D. (2002) Modern Applied Statistics with S, $4^{\text {th }}$ edn. Springer, New York.

Weng, C., Hooghiemstra, H. \& Duivenvoorden, J.F. (2006) Challenges in estimating past plant diversity from fossil pollen data: statistical assessment, problems, and possible solutions. Diversity and Distributions, 12, 310-318.

Willemstein, S.C. (1987) An Evolutionary Basis for Pollination Ecology. (Leiden Botanical Series). E. J. Brill, Leiden.

Received 1 September 2014; accepted 26 March 2015

Handling Editor: Matt McGlone

\section{Supporting Information}

Additional Supporting Information may be found in the online version of this article:

Appendix S1. Characteristics of the sampled lakes.

Appendix S2. Fall speed and PPEs of the pollen taxa 


\section{SUPPORTING INFORMATION}

\section{Appendix S1.}

Characteristics of the sampled lakes

\begin{tabular}{|c|c|c|c|c|c|c|}
\hline No & Name & $\begin{array}{l}\text { Latitude } \\
\text { (decima }\end{array}$ & $\begin{array}{l}\text { Longitude } \\
\text { egrees) }\end{array}$ & Size (ha) & Radius (m) & Depth $(\mathrm{m})$ \\
\hline 1 & Steinsee & 53.3184 & 13.6226 & 6.7 & 146 & 3.5 \\
\hline 2 & Petznicksee & 53.3155 & 13.6093 & 13.1 & 204 & 7.3 \\
\hline 3 & Kleiner Petznicksee & 53.3114 & 13.6018 & 5.1 & 127 & 2 \\
\hline 4 & Hausseebruch & 53.2452 & 13.5306 & 3 & 98 & 10.1 \\
\hline 5 & Tiefer See & 53.2352 & 13.3631 & 17.2 & 234 & 33.7 \\
\hline 6 & Tiefer Clöwen & 53.2333 & 13.5311 & 8.5 & 165 & 10.3 \\
\hline 7 & Poviestsee & 53.2239 & 13.5124 & 22 & 265 & 11.7 \\
\hline 8 & Kleiner Rathsburgsee & 53.2006 & 13.9394 & 3.2 & 101 & 6.6 \\
\hline 9 & Kleiner Lychensee & 53.1964 & 13.2704 & 8.5 & 165 & 13.7 \\
\hline 10 & Bugsee & 53.1930 & 13.9100 & 1.5 & 69 & 6 \\
\hline 11 & Kleiner Trinsee & 53.1580 & 13.8674 & 1.1 & 59 & 5.6 \\
\hline 12 & Kleiner Zermittensee & 53.1440 & 12.8227 & 5.8 & 136 & 7.3 \\
\hline 13 & Aalgastsee & 53.1391 & 13.9050 & 0.8 & 51 & 3.3 \\
\hline 14 & Weißesee & 53.1368 & 13.1089 & 5.8 & 136 & 8.2 \\
\hline 15 & Glabatzsee & 53.1361 & 12.9745 & 2 & 80 & 7.3 \\
\hline 16 & Temnitzsee & 53.1217 & 13.6462 & 9.9 & 178 & 6.7 \\
\hline 17 & Plötzensee & 53.1148 & 12.9704 & 5.7 & 135 & 8.8 \\
\hline 18 & Kleiner Gollinsee & 53.0289 & 13.5882 & 3.2 & 101 & 3.3 \\
\hline 19 & Teufelssee & 53.0200 & 12.8263 & 4.8 & 124 & 12 \\
\hline 20 & Heiliger See & 53.0156 & 13.8720 & 9.1 & 170 & 10.8 \\
\hline 21 & Dovinsee & 52.9980 & 13.7881 & 20.8 & 257 & 7 \\
\hline 22 & Schwarzersee & 52.9940 & 13.9030 & 3.3 & 103 & 4.7 \\
\hline 23 & Kleiner Plunzsee & 52.9927 & 13.9359 & 2.8 & 94 & 3.8 \\
\hline 24 & Runder Köllnsee & 52.9806 & 13.6685 & 2.7 & 93 & 3.9 \\
\hline 25 & Grimnitzsee & 52.9787 & 13.7770 & 782 & 1578 & 6.2 \\
\hline 26 & Papensee & 52.9140 & 13.2390 & 5.9 & 137 & 8.3 \\
\hline 27 & Buckowsee & 52.8132 & 13.6087 & 13.8 & 210 & 8.8 \\
\hline 28 & Schiebelsee & 52.7457 & 14.0463 & 0.5 & 40 & 4.1 \\
\hline 29 & Sonnenburger Fenn & 52.7446 & 14.0419 & 2.3 & 86 & 3.5 \\
\hline 30 & Baasee & 52.7433 & 14.0258 & 2.2 & 84 & 3.6 \\
\hline 31 & Röthsee & 52.6949 & 13.9429 & 3.3 & 103 & 2.7 \\
\hline 32 & Modderpfuhl & 52.6796 & 13.9084 & 1.7 & 74 & 3.8 \\
\hline 33 & Sternebecker See & 52.6793 & 14.0025 & 7.7 & 157 & 10.8 \\
\hline 34 & Piechesee & 52.6596 & 13.9211 & 4.5 & 120 & 3 \\
\hline 35 & Blumenthalsee & 52.6517 & 13.9272 & 8.4 & 164 & 4.2 \\
\hline 36 & Staffsee & 52.5944 & 14.1890 & 9.6 & 175 & 3.8 \\
\hline 37 & Kleiner Tornowsee & 52.5795 & 14.0930 & 3.8 & 110 & 10 \\
\hline 38 & Schwarzer See & 52.5554 & 14.0835 & 7.1 & 150 & 4.3 \\
\hline
\end{tabular}




\begin{tabular}{|c|c|c|c|c|c|c|}
\hline 39 & Kesselsee & 52.5292 & 14.0796 & 2.7 & 93 & 7.8 \\
\hline 40 & Kessel See & 52.4121 & 14.3562 & 3.5 & 106 & 1.2 \\
\hline 41 & Karbuschsee & 52.1867 & 13.6543 & 12.2 & 197 & 17.5 \\
\hline 42 & Kleiner Treppelsee & 52.1326 & 14.4585 & 5.4 & 131 & 4.5 \\
\hline 43 & Ziskensee & 52.1060 & 14.4699 & 2.6 & 91 & 4.4 \\
\hline 44 & Klautzkesee & 52.0997 & 14.5223 & 6.4 & 143 & 1.8 \\
\hline 45 & Rähdensee & 52.0707 & 14.4465 & 11.8 & 194 & 6.3 \\
\hline 46 & Buchwaldsee & 52.0239 & 14.6300 & 1.9 & 78 & 2.3 \\
\hline 47 & Kleinsee & 51.9420 & 14.5101 & 14 & 211 & 2 \\
\hline 48 & Großsee & 51.9330 & 14.4719 & 31.7 & 318 & 8.3 \\
\hline 49 & Deulowitzer See & 51.9238 & 14.6467 & 13.9 & 210 & 4 \\
\hline 50 & Teersee & 51.9193 & 14.2263 & 8 & 160 & 3.7 \\
\hline
\end{tabular}




\section{SUPPORTING INFORMATION}

\section{Appendix S2.}

Fall speed and PPEs of the pollen taxa

\begin{tabular}{|c|c|c|c|c|c|}
\hline Pollen taxa & Fall speed & Reference & PPEs & & Reference \\
\hline Abies & 0.12 & Eisenhut 1961 & & 7.35 & Soepboer et al. 2007 \\
\hline Acer & 0.056 & $\begin{array}{l}\text { Sugita, Gaillard \& } \\
\text { Broström } 1999\end{array}$ & & 0.22 & $\begin{array}{l}\text { Sugita, Gaillard \& } \\
\text { Broström } 1999\end{array}$ \\
\hline Alnus & 0.021 & Eisenhut 1961 & & 2.74 & $\begin{array}{l}\text { Matthias, Nielsen \& } \\
\text { Giesecke } 2012\end{array}$ \\
\hline Ambrosia-type & 0.013 & calculated & & 0.4 & estimated \\
\hline Androsace & 0.009 & calculated & & 0.1 & estimated \\
\hline Apiaceae & 0.048 & calculated & & 0.1 & estimated \\
\hline Artemisia & 0.017 & calculated & & 0.4 & estimated \\
\hline $\begin{array}{l}\text { Asteraceae } \\
\text { undifferentiated }\end{array}$ & 0.037 & calculated & & 0.13 & Soepboer et al. 2007 \\
\hline Astragalus-type & 0.024 & calculated & & 0.1 & estimated \\
\hline Avena-type & 0.06 & calculated & & 0.1 & estimated \\
\hline Berula erecta-group & 0.019 & calculated & & 0.1 & estimated \\
\hline Betula & 0.022 & Eisenhut 1961 & & 1.7 & $\begin{array}{l}\text { Matthias, Nielsen \& } \\
\text { Giesecke } 2012\end{array}$ \\
\hline Brassicaceae & 0.016 & calculated & & 0.1 & estimated \\
\hline Bruckenthalia & 0.013 & calculated & & 0.2 & estimated \\
\hline Buxus & 0.037 & calculated & & 0.2 & estimated \\
\hline Calluna & 0.038 & $\begin{array}{l}\text { Broström, Sugita \& } \\
\text { Gaillard } 2004\end{array}$ & & 0.82 & $\begin{array}{l}\text { Broström, Sugita \& } \\
\text { Gaillard } 2004\end{array}$ \\
\hline Cannbinaceae & 0.016 & calculated & & 0.4 & estimated \\
\hline Capsicum-type & 0.027 & calculated & & 0.1 & estimated \\
\hline Cariophyllaceae & 0.048 & calculated & & 0.1 & estimated \\
\hline Carpinus & 0.042 & Eisenhut 1961 & & 1.67 & $\begin{array}{l}\text { Matthias, Nielsen \& } \\
\text { Giesecke } 2012\end{array}$ \\
\hline Carya & 0.076 & calculated & & 0.4 & estimated \\
\hline Castanea & 0.007 & calculated & & 0.2 & estimated \\
\hline Celtis CF & 0.035 & calculated & & 0.4 & estimated \\
\hline Centaurea cyanus & 0.041 & calculated & & 0.1 & estimated \\
\hline $\begin{array}{l}\text { Centaurea } \\
\text { undifferentiated }\end{array}$ & 0.088 & calculated & & 0.1 & estimated \\
\hline $\begin{array}{l}\text { Cerialia } \\
\text { undifferentiated }\end{array}$ & 0.06 & calculated & & 0.1 & estimated \\
\hline Chamaenerion & 0.109 & calculated & & 0.1 & estimated \\
\hline Chenopodiaceae & 0.019 & calculated & & 0.4 & estimated \\
\hline Chimaphila umbellata & 0.046 & calculated & & 0.1 & estimated \\
\hline Circaea & 0.053 & calculated & & 0.1 & estimated \\
\hline Cirsium & 0.076 & calculated & & 0.1 & estimated \\
\hline Clethra & 0.011 & calculated & & 0.1 & estimated \\
\hline Cornus & 0.076 & calculated & & 0.1 & estimated \\
\hline
\end{tabular}




\begin{tabular}{|c|c|c|c|c|}
\hline Corylus & 0.025 & Gregory 1973 & 1.91 & Soepboer et al. 2007 \\
\hline Crepis-type & 0.059 & calculated & 0.1 & estimated \\
\hline Cyperaceae & 0.035 & $\begin{array}{l}\text { Sugita, Gaillard \& } \\
\text { Broström } 1999\end{array}$ & 0.18 & $\begin{array}{l}\text { Broström, Sugita \& } \\
\text { Gaillard } 2004\end{array}$ \\
\hline Drosera & 0.091 & calculated & 0.1 & estimated \\
\hline Echium & 0.011 & calculated & 0.1 & estimated \\
\hline Empetrum & 0.041 & calculated & 0.2 & estimated \\
\hline Eucalyptus CF & 0.033 & calculated & 0.1 & estimated \\
\hline Fagopyrum & 0.061 & calculated & 0.1 & estimated \\
\hline Fagus & 0.057 & Gregory 1973 & 1.03 & $\begin{array}{l}\text { Matthias, Nielsen \& } \\
\text { Giesecke } 2012\end{array}$ \\
\hline $\begin{array}{l}\text { Fenestrate } \\
\text { undifferentiated }\end{array}$ & 0.053 & calculated & 0.1 & estimated \\
\hline Filipendula & 0.006 & $\begin{array}{l}\text { Broström, Sugita \& } \\
\text { Gaillard } 2004\end{array}$ & 0.44 & $\begin{array}{l}\text { Broström, Sugita \& } \\
\text { Gaillard } 2004\end{array}$ \\
\hline Fothergila major & 0.044 & calculated & 0.1 & estimated \\
\hline Frangula alnus & 0.016 & calculated & 0.1 & estimated \\
\hline Fraxinus & 0.022 & Eisenhut 1961 & 1.19 & $\begin{array}{l}\text { Matthias, Nielsen \& } \\
\text { Giesecke } 2012\end{array}$ \\
\hline Gratiola officinalis & 0.012 & calculated & 0.1 & estimated \\
\hline Hedera helix & 0.07 & calculated & 0.1 & estimated \\
\hline Helianthus & 0.059 & calculated & 0.1 & estimated \\
\hline Helleborus foetidus & 0.022 & calculated & 0.1 & estimated \\
\hline Heracleum-type & 0.07 & calculated & 0.1 & estimated \\
\hline Hordeum-type & 0.06 & calculated & 0.1 & estimated \\
\hline $\begin{array}{l}\text { Hypericum } \\
\text { perforatum-type }\end{array}$ & 0.012 & calculated & 0.1 & estimated \\
\hline $\begin{array}{l}\text { Hypericum } \\
\text { undifferentiated }\end{array}$ & 0.012 & calculated & 0.1 & estimated \\
\hline Ilex & 0.039 & calculated & 0.1 & estimated \\
\hline Jasione & 0.02 & calculated & 0.1 & estimated \\
\hline Juglans & 0.07 & calculated & 0.4 & estimated \\
\hline Juniperus & 0.016 & $\begin{array}{l}\text { Sugita, Gaillard \& } \\
\text { Broström } 1999\end{array}$ & 0.37 & $\begin{array}{l}\text { Sugita, Gaillard \& } \\
\text { Broström } 1999\end{array}$ \\
\hline Lactuca-type & 0.053 & calculated & 0.1 & estimated \\
\hline Larix/Pseudotsuga & 0.126 & Eisenhut 1961 & 1.55 & $\begin{array}{l}\text { Matthias, Nielsen \& } \\
\text { Giesecke } 2012\end{array}$ \\
\hline Lobelia dortmanna & 0.024 & calculated & 0.1 & estimated \\
\hline Marrubium & 0.027 & calculated & 0.1 & estimated \\
\hline Matricaria-type & 0.027 & calculated & 0.1 & estimated \\
\hline Melampyrum & 0.013 & calculated & 0.1 & estimated \\
\hline Mentha-type & 0.033 & calculated & 0.1 & estimated \\
\hline Myrica gale & 0.029 & calculated & 0.4 & estimated \\
\hline Nigella & 0.056 & calculated & 0.1 & estimated \\
\hline Ostyra & 0.031 & calculated & 0.4 & estimated \\
\hline Persicaria amphibia & 0.105 & calculated & 0.1 & estimated \\
\hline Picea & 0.056 & Eisenhut 1961 & 0.28 & $\begin{array}{l}\text { Matthias, Nielsen \& } \\
\text { Giesecke } 2012\end{array}$ \\
\hline
\end{tabular}




\begin{tabular}{|c|c|c|c|c|}
\hline Pinus* & 0.031 & Eisenhut 1961 & 1 & $\begin{array}{l}\text { Matthias, Nielsen \& } \\
\text { Giesecke } 2012\end{array}$ \\
\hline Plantago albicans & 0.029 & calculated & 0.4 & estimated \\
\hline $\begin{array}{l}\text { Plantago cornopus- } \\
\text { type }\end{array}$ & 0.029 & calculated & 0.4 & estimated \\
\hline Plantago lanceolata & 0.029 & $\begin{array}{l}\text { Broström, Sugita \& } \\
\text { Gaillard } 2004\end{array}$ & 0.34 & Soepboer et al. 2007 \\
\hline $\begin{array}{l}\text { Plantago mayor- } \\
\text { media-type }\end{array}$ & 0.029 & calculated & 0.4 & estimated \\
\hline $\begin{array}{l}\text { Plantago } \\
\text { undifferentiated }\end{array}$ & 0.029 & calculated & 0.4 & estimated \\
\hline Poaceae $(<37 \mu \mathrm{m})$ & 0.035 & $\begin{array}{l}\text { Broström, Sugita \& } \\
\text { Gaillard } 2004\end{array}$ & 0.74 & Soepboer et al. 2007 \\
\hline $\begin{array}{l}\text { Polygonum aviculare- } \\
\text { type }\end{array}$ & 0.019 & calculated & 0.1 & estimated \\
\hline $\begin{array}{l}\text { Polygonum } \\
\text { undifferentiated }\end{array}$ & 0.019 & calculated & 0.1 & estimated \\
\hline Populus & 0.025 & Eisenhut 1961 & 0.47 & $\begin{array}{l}\text { Matthias, Nielsen \& } \\
\text { Giesecke } 2012\end{array}$ \\
\hline Potentilla-type & 0.017 & calculated & 0.1 & estimated \\
\hline Primula clusiana-type & 0.012 & calculated & 0.1 & estimated \\
\hline Primula farinosa-type & 0.007 & calculated & 0.1 & estimated \\
\hline Primula veris-group & 0.017 & calculated & 0.1 & estimated \\
\hline Quercus & 0.035 & Eisenhut 1961 & 0.38 & $\begin{array}{l}\text { Matthias, Nielsen \& } \\
\text { Giesecke } 2012\end{array}$ \\
\hline Ranunculus parviflorus & 0.053 & calculated & 0.1 & estimated \\
\hline Ranunculus acris-type & 0.014 & $\begin{array}{l}\text { Broström, Sugita \& } \\
\text { Gaillard } 2004\end{array}$ & 0.68 & $\begin{array}{l}\text { Broström, Sugita \& } \\
\text { Gaillard } 2004\end{array}$ \\
\hline $\begin{array}{l}\text { Ranunculus arvensis- } \\
\text { groupe }\end{array}$ & 0.091 & calculated & 0.1 & estimated \\
\hline Rhamnus-Typ & 0.013 & calculated & 0.1 & estimated \\
\hline $\begin{array}{l}\text { Rubiaceae } \\
\text { undifferentiated }\end{array}$ & 0.019 & Bröström et al. 2004 & 0.7 & estimated \\
\hline Rumex acetosa-type & 0.018 & $\begin{array}{l}\text { Broström, Sugita \& } \\
\text { Gaillard } 2004\end{array}$ & 0.83 & $\begin{array}{l}\text { Broström, Sugita \& } \\
\text { Gaillard } 2004\end{array}$ \\
\hline Rumex acetosella-type & 0.018 & calculated & 0.4 & estimated \\
\hline Salix & 0.022 & Gregory 1973 & 0.22 & $\begin{array}{l}\text { Broström, Sugita \& } \\
\text { Gaillard } 2004\end{array}$ \\
\hline Sambucus & 0.017 & calculated & 0.1 & estimated \\
\hline Saxifraga stellaris-type & 0.01 & calculated & 0.1 & estimated \\
\hline $\begin{array}{l}\text { Saxifraga } \\
\text { undifferentiated }\end{array}$ & 0.027 & calculated & 0.1 & estimated \\
\hline Secale & 0.06 & Gregory 1973 & 0.2 & estimated \\
\hline Senecio-type & 0.031 & calculated & 0.1 & estimated \\
\hline Silene-type & 0.061 & calculated & 0.1 & estimated \\
\hline Solanum dulcamara & 0.006 & calculated & 0.1 & estimated \\
\hline Solanum nigrum-type & 0.022 & calculated & 0.1 & estimated \\
\hline Solidago & 0.031 & calculated & 0.1 & estimated \\
\hline Sorbus-group & 0.037 & calculated & 0.1 & estimated \\
\hline Spergularia-Typ & 0.016 & calculated & 0.1 & estimated \\
\hline Sterculia & 0.051 & calculated & 0.2 & estimated \\
\hline
\end{tabular}




\begin{tabular}{lrl}
\hline Symphytum & 0.022 calculated & 0.1 estimated \\
Taxus CF & 0.017 calculated & 0.4 estimated \\
Thalictrum & 0.013 calculated & 0.2 estimated \\
Tilia cordata & 0.032 Eisenhut 1961 & $0.26 \begin{array}{l}\text { Matthias, Nielsen \& } \\
\text { Giesecke 2012 }\end{array}$ \\
Tilia platyphyllos & 0.032 Eisenhut 1961 & 0.26 Matthias, Nielsen \& \\
Trifolium & 0.048 calculated & 0.1 estimated \\
Triticum-type & 0.06 calculated & 0.1 estimated \\
Ulmus & 0.032 Dyakowska 1936 & 0.4 estimated \\
Urtica & 0.011 calculated & 0.2 estimated \\
Valeriana & 0.076 calculated & 0.1 estimated \\
Viscum & 0.056 calculated & 0.1 estimated \\
Zea mays & 0.148 calculated & 0.1 estimated \\
\hline
\end{tabular}

*Reference taxon

\section{References:}

Broström, A., Sugita, S. \& Gaillard, M.J. (2004) Pollen productivity estimates for reconstruction of past vegetation cover in the cultural landscape of southern Sweden. The Holocene, 14, 371384.

Dyakowska, J. (1936) Research on the rapidity of the falling down of pollen of some trees. Bulletin international de l'Academie polonaise des sciences et des lettres, Classe des Sciences mathematiques et naturelles. Serie B, Sciences naturelles, III, 155-69.

Eisenhut, G. (1961) Untersuchung über die Morphologie und Ökologie der Pollenkörner heimischer und fremdländischer Waldbäume. Paul Parey, Hamburg.

Matthias, I., Nielsen, A.B. \& Giesecke, T. (2012) Evaluating the effect of flowering age and forest structure on pollen productivity estimates. Vegetation History and Archaeobotany, 21, 471484.

Gregory, P.H. (1973) The microbiology of the atmosphere. Leonard Hill, Aylesbury.

Soepboer, W., Sugita. S., Lotter, A.F., Van Leuwen, J.F.N. \& Van der Knaap, W.O. (2007) Pollen productivity estimates for quantitative reconstruction of vegetation cover on the Swiss Plateau. The Holocene, 17, 1-13.

Sugita, S., Gaillard, M.J. \& Broström, A. (1999) Landscape openness and pollen records: A simulation approach. The Holocene, 9, 409-421. 


\section{Chapter 5}

\section{Synthesis}

The outcome of this Ph.D. thesis contributes to a further understanding in the pollen-vegetation relationship. The use of pollen data from small to medium sized lakes in Brandenburg combined with detailed vegetation data has yielded novel insights in pollen dispersal and deposition. The results show how local and regional vegetation is captured in the pollen sample and to what extent pollen assembles are reflecting landscape diversity. These results will help interpreting pollen diagrams and provide for quantitative vegetation reconstructions.

\subsection{Discussion of the main research outcomes}

\section{Influence of flowering age and forest structure on pollen productivity estimates}

The first manuscript (chapter 2 ) in the thesis focuses on pollen productivity estimates (PPE) and evaluates the effect of flowering age and forest structure on PPE calculations. The results demonstrate that for some taxa flowering age and forest structure have a strong influence on PPE calculations, which can be explained by the different autecology of single tree species. Based on the forest inventory data from Brandenburg three different groups could be distinguished. (1) In the cases where taxa are fast growing and reach their flowering age quickly, differences of flowering age and/or forest structure have little influence e.g. for Betula and Alnus trees. (2) The second group consists of taxa that are rarely found in the understory, while their flowering age may directly affect the relationship between pollen and vegetation, examples are Fraxinus and Picea. (3) The third group consists of trees (mainly Fagus and Carpinus) where the abundance in the understory has a larger effect on the relationship between pollen and vegetation than the flowering age. Regional variations in forest structure and age might be a potential reason for differences in previous PPE calculations, e.g. studies that were compared in Broström et al. (2008).

However, understory trees might be also an important component for modelling pollen dispersal (Tauber, 1965). Tauber (1967) suggests that the trunk space component is a significant component of the total pollen deposited at the site. This component is not considered in the applied dispersal model (Prentice, 1985, 1988; Sugita, 1994; Sugita et al., 1999). For the PPE calculation 10 lakes were omitted that were located within high dense Fagus-stands. When considering these lakes, excessive PPEs for Fagus and weak results for other taxa were obtained, indicating that the local abundance of Fagus around the lakes was not adequately considered in the dispersal models. The above-canopy pollen component may not be much influenced by pollen coming from the understory. However, 
understory trees near a lake may contribute much to the total pollen loading at the site through the trunk space flow of pollen (Tauber, 1965).

\section{Relevant source area of pollen}

With $7 \mathrm{~km}$ the relevant source area of pollen (RSAP) is in Brandenburg rather large compared with previous studies that used lakes of similar size, where the RSAP ranges between 0.8 and $2 \mathrm{~km}$ (Nielsen and Sugita, 2005; Soepboer et al., 2007; Hjelle and Sugita, 2012; Poska et al., 2011). RSAP may be affected by vegetation classification (Poska et al., 2011), which was demonstrated for moss polsters and different heath vegetation surveys (Bunting and Hjelle, 2010). However, with or without considering flowering age and/or forest structure in the datasets, the RSAP stay same in all cases. One explanation might be the configuration of vegetation units which may be the same in all situations, and the reduction of trees generally affects their presence less than their abundance. The most likely reason for explaining the large RSAP is the distribution of vegetation types and forest taxa in Brandenburg, which is a well-known factor in controlling the size of the RSAP (Sugita et al., 1999; Bunting et al., 2004; Nielsen and Sugita, 2005; Hellmann et al., 2009). The landscape in Brandenburg is characterised by glacial sediments of the Quaternary, where three geomorphological units (outwash plains, till plains and terminal moraines) dominate the landscape structure and vegetationtype patch size. Whereas the extensive outwash plains are often covered by Pinus, the nutrient-rich till plains are often cleared for agricultural purposes and Fagus-dominated stands often grow on nutrient-rich soils on terminal moraines that are too steep for agricultural use. These vegetation types partly occur over several kilometres or mix with further geomorphological features creating small-scaled vegetation patterns. The vegetation pattern of previous studies that aim to calculate PPE are characterised by much smaller vegetation patchiness and obtained a smaller RSAP (Soepboer et al., 2007; Poska et al., 2011). These results demonstrate the dependency of RSAP on the vegetation patch size (Bunting et al., 2004; Hellman et al., 2009) for the selected lakes and indicate a large effective patch sizes for the Brandenburg region (chapter 2).

\section{Pollen productivity estimates}

The obtained PPEs are in general similar to values that were calculated in earlier studies (Broström et al., 2008). The estimates for Alnus are similar to values that were obtained from lakes (Poska et al., 2011), whereas Alnus PPEs from moss polsters are much smaller (Southern Sweden: Broström et al., 2004; Central Bohemia: Abraham and Kozáková, 2012). This may be a result of the trunk-space component not being adequately represented in the distance weightings. Whereas Alnus is growing close to the lake where a large number of pollen may be carried into the trunk space, or simply drop into the lake, moss polsters from upland vegetation is in general more distant to Alnus trees. PPE 
values for Carpinus agree with results from Switzerland (Soepboer et al., 2007), where Carpinus is a stronger pollen producer than Pinus. In this study it could be demonstrated that PPEs for Carpinus strongly depend on the forest structure.

As mentioned above the transport of Fagus-pollen through the trunk-space has a strong influence at sites within Fagus-dominated forest and might explain high PPEs for Fagus that were obtained in a study conducted in the area just north of Brandenburg (Theuerkauf et al., 2013). However, the here presented PPE for Fagus is similar to the value obtained in southern Sweden, where both Pinus and Fagus are abundant. Also the PPE for Picea is similar to the estimate from southern Sweden. Values of Larix and Pseudotsuga are difficult to interpret, because pollen of both trees cannot be differentiated.

PPE values for Quercus are very low in comparison to most PPE studies (Broström et al., 2008). Similar results have only been obtained for the area of Central Bohemia (Abraham and Kozáková, 2012). The small pollen production might result from Quercus trees in Brandenburg being severely damaged by insects and/or fungi over the last years (Möller et al., 2010). This can cause a complete defoliation of the canopy, influencing its resource allocation and potentially reducing if not stopping the pollen production. An additional fact might be the age structure of Quercus stands in Brandenburg, which is skewed towards younger trees that may not produce the same amount of pollen as older trees. These factors might explain a somewhat lower PPE. The difference compared to the estimates from Switzerland is about threefold and thus difficult to explain by these factors alone. The calculated PPE values for Tilia cordata corresponds well with values for Tilia that were estimated in Southern Sweden (Sugita et al., 1999). Values for Tilia platyphyllos were similar to T. cordata. However, T. platyphyllos is rare in the region and thus the final analysis was restricted to $T$. cordata. The use of PPEs from ERV submodel 3, based on all flowering trees, might be the most appropriate choice for vegetation reconstructions. The best fit for Pinus is reached in the submodel 3 as well as the lowest likelihood function scores, which indicates a general better fit to the data across all taxa (chapter 2).

\section{Pollen accumulation rates and absolute pollen productivity}

The second manuscript (chapter 3 ) and the supplementary material focus on absolute values, using modern pollen accumulation rates (PAR) from lake sediments and the standing volume (SV) of trees surrounding the lakes. The obtained PAR values for single taxa in Brandenburg are higher than values that were obtained from Tauber traps in the Pollen Monitoring Program (Hicks et al., 2001; Giesecke et al., 2010a). The higher values might be explained by lake internal processes, such as sediment focussing, where more sediment is carried into the deepest part of the lake (e.g. Lehman, 1975; Likens and Davis, 1975; Davis et al., 1984). As only one core per lake was taken, this process cannot 
be estimated for the present study. However, it is very unlikely that the sedimentation of all investigated lakes will be affected by this process in the same way. Also no correlation between particular high PAR and lake size or depth are detected in the used dataset. In most lakes redeposition occurs and might explain the attenuation of the ${ }^{137} \mathrm{Cs}$ signal in some cores and is further the reason why the ${ }^{210} \mathrm{~Pb}$ dating of two lakes has failed. However, in four lakes the fallout peak of

${ }^{137}$ Cs suggest little or no redepositions and the PARs of the two time slice showing a strong linear correlation to the tree SV. Unfortunately no pollen deposition obtained in Tauber traps exist for the study region, but e.g. values obtained in Tauber traps from the Draved Forest, Denmark (Andersen, 1974; Nielsen et al., 2010), show PAR for Fagus in a similar range (ca. 10,000 grains $\mathrm{cm}^{-2} \mathrm{a}^{-1}$ ) as obtained for lakes in Brandenburg that are located within a Fagus stand. Thus, reported PAR values in this study seem to represent modern PARs in the north eastern region in Germany, with negligible influence of lake internal processes.

The lower PAR in Fenoscandia (e.g. Giesecke and Fontana, 2008; Seppä et al., 2009; Sugita et al., 2010) and the higher PAR obtained in central Europe e.g. Denmark (Andersen, 1974) and Germany (Theurkauf and Joosten, 2012; and this study) as well as differences in absolute pollen productivity (aPPE) between the obtained values from Sugita et al. (2010) and in this study; might be explained by the influence of the net primary production of the standing biomass and may explain higher pollen productions rates obtained in Brandenburg (this study) compared to northern Scandinavia (Sugita et al., 2010).

\section{Importance of local vegetation and landscape pattern}

The results in the second manuscript (chapter 3) show that site differences in PAR for Pinus, Fagus and Quercus can be explained by the SV within a distance of tens to few hundred metres from the lake shore. The comparisons show further that the goodness of fit between PAR and distanceweighted tree abundance is not improving with distance after the first few hundred metres, and it is even slightly worsening. Best correlations are found for Carpinus, Betula and Fagus in distances of 1$2.5 \mathrm{~km}$, which might be explained by the landscape structure. Forests in Brandenburg are in general restricted to extensive outwash plains that are largely covered by Pinus sometimes accompanied by Quercus trees and to smaller patches of terminal moraines that often dominated by Fagus, occasionally with an admixture of Carpinus and Betula. Especially in case of Fagus a strong relationship occurs between SV in $200 \mathrm{~m}$ and $2 \mathrm{~km}$ around all but two sites.

Nevertheless, the strong correlation of PAR and the close vegetation around the lakes explains a high proportion of variations in PARs between sites, indicating the major importance of the trunk-space component and supports further Tauber's (1965) conceptual model of pollen dispersal and deposition. However, the source area of pollen that explains best site to site variations of the single 
taxa is much smaller than the RSAP, because the vegetation close to the lake shore explains most of PAR site to site variation. Whereas for the RSAP all taxa that are included in the analysis is considered and thus the distance where all the taxa in the vegetation around the site is matters, also taxa that may be far away at some sites.

\section{Extra-local vegetation and large lake}

Not all pollen deposited in the lake are received from close vegetation. The importance of local and regional vegetation is demonstrated by differences of PAR from the Kleiner Treppelsee and Schwarzer See. In both cases the lakes are similar in size and surrounded by the same abundance of Fagus trees within the first $300 \mathrm{~m}$ from the lake, but Fagus PAR in the Schwarzer See is twice the value in the Kleiner Treppelsee, in the latter case Fagus trees are rare in the further region. This indicates that as much as the half of the pollen from the Schwarzer See originates from a distance larger than $300 \mathrm{~m}$.

It is in general assumed that larger lakes receive a smaller contribution of pollen from the close vegetation and thereby have a lower PAR. This is also considered in the dispersal-models (e.g. Prentice, 1985; Sugita et al., 1999), where distant vegetation is strongly down weighted and as no terrestrial pollen is produced on the lake. These models simulate decreasing pollen accumulation with increasing basin size. However, the three large lakes, included in this analysis, show in general a higher PAR per SV (see chapter 3 ) as in the case of Pinus or similar values for Fagus values for the Glabatzsee (2 ha) and Dovinsee (20 ha). Further, the PAR values reported by Davis et al. (1973) show an increasing trend with lake size for lakes that are smaller than $100 \mathrm{ha}$, whereas the PAR of the four larger lakes do not follow this trend. If proportionally less pollen is received in large lakes from the close vegetation, these lakes must receive pollen from the regional vegetation. Tauber (1965) proposed the idea that large lakes with a long wind fetch would receive an absolute higher quantity of pollen from the canopy component. The higher PAR of the three larger lakes in Brandenburg would support this preposition (see detailed discussion in chapter 3 ).

\section{Insight of pollen diversity into landscape diversity and patchiness}

The use of pollen diversity providing insights into landscape diversity and patchiness was discussed in the third manuscript (chapter 4). While exploring the use of different pollen indices results of the Shannon-Index and the rarefaction analysis to a number of $10\left(E\left(T_{10}\right)\right.$ show similar characteristics of the abundance distribution in pollen sample, and differ to palynological richness or to results of rarefaction analysis to high numbers. Therefore $\mathrm{E}\left(\mathrm{T}_{10}\right)$ is used describing pollen diversity.

The results show that pollen diversity is mainly influenced by three factors: local patchiness in one $\mathrm{km}$, regional non-forested area in $7 \mathrm{~km}$ and the relationship between lake perimeter and size. 


\section{Local vegetation and patchiness}

When comparing pollen diversity with the patchiness at different distances, best relationship could be obtained within one $\mathrm{km}$ and decreases with when considering patchiness in large distances. The good correlation between patchiness and pollen diversity for the close distance might be explained by the higher probability to detect pollen from low pollen producing or/and rare taxa. If this would be the case a correlation with pollen richness should be observed, which cannot be observed. The comparison of PAR and the SV show that most pollen originates from local sources. So it might be that the patchiness within a few hundred metres is capturing the diversity aspect, which is related to the pollen diversity.

The ratio lake shore/lake size is strongly correlated to pollen diversity and may function in a similar way as the patchiness parameter, while both are not correlated to each other. A longer shoreline in comparison to the lake size increases the probability of different vegetation bordering the lake and leading to a larger representation of their pollen, although no correlation to pollen richness exist. This parameter should not change much through time at most sites (chapter 4).

\section{Openess}

The comparison of pollen diversity and the landscape structure in chapter 4 show that palynological diversity and richness is strongest influenced by the non-forested area within $7 \mathrm{~km}$. The importance of non-forested area was presented and/or interpreted in earlier studies (e.g. Seppä, 1998; Poska et al., 2004; Berglund et al. 2008; Meltsov et al., 2013). This relationship might be explained by following factors: most trees are higher pollen producers than herbs and hence to detect pollen from herbs has a lower probability to be detected in a forested landscape (Odgaard, 1999). Pollen from herbs have a lower chance of being dispersed fare when the herbs are growing under the canopy rather than in the open (e.g. Andersen, 1970; Tauber, 1977). In Europe the herbaceous flora is richer in taxa than the tree flora.

The non-forested area and the area covered by the dominant tree species Pinus are negatively correlated within a distance of $7 \mathrm{~km}$. The proportion of large homogeneous floristically poor pine forest is described by the 'Pinus cover within $7 \mathrm{~km}$ ' variable. Similar but stronger than the nonforested area, Pinus cover is negatively correlated with diversity of pollen. This circumstance might be the effect of the dominance of a single pollen type in the sample than the reduced floristic diversity of extensive pine monocultures that leads to the good correlation to the diversity of pollen. Goring et al. (2013) have failed to show a correlation between floristic and palynological diversity. One reason for the lacking relationship might be because of the use of low resolution vegetation data, where close vegetation differences cannot be distinguished. 


\section{Insight of wind-pollinated and adjusted pollen representation}

Most abundant taxa in the study area are wind-pollinated taxa. Therefore, the reduction of the dataset to anemophilous pollinated taxa show only little differences for the relationship between landscape factors and pollen diversity and richness. The adjustment of this dataset in the REVEALS model show similar correlations. The reason for only small differences between the original counts and the adjustments might be explained by rather similarly high PPEs for the main tree species, where the pollen production/dispersal bias is similar.

However, the REVEALS adjustments for the full pollen spectrum of the sample show much weaker correlation to the landscape parameters in comparison to the original data. This may be due to large uncertainties in pollen productivity estimates for the rare taxa, where no PPE values are available and high errors in the assessment of the true abundance of rare pollen types in the sample.

\section{Diversity, evenness and palynological richness}

The results of this study show that the presumed pollen production and dispersal bias (Birks and Line, 1992) may not have a strong effect, which might be explained by the importance of the local vegetation (chapter 3; chapter 4). If a low pollen producer is abundant close to the lake, the pollen will be abundant in the sediment. Further, pollen richness seems little influenced by local vegetation patterns and the relationship to the non-forested area, although significant, is not strong. This may be explained by gardens, villages or other land use that was not considered in the analysis. Nevertheless, the smaller but more detailed dataset from Meltsov et al. (2013) show a strong correlation of pollen richness and non-forested area that was increasing with the distance. This led to the idea that pollen richness corresponds to a wider area and the signal of pollen diversity may be driven by more local vegetation pattern.

With the determination of diversity and richness, it is possible to obtain pollen type evenness. Following the concept, that evenness is equal to diversity divided by richness (Hill, 1973; Tuomito, 2012) and using the rarefaction calculations for diversity and richness. Results of this evenness index show significant correlations with lake perimeter/size and number of different polygons. When applying this index on a postglacial pollen diagram (Brande, 1996) the results show with the onset of human land-use that diversity $E\left(T_{10}\right)$ increases slower than richness $E\left(T_{739}\right)$ resulting in a decline in evenness. The low evenness reflects the enhanced human land-use, which seems to be counter intuitive when thinking about the landscape, but the index describes the abundance distribution of pollen types in these samples, showing a large number of rare pollen types (chapter 4). 


\subsection{Future challenges}

In a previous study, it could be demonstrated that the vegetation survey for meadow vegetation has an influence on PPE calculation (Bunting and Hjelle, 1010). Vegetation survey of forest stands might be a more ambitious task, because they are multi-layered and both SV (biomass data) as well as vegetation cover (e.g. canopy, superstructure) can be collected. Therewith, the different vegetation mapping might have a strong influence on PPE calculations similar to the effect of considering flowering age and/or forest structure and a study that focusses on this question may provide a further understanding in regional variations of PPEs or aPPEs for tree taxa.

The possible effect of lake internal processes (such as sediment focussing) on PAR of the obtained lake sediments might be clarified within a future study that monitors the pollen deposition in Tauber traps in the Brandenburg region. Additional, a study that collect and compare all available PARs from lake sediments (e.g. Davis et al., 1973; Koff, 1998) may further reveal a better understanding of the importance of lake size, shore line and the climate influence on pollen accumulation and production. If lake internal processes are not the limiting factor for using PAR as a measurement for quantitative vegetation reconstruction, studies focusing on absolute values might also be helpful in developing and evaluation further dispersal models. Based on the observation within this study the development of a numerical dispersal model that considers the trunk-space component, as proposed in the conceptual model from Tauber (1965) and first attempted in the ad hoc dispersal model from Sjögren et al. (2010), are required to capture the pollen-vegetation relation more precisely.

\subsection{References}

Abraham, V. \& Kozáková, R. (2012): Relative pollen productivity estimates in the modern agricultural landscape of Central Bohemia (Czech Republic). Review of Palaeobotany and Palynology, 179: 1-12.

Andersen, S.T. (1970): The relative pollen productivity and pollen representation of north European trees, and correction factors for tree pollen spectra determined by surface pollen analyses from forests. Danmarks geologiske undersøgelse. Raekke 2, 96: 1-99.

Andersen, S.Th. (1974): Wind conditions and pollen deposition in a mixed deciduous forest. II. Seasonal and annual pollen deposition 1967-1972. Grana, 14: 64-77.

Berglund, B.E., Gaillard, M.-J., Björkman, L. \& Persson, T. (2008): Long-term changes in floristic diversity in southern Sweden: palynological richness, vegetation dynamics and land-use. Vegetation History and Archaeobotany, 17: 573-583.

Birks, H.J.B. \& Line, J.M. (1992): The use of rarefaction analysis for estimating palynological richness from Quaternary pollen-analytical data. The Holocene, 2: 1-10.

Brande, A. (1996): Berlin. In: Berglund, B.E., Birks, H.J.B., Ralska-Jasiewiczowa, M. \& Wright, H.E. (Eds.). Palaeoecological events during the last 15000 years: regional syntheses of palaeoecological studies of lakes and mires in Europe. John Wiley \& Sons, Chichester, pp 518523.

Broström, A., Sugita, S. \& Gaillard, M.-J. (2004): Pollen productivity estimates for reconstruction of past vegetation cover in the cultural landscape of southern Sweden. The Holocene, 14: 371384. 
Broström, A., Nielsen, B., Gaillard, M.-J., Hjelle, K.L., Mazier, F., Binney, H., Bunting, M.J., Fyfe, R., Meltsov, V., Poska, A., Räsänen, S., Soepboer, W., Von Stedingk, H., Suutari, H. \& Sugita, S. (2008): Pollen productivity estimates of key European plant taxa for quantitative reconstruction of past vegetation: a review. Vegetation History and Archaeobotany, 17: 461478.

Bunting, M.J., Gaillard, M.-J., Sugita, S., Middleton, R. \& Broström, A. (2004): Vegetation structure and pollen source area. The Holocene 14: 651-660.

Bunting, M.J. \& Hjelle, K.L. (2010): Effect of vegetation data collection strategies on estimates of relevant source area of pollen (RSAP) and relative pollen productivity estimates (relative PPE) for non-arboreal taxa. Vegetation History and Archaeobotany, 19: 365-374.

Davis, M.B., Brubaker, L.B. \& Webb, T. (1973): Calibration of absolute pollen influx. In: Birks, H.J.B., West, R.G. (Eds.), Quaternary Plant Ecology. Blackwell Scientific Publications, Oxford, pp. 925.

Davis, M.B., Moeller, R.E. \& Ford, J. (1984): Sediment focusing and pollen influx. In: Haworth, E.Y., Lund, J.W.G. (Eds.), Lake Sediments and Environmental History. Univ. Leicester Press, Leicester UK, pp. 261-293.

Giesecke, T. \& Fontana, S.L. (2008): Revisiting pollen accumulation rates from Swedish lake sediments. The Holocene, 18: 293-305.

Giesecke, T., Fontana, S.L., van der Knaap, W.O., Pardoe, H.S. \& Pidek, I.A., (2010): From early pollen trapping experiments to the Pollen Monitoring Programme. Vegetation History and Archaeobotany, 19: 247-258.

Goring, S., Lacourse, T., Pellatt, M.G. \& Mathewes, R.W. (2013): Pollen assemblage richness does not reflect regional plant species richness: a cautionary tale. Journal of Ecology, 101: 1137-1145.

Hellman, S., Gaillard, M.-J., Bunting, M.J. \& Mazier, F. (2009): Estimating the relevant source area of pollen in the past cultural landscapes of southern Sweden-a forward modelling approach. Rev Palaeobot Palynol 153: 259-271.

Hicks, S., Tinsley, H., Huusko, A., Jensen, C., Hattestrand, M., Gerasimides, A. \& Kvavadze, E. (2001): Some comments on spatial variation in arboreal pollen deposition: first records from the Pollen Monitoring Programme (PMP). Review of Palaeobotany and Palynology, 117: 183-194.

Hill, M.O. (1973): Diversity and evenness: a unifying notation and its consequences. Ecology, 54: 427432.

Hjelle, K.L. \& Sugita, S. (2012): Estimating pollen productivity and relevant source area of pollen using lake sediments in Norway: How does lake size variation affect the estimates? The Holocene, 22: 313-324.

Koff, T. (1998): Pollen influx in lake Matsimäe and its catchment. Proceedings of the Estonian Academy of Sciences, Biology and Ecology, 47: 247-258.

Lehman, J.T. (1975): Reconstructing the rate of accumulation of lake sediment: the effect of sediment focusing. Quaternary Research, 5: 541-550.

Likens, G.E. \& Davis, M.B. (1975): Post-glacial History of Mirror Lake and its Watershed in New Hampshire: an Initial Report. In: Mitteilungen Internationale Vereinigung für Theoretische und Angewandte Limnologie, 19, pp. 982-993.

Meltsov, V., Poska, A., Reitlau, T., Sammul, M. \& Kull, T. (2013): The role of landscape structure in determining palynological and floristic richness. Vegetation History and Archaeobotany, 22: 39-49.

Möller K, Heydeck P, Hielscher K, Engelmann A, Wenk M, Schulz P-M, Dahms C, Born B, Dietz H, Braunschweig, A. (2010): Waldschutzbericht 2010. Jahresbericht der Hauptstelle für Waldschutz. Landeskompetenzzentrum Forst Eberswalde. http://forst.brandenburg.de/sixcms/media.php/4055/ws2010.pdf. Accessed: 07.March 2012.

Nielsen, A.B. \& Sugita, S. (2005): Estimating relevant source area of pollen for small Danish lakes around AD 1800. Holocene, 15: 1006-1020.

Nielsen, A.B., Moller, P.F., Giesecke, T., Stavngaard, B., Fontana, S.L. \& Bradshaw, R.H.W. (2010): The effect of climate conditions on inter-annual flowering variability monitored by pollen traps 
below the canopy in Draved Forest, Denmark. Vegetation History and Archaeobotany, 19: 309-323.

Odgaard, B.V. (1999): Fossil pollen as a record of past biodiversity. Journal of Biogeography, 26: 7-17.

Poska, A., Saarse, L. \& Veski, S. (2004): Reflections of pre- and early-agrarian human impact in the pollen diagrams of Estonia. Palaeogeography, Palaeoclimatology, Palaeoecology, 209: 37-50.

Poska, A., Meltsov, V., Sugita, S. \& Vassiljev, J. (2011): Relative pollen productivity estimates of major anemophilous taxa and relevant source area of pollen in a cultural landscape of the hemiboreal forest zone (Estonia). Review of Palaeobotany and Palynolnology, 167: 30-39.

Prentice, I.C. (1985): Pollen representation, source area, and basin size: toward a unified theory of pollen analysis. Quaternary Research, 23: 76-86.

Prentice, I.C. (1988): Records of vegetation in time and space: the principles of pollen analysis. In: Huntley B, Webb TIII (Eds.) Vegetation History. Kluwer, Dordrecht, pp 17-42.

Seppä, H. (1998): Postglacial trends in palynological richness in the northern Fennoscandian tree-line area and their ecological interpretation. The Holocene, 8: 43-53.

Seppä, H., Alenius, T., Muukkonen, P., Giesecke, T., Miller, P.A. \& Ojala, A.E.K. (2009): Calibrated pollen accumulation rates as a basis for quantitative tree biomass reconstructions. The Holocene, 19: 209-220.

Sjögren, P., Connor, S.E. \& van der Knaap, W.O. (2010): The development of composite pollendispersal functions for estimating absolute pollen productivity in the Swiss Alps. Vegetation History and Archaeobotany, 19: 341-349.

Soepboer, W., Sugita, S., Lotter, A.F., Van Leuwen, J.F.N. \& Van der Knaap, W.O. (2007): Pollen productivity estimates for quantitative reconstruction of vegetation cover on the Swiss Plateau. The Holocene, 17: 1-13.

Sugita, S. (1994): Pollen representation of vegetation in quaternary sediments: theory and method in patchy vegetation. Journal of Ecology, 82: 881-897.

Sugita, S., Gaillard, M.J. \& Broström, A. (1999): Landscape openness and pollen records: A simulation approach. The Holocene, 9: 409-421.

Sugita, S., Hicks, S. \& Sormunen, H., (2010): Absolute pollen productivity and pollen-vegetation relationships in northern Finland. Journal of Quaternary Science, 25: 724-736.

Tauber, H. (1965): Differential pollen dispersion and the interpretation of pollen diagrams. Danmarks Geologiske Undersogelse, 89: 1-69.

Tauber, H. (1967): Investigations of the mode of pollen transfer in forested areas. Review of Palaeobotany and Palynology, 3:277-286.

Tauber, H. (1977): Investigations of aerial pollen transport in a forested area. Dansk Botanisk Arkiv, 32: 1-221.

Theuerkauf, M. \& Joosten, H. (2012): Younger Dryas cold stage vegetation patterns of central Europe - climate, soil and relief controls. Boreas, 41: 391-407.

Theuerkauf, M., Kuparinen, M. \& H. Joosten (2013): Pollen productivity estimates strongly depend on assumed pollen dispersal. The Holocene, 23: 14-24.

Tuomisto, H. (2012): An updated consumer's guide to evenness and related indices. Oikos, 121: $1203-1218$. 
Appendix I

\section{Brandenburg Lake Dating Project}




\title{
Brandenburg Lake Dating Project
}

\section{PART I}

(May 2011)

\author{
From P.G. Appleby and G.T. Piliposian \\ Environmental Radioactivity Research Centre \\ University of Liverpool
}

\section{Work Program}

Dating by ${ }^{210} \mathrm{~Pb}$ and ${ }^{137} \mathrm{Cs}$ was carried out on sediment cores from 15 lakes in Brandenburg, eastern Germany, as listed below:

$\begin{array}{ll}\text { See } 23 & \text { Kleiner Treppelsee } \\ \text { See } 67 & \text { Kesselsee } \\ \text { See 71 } & \text { Schwarzersee } \\ \text { See } 72 & \text { Heiligensee } \\ \text { See 76 } & \text { Teufelssee } \\ \text { See 79 } & \text { Glabatzsee } \\ \text { See } 81 & \text { Kleiner Lychensee } \\ \text { See } 86 & \text { Baasee } \\ \text { See } 89 & \text { Großsee } \\ \text { See 90 } & \text { Ziskensee } \\ \text { See } 94 & \text { Schiebelsee } \\ \text { See } 97 & \text { Bugsee } \\ \text { See 102 } & \text { Piechesee } \\ \text { See } 108 & \text { Aalgastsee } \\ \text { See } 111 & \text { Papensee }\end{array}$

$\begin{array}{cc}\text { Latitude } & \begin{array}{c}\text { Longitude } \\ 52^{\circ} 44^{\prime} 55^{\prime \prime} \mathrm{N}\end{array} \\ 14^{\circ} 03^{\prime} 28^{\prime \prime} \mathrm{E} \\ 52^{\circ} 31^{\prime} 48^{\prime \prime} \mathrm{N} & 14^{\circ} 04^{\prime} 51^{\prime \prime} \mathrm{E} \\ 52^{\circ} 59^{\prime} 42^{\prime \prime} \mathrm{N} & 13^{\circ} 54^{\prime} 15^{\prime \prime} \mathrm{E} \\ 53^{\circ} 00^{\prime} 57^{\prime \prime} \mathrm{N} & 13^{\circ} 52^{\prime} 21^{\prime \prime} \mathrm{E} \\ 53^{\circ} 01^{\prime} 14^{\prime \prime} \mathrm{N} & 12^{\circ} 49^{\prime} 40^{\prime \prime} \mathrm{E} \\ 53^{\circ} 08^{\prime} 11^{\prime \prime} \mathrm{N} & 12^{\circ} 58^{\prime} 28^{\prime \prime} \mathrm{E} \\ 53^{\circ} 11^{\prime} 47^{\prime \prime} \mathrm{N} & 13^{\circ} 16^{\prime} 13^{\prime \prime} \mathrm{E} \\ 52^{\circ} 44^{\prime} 36^{\prime \prime} \mathrm{N} & 14^{\circ} 01^{\prime} 34^{\prime \prime} \mathrm{E} \\ 51^{\circ} 55^{\prime} 58^{\prime \prime} \mathrm{N} & 14^{\circ} 28^{\prime} 18^{\prime \prime} \mathrm{E} \\ 52^{\circ} 06^{\prime} 21^{\prime \prime} \mathrm{N} & 14^{\circ} 28^{\prime} 12^{\prime \prime} \mathrm{E} \\ 52^{\circ} 44^{\prime} 55^{\prime \prime} \mathrm{N} & 14^{\circ} 03^{\prime} 28^{\prime \prime} \mathrm{E} \\ 53^{\circ} 11^{\prime} 31^{\prime \prime} \mathrm{N} & 13^{\circ} 54^{\prime} 33^{\prime \prime} \mathrm{E} \\ 52^{\circ} 39^{\prime} 36^{\prime \prime} \mathrm{N} & 13^{\circ} 55^{\prime} 16^{\prime \prime} \mathrm{E} \\ 53^{\circ} 08^{\prime} 21^{\prime \prime} \mathrm{N} & 13^{\circ} 54^{\prime} 19^{\prime \prime} \mathrm{E} \\ 52^{\circ} 54^{\prime} 52^{\prime \prime} \mathrm{N} & 13^{\circ} 14^{\prime} 18^{\prime \prime} \mathrm{E}\end{array}$

\section{Methods}

Sub-samples from each core were analysed for ${ }^{210} \mathrm{~Pb},{ }^{226} \mathrm{Ra}$, and ${ }^{137} \mathrm{Cs}$ by direct gamma assay in the Liverpool University Environmental Radioactivity Laboratory, using an Ortec HPGe GMX series coaxial low background intrinsic germanium detector (Appleby et al., 1986). ${ }^{210} \mathrm{~Pb}$ was determined via its gamma emissions at $46.5 \mathrm{keV}$, and ${ }^{226} \mathrm{Ra}$ by the $295 \mathrm{keV}$ and $352 \mathrm{keV} \gamma$-rays emitted by its daughter radionuclide ${ }^{214} \mathrm{~Pb}$ following 3 weeks storage in sealed containers to allow radioactive equilibration. ${ }^{137} \mathrm{Cs}$ was measured by its emissions at $662 \mathrm{keV}$. The absolute efficiencies of the detectors were determined using calibrated sources and sediment samples of known activity. Corrections were made for the effect of self absorption of low energy $\gamma$-rays within the sample (Appleby et al., 1992).

\section{Results}

The results of the radiometric analyses carried out on each core are given in Tables 1-15 and shown graphically in Figures $1 . i-15$.i. Supported ${ }^{210} \mathrm{~Pb}$ activity was assumed to be equal to the measured ${ }^{226} \mathrm{Ra}$ activity, and unsupported ${ }^{210} \mathrm{~Pb}$ activity calculated by subtracting supported ${ }^{210} \mathrm{~Pb}$ from the measured total ${ }^{210} \mathrm{~Pb}$ activity. Table 16 summarises a number of key radiometric parameters for each core, including the maximum ${ }^{210} \mathrm{~Pb}$ concentration, the radiometric inventories, and the ${ }^{210} \mathrm{~Pb}$ flux. Although most cores did not penetrate to the full depth at which total ${ }^{210} \mathrm{~Pb}$ activity reaches equilibrium with the supporting ${ }^{226} \mathrm{Ra}\left(\sim 6{ }^{210} \mathrm{~Pb}\right.$ half-lives), in most cases reliable estimates of the missing unsupported ${ }^{210} \mathrm{~Pb}$ inventory were possible, allowing calculation of radiometric dates using the $\mathrm{CRS}^{210} \mathrm{~Pb}$ dating model (Appleby and Oldfield, 1978). Use of the alternative CIC dating model was 
in most cases being precluded by irregularities in the ${ }^{210} \mathrm{~Pb}$ records, or by obvious discrepancies with the ${ }^{137}$ Cs dates.

Chronostratigraphic dates were determined where possible from the ${ }^{137} \mathrm{Cs}$ records. Four of the cores (Sees 72, 81, 97 and 108) had well defined peaks identifying fallout from the 1986 Chernobyl accident and the 1963 fallout maximum from the atmospheric nuclear weapons tests. At other sites the ${ }^{137} \mathrm{Cs}$ records were less distinct, though in most cases it was possible to make reasonable estimates of at least one of these dates. Where there were reasonably well defined ${ }^{137} \mathrm{Cs}$ dates, and significant discrepancies with the raw CRS model ${ }^{210} \mathrm{~Pb}$ dates, corrections to the ${ }^{210} \mathrm{~Pb}$ dates were calculated using the ${ }^{137} \mathrm{Cs}$ dates as reference points (Appleby, 2001). Such discrepancies are caused by variations in the ${ }^{210} \mathrm{~Pb}$ supply rate at the core site due to local factors such as changes in the pattern of sedimentation, sediment slumps, or catchment disturbances. In most cases these discrepancies were however relatively small. Definitive chronologies for each core based on an assessment of all the relevant radiometric data are shown in Figures 1.ii-15.ii and given in detail in Tables 17-31.

\section{Kleiner Treppelsee (Brandenburg See 23)}

Lead-210 Activity

The base of this core fell somewhat short of the ${ }^{210} \mathrm{~Pb} /{ }^{226} \mathrm{Ra}$ equilibrium depth, limiting the period of time spanned by the core to no more than around three ${ }^{210} \mathrm{~Pb}$ half-lives ( 70 years). Unsupported ${ }^{210} \mathrm{~Pb}$ concentrations (Figure 1.i(b)) varied irregularly with depth suggesting some fluctuations in the sedimentation rate, though since the overall trend is more or less exponential there does not appear to have been any systematic change during the period of time spanned by the core.

\section{Artificial Fallout Radionuclides}

${ }^{137}$ Cs concentrations (Figure 1.i(c)), were relatively low and without a well defined maximum value. The steep increase in concentrations above $\sim 25 \mathrm{~cm}$ may record the increasing levels of fallout in the late $1950 \mathrm{~s}$ from the atmospheric testing of nuclear weapons, and the initial peak at $18.5 \mathrm{~cm}$ the 1963 fallout maximum. Relatively high concentrations at around $12.5 \mathrm{~cm}$ may record fallout from the 1986 Chernobyl accident, though the record is not clear.

\section{Core Chronology}

Although dates calculated using the standard ${ }^{210} \mathrm{~Pb}$ models are both problematic, the $\mathrm{CIC}$ model because of irregular variations in the ${ }^{210} \mathrm{~Pb}$ activity versus depth and the CRS model because of the incomplete ${ }^{210} \mathrm{~Pb}$ record, both suggest a relatively uniform sedimentation rate, particularly during the past 50 years with a mean value for this period of $0.042 \mathrm{~g} \mathrm{~cm}^{-2} \mathrm{y}^{-1}\left(0.46 \mathrm{~cm} \mathrm{y}^{-1}\right)$. This accumulation rate would place 1963 at a depth of around $20.5 \mathrm{~cm}$ and 1986 at around $11.5 \mathrm{~cm}$, in relatively good agreement with the depths suggested by the ${ }^{137} \mathrm{Cs}$ record. Both ${ }^{210} \mathrm{~Pb}$ models also suggest a slightly lower sedimentation rate in the years before 1960. The best estimate for the mean sedimentation rate during this period is $0.034 \mathrm{~g} \mathrm{~cm}^{-2} \mathrm{y}^{-1}\left(0.31 \mathrm{~cm} \mathrm{y}^{-1}\right)$, dating the base of the core at $29 \mathrm{~cm}$ to the late 1930s. A detailed chronology based on these results is shown in Figure 1.ii and given in detail in Table 17.

\section{Kesselsee (Brandenburg See 67)}

\section{Lead-210 Activity}

This core too did not quite reach the ${ }^{210} \mathrm{~Pb} /{ }^{226} \mathrm{Ra}$ equilibrium depth, total ${ }^{210} \mathrm{~Pb}$ activity significantly exceeding that of the supporting ${ }^{226} \mathrm{Ra}$ in all samples down to the base of the core at $40 \mathrm{~cm}$ (Figure 2.i(a)). Unsupported ${ }^{210} \mathrm{~Pb}$ activity (Figure $2 . i(b)$ ) was relatively constant in the top $15 \mathrm{~cm}$, but below this declined more or less exponentially with depth suggesting relatively uniform sedimentation during the period of time spanned by sediments below $15 \mathrm{~cm}$. There are two possible explanations for the uniform activity in the top $15 \mathrm{~cm}$ of the core, mixing of the near surface sediments by physical or biological processes, or a recent acceleration in the sedimentation rate. 


\section{Artificial Fallout Radionuclides}

${ }^{137} \mathrm{Cs}$ activity too is relatively uniform in the upper part of the core, in this case down to a depth of around $25 \mathrm{~cm}$ (Figure 2.i(c)). There are again two possible explanations, extensive mixing of the near surface sediments, or continued inputs of ${ }^{137} \mathrm{Cs}$ e.g. by soil erosion from the catchment. Assuming that the profile is a true record of ${ }^{137} \mathrm{Cs}$ inputs, the steep increase in concentrations above $\sim 30 \mathrm{~cm}$ may record the increasing levels of fallout in the late 1950s from the atmospheric testing of nuclear weapons. This would place 1963, the year of maximum fallout, at a depth of around $25 \mathrm{~cm}$.

\section{Core Chronology}

${ }^{210} \mathrm{~Pb}$ dates calculated using the CRS model place 1963 at a depth of $25 \mathrm{~cm}$, in good agreement with the value suggested by the ${ }^{137} \mathrm{Cs}$ record. Since extensive mixing would make this level of agreement unlikely, we suppose that the ${ }^{210} \mathrm{~Pb}$ profile is a true record, and that the CRS model dates are reliable. The results of the ${ }^{210} \mathrm{~Pb}$ calculations, shown in Figure 2.ii and given in detail in Table 18, suggest a relatively uniform sedimentation from the late $19^{\text {th }}$ century through to the mid 1950 s, with a mean value for this period of $0.015 \mathrm{~g} \mathrm{~cm}^{-2} \mathrm{y}^{-1}\left(0.22 \mathrm{~cm} \mathrm{y}^{-1}\right)$. During the next 40 years, up to around 1990, there was a small increase to a value of around $0.021 \mathrm{~g} \mathrm{~cm}^{-2} \mathrm{y}^{-1}\left(0.40 \mathrm{~cm} \mathrm{y}^{-1}\right)$. This was followed by a more rapid increase during the past decade to a contemporary value of more than $0.040 \mathrm{~g} \mathrm{~cm}^{-2} \mathrm{y}^{-1}$ $\left(1.1 \mathrm{~cm} \mathrm{y}^{-1}\right)$. The much greater rise in the volumetric accumulation rate $\left(\mathrm{cm} \mathrm{y}^{-1}\right)$ is largely due to the greatly reduced dry bulk density of the near surface sediments.

\section{Schwarzersee (Brandenburg See 71)}

\section{Lead-210 Activity}

Total ${ }^{210} \mathrm{~Pb}$ activity effectively reaches equilibrium with the supporting ${ }^{226} \mathrm{Ra}$ at the base of the core, at a depth of around $42 \mathrm{~cm}$ (Figure $3 . \mathrm{i}(\mathrm{a})$ )). The unsupported ${ }^{210} \mathrm{~Pb}$ profile (Figure $3 . \mathrm{i}(\mathrm{b})$ ) is similar to that in See 67 with an upper zone of relatively uniform activity extending in this case to a depth of around $13 \mathrm{~cm}$, and a deeper zone in which it declines more or less exponentially with depth apart from a small non-monotonic feature between $20-25 \mathrm{~cm}$.

\section{Artificial Fallout Radionuclides}

${ }^{137} \mathrm{Cs}$ concentrations were relatively uniform in the uppermost $13 \mathrm{~cm}$ (Figure $3 . \mathrm{i}(\mathrm{c})$ ), but below this declined steeply with depth. The high maximum concentration and inventory (Table 16) suggest that this core may have been significantly impacted by fallout from the 1986 Chernobyl accident. Assuming this to be the case, sediments above $13 \mathrm{~cm}$, the depth at which concentrations reached their highest level, will all post-date 1986. There is no clear record of the 1963 nuclear weapons fallout maximum, possibly because it has been masked by down-core migration of the Chernobyl ${ }^{137}$ Cs.

\section{Core Chronology}

${ }^{210} \mathrm{~Pb}$ dates calculated using the CRS model place 1986 at a depth of $12 \mathrm{~cm}$, supporting the suggestion that the high ${ }^{137} \mathrm{Cs}$ concentrations in this core are a record of Chernobyl fallout. The results, shown in Figure 3.ii and given in detail in Table 19, suggest relatively uniform sedimentation from the late $19^{\text {th }}$ century through to around 1980, apart from a brief episode of rapid accumulation in the late 1950s. The mean sedimentation rate excluding this event was $0.014 \mathrm{~g} \mathrm{~cm}^{-2} \mathrm{y}^{-1}\left(0.20 \mathrm{~cm} \mathrm{y}^{-1}\right.$ in the older more compacted sediments, increasing to $0.30 \mathrm{~cm} \mathrm{y}^{-1}$ in the more recent less compacted sediments). Since the mid-1980s there appears to have been a more sustained increase in the sedimentation rate, resulting in a present day value of around $0.030 \mathrm{~g} \mathrm{~cm}^{-2} \mathrm{y}^{-1}\left(0.90 \mathrm{~cm} \mathrm{y}^{-1}\right)$. The ${ }^{210} \mathrm{~Pb}$ dates place 1963 at a depth of $18 \mathrm{~cm}$. The only indication that these sediments might record the weapons fallout maximum is a small rise in the ${ }^{137} \mathrm{Cs} /{ }^{210} \mathrm{~Pb}$ activity ratio at around this depth.

\section{Heiligensee (Brandenburg See 72)}

\section{Lead-210 Activity}

Total ${ }^{210} \mathrm{~Pb}$ activity at the base of this core $(34 \mathrm{~cm}$, Figure $4 . i(\mathrm{a}))$ was still significantly higher than that of the supporting ${ }^{226} \mathrm{Ra}$, limiting the chronology by around one ${ }^{210} \mathrm{~Pb}$ half-life (22 years). Unsupported ${ }^{210} \mathrm{~Pb}$ concentrations declined irregularly with depth (Figure 4.i(b)). The maximum concentration 
occurred significantly below the surface of the core at a depth of $4.5 \mathrm{~cm}$, and there were significant non-monotonic features, at $11.5 \mathrm{~cm}, 17.6 \mathrm{~cm}$ and $24.5 \mathrm{~cm}$, suggesting several episodes of rapid accumulation due e.g. to sediment slumps or catchment disturbances. The features at $11.5 \mathrm{~cm}$ and $24.5 \mathrm{~cm}$ coincide with layers of dense sediment.

\section{Artificial Fallout Radionuclides}

The ${ }^{137} \mathrm{Cs}$ activity versus depth profile (Figure 4.i(c)) has two well defined peaks, at $9.5 \mathrm{~cm}$ and 19.5 $\mathrm{cm}$. The more recent peak almost certainly records fallout from the 1986 Chernobyl accident. Evidence that the earlier peak records the 1963 fallout maximum from the atmospheric testing of nuclear weapons is supported by the presence of a small peak in ${ }^{241} \mathrm{Am}$ concentrations at the same depth (Appleby et al., 1991).

\section{Core Chronology}

The raw CRS model ${ }^{210} \mathrm{~Pb}$ dates place 1986 at a depth of $9 \mathrm{~cm}$ and 1963 at a depth of $18.5 \mathrm{~cm}$, in good agreement with the depths suggested by the ${ }^{137} \mathrm{Cs} /{ }^{241} \mathrm{Am}$ record. These suggest a relatively uniform sedimentation rate of $0.069 \mathrm{~g} \mathrm{~cm}^{-2} \mathrm{y}^{-1}\left(0.35 \mathrm{~cm} \mathrm{y}^{-1}\right)$ punctuated by brief episodes of rapid accumulation in the early 1980s, late 1960 s and late 1940 s or early 1950 s. Small corrections to the ${ }^{210} \mathrm{~Pb}$ dates were made using the ${ }^{137} \mathrm{Cs} /{ }^{241} \mathrm{Am}$ dates as reference points (Appleby, 2001). The result of these are shown in Figure 4.ii and given in detail in Table 20.

\section{Teufelssee (Brandenburg See 76)}

\section{Lead-210 Activity}

Total ${ }^{210} \mathrm{~Pb}$ activity effectively reaches equilibrium with the supporting ${ }^{226} \mathrm{Ra}$ at a depth of around 30 $\mathrm{cm}$ (Figure 5.i(a)). Unsupported ${ }^{210} \mathrm{~Pb}$ concentrations (Figure $5 . \mathrm{i}(\mathrm{b})$ ) vary irregularly with depth with a major non-monotonic feature between $14-20 \mathrm{~cm}$ that may record a significant episode of rapid accumulation.

\section{Artificial Fallout Radionuclides}

${ }^{137} \mathrm{Cs}$ activity has a well defined peak at $9.5 \mathrm{~cm}$ (Figure $5 . \mathrm{i}(\mathrm{c})$ ). The low activity and presence of traces of ${ }^{241} \mathrm{Am}$ at the same depth suggest that this feature records the 1963 fallout maximum from the atmospheric testing of nuclear weapons.

\section{Core Chronology}

${ }^{210} \mathrm{~Pb}$ dates calculated using the CRS model place 1963 at a depth of around $11 \mathrm{~cm}$, a little below the

${ }^{137} \mathrm{Cs}$ peak but sufficiently close to support the suggestion that this feature records the 1963 fallout maximum. Two possible causes of such a discrepancy are a recent reduction in the ${ }^{210} \mathrm{~Pb}$ supply rate to the sediments, or loss of a small amount of sediment from the top of the core shortly before or during coring, though neither of these is supported by other data. The more or less exponential ${ }^{210} \mathrm{~Pb}$ activity versus depth relationship in the top $13 \mathrm{~cm}$ of the core suggests relatively uniform accumulation in recent decades and appears to preclude significant changes in the ${ }^{210} \mathrm{~Pb}$ supply rate. Further, a count of the number of laminations detected in post-1963 sections (the top $10 \mathrm{~cm}$ ) appears to rule out the possibility a significant loss of sediment from the top of the core. Making reasonable estimates for those sections $(0-1 \mathrm{~cm}$ and $8-9 \mathrm{~cm})$ where the laminae were not distinct, the top $10 \mathrm{~cm}$ of the core (spanning 46 years) is estimated to contain around 44 laminae. It thus appears that the laminae are annual and the core substantially intact. Estimates of the number of laminae contained within the top $13 \mathrm{~cm}$ of the core date the onset of the period of relatively uniform accumulation spanned by this section of the core to around $1946 .{ }^{210} \mathrm{~Pb}$ calculations using this date as a reference point confirm that during this period there were no major changes in the sedimentation rate. Calculations using the 1963 date as a reference point give a similar result. In view of this the most reliable method for calculating post-1946 dates is to determine them from the mean sedimentation rate for this period of $0.033 \mathrm{~g} \mathrm{~cm}^{-2} \mathrm{y}^{-1}\left(0.21 \mathrm{~cm} \mathrm{y}^{-1}\right)$. Dates of the pre-1946 sediments are more problematic. The non-monotonic feature in the ${ }^{210} \mathrm{~Pb}$ record between $14-20 \mathrm{~cm}$ almost certainly records a brief episode of rapid accumulation that in the 18-19 $\mathrm{cm}$ section diluted the fallout ${ }^{210} \mathrm{~Pb}$ concentration to values close to the limit of detection. In the absence of further 
chronostratigraphic evidence, dates for this part of the core have been based on calculations using the CRS model. These date the episode of rapid accumulation to around 1930, and also suggest that sedimentation rates prior to this event were comparable to those in recent decades. Dates based on all these considerations are shown in Figure 5.ii and given in detail in Table 21.

\section{Glabatzsee (Brandenburg See 79)}

\section{Lead-210 Activity}

The ${ }^{210} \mathrm{~Pb} /{ }^{226} \mathrm{Ra}$ equilibrium depth appears to be a little below the base of the core, at a depth of around $42 \mathrm{~cm}$ (Figure 6.i(a)). Unsupported ${ }^{210} \mathrm{~Pb}$ concentrations (Figure 6.i(b)) have a maximum value below the surface of the core, at a depth of $4.5 \mathrm{~cm}$, and thereafter decline only slightly down to a depth of around $15 \mathrm{~cm}$. Below this the decline is much steeper and more or less exponential. These results suggest a relatively uniform sedimentation rate at least in the older sections of the core. The reduced gradient in the upper sections could be due to mixing, or to a recent increase in the sedimentation rate.

\section{Artificial Fallout Radionuclides}

${ }^{137} \mathrm{Cs}$ concentrations rise steeply above a depth of around $20 \mathrm{~cm}$ and reach a small peak at $12.5 \mathrm{~cm}$ depth (Figure 6.i(c)). Above the peak relatively high ${ }^{137} \mathrm{Cs}$ concentrations are sustained right through to the top of the core. Although the relatively modest ${ }^{137} \mathrm{Cs}$ concentrations and inventory suggest that this peak could record the 1963 fallout maximum from the atmospheric testing of nuclear weapons, because of its relative proximity to the top of the core it could equally well record fallout from the 1986 Chernobyl accident.

\section{Core Chronology}

Raw CRS model dates place 1986 at a depth of around $11 \mathrm{~cm}$ and 1963 at a depth of around $17 \mathrm{~cm}$. Assuming the ${ }^{210} \mathrm{~Pb}$ dates to be reasonably accurate it appears that the ${ }^{137} \mathrm{Cs}$ peak at $12.5 \mathrm{~cm}$ probably records fallout from the 1986 Chernobyl accident, though in view of the uncertainty in the provenance of this feature it is probably safer to base the chronology on the ${ }^{210} \mathrm{~Pb}$ dates alone. These result, shown in Figure 6.ii and given in detail in Table 22, indicate a relatively uniform sedimentation rate from the latter part of the $19^{\text {th }}$ century through to the early 1980 s with a mean value during this period of $0.015 \mathrm{~g} \mathrm{~cm}^{-2} \mathrm{y}^{-1}\left(0.27 \mathrm{~cm} \mathrm{y}^{-1}\right)$. Since then there appears to have been a small increase to a present day value of more than $0.020 \mathrm{~g} \mathrm{~cm}^{-2} \mathrm{y}^{-1}\left(0.60 \mathrm{~cm} \mathrm{y}^{-1}\right)$.

\section{Kleiner Lychensee (Brandenburg See 81)}

\section{Lead-210 Activity}

Total ${ }^{210} \mathrm{~Pb}$ activity reaches equilibrium with the supporting ${ }^{226} \mathrm{Ra}$ at a depth significantly greater than that the base of the core (Figure 7.i(a)), limiting the chronology by around two ${ }^{210} \mathrm{~Pb}$ half-lives (44 years). Although there are some small irregularities in the unsupported ${ }^{210} \mathrm{~Pb}$ activity versus depth profile (Figure 7.i(b)), since the overall decline is more or less exponential there does not appear to have been any significant systematic change in the sedimentation rate though there may have been some short-term fluctuations.

\section{Artificial Fallout Radionuclides}

The ${ }^{137} \mathrm{Cs}$ activity versus depth profile (Figure 7.i(c)) has two well defined peaks, at $10.5 \mathrm{~cm}$ and 18.5 $\mathrm{cm}$. The more recent peak almost certainly records fallout from the 1986 Chernobyl accident. Evidence that the earlier peak records the 1963 fallout maximum from the atmospheric testing of nuclear weapons is supported by the presence of a small peak in ${ }^{241} \mathrm{Am}$ concentrations at the same depth (Appleby et al., 1991).

\section{Core Chronology}

The raw CRS model ${ }^{210} \mathrm{~Pb}$ dates place 1986 at a depth of $11.5 \mathrm{~cm}$ and 1963 at $19.5 \mathrm{~cm}$, in good agreement with the depths suggested by the ${ }^{137} \mathrm{Cs}$ record. Revised dates incorporating a small correction using the ${ }^{137} \mathrm{Cs} /{ }^{241} \mathrm{Am}$ dates as reference points (Appleby, 2001) are shown in Figure 7.ii and given in detail in Table 23. These indicate a relatively uniform sedimentation rate since the latter 
part of the $19^{\text {th }}$ century with a mean value during this period of $0.015 \mathrm{~g} \mathrm{~cm}^{-2} \mathrm{y}^{-1}\left(0.35 \mathrm{~cm} \mathrm{y}^{-1}\right)$, though with some fluctuations and a slightly higher value in the second half of the $20^{\text {th }}$ century.

\section{Baasee (Brandenburg See 86)}

\section{Lead-210 Activity}

This core appears to have an incomplete record spanning no more than a few decades. Total ${ }^{210} \mathrm{~Pb}$ activity in the deepest sample is well in excess of the supporting ${ }^{226} \mathrm{Ra}$ (Figure $8 . \mathrm{i}(\mathrm{a})$ ), severely compromising use of the CRS dating model. Further, the unsupported ${ }^{210} \mathrm{~Pb}$ activity versus depth profile (Figure 8.i(b)) is quite irregular, precluding use of the $\mathrm{CIC}$ model. Concentrations decline slowly but regularly in the top $27 \mathrm{~cm}$ of the core, but beneath this decline steeply before stabilising again in the section between $34-42 \mathrm{~cm}$.

\section{Artificial Fallout Radionuclides}

${ }^{137}$ Cs concentrations follow a similar pattern (Figure 8.i(c)), remaining virtually constant in the top 27 $\mathrm{cm}$ but then declining steeply in the deeper sections. The high concentrations and high inventory (Table 16) in the top $27 \mathrm{~cm}$ suggest that these sediments have been severely impacted by Chernobyl fallout. The relatively high residual concentrations in the basal sample further suggest that the entire core post-dates the late 1950 s period of high fallout from the atmospheric testing of nuclear weapons.

\section{Core Chronology}

The gradient of the top $27 \mathrm{~cm}$ of the unsupported ${ }^{210} \mathrm{~Pb}$ profile suggests that this section of the core spans no more than $2-3{ }^{210} \mathrm{~Pb}$ half-lives, supporting the inference from the ${ }^{137} \mathrm{Cs}$ record that these sediments all post-date 1986 . Figure 8 .ii shows a tentative ${ }^{210} \mathrm{~Pb}$ chronology calculating by assuming reference dates of 1986 for sediments at $27 \mathrm{~cm}$ depth and 1955 for sediments at $42 \mathrm{~cm}$ depth. Given the problematic nature of the record the results, given in detail in Table 24, should not however be regarded with any certainty unless supported by other evidence.

\section{Großsee (Brandenburg See 89)}

Lead-210 Activity

Total ${ }^{210} \mathrm{~Pb}$ activity reaches equilibrium with the supporting ${ }^{226} \mathrm{Ra}$ at a depth of around $37 \mathrm{~cm}$ (Figure 9.i(a)). Unsupported ${ }^{210} \mathrm{~Pb}$ is almost constant in the top $11 \mathrm{~cm}$ of the core but thereafter decreases with depth in a more regular way though with an increasingly steep gradient (Figure 9.i(b)). These results suggest a steadily increasing sedimentation rate during the period of more than 100 years spanned by the ${ }^{210} \mathrm{~Pb}$ record.

\section{Artificial Fallout Radionuclides}

The ${ }^{137} \mathrm{Cs}$ activity versus depth profile (Figure 9.i(c)) has a broad double peak between 8-14 cm. The high concentrations in the peak suggest that this feature records fallout from the 1986 Chernobyl accident, though the absence of a second deeper peak identifying the 1963 fallout maximum make this attribution uncertain.

\section{Core Chronology}

${ }^{210} \mathrm{~Pb}$ dates calculated using the CRS model dates place 1963 at a depth of around $18 \mathrm{~cm}$ and 1986 at $12.5 \mathrm{~cm}$, suggesting that the ${ }^{137} \mathrm{Cs}$ peak at $12.5 \mathrm{~cm}$ does indeed record the 1986 event. The apparent absence of any feature record the 1963 event could be due to downwards migration of the Chernobyl ${ }^{137} \mathrm{Cs}$, masking the earlier peak. The ${ }^{210} \mathrm{~Pb}$ results, shown (Figure 9.ii) and given in detail in Table 25, suggest a late $19^{\text {th }}$ century sedimentation rate of $0.011 \mathrm{~g} \mathrm{~cm}^{-2} \mathrm{y}^{-1}\left(0.14 \mathrm{~cm} \mathrm{y}^{-1}\right)$. During the $20^{\text {th }}$ century this increased steadily to a value of $0.020 \mathrm{~g} \mathrm{~cm}^{-2} \mathrm{y}^{-1}\left(0.36 \mathrm{~cm} \mathrm{y}^{-1}\right)$ in the $1980 \mathrm{~s}$, with a further increase during the past decade to a value of around $0.030 \mathrm{~g} \mathrm{~cm}^{-2} \mathrm{y}^{-1}\left(0.75 \mathrm{~cm} \mathrm{y}^{-1}\right)$.

\section{Ziskensee (Brandenburg See 90)}

\section{Lead-210 Activity}

The ${ }^{210} \mathrm{~Pb} /{ }^{226} \mathrm{Ra}$ equilibrium depth lies significantly below the base of the core at a depth of around $45 \mathrm{~cm}$ (Figure 10.i(a)), limiting the ${ }^{210} \mathrm{~Pb}$ chronology by about one half-life ( 22 years). The 
unsupported ${ }^{210} \mathrm{~Pb}$ activity versus depth profile (Figure $10 . \mathrm{i}(\mathrm{b})$ ) has two relatively distinct zones. Down to $28.5 \mathrm{~cm}$ concentrations decline regularly but relatively slowly with depth. Below this the decline continues though with a much steeper gradient. These results suggest a relatively slow sedimentation rate in the early part of the record, succeeded in the middle of the $20^{\text {th }}$ century by a distinct change in regime that led to much higher sedimentation rates in more recent times.

\section{Artificial Fallout Radionuclides}

The ${ }^{137} \mathrm{Cs}$ activity versus depth profile (Figure $10 . \mathrm{i}(\mathrm{c})$ ) does not have a clear record of ${ }^{137} \mathrm{Cs}$ fallout. High concentrations above $17 \mathrm{~cm}$ peaking at $8.5 \mathrm{~cm}$ may record fallout from the 1986 Chernobyl accident, though since there is no evidence of a second older peak recording the 1963 weapons fallout maximum this attribution is not certain.

\section{Core Chronology}

${ }^{210} \mathrm{~Pb}$ dates calculated using the CRS model dates place 1986 at a depth of around $13 \mathrm{~cm}$ and 1963 at $20.5 \mathrm{~cm}$, suggesting that the high ${ }^{137} \mathrm{Cs}$ peak concentrations peaking at $8.5 \mathrm{~cm}$ probably record the 1986 event. The apparent absence of any distinct feature recording the 1963 event could be due to downwards migration of the Chernobyl ${ }^{137} \mathrm{Cs}$, masking the earlier peak. In the absence of good ${ }^{137} \mathrm{Cs}$ dates the chronology for this core, shown in (Figure 10.ii) and given in detail in Table 26, has been based entirely on the ${ }^{210} \mathrm{~Pb}$ results. These suggest a period of relatively uniform sedimentation in the late $19^{\text {th }}$ and early $20^{\text {th }}$ century with a mean accumulation rate of $0.011 \mathrm{~g} \mathrm{~cm}^{-2} \mathrm{y}^{-1}\left(0.21 \mathrm{~cm} \mathrm{y}^{-1}\right)$. In the second half the $20^{\text {th }}$ century this appears to have increased steadily, the current value being estimated to be around $0.030 \mathrm{~g} \mathrm{~cm}^{-2} \mathrm{y}^{-1}\left(\sim 1.0 \mathrm{~cm} \mathrm{y}^{-1}\right)$.

\section{Schiebelsee (Brandenburg See 94)}

\section{Lead-210 Activity}

The ${ }^{210} \mathrm{~Pb} /{ }^{226} \mathrm{Ra}$ equilibrium depth lies significantly below the base of the core at a depth of around $45 \mathrm{~cm}$ (Figure 11.i(a)), limiting the ${ }^{210} \mathrm{~Pb}$ chronology by about one half-life ( 22 years). The unsupported ${ }^{210} \mathrm{~Pb}$ activity versus depth profile (Figure $11 . \mathrm{i}(\mathrm{b})$ ) varies irregularly with depth with several non-monotonic features presumably recording episodes of rapid sedimentation. One of these features, between $19-23 \mathrm{~cm}$, coincides with a layer of dense sediment that may record an event such as a sediment slump of older more compacted marginal sediments or enhanced erosion caused by a significant catchment disturbance. Sediments above $19 \mathrm{~cm}$ are generally much less dense that those beneath this depth, suggesting a distinct change in conditions in the lake in the latter half of the $20^{\text {th }}$ century.

\section{Artificial Fallout Radionuclides}

The ${ }^{137} \mathrm{Cs}$ activity versus depth profile (Figure $11 . \mathrm{i}(\mathrm{c})$ ) has a well defined peak at $20.5 \mathrm{~cm}$. The high concentrations in the peak suggest that this feature records fallout from the 1986 Chernobyl accident. A distinct shoulder in the ${ }^{137} \mathrm{Cs}$ record between $26-33 \mathrm{~cm}$ may record the period of maximum weapons fallout in the 1960s, the peak itself being obscured by the downwards migration of Chernobyl ${ }^{137} \mathrm{Cs}$.

\section{Core Chronology}

${ }^{210} \mathrm{~Pb}$ dates calculated using the CRS model dates place 1986 at a depth of around $18 \mathrm{~cm}$ and 1963 at $27.5 \mathrm{~cm}$. Although these are in reasonable agreement with the depths suggested by the ${ }^{137} \mathrm{Cs}$ record there are small but significant discrepancies due possibly to changes in the ${ }^{210} \mathrm{~Pb}$ supply rate caused by changes in the lake regime, disruptions to the sediment record caused by episodes of rapid accumulation, and errors in the estimation of the ${ }^{210} \mathrm{~Pb}$ inventory below the base of the core. Figure 11.ii shows corrected CRS model ${ }^{210} \mathrm{~Pb}$ dates calculated using the well defined $1986{ }^{137} \mathrm{Cs}$ date as a reference point (Appleby, 2001). The results, given in detail in Table 27, indicate a mean sedimentation rate since the beginning of the $20^{\text {th }}$ century of $0.063 \mathrm{~g} \mathrm{~cm}^{-2} \mathrm{y}^{-1}\left(0.43 \mathrm{~cm} \mathrm{y}^{-1}\right)$, though with episodes of rapid accumulation in the 1980s and 1960s. The 1980s event coincides with the layer of dense sediment between $19-23 \mathrm{~cm}$. Although the post-1950 dates for this core should be 
fairly reliable, because of the irregularities in the ${ }^{210} \mathrm{~Pb}$ record near the base of the core the early $20^{\text {th }}$ century dates are much less certain.

\section{Bugsee (Brandenburg See 97)}

This core too has an incomplete record with total ${ }^{210} \mathrm{~Pb}$ activity at the base of the core remaining significantly above that of the supporting ${ }^{226} \mathrm{Ra}$ (Figure $12 . \mathrm{i}(\mathrm{a})$ ). Unsupported ${ }^{210} \mathrm{~Pb}$ concentrations (Figure 12.i(b)) vary irregularly with depth. The maximum value occurs below the surface of the core at a depth of $4.5 \mathrm{~cm}$, and deeper in the core there is a major non-monotonic feature in a layer of dense sediment between $11-16 \mathrm{~cm}$ also characterised by high ${ }^{226} \mathrm{Ra}$ concentrations. The most likely cause of this feature is a brief episode of rapid soil erosion due to a substantial disturbance in the catchment.

\section{Artificial Fallout Radionuclides}

The ${ }^{137} \mathrm{Cs}$ activity versus depth profile (Figure 12.i(c)) has two well defined peaks, a broad peak between 11-15 cm that coincides with the dense inwash layer, and a similar but smaller peak between $22-25 \mathrm{~cm}$. The presence of a traces of ${ }^{241} \mathrm{Am}$ at the same depth suggests that the earlier peak records the 1963 fallout maximum from the atmospheric testing of nuclear weapons (Appleby et al., 1991). The position of the more recent peak indicates that it most probably records the 1986 Chernobyl accident, though its coincidence with the dense layer at this depth is a little surprising and may indicate that much of this ${ }^{137} \mathrm{Cs}$ was brought in on catchment soils.

\section{Core Chronology}

The raw ${ }^{210} \mathrm{~Pb}$ dates for this core are very uncertain. The irregular nature of the ${ }^{210} \mathrm{~Pb}$ record precludes use of the CIC model, and its incomplete nature makes use of the CRS model highly problematic. The CRS model calculations do however place 1963 at a depth of $19.5 \mathrm{~cm}$ and 1986 at $10.5 \mathrm{~cm}$, in reasonable proximity to the depths suggested by the ${ }^{137} \mathrm{Cs}$ record. Corrected ${ }^{210} \mathrm{~Pb}$ dates have accordingly been calculated using the ${ }^{137} \mathrm{Cs}$ dates as reference points (Appleby, 2001). The results, shown in Figure 12.ii and given in detail in Table 28, date the episode of rapid sedimentation to the early 1980s. Excluding this feature the core appears to have had a relatively uniform sedimentation rate with a mean value of around $0.085 \mathrm{~g} \mathrm{~cm}^{-2} \mathrm{y}^{-1}\left(0.40 \mathrm{~cm} \mathrm{y}^{-1}\right)$. The base of the core is dated to the mid- $20^{\text {th }}$ century.

\section{Piechesee (Brandenburg See 102)}

\section{Lead-210 Activity}

This core appears to have an extremely rapid sedimentation rate and in consequence largely incomplete radiometric records. Total ${ }^{210} \mathrm{~Pb}$ activity is well in excess of the supporting ${ }^{226} \mathrm{Ra}$ in all samples right down to the base of the core at $39 \mathrm{~cm}$ (Figure 13.i(a)). Unsupported ${ }^{210} \mathrm{~Pb}$ concentrations show very little decline (Figure 13.i(b)) and the entire core probably spans not much more than a single ${ }^{210} \mathrm{~Pb}$ half-life (22 years).

\section{Artificial Fallout Radionuclides}

${ }^{137} \mathrm{Cs}$ concentrations follow a similar pattern (Figure 13.i(c)), remaining virtually constant down to top $37 \mathrm{~cm}$ and showing a decline only in the deepest sample. The high concentrations and high inventory (Table 16) suggest that these sediments have been severely impacted by Chernobyl fallout and that the entire core post-dates the 1986 Chernobyl accident.

\section{Core Chronology}

The poor radiometric records make it impossible to determine a reliable chronology for this core. A rough estimate of the chronology can be made by supposing that the reduction in ${ }^{137} \mathrm{Cs}$ concentrations below $37 \mathrm{~cm}$ indicates a date for this sample of around 1986. This suggests a mean sedimentation rate during the past two decades of around $0.11 \mathrm{~g} \mathrm{~cm}^{-2} \mathrm{y}^{-1}\left(1.6 \mathrm{~cm} \mathrm{y}^{-1}\right)$. However, the results of these calculations, shown in Figure 13.ii and given in detail in Table 29, should not be regarded with any certainty unless supported by other evidence. 


\section{Aalgastsee (Brandenburg See 108)}

\section{Lead-210 Activity}

Total ${ }^{210} \mathrm{~Pb}$ activity in this core appeared to reach equilibrium with that of the supporting ${ }^{226} \mathrm{Ra}$ at a depth of around $22 \mathrm{~cm}$ (Figure 14.i(a)). The abrupt disappearance of unsupported ${ }^{210} \mathrm{~Pb}$ below $20 \mathrm{~cm}$ (Figure 14.i(b)) suggests however that this depth marks a hiatus in the sediment record rather than true ${ }^{210} \mathrm{~Pb} /{ }^{226} \mathrm{Ra}$ equilibrium, with relatively modern sediments in the uppermost $20 \mathrm{~cm}$ of the core sitting directly on top of much older material below.

\section{Artificial Fallout Radionuclides}

The ${ }^{137} \mathrm{Cs}$ activity versus depth profile (Figure $14 . i(\mathrm{c})$ ) has two reasonably well defined peaks. Relatively high concentrations in the more recent peak between $6-9 \mathrm{~cm}$ suggest that this feature records fallout from the 1986 Chernobyl accident. The deeper peak at $18.5 \mathrm{~cm}$ presumably records the 1963 fallout maximum from the atmospheric testing of nuclear weapons.

\section{Core Chronology}

The raw CRS model dates place 1963 at a depth of $13.5 \mathrm{~cm}$, significantly above the depth suggested by the ${ }^{137} \mathrm{Cs}$ record, supporting the suggestion of a hiatus in the sediment record at $22 \mathrm{~cm}$. Corrected CRS model dates calculated using the ${ }^{137} \mathrm{Cs}$ dates as reference points (Appleby, 2001) date the hiatus to the late 1950s. Relatively high sedimentation rates persisted for another 20 years or so with a mean sedimentation rate during $1963-86$ of $0.48 \mathrm{~g} \mathrm{~cm}^{-2} \mathrm{y}^{-1}\left(0.48 \mathrm{~cm} \mathrm{y}^{-1}\right)$ compared to $0.25 \mathrm{~g} \mathrm{~cm}^{-2} \mathrm{y}^{-1}$ $\left(0.33 \mathrm{~cm} \mathrm{y}^{-1}\right)$ during the post-1986 period. The results of these calculations are shown in Figure 14.ii and given in detail in Table 30.

\section{Papensee (Brandenburg See 111)}

\section{Lead-210 Activity}

Total ${ }^{210} \mathrm{~Pb}$ activity reaches equilibrium with the supporting ${ }^{226} \mathrm{Ra}$ a little below the base of the core at a depth of around $42 \mathrm{~cm}$ (Figure $15 . i(a)$ ), limiting the ${ }^{210} \mathrm{~Pb}$ chronology by about one ${ }^{210} \mathrm{~Pb}$ half-life ( 22 years). Although the unsupported ${ }^{210} \mathrm{~Pb}$ declines relatively slowly with depth in the top $20 \mathrm{~cm}$ of the core and much more steeply in the deeper sections (Figure 15.i(b)), this is partly a result of the fact that sediments in the upper section have a much lower dry bulk density than sediments in the deeper layers. When plotted against cumulative dry mass the profile does not deviate significantly from an exponential relationship and suggests that, although there may have been some fluctuations in the sedimentation rate, there hasn't been any major long-term change.

\section{Artificial Fallout Radionuclides}

The ${ }^{137} \mathrm{Cs}$ activity versus depth profile (Figure $15 . \mathrm{i}(\mathrm{c})$ ) has a double peak between $13-22 \mathrm{~cm}$. The steep increase in concentrations above $28 \mathrm{~cm}$ suggests that sediments between $17-23 \mathrm{~cm}$ covering the earlier peak may date from the period of maximum fallout from the atmospheric testing of nuclear weapons in the early 1960s, and those between 13-17 cm covering the second peak fallout from the 1986 Chernobyl accident.

\section{Core Chronology}

${ }^{210} \mathrm{~Pb}$ dates calculated using the CRS model dates place 1963 at a depth of around $21.5 \mathrm{~cm}$ and 1986 at $15 \mathrm{~cm}$, in good agreement with the depths suggested by the ${ }^{137} \mathrm{Cs}$ record (Figure 15.ii). Since the discrepancies are minor and the ${ }^{137} \mathrm{Cs}$ dates not sufficiently accurate to warrant any correction, the raw ${ }^{210} \mathrm{~Pb}$ dates form the basis of the detailed results given in Table 31. These suggest a relatively uniform sedimentation rate from the latter part of the $19^{\text {th }}$ century through to the middle of the $20^{\text {th }}$ century with a mean value during this period of $0.025 \mathrm{~g} \mathrm{~cm}^{-2} \mathrm{y}^{-1}\left(0.21 \mathrm{~cm} \mathrm{y}^{-1}\right)$. Since then the accumulation rate appears to have been more variable with a small reduction in the 1960s followed by a more significant increase during the past two decades. 


\section{References}

Appleby, P.G. (2001): Chronostratigraphic techniques in recent sediments, in Tracking Environmental Change Using Lake Sediments Volume 1: Basin Analysis, Coring, and Chronological Techniques, (eds W M Last \& J P Smol), Kluwer Academic, pp. 171-203.

Appleby, P.G., Nolan, P.J., Gifford, D.W., Godfrey, M.J., Oldfield, F., Anderson, N.J. \& Battarbee, R.W. (1986): ${ }^{210} \mathrm{~Pb}$ dating by low background gamma counting. Hydrobiologia, 141: 21-27.

Appleby, P.G. \& Oldfield, F. (1978): The calculation of ${ }^{210} \mathrm{~Pb}$ dates assuming a constant rate of supply of unsupported ${ }^{210} \mathrm{~Pb}$ to the sediment. Catena, 5: 1-8.

Appleby, P.G., Richardson, N. \& Nolan, P.J. (1991): ${ }^{241}$ Am dating of lake sediments. Hydrobiologia, 214: 35-42.

Appleby, P.G., Richardson, N. \& Nolan, P.J. (1992): Self-absorption corrections for well-type germaniun detectors. Nucl. Inst. \& Methods B, 71: 228-233. 
Table 1. Fallout radionuclide concentrations in the Kleiner Treppelsee (Brandenburg See 23) sediment core

\begin{tabular}{|c|c|c|c|c|c|c|c|c|c|}
\hline \multicolumn{10}{|c|}{${ }^{210} \mathrm{~Pb}$} \\
\hline \multicolumn{2}{|c|}{ Depth } & \multicolumn{2}{|c|}{ Total } & \multicolumn{2}{|c|}{ Unsupported } & \multicolumn{2}{|c|}{ Supported } & \multicolumn{2}{|c|}{${ }^{137} \mathrm{Cs}$} \\
\hline $\mathrm{cm}$ & $\mathrm{g} \mathrm{cm}^{-2}$ & $\mathrm{~Bq} \mathrm{~kg}{ }^{-1}$ & \pm & $\mathrm{Bq} \mathrm{kg}^{-1}$ & \pm & $\mathrm{Bq} \mathrm{kg}^{-1}$ & \pm & $\mathrm{Bq} \mathrm{kg}{ }^{-1}$ & \pm \\
\hline 0.5 & 0.02 & 210.5 & 27.0 & 191.3 & 27.8 & 19.2 & 6.6 & 14.5 & 4.9 \\
\hline 2.5 & 0.13 & 257.1 & 16.0 & 231.3 & 16.4 & 25.8 & 3.5 & 19.4 & 2.8 \\
\hline 4.5 & 0.28 & 197.9 & 21.1 & 179.2 & 21.6 & 18.7 & 4.7 & 11.5 & 4.0 \\
\hline 6.5 & 0.45 & 207.3 & 18.8 & 178.0 & 19.4 & 29.3 & 4.6 & 27.7 & 3.6 \\
\hline 8.5 & 0.64 & 199.8 & 23.2 & 178.2 & 23.9 & 21.5 & 5.9 & 28.2 & 4.4 \\
\hline 10.5 & 0.83 & 137.1 & 19.2 & 119.7 & 19.7 & 17.4 & 4.3 & 24.9 & 3.4 \\
\hline 12.5 & 1.04 & 156.1 & 22.8 & 139.4 & 23.3 & 16.7 & 5.0 & 37.4 & 4.4 \\
\hline 14.5 & 1.24 & 115.2 & 19.2 & 86.9 & 20.0 & 28.2 & 5.5 & 23.1 & 3.6 \\
\hline 16.5 & 1.46 & 108.7 & 22.0 & 82.5 & 22.8 & 26.2 & 5.6 & 26.9 & 4.2 \\
\hline 18.5 & 1.67 & 85.9 & 18.7 & 56.9 & 19.2 & 29.1 & 4.5 & 30.5 & 3.7 \\
\hline 20.5 & 1.89 & 80.6 & 13.6 & 58.3 & 13.9 & 22.4 & 3.2 & 24.5 & 2.8 \\
\hline 22.5 & 2.12 & 95.4 & 13.2 & 80.2 & 13.7 & 15.2 & 3.4 & 15.1 & 2.4 \\
\hline 24.5 & 2.34 & 82.0 & 15.7 & 70.1 & 16.1 & 11.9 & 3.9 & 13.5 & 3.0 \\
\hline 26.5 & 2.55 & 47.9 & 13.1 & 31.7 & 13.3 & 16.2 & 2.8 & 2.5 & 2.2 \\
\hline 28.5 & 2.76 & 46.3 & 15.6 & 33.4 & 15.9 & 13.0 & 3.3 & 4.1 & 2.5 \\
\hline
\end{tabular}

Table 2. Fallout radionuclide concentrations in the Kesselsee (Brandenburg See 67) sediment core

\begin{tabular}{|c|c|c|c|c|c|c|c|c|c|}
\hline \multicolumn{10}{|c|}{${ }^{210} \mathrm{~Pb}$} \\
\hline \multicolumn{2}{|c|}{ Depth } & \multicolumn{2}{|c|}{ Total } & \multicolumn{2}{|c|}{ Unsupported } & \multicolumn{2}{|c|}{ Supported } & \multicolumn{2}{|c|}{${ }^{137} \mathrm{Cs}$} \\
\hline $\mathrm{cm}$ & $\mathrm{g} \mathrm{cm}^{-2}$ & $\mathrm{~Bq} \mathrm{~kg}{ }^{-1}$ & \pm & $\mathrm{Bq} \mathrm{kg}{ }^{-1}$ & \pm & $\mathrm{Bq} \mathrm{kg}{ }^{-1}$ & \pm & $\mathrm{Bq} \mathrm{kg}{ }^{-1}$ & \pm \\
\hline 0.5 & 0.02 & 321.9 & 19.2 & 274.0 & 19.7 & 47.8 & 4.2 & 166.1 & 4.7 \\
\hline 2.5 & 0.08 & 353.5 & 17.3 & 318.0 & 17.6 & 35.5 & 3.3 & 170.9 & 4.0 \\
\hline 4.5 & 0.16 & 386.0 & 14.9 & 345.3 & 15.1 & 40.7 & 2.6 & 169.3 & 3.9 \\
\hline 8.5 & 0.32 & 356.9 & 10.5 & 320.3 & 10.7 & 36.6 & 2.0 & 159.0 & 2.7 \\
\hline 12.5 & 0.50 & 353.4 & 10.6 & 315.0 & 10.8 & 38.4 & 1.9 & 165.3 & 2.5 \\
\hline 14.5 & 0.59 & 372.3 & 16.5 & 342.8 & 16.7 & 29.5 & 2.8 & 155.7 & 4.1 \\
\hline 16.5 & 0.69 & 340.1 & 12.5 & 306.8 & 12.7 & 33.3 & 2.1 & 162.9 & 3.1 \\
\hline 18.5 & 0.79 & 297.5 & 20.7 & 252.2 & 21.1 & 45.3 & 4.4 & 175.8 & 5.6 \\
\hline 20.5 & 0.90 & 277.1 & 16.5 & 235.6 & 16.8 & 41.5 & 3.5 & 160.0 & 4.0 \\
\hline 22.5 & 1.02 & 227.5 & 15.9 & 194.3 & 16.1 & 33.2 & 2.8 & 162.7 & 4.4 \\
\hline 24.5 & 1.14 & 221.7 & 12.0 & 185.3 & 12.2 & 36.4 & 2.5 & 161.2 & 3.7 \\
\hline 26.5 & 1.27 & 219.2 & 13.8 & 174.4 & 14.1 & 44.8 & 3.0 & 138.0 & 3.7 \\
\hline 28.5 & 1.39 & 190.0 & 11.0 & 149.3 & 11.2 & 40.7 & 2.3 & 116.6 & 2.8 \\
\hline 30.5 & 1.52 & 161.9 & 11.8 & 107.6 & 12.2 & 54.3 & 3.1 & 99.5 & 2.9 \\
\hline 32.5 & 1.65 & 121.6 & 9.6 & 74.2 & 9.9 & 47.4 & 2.4 & 71.5 & 2.2 \\
\hline 34.5 & 1.78 & 93.3 & 10.2 & 55.1 & 10.5 & 38.2 & 2.4 & 45.9 & 2.6 \\
\hline 36.5 & 1.92 & 95.3 & 10.6 & 48.4 & 10.9 & 46.9 & 2.5 & 39.5 & 2.1 \\
\hline 39.5 & 2.15 & 70.5 & 7.5 & 29.7 & 7.7 & 40.8 & 1.9 & 28.5 & 1.7 \\
\hline
\end{tabular}


Table 3. Fallout radionuclide concentrations in the Schwarzersee (See 71) sediment core

\begin{tabular}{|c|c|c|c|c|c|c|c|c|c|}
\hline \multicolumn{10}{|c|}{${ }^{210} \mathrm{~Pb}$} \\
\hline \multicolumn{2}{|c|}{ Depth } & \multicolumn{2}{|c|}{ Total } & \multicolumn{2}{|c|}{ Unsupported } & \multicolumn{2}{|c|}{ Supported } & \multicolumn{2}{|c|}{${ }^{137} \mathrm{Cs}$} \\
\hline $\mathrm{cm}$ & $\mathrm{g} \mathrm{cm}^{-2}$ & $\mathrm{~Bq} \mathrm{~kg}{ }^{-1}$ & \pm & $\mathrm{Bq} \mathrm{kg}^{-1}$ & \pm & $\mathrm{Bq} \mathrm{kg}^{-1}$ & \pm & $\mathrm{Bq} \mathrm{kg}{ }^{-1}$ & \pm \\
\hline 0.5 & 0.01 & 426.4 & 16.9 & 388.0 & 17.1 & 38.4 & 2.8 & 418.3 & 5.5 \\
\hline 2.5 & 0.07 & 342.1 & 21.2 & 294.1 & 21.7 & 48.0 & 4.4 & 416.9 & 6.9 \\
\hline 4.5 & 0.15 & 369.3 & 15.4 & 329.8 & 15.7 & 39.5 & 3.1 & 447.1 & 6.4 \\
\hline 8.5 & 0.33 & 360.1 & 14.2 & 327.3 & 14.5 & 32.8 & 2.5 & 428.7 & 5.0 \\
\hline 10.5 & 0.44 & 377.5 & 19.9 & 347.5 & 20.2 & 30.0 & 3.3 & 424.7 & 6.9 \\
\hline 12.5 & 0.57 & 342.0 & 10.6 & 306.8 & 10.7 & 35.3 & 1.6 & 415.1 & 3.5 \\
\hline 14.5 & 0.67 & 312.2 & 17.9 & 281.8 & 18.2 & 30.4 & 3.4 & 404.7 & 6.6 \\
\hline 16.5 & 0.79 & 239.9 & 11.5 & 204.4 & 11.8 & 35.5 & 2.3 & 324.7 & 4.2 \\
\hline 18.5 & 0.91 & 167.0 & 10.5 & 133.7 & 10.7 & 33.3 & 2.1 & 210.4 & 3.2 \\
\hline 20.5 & 1.04 & 130.3 & 14.0 & 85.6 & 14.4 & 44.6 & 3.6 & 173.3 & 4.0 \\
\hline 22.5 & 1.17 & 124.9 & 9.9 & 91.1 & 10.0 & 33.7 & 1.8 & 141.8 & 2.9 \\
\hline 24.5 & 1.29 & 128.8 & 11.7 & 93.7 & 12.1 & 35.0 & 2.9 & 134.2 & 3.7 \\
\hline 28.5 & 1.56 & 86.9 & 8.6 & 52.5 & 8.8 & 34.4 & 1.9 & 65.9 & 2.2 \\
\hline 32.5 & 1.83 & 75.5 & 10.5 & 38.4 & 10.8 & 37.1 & 2.5 & 42.7 & 2.1 \\
\hline 35.5 & 2.04 & 54.9 & 7.0 & 22.2 & 7.2 & 32.7 & 1.6 & 30.3 & 1.3 \\
\hline 38.5 & 2.26 & 50.7 & 8.5 & 11.1 & 8.7 & 39.5 & 2.1 & 23.7 & 1.6 \\
\hline 41.5 & 2.52 & 36.6 & 8.0 & 5.4 & 8.1 & 31.1 & 1.8 & 16.0 & 1.6 \\
\hline
\end{tabular}

Table 4. Fallout radionuclide concentrations in the Heiligensee (Brandenburg See 72) sediment core

\begin{tabular}{|c|c|c|c|c|c|c|c|c|c|}
\hline \multicolumn{10}{|c|}{${ }^{210} \mathrm{~Pb}$} \\
\hline \multicolumn{2}{|c|}{ Depth } & \multicolumn{2}{|c|}{ Total } & \multicolumn{2}{|c|}{ Unsupported } & \multicolumn{2}{|c|}{ Supported } & \multicolumn{2}{|c|}{${ }^{137} \mathrm{Cs}$} \\
\hline $\mathrm{cm}$ & $\mathrm{g} \mathrm{cm}^{-2}$ & $\mathrm{~Bq} \mathrm{~kg}^{-1}$ & \pm & $\mathrm{Bq} \mathrm{kg}{ }^{-1}$ & \pm & $\mathrm{Bq} \mathrm{kg}^{-1}$ & \pm & $\mathrm{Bq} \mathrm{kg}{ }^{-1}$ & \pm \\
\hline 0.5 & 0.02 & 170.5 & 13.1 & 149.0 & 13.4 & 21.5 & 2.6 & 5.1 & 1.5 \\
\hline 2.5 & 0.20 & 201.5 & 10.8 & 175.1 & 10.9 & 26.4 & 1.8 & 17.8 & 1.7 \\
\hline 4.5 & 0.44 & 254.8 & 13.2 & 233.4 & 13.4 & 21.4 & 2.3 & 21.1 & 1.8 \\
\hline 6.5 & 0.79 & 158.3 & 10.8 & 130.8 & 11.0 & 27.5 & 2.1 & 52.6 & 2.1 \\
\hline 8.5 & 1.14 & 96.0 & 9.1 & 74.3 & 9.4 & 21.7 & 2.0 & 83.6 & 2.2 \\
\hline 9.5 & 1.36 & 90.3 & 8.7 & 67.3 & 8.9 & 23.0 & 1.8 & 275.1 & 3.4 \\
\hline 10.5 & 1.60 & 69.6 & 8.1 & 40.6 & 8.3 & 29.0 & 1.8 & 214.5 & 3.3 \\
\hline 11.5 & 1.93 & 51.9 & 9.3 & 18.1 & 9.5 & 33.8 & 2.1 & 29.2 & 1.7 \\
\hline 12.5 & 2.25 & 81.5 & 10.6 & 49.0 & 10.9 & 32.5 & 2.2 & 22.0 & 1.9 \\
\hline 14.5 & 2.66 & 61.3 & 9.0 & 38.0 & 9.2 & 23.3 & 1.8 & 19.1 & 1.4 \\
\hline 16.5 & 3.19 & 61.2 & 8.4 & 24.4 & 8.6 & 36.8 & 1.9 & 32.2 & 1.6 \\
\hline 17.5 & 3.45 & 40.7 & 9.4 & 13.8 & 9.6 & 26.9 & 2.0 & 47.8 & 2.3 \\
\hline 18.5 & 3.72 & 84.0 & 10.6 & 49.2 & 10.8 & 34.7 & 2.2 & 84.8 & 2.4 \\
\hline 19.5 & 3.98 & 59.8 & 10.0 & 31.9 & 10.2 & 28.0 & 2.0 & 110.1 & 2.5 \\
\hline 20.5 & 4.27 & 58.3 & 7.7 & 28.9 & 7.9 & 29.4 & 1.6 & 44.1 & 1.6 \\
\hline 22.5 & 4.94 & 58.0 & 7.8 & 22.4 & 8.0 & 35.6 & 1.9 & 30.6 & 1.5 \\
\hline 24.5 & 5.65 & 38.9 & 5.9 & 5.2 & 6.1 & 33.7 & 1.4 & 18.9 & 1.1 \\
\hline 27.5 & 6.48 & 42.0 & 6.9 & 21.5 & 7.1 & 20.5 & 1.4 & 0.0 & 0.0 \\
\hline 30.5 & 7.24 & 46.0 & 7.8 & 13.8 & 8.0 & 32.2 & 1.9 & 2.4 & 1.0 \\
\hline 33.5 & 8.07 & 37.8 & 7.4 & 13.3 & 7.6 & 24.5 & 1.5 & 0.0 & 0.0 \\
\hline
\end{tabular}


Table 5. Fallout radionuclide concentrations in the Teufelssee (Brandenburg See 76) sediment core

\begin{tabular}{|c|c|c|c|c|c|c|c|c|c|}
\hline \multicolumn{10}{|c|}{${ }^{210} \mathrm{~Pb}$} \\
\hline \multicolumn{2}{|c|}{ Depth } & \multicolumn{2}{|c|}{ Total } & \multicolumn{2}{|c|}{ Unsupported } & \multicolumn{2}{|c|}{ Supported } & \multicolumn{2}{|c|}{${ }^{137} \mathrm{Cs}$} \\
\hline $\mathrm{cm}$ & $\mathrm{g} \mathrm{cm}^{-2}$ & $\mathrm{~Bq} \mathrm{~kg}^{-1}$ & \pm & $\mathrm{Bq} \mathrm{kg}^{-1}$ & \pm & $\mathrm{Bq} \mathrm{kg}{ }^{-1}$ & \pm & $\mathrm{Bq} \mathrm{kg}^{-1}$ & \pm \\
\hline 0.5 & 0.05 & 309.3 & 13.9 & 277.3 & 14.3 & 32.0 & 3.0 & 1.2 & 2.3 \\
\hline 2.5 & 0.33 & 283.2 & 12.4 & 251.6 & 12.6 & 31.6 & 2.3 & 3.4 & 1.3 \\
\hline 4.5 & 0.64 & 201.5 & 11.6 & 169.8 & 11.8 & 31.7 & 2.4 & 6.6 & 1.5 \\
\hline 6.5 & 0.98 & 168.4 & 11.0 & 136.4 & 11.2 & 32.0 & 2.1 & 11.0 & 1.5 \\
\hline 7.5 & 1.19 & 182.5 & 12.9 & 147.7 & 13.2 & 34.8 & 2.8 & 6.1 & 1.6 \\
\hline 8.5 & 1.38 & 150.7 & 10.5 & 107.2 & 10.8 & 43.5 & 2.3 & 16.0 & 1.8 \\
\hline 9.5 & 1.53 & 145.2 & 13.9 & 105.5 & 14.3 & 39.7 & 3.2 & 36.6 & 2.4 \\
\hline 10.5 & 1.70 & 155.3 & 12.6 & 110.3 & 12.9 & 45.0 & 2.8 & 14.1 & 1.8 \\
\hline 12.5 & 2.02 & 144.4 & 10.0 & 84.5 & 10.3 & 59.9 & 2.3 & 0.9 & 0.8 \\
\hline 14.5 & 2.40 & 73.2 & 11.1 & 30.5 & 11.3 & 42.7 & 2.4 & 0.0 & 0.0 \\
\hline 16.5 & 2.78 & 61.0 & 9.1 & 15.1 & 9.4 & 45.9 & 2.2 & 0.0 & 0.0 \\
\hline 18.5 & 3.21 & 50.7 & 8.8 & 1.9 & 9.1 & 48.7 & 2.3 & 0.3 & 1.4 \\
\hline 20.5 & 3.67 & 79.6 & 7.3 & 30.6 & 7.5 & 49.1 & 1.7 & 3.0 & 1.1 \\
\hline 22.5 & 4.12 & 78.1 & 7.1 & 20.6 & 7.3 & 57.5 & 1.6 & 3.9 & 0.9 \\
\hline 24.5 & 4.59 & 74.8 & 7.6 & 30.6 & 7.8 & 44.2 & 1.8 & 0.0 & 0.0 \\
\hline 26.5 & 5.12 & 65.1 & 7.7 & 7.5 & 7.9 & 57.7 & 1.9 & 2.8 & 1.0 \\
\hline 28.5 & 5.64 & 57.6 & 6.7 & 8.6 & 6.8 & 49.0 & 1.5 & 0.0 & 0.0 \\
\hline
\end{tabular}

Table 6. Fallout radionuclide concentrations in the Glabatzsee (Brandenburg See 79) sediment core

\begin{tabular}{|c|c|c|c|c|c|c|c|c|c|}
\hline \multicolumn{10}{|c|}{${ }^{210} \mathrm{~Pb}$} \\
\hline \multicolumn{2}{|c|}{ Depth } & \multicolumn{2}{|c|}{ Total } & \multicolumn{2}{|c|}{ Unsupported } & \multicolumn{2}{|c|}{ Supported } & \multicolumn{2}{|c|}{${ }^{137} \mathrm{Cs}$} \\
\hline $\mathrm{cm}$ & $\mathrm{g} \mathrm{cm}^{-2}$ & $\mathrm{~Bq} \mathrm{~kg}^{-1}$ & \pm & $\mathrm{Bq} \mathrm{kg}{ }^{-1}$ & \pm & $\mathrm{Bq} \mathrm{kg}^{-1}$ & \pm & $\mathrm{Bq} \mathrm{kg}{ }^{-1}$ & \pm \\
\hline 0.5 & 0.01 & 443.9 & 22.7 & 409.4 & 23.2 & 34.5 & 4.9 & 103.3 & 4.6 \\
\hline 2.5 & 0.08 & 482.8 & 20.3 & 457.7 & 20.6 & 25.1 & 3.5 & 109.1 & 3.8 \\
\hline 4.5 & 0.15 & 509.1 & 15.4 & 493.6 & 15.5 & 15.5 & 1.8 & 106.8 & 3.0 \\
\hline 8.5 & 0.31 & 382.9 & 11.7 & 363.7 & 11.9 & 19.2 & 2.1 & 107.0 & 2.5 \\
\hline 10.5 & 0.39 & 363.8 & 14.5 & 343.0 & 14.8 & 20.7 & 3.0 & 102.5 & 3.2 \\
\hline 12.5 & 0.48 & 372.1 & 11.8 & 349.4 & 12.0 & 22.7 & 2.0 & 117.0 & 2.4 \\
\hline 14.5 & 0.57 & 336.6 & 13.5 & 317.3 & 13.7 & 19.3 & 2.4 & 108.2 & 3.3 \\
\hline 16.5 & 0.68 & 209.0 & 12.7 & 187.5 & 12.9 & 21.4 & 2.0 & 76.5 & 2.7 \\
\hline 18.5 & 0.78 & 154.1 & 9.6 & 138.2 & 9.8 & 15.9 & 1.7 & 50.3 & 1.9 \\
\hline 20.5 & 0.89 & 140.3 & 9.8 & 123.0 & 10.0 & 17.4 & 1.8 & 27.3 & 1.6 \\
\hline 22.5 & 0.99 & 113.0 & 7.4 & 94.7 & 7.5 & 18.3 & 1.6 & 23.1 & 1.3 \\
\hline 24.5 & 1.09 & 105.4 & 8.2 & 91.6 & 8.4 & 13.8 & 1.6 & 22.3 & 1.4 \\
\hline 28.5 & 1.29 & 62.3 & 10.6 & 41.6 & 10.9 & 20.7 & 2.3 & 18.4 & 2.3 \\
\hline 32.5 & 1.53 & 55.4 & 6.7 & 37.5 & 6.8 & 17.8 & 1.5 & 16.5 & 1.4 \\
\hline 35.5 & 1.69 & 43.5 & 6.5 & 32.3 & 6.6 & 11.2 & 1.4 & 11.9 & 1.0 \\
\hline 39.5 & 1.94 & 24.6 & 6.3 & 14.0 & 6.4 & 10.6 & 1.1 & 8.1 & 1.1 \\
\hline
\end{tabular}


Table 7. Fallout radionuclide concentrations in the Kleiner Lychensee (Brandenburg See 81) sediment core

\begin{tabular}{|c|c|c|c|c|c|c|c|c|c|}
\hline \multicolumn{10}{|c|}{${ }^{210} \mathrm{~Pb}$} \\
\hline \multicolumn{2}{|c|}{ Depth } & \multicolumn{2}{|c|}{ Total } & \multicolumn{2}{|c|}{ Unsupported } & \multicolumn{2}{|c|}{ Supported } & \multicolumn{2}{|c|}{${ }^{137} \mathrm{Cs}$} \\
\hline $\mathrm{cm}$ & $\mathrm{g} \mathrm{cm}^{-2}$ & $\mathrm{~Bq} \mathrm{~kg}{ }^{-1}$ & \pm & $\mathrm{Bq} \mathrm{kg}^{-1}$ & \pm & $\mathrm{Bq} \mathrm{kg}{ }^{-1}$ & \pm & $\mathrm{Bq} \mathrm{kg}{ }^{-1}$ & \pm \\
\hline 0.5 & 0.01 & 794.3 & 33.0 & 767.1 & 33.4 & 27.2 & 5.2 & 17.5 & 3.5 \\
\hline 2.5 & 0.06 & 868.3 & 44.8 & 820.3 & 45.6 & 48.0 & 8.6 & 23.5 & 5.0 \\
\hline 4.5 & 0.12 & 673.6 & 24.8 & 649.9 & 25.0 & 23.7 & 3.6 & 45.4 & 3.7 \\
\hline 6.5 & 0.20 & 514.7 & 18.2 & 496.2 & 18.4 & 18.5 & 2.4 & 58.9 & 2.9 \\
\hline 8.5 & 0.26 & 574.8 & 27.5 & 538.2 & 28.0 & 36.6 & 5.2 & 137.8 & 5.7 \\
\hline 10.5 & 0.34 & 470.3 & 19.4 & 445.7 & 19.7 & 24.6 & 3.2 & 184.2 & 4.3 \\
\hline 12.5 & 0.42 & 343.4 & 14.5 & 316.2 & 14.7 & 27.2 & 2.3 & 32.9 & 2.3 \\
\hline 14.5 & 0.55 & 311.3 & 17.4 & 290.7 & 17.6 & 20.6 & 2.9 & 43.6 & 2.5 \\
\hline 16.5 & 0.66 & 256.6 & 13.7 & 234.5 & 14.0 & 22.1 & 2.6 & 62.2 & 2.5 \\
\hline 18.5 & 0.76 & 174.2 & 14.4 & 149.3 & 14.6 & 25.0 & 2.5 & 74.1 & 3.1 \\
\hline 20.5 & 0.86 & 182.4 & 13.3 & 151.5 & 13.5 & 30.9 & 2.5 & 56.0 & 2.8 \\
\hline 22.5 & 0.95 & 183.2 & 15.6 & 163.4 & 15.9 & 19.8 & 3.3 & 34.0 & 2.7 \\
\hline 24.5 & 1.03 & 166.0 & 14.7 & 144.4 & 15.1 & 21.6 & 3.4 & 2.0 & 2.0 \\
\hline 26.5 & 1.10 & 183.9 & 12.6 & 158.2 & 12.8 & 25.7 & 2.5 & 6.0 & 1.6 \\
\hline 28.5 & 1.18 & 154.5 & 12.1 & 131.0 & 12.3 & 23.5 & 2.2 & 8.1 & 1.9 \\
\hline 30.5 & 1.26 & 134.8 & 11.5 & 105.7 & 11.8 & 29.1 & 2.5 & 15.8 & 1.6 \\
\hline 32.5 & 1.33 & 112.7 & 11.9 & 83.8 & 12.3 & 28.9 & 2.9 & 3.5 & 1.9 \\
\hline 34.5 & 1.42 & 66.0 & 9.9 & 48.9 & 10.0 & 17.0 & 2.0 & 0.7 & 1.5 \\
\hline 37.5 & 1.56 & 86.4 & 10.1 & 62.7 & 10.4 & 23.7 & 2.3 & 0.0 & 0.0 \\
\hline 41.5 & 1.77 & 61.0 & 8.8 & 35.1 & 9.0 & 25.8 & 1.8 & 2.5 & 1.5 \\
\hline
\end{tabular}

Table 8. Fallout radionuclide concentrations in the Baasee (Brandenburg See 86) sediment core

\begin{tabular}{|c|c|c|c|c|c|c|c|c|c|}
\hline \multicolumn{10}{|c|}{${ }^{210} \mathrm{~Pb}$} \\
\hline \multicolumn{2}{|c|}{ Depth } & \multicolumn{2}{|c|}{ Total } & \multicolumn{2}{|c|}{ Unsupported } & \multicolumn{2}{|c|}{ Supported } & \multicolumn{2}{|c|}{${ }^{137} \mathrm{Cs}$} \\
\hline $\mathrm{cm}$ & $\mathrm{g} \mathrm{cm}^{-2}$ & $\mathrm{~Bq} \mathrm{~kg}{ }^{-1}$ & \pm & $\mathrm{Bq} \mathrm{kg}^{-1}$ & \pm & $\mathrm{Bq} \mathrm{kg}^{-1}$ & \pm & $\mathrm{Bq} \mathrm{kg}{ }^{-1}$ & \pm \\
\hline 0.5 & 0.01 & 397.2 & 27.9 & 351.0 & 28.5 & 46.2 & 5.9 & 368.3 & 8.3 \\
\hline 2.5 & 0.09 & 387.2 & 23.2 & 353.3 & 23.5 & 33.9 & 3.5 & 372.4 & 7.4 \\
\hline 4.5 & 0.18 & 386.2 & 10.7 & 356.1 & 10.9 & 30.1 & 2.1 & 353.1 & 3.6 \\
\hline 8.5 & 0.37 & 332.6 & 15.4 & 292.2 & 15.7 & 40.4 & 3.1 & 377.7 & 4.9 \\
\hline 12.5 & 0.59 & 356.8 & 13.0 & 320.6 & 13.2 & 36.2 & 2.3 & 359.9 & 4.7 \\
\hline 16.5 & 0.82 & 320.5 & 14.5 & 279.0 & 14.8 & 41.5 & 2.8 & 363.0 & 4.7 \\
\hline 20.5 & 1.08 & 292.2 & 21.2 & 250.8 & 21.7 & 41.4 & 4.3 & 356.4 & 7.1 \\
\hline 24.5 & 1.35 & 275.0 & 18.8 & 235.5 & 19.3 & 39.5 & 4.1 & 353.3 & 6.7 \\
\hline 26.5 & 1.48 & 264.3 & 13.2 & 230.1 & 13.4 & 34.2 & 2.4 & 351.5 & 4.9 \\
\hline 28.5 & 1.62 & 164.8 & 12.2 & 130.0 & 12.5 & 34.8 & 2.5 & 218.6 & 3.7 \\
\hline 30.5 & 1.77 & 137.4 & 9.2 & 100.4 & 9.5 & 37.0 & 2.0 & 205.3 & 3.0 \\
\hline 32.5 & 1.93 & 127.5 & 10.9 & 91.5 & 11.2 & 36.1 & 2.5 & 196.3 & 3.5 \\
\hline 34.5 & 2.09 & 97.9 & 8.6 & 62.1 & 8.9 & 35.8 & 2.2 & 159.7 & 2.6 \\
\hline 36.5 & 2.26 & 87.3 & 8.3 & 60.3 & 8.5 & 27.0 & 1.4 & 141.0 & 2.5 \\
\hline 39.5 & 2.55 & 89.7 & 7.2 & 51.4 & 7.7 & 38.3 & 2.5 & 92.8 & 2.3 \\
\hline 41.5 & 2.76 & 104.8 & 7.3 & 65.9 & 7.5 & 38.9 & 1.6 & 75.7 & 1.9 \\
\hline
\end{tabular}


Table 9. Fallout radionuclide concentrations in the Großsee (Brandenburg See 89) sediment core

\begin{tabular}{|c|c|c|c|c|c|c|c|c|c|}
\hline \multicolumn{10}{|c|}{${ }^{210} \mathrm{~Pb}$} \\
\hline \multicolumn{2}{|c|}{ Depth } & \multicolumn{2}{|c|}{ Total } & \multicolumn{2}{|c|}{ Unsupported } & \multicolumn{2}{|c|}{ Supported } & \multicolumn{2}{|c|}{${ }^{137} \mathrm{Cs}$} \\
\hline $\mathrm{cm}$ & $\mathrm{g} \mathrm{cm}^{-2}$ & $\mathrm{~Bq} \mathrm{~kg}{ }^{-1}$ & \pm & $\mathrm{Bq} \mathrm{kg}{ }^{-1}$ & \pm & $\mathrm{Bq} \mathrm{kg}{ }^{-1}$ & \pm & $\mathrm{Bq} \mathrm{kg}{ }^{-1}$ & \pm \\
\hline 0.5 & 0.01 & 656.7 & 21.3 & 626.1 & 21.6 & 30.5 & 3.4 & 253.8 & 5.3 \\
\hline 2.5 & 0.09 & 586.0 & 18.8 & 547.8 & 19.0 & 38.2 & 3.2 & 251.1 & 4.6 \\
\hline 4.5 & 0.18 & 558.0 & 16.4 & 524.6 & 16.7 & 33.4 & 2.8 & 243.7 & 4.4 \\
\hline 8.5 & 0.37 & 595.2 & 14.2 & 562.2 & 14.4 & 33.0 & 2.3 & 280.4 & 3.7 \\
\hline 10.5 & 0.48 & 588.6 & 13.8 & 560.2 & 14.0 & 28.4 & 2.0 & 267.2 & 3.6 \\
\hline 12.5 & 0.59 & 504.4 & 18.1 & 465.0 & 18.4 & 39.4 & 2.9 & 298.0 & 5.5 \\
\hline 14.5 & 0.70 & 391.5 & 14.3 & 356.8 & 14.6 & 34.7 & 2.8 & 273.6 & 4.2 \\
\hline 16.5 & 0.82 & 389.4 & 20.5 & 348.8 & 20.9 & 40.6 & 4.0 & 258.7 & 5.8 \\
\hline 20.5 & 1.08 & 277.9 & 17.7 & 244.0 & 18.1 & 34.0 & 3.4 & 185.7 & 4.8 \\
\hline 24.5 & 1.35 & 183.5 & 13.8 & 151.9 & 14.1 & 31.6 & 3.0 & 115.2 & 3.3 \\
\hline 26.5 & 1.48 & 168.8 & 14.5 & 131.9 & 14.9 & 37.0 & 3.4 & 117.0 & 3.9 \\
\hline 28.5 & 1.62 & 154.3 & 14.4 & 117.7 & 14.7 & 36.5 & 3.1 & 87.6 & 3.1 \\
\hline 30.5 & 1.77 & 117.6 & 10.9 & 85.7 & 11.1 & 31.9 & 2.4 & 67.8 & 2.8 \\
\hline 32.5 & 1.93 & 89.3 & 10.2 & 58.1 & 10.5 & 31.2 & 2.3 & 58.1 & 2.3 \\
\hline 34.5 & 2.09 & 67.0 & 12.3 & 32.1 & 12.7 & 34.9 & 3.0 & 38.4 & 2.4 \\
\hline 36.5 & 2.26 & 38.4 & 8.9 & 6.3 & 9.2 & 32.1 & 2.2 & 32.8 & 1.7 \\
\hline 37.5 & 2.35 & 35.7 & 12.9 & 6.4 & 13.3 & 29.3 & 3.2 & 27.7 & 2.5 \\
\hline
\end{tabular}

Table 10. Fallout radionuclide concentrations in the Ziskensee (Brandenburg See 90) sediment core

\begin{tabular}{|c|c|c|c|c|c|c|c|c|c|}
\hline \multicolumn{10}{|c|}{${ }^{210} \mathrm{~Pb}$} \\
\hline \multicolumn{2}{|c|}{ Depth } & \multicolumn{2}{|c|}{ Total } & \multicolumn{2}{|c|}{ Unsupported } & \multicolumn{2}{|c|}{ Supported } & \multicolumn{2}{|c|}{${ }^{137} \mathrm{Cs}$} \\
\hline $\mathrm{cm}$ & $\mathrm{g} \mathrm{cm}^{-2}$ & $\mathrm{~Bq} \mathrm{~kg}^{-1}$ & \pm & $\mathrm{Bq} \mathrm{kg}^{-1}$ & \pm & $\mathrm{Bq} \mathrm{kg}^{-1}$ & \pm & $\mathrm{Bq} \mathrm{kg}^{-1}$ & \pm \\
\hline 1.0 & 0.02 & 551.1 & 16.7 & 521.0 & 16.9 & 30.1 & 2.6 & 222.7 & 4.3 \\
\hline 2.5 & 0.07 & 554.8 & 21.8 & 523.2 & 22.1 & 31.6 & 4.1 & 219.2 & 5.2 \\
\hline 4.5 & 0.15 & 536.7 & 12.5 & 509.3 & 12.7 & 27.4 & 2.4 & 209.9 & 3.2 \\
\hline 8.5 & 0.35 & 472.7 & 14.0 & 446.4 & 14.1 & 26.3 & 2.4 & 241.6 & 3.5 \\
\hline 12.5 & 0.54 & 429.7 & 12.5 & 397.8 & 12.8 & 31.9 & 2.3 & 231.4 & 3.6 \\
\hline 16.5 & 0.76 & 365.9 & 19.6 & 348.5 & 19.8 & 17.4 & 2.8 & 221.2 & 5.6 \\
\hline 20.5 & 0.98 & 303.5 & 16.5 & 282.6 & 16.7 & 20.9 & 2.6 & 204.9 & 5.0 \\
\hline 24.5 & 1.18 & 221.4 & 12.6 & 198.1 & 12.8 & 23.3 & 2.4 & 162.5 & 3.3 \\
\hline 28.5 & 1.37 & 185.9 & 10.8 & 162.1 & 11.0 & 23.8 & 2.2 & 148.5 & 3.0 \\
\hline 30.5 & 1.47 & 103.1 & 11.5 & 78.8 & 11.7 & 24.2 & 2.3 & 67.4 & 2.5 \\
\hline 32.5 & 1.57 & 81.7 & 10.0 & 67.9 & 10.1 & 13.9 & 1.8 & 44.1 & 2.3 \\
\hline 34.5 & 1.66 & 52.0 & 9.1 & 36.1 & 9.3 & 15.9 & 1.9 & 32.3 & 2.2 \\
\hline 36.5 & 1.76 & 59.2 & 7.5 & 40.1 & 7.7 & 19.1 & 1.6 & 25.5 & 1.4 \\
\hline 38.5 & 1.87 & 47.2 & 7.9 & 28.0 & 8.0 & 19.2 & 1.7 & 16.5 & 1.2 \\
\hline 40.5 & 1.98 & 44.8 & 7.5 & 26.4 & 7.8 & 18.4 & 1.9 & 16.5 & 1.4 \\
\hline
\end{tabular}


Table 11. Fallout radionuclide concentrations in the Schiebelsee (Brandenburg See 94) sediment core

\begin{tabular}{|c|c|c|c|c|c|c|c|c|c|}
\hline \multicolumn{10}{|c|}{${ }^{210} \mathrm{~Pb}$} \\
\hline \multicolumn{2}{|c|}{ Depth } & \multicolumn{2}{|c|}{ Total } & \multicolumn{2}{|c|}{ Unsupported } & \multicolumn{2}{|c|}{ Supported } & \multicolumn{2}{|c|}{${ }^{137} \mathrm{Cs}$} \\
\hline $\mathrm{cm}$ & $\mathrm{g} \mathrm{cm}^{-2}$ & $\mathrm{~Bq} \mathrm{~kg}{ }^{-1}$ & \pm & $\mathrm{Bq} \mathrm{kg}^{-1}$ & \pm & $\mathrm{Bq} \mathrm{kg}{ }^{-1}$ & \pm & $\mathrm{Bq} \mathrm{kg}{ }^{-1}$ & \pm \\
\hline 0.5 & 0.01 & 385.3 & 24.5 & 336.4 & 24.9 & 48.9 & 4.8 & 189.1 & 5.7 \\
\hline 2.5 & 0.09 & 361.1 & 28.0 & 295.2 & 28.7 & 65.9 & 6.1 & 221.3 & 6.4 \\
\hline 4.5 & 0.20 & 379.7 & 13.8 & 337.3 & 14.0 & 42.4 & 2.4 & 213.1 & 4.1 \\
\hline 8.5 & 0.48 & 278.8 & 18.1 & 246.3 & 18.5 & 32.5 & 3.6 & 231.0 & 5.0 \\
\hline 12.5 & 0.80 & 328.7 & 11.8 & 284.5 & 11.9 & 44.2 & 2.0 & 254.7 & 3.6 \\
\hline 16.5 & 1.18 & 260.9 & 14.3 & 223.5 & 14.6 & 37.5 & 2.6 & 271.8 & 4.6 \\
\hline 18.5 & 1.47 & 223.2 & 13.2 & 170.8 & 13.5 & 52.4 & 2.8 & 323.2 & 4.8 \\
\hline 20.5 & 1.93 & 157.9 & 15.9 & 98.4 & 16.2 & 59.5 & 3.1 & 347.5 & 5.2 \\
\hline 22.5 & 2.31 & 126.8 & 13.6 & 82.5 & 13.9 & 44.2 & 3.0 & 268.9 & 4.5 \\
\hline 24.5 & 2.61 & 159.3 & 12.7 & 116.4 & 12.9 & 42.9 & 2.5 & 133.0 & 3.6 \\
\hline 26.5 & 2.95 & 122.0 & 11.2 & 79.1 & 11.8 & 42.9 & 3.5 & 103.0 & 3.3 \\
\hline 28.5 & 3.34 & 101.1 & 6.8 & 55.4 & 7.0 & 45.8 & 1.5 & 107.4 & 1.8 \\
\hline 32.5 & 4.18 & 92.8 & 7.4 & 52.1 & 7.6 & 40.7 & 1.5 & 101.4 & 1.7 \\
\hline 36.5 & 4.89 & 102.6 & 7.4 & 57.2 & 7.6 & 45.4 & 1.6 & 96.4 & 1.9 \\
\hline 38.5 & 5.31 & 81.9 & 10.3 & 35.9 & 10.5 & 46.0 & 2.4 & 81.9 & 2.7 \\
\hline 40.5 & 5.76 & 95.1 & 6.6 & 51.5 & 7.3 & 43.6 & 3.0 & 68.3 & 2.1 \\
\hline 42.5 & 6.28 & 58.9 & 5.2 & 19.9 & 5.4 & 39.0 & 1.3 & 24.4 & 1.1 \\
\hline
\end{tabular}

Table 12. Fallout radionuclide concentrations in the Bugsee (Brandenburg See 97) sediment core

\begin{tabular}{|c|c|c|c|c|c|c|c|c|c|}
\hline \multicolumn{10}{|c|}{${ }^{210} \mathrm{~Pb}$} \\
\hline \multicolumn{2}{|c|}{ Depth } & \multicolumn{2}{|c|}{ Total } & \multicolumn{2}{|c|}{ Unsupported } & \multicolumn{2}{|c|}{ Supported } & \multicolumn{2}{|c|}{${ }^{137} \mathrm{Cs}$} \\
\hline $\mathrm{cm}$ & $\mathrm{g} \mathrm{cm}^{-2}$ & $\mathrm{~Bq} \mathrm{~kg}^{-1}$ & \pm & $\mathrm{Bq} \mathrm{kg}^{-1}$ & \pm & $\mathrm{Bq} \mathrm{kg}^{-1}$ & \pm & $\mathrm{Bq} \mathrm{kg}^{-1}$ & \pm \\
\hline 0.5 & 0.04 & 153.1 & 15.2 & 134.6 & 15.6 & 18.5 & 3.3 & 11.8 & 2.0 \\
\hline 2.5 & 0.33 & 164.2 & 16.0 & 138.7 & 16.2 & 25.5 & 2.8 & 16.2 & 2.5 \\
\hline 4.5 & 0.64 & 181.4 & 12.3 & 162.6 & 12.6 & 18.8 & 2.6 & 16.3 & 2.0 \\
\hline 6.5 & 1.12 & 119.1 & 10.9 & 107.3 & 11.1 & 11.8 & 2.2 & 18.3 & 2.0 \\
\hline 8.5 & 1.59 & 113.1 & 12.6 & 96.9 & 13.0 & 16.3 & 3.0 & 36.4 & 2.6 \\
\hline 10.5 & 2.04 & 105.0 & 12.0 & 80.1 & 12.3 & 25.0 & 2.8 & 129.3 & 3.6 \\
\hline 12.5 & 2.81 & 69.4 & 5.9 & 26.0 & 6.1 & 43.4 & 1.4 & 139.3 & 2.0 \\
\hline 14.5 & 3.82 & 54.0 & 6.9 & 8.8 & 7.0 & 45.1 & 1.6 & 126.4 & 2.2 \\
\hline 16.5 & 4.51 & 73.2 & 14.4 & 56.8 & 14.9 & 16.4 & 3.5 & 37.7 & 3.1 \\
\hline 18.5 & 4.90 & 70.6 & 13.6 & 58.3 & 13.9 & 12.3 & 3.0 & 18.1 & 2.7 \\
\hline 20.5 & 5.29 & 83.3 & 14.6 & 72.0 & 15.1 & 11.3 & 3.7 & 24.7 & 2.9 \\
\hline 22.5 & 5.71 & 52.2 & 9.5 & 40.2 & 9.8 & 12.0 & 2.4 & 55.6 & 2.3 \\
\hline 24.5 & 6.17 & 81.6 & 12.1 & 52.9 & 12.5 & 28.8 & 2.8 & 50.3 & 2.8 \\
\hline 26.5 & 6.71 & 57.2 & 8.5 & 30.6 & 8.7 & 26.5 & 1.9 & 18.0 & 1.7 \\
\hline 27.5 & 7.02 & 59.4 & 10.0 & 23.3 & 10.2 & 36.1 & 2.3 & 11.6 & 1.7 \\
\hline
\end{tabular}


Table 13. Fallout radionuclide concentrations in the Piechesee (Brandenburg See 102) sediment core

\begin{tabular}{|c|c|c|c|c|c|c|c|c|c|}
\hline \multicolumn{10}{|c|}{${ }^{210} \mathrm{~Pb}$} \\
\hline \multicolumn{2}{|c|}{ Depth } & \multicolumn{2}{|c|}{ Total } & \multicolumn{2}{|c|}{ Unsupported } & \multicolumn{2}{|c|}{ Supported } & \multicolumn{2}{|c|}{${ }^{137} \mathrm{Cs}$} \\
\hline $\mathrm{cm}$ & $\mathrm{g} \mathrm{cm}^{-2}$ & $\mathrm{~Bq} \mathrm{~kg}^{-1}$ & \pm & $\mathrm{Bq} \mathrm{kg}{ }^{-1}$ & \pm & $\mathrm{Bq} \mathrm{kg}^{-1}$ & \pm & $\mathrm{Bq} \mathrm{kg}^{-1}$ & \pm \\
\hline 0.5 & 0.02 & 342.1 & 17.4 & 302.1 & 17.7 & 39.9 & 3.4 & 439.3 & 6.4 \\
\hline 2.5 & 0.09 & 394.5 & 14.1 & 358.8 & 14.4 & 35.7 & 2.4 & 420.9 & 4.7 \\
\hline 4.5 & 0.18 & 401.1 & 11.9 & 369.2 & 12.0 & 31.8 & 2.0 & 423.1 & 4.5 \\
\hline 8.5 & 0.41 & 392.6 & 10.9 & 362.5 & 11.1 & 30.1 & 1.7 & 403.9 & 3.7 \\
\hline 12.5 & 0.65 & 344.4 & 10.0 & 313.0 & 10.1 & 31.3 & 1.8 & 394.1 & 3.4 \\
\hline 16.5 & 0.93 & 349.9 & 15.8 & 322.2 & 16.0 & 27.7 & 2.7 & 415.5 & 5.8 \\
\hline 20.5 & 1.22 & 363.2 & 15.1 & 337.5 & 15.3 & 25.7 & 2.1 & 413.2 & 5.7 \\
\hline 24.5 & 1.53 & 309.7 & 11.1 & 279.5 & 11.3 & 30.3 & 1.9 & 403.0 & 3.9 \\
\hline 28.5 & 1.83 & 302.4 & 10.1 & 277.8 & 10.3 & 24.6 & 1.7 & 445.3 & 4.1 \\
\hline 30.5 & 2.00 & 335.7 & 15.6 & 305.2 & 15.9 & 30.5 & 2.7 & 451.2 & 5.7 \\
\hline 32.5 & 2.15 & 336.1 & 8.9 & 312.0 & 9.0 & 24.1 & 1.3 & 452.4 & 3.2 \\
\hline 34.5 & 2.30 & 242.2 & 16.7 & 220.6 & 17.0 & 21.6 & 3.3 & 454.5 & 6.3 \\
\hline 36.5 & 2.43 & 330.8 & 10.6 & 299.8 & 10.8 & 31.0 & 2.0 & 489.5 & 3.8 \\
\hline 38.5 & 2.55 & 223.4 & 15.7 & 187.4 & 16.0 & 36.0 & 3.2 & 269.9 & 5.0 \\
\hline
\end{tabular}

Table 14. Fallout radionuclide concentrations in the Aalgastsee (Brandenburg See 108) sediment core

\begin{tabular}{|c|c|c|c|c|c|c|c|c|c|}
\hline \multicolumn{10}{|c|}{${ }^{210} \mathrm{~Pb}$} \\
\hline \multicolumn{2}{|c|}{ Depth } & \multicolumn{2}{|c|}{ Total } & \multicolumn{2}{|c|}{ Unsupported } & \multicolumn{2}{|c|}{ Supported } & \multicolumn{2}{|c|}{${ }^{137} \mathrm{Cs}$} \\
\hline $\mathrm{cm}$ & $\mathrm{g} \mathrm{cm}^{-2}$ & $\mathrm{~Bq} \mathrm{~kg}^{-1}$ & \pm & $\mathrm{Bq} \mathrm{kg}^{-1}$ & \pm & $\mathrm{Bq} \mathrm{kg}^{-1}$ & \pm & $\mathrm{Bq} \mathrm{kg}^{-1}$ & \pm \\
\hline 0.5 & 0.01 & 364.6 & 20.7 & 337.9 & 21.1 & 26.7 & 4.3 & 114.1 & 4.6 \\
\hline 2.5 & 0.14 & 330.2 & 12.6 & 307.9 & 12.8 & 22.3 & 2.3 & 108.1 & 2.7 \\
\hline 4.5 & 0.29 & 311.0 & 10.8 & 293.1 & 10.9 & 17.9 & 1.6 & 119.7 & 2.7 \\
\hline 6.5 & 0.48 & 236.3 & 14.7 & 218.7 & 14.9 & 17.5 & 2.5 & 124.5 & 4.2 \\
\hline 8.5 & 0.69 & 208.1 & 7.6 & 191.0 & 7.7 & 17.0 & 1.4 & 124.0 & 2.0 \\
\hline 10.5 & 0.90 & 171.9 & 12.8 & 159.6 & 12.9 & 12.3 & 2.2 & 72.9 & 2.8 \\
\hline 12.5 & 1.10 & 174.3 & 7.8 & 156.9 & 7.9 & 17.4 & 1.3 & 58.1 & 1.7 \\
\hline 14.5 & 1.28 & 129.5 & 13.4 & 113.9 & 13.7 & 15.6 & 2.9 & 46.1 & 2.5 \\
\hline 16.5 & 1.50 & 134.7 & 8.0 & 118.7 & 8.1 & 16.0 & 1.5 & 49.7 & 1.6 \\
\hline 18.5 & 1.70 & 109.3 & 6.6 & 91.5 & 6.7 & 17.7 & 1.3 & 55.6 & 1.4 \\
\hline 20.5 & 1.89 & 68.7 & 7.3 & 48.8 & 7.5 & 19.9 & 1.9 & 29.0 & 1.4 \\
\hline 22.5 & 2.10 & 21.3 & 5.0 & 2.5 & 5.2 & 18.9 & 1.4 & 20.2 & 1.1 \\
\hline 24.5 & 2.35 & 12.6 & 5.1 & -1.2 & 5.2 & 13.8 & 1.2 & 23.6 & 1.0 \\
\hline 28.5 & 2.94 & 25.4 & 6.1 & 3.6 & 6.2 & 21.9 & 1.4 & 21.2 & 1.2 \\
\hline 32.5 & 3.60 & 26.9 & 6.3 & 0.8 & 6.5 & 26.1 & 1.5 & 23.0 & 1.1 \\
\hline 36.5 & 4.21 & 19.9 & 5.2 & -1.6 & 5.4 & 21.5 & 1.3 & 15.6 & 1.2 \\
\hline
\end{tabular}


Table 15. Fallout radionuclide concentrations in the Papensee (Brandenburg See 111) sediment core

\begin{tabular}{|c|c|c|c|c|c|c|c|c|c|}
\hline \multicolumn{10}{|c|}{${ }^{210} \mathrm{~Pb}$} \\
\hline \multicolumn{2}{|c|}{ Depth } & \multicolumn{2}{|c|}{ Total } & \multicolumn{2}{|c|}{ Unsupported } & \multicolumn{2}{|c|}{ Supported } & \multicolumn{2}{|c|}{${ }^{137} \mathrm{Cs}$} \\
\hline $\mathrm{cm}$ & $\mathrm{g} \mathrm{cm}^{-2}$ & $\mathrm{~Bq} \mathrm{~kg}{ }^{-1}$ & \pm & $\mathrm{Bq} \mathrm{kg}{ }^{-1}$ & \pm & $\mathrm{Bq} \mathrm{kg}{ }^{-1}$ & \pm & $\mathrm{Bq} \mathrm{kg}{ }^{-1}$ & \pm \\
\hline 1.0 & 0.01 & 604.5 & 16.6 & 571.8 & 16.8 & 32.8 & 3.0 & 124.1 & 3.3 \\
\hline 2.5 & 0.05 & 569.0 & 21.1 & 531.2 & 21.5 & 37.8 & 3.8 & 140.4 & 4.4 \\
\hline 4.5 & 0.16 & 468.4 & 18.3 & 435.5 & 18.5 & 32.9 & 2.8 & 153.3 & 4.1 \\
\hline 8.5 & 0.38 & 400.6 & 11.4 & 363.8 & 11.6 & 36.8 & 2.1 & 164.9 & 2.6 \\
\hline 12.5 & 0.64 & 308.0 & 13.5 & 264.2 & 13.7 & 43.8 & 2.5 & 189.0 & 3.7 \\
\hline 14.5 & 0.79 & 326.1 & 22.8 & 284.8 & 23.3 & 41.3 & 4.9 & 210.7 & 7.1 \\
\hline 16.5 & 0.94 & 334.9 & 12.2 & 301.2 & 12.5 & 33.7 & 2.3 & 186.2 & 3.3 \\
\hline 18.5 & 1.11 & 327.8 & 20.0 & 287.4 & 20.3 & 40.4 & 3.7 & 195.1 & 6.1 \\
\hline 20.5 & 1.27 & 309.0 & 13.4 & 267.2 & 13.7 & 41.8 & 2.9 & 182.9 & 3.6 \\
\hline 22.5 & 1.43 & 244.2 & 12.5 & 206.8 & 12.7 & 37.4 & 2.2 & 159.4 & 3.2 \\
\hline 24.5 & 1.61 & 160.9 & 8.3 & 123.4 & 8.5 & 37.4 & 1.6 & 70.2 & 1.8 \\
\hline 28.5 & 2.06 & 93.7 & 9.8 & 57.3 & 10.0 & 36.3 & 2.0 & 25.8 & 1.5 \\
\hline 32.5 & 2.52 & 61.1 & 7.6 & 30.4 & 7.8 & 30.8 & 1.8 & 11.0 & 1.4 \\
\hline 34.5 & 2.77 & 87.7 & 6.6 & 44.2 & 6.8 & 43.4 & 1.4 & 10.8 & 0.8 \\
\hline 36.5 & 3.03 & 60.5 & 8.4 & 19.9 & 8.5 & 40.7 & 1.6 & 8.6 & 1.1 \\
\hline 38.5 & 3.28 & 60.5 & 5.5 & 20.8 & 5.7 & 39.6 & 1.4 & 6.0 & 0.9 \\
\hline
\end{tabular}

Table 16. Radionuclide parameters for the Brandenburg lakes sediment cores

\begin{tabular}{|c|c|c|c|c|c|c|c|c|}
\hline \multirow{3}{*}{ Core } & \multicolumn{6}{|c|}{ Unsupported ${ }^{210} \mathrm{~Pb}$} & \multirow{2}{*}{\multicolumn{2}{|c|}{$\begin{array}{c}{ }^{137} \mathrm{Cs} \\
\text { Inventory }\end{array}$}} \\
\hline & \multicolumn{2}{|c|}{$\begin{array}{l}\text { Maximum } \\
\text { activity }\end{array}$} & \multicolumn{2}{|c|}{ Inventory } & \multicolumn{2}{|c|}{ Flux } & & \\
\hline & $\mathrm{Bq} \mathrm{kg}^{-1}$ & \pm & $\mathrm{Bq} \mathrm{m}^{-2}$ & \pm & $\mathrm{Bq} \mathrm{m}^{-2} \mathrm{y}^{-1}$ & \pm & $\mathrm{Bq} \mathrm{m}^{-2}$ & \pm \\
\hline See 23 & 191 & 28 & 3229 & 159 & 101 & 6 & 584 & 27 \\
\hline See 67 & 274 & 20 & 4334 & 92 & 135 & 4 & 2685 & 38 \\
\hline See 71 & 388 & 17 & 3484 & 93 & 109 & 3 & 4840 & 75 \\
\hline See 72 & 233 & 13 & 3581 & 179 & 112 & 6 & 3405 & 59 \\
\hline See 76 & 277 & 14 & 3994 & 154 & 124 & 5 & 247 & 15 \\
\hline See 79 & 494 & 15 & 3402 & 77 & 106 & 3 & 1000 & 18 \\
\hline See 81 & 820 & 46 & 4377 & 95 & 136 & 3 & 673 & 15 \\
\hline See 86 & 356 & 11 & 5683 & 141 & 177 & 7 & 7443 & 141 \\
\hline See 89 & 626 & 22 & 6120 & 134 & 191 & 4 & 3853 & 62 \\
\hline See 90 & 523 & 22 & 5269 & 123 & 164 & 4 & 3123 & 58 \\
\hline See 94 & 337 & 14 & 7242 & 212 & 226 & 7 & 10337 & 157 \\
\hline See 97 & 139 & 16 & 4597 & 233 & 143 & 8 & 4458 & 105 \\
\hline See 102 & 369 & 12 & 10031 & 196 & 312 & 34 & 10729 & 162 \\
\hline See 108 & 338 & 21 & 3372 & 91 & 105 & 3 & 2045 & 34 \\
\hline See 111 & 572 & 17 & 5880 & 138 & 183 & 5 & 3108 & 53 \\
\hline
\end{tabular}


Table 17. ${ }^{210} \mathrm{~Pb}$ chronology of the Kleiner Treppelsee (Brandenburg See 23) sediment core

\begin{tabular}{|c|c|c|c|c|c|c|c|}
\hline \multicolumn{2}{|c|}{ Depth } & \multicolumn{3}{|c|}{ Chronology } & \multicolumn{3}{|c|}{ Sedimentation Rate } \\
\hline & & Date & Age & & & & \\
\hline $\mathrm{cm}$ & $\mathrm{g} \mathrm{cm}^{-2}$ & $A D$ & y & \pm & $\mathrm{g} \mathrm{cm}^{-2} \mathrm{y}^{-1}$ & $\mathrm{~cm} \mathrm{y}^{-1}$ & $\pm(\%)$ \\
\hline 0.0 & 0.00 & 2009 & 0 & 0 & & & \\
\hline 0.5 & 0.02 & 2009 & 0 & 1 & 0.049 & 0.83 & 15.3 \\
\hline 2.5 & 0.13 & 2006 & 3 & 2 & 0.041 & 0.66 & 8.8 \\
\hline 4.5 & 0.28 & 2003 & 6 & 2 & 0.045 & 0.55 & 13.3 \\
\hline 6.5 & 0.45 & 1999 & 10 & 2 & 0.042 & 0.45 & 12.5 \\
\hline 8.5 & 0.64 & 1994 & 15 & 2 & 0.038 & 0.43 & 15.0 \\
\hline 10.5 & 0.83 & 1989 & 20 & 2 & 0.045 & 0.41 & 18.0 \\
\hline 12.5 & 1.04 & 1984 & 25 & 2 & 0.036 & 0.38 & 18.6 \\
\hline 14.5 & 1.24 & 1979 & 30 & 3 & 0.045 & 0.39 & 24.6 \\
\hline 16.5 & 1.46 & 1974 & 35 & 3 & 0.042 & 0.41 & 29.1 \\
\hline 18.5 & 1.67 & 1969 & 40 & 3 & 0.048 & 0.43 & 35.2 \\
\hline 20.5 & 1.89 & 1964 & 45 & 4 & 0.043 & 0.36 & 26.3 \\
\hline 22.5 & 2.12 & 1958 & 51 & 4 & 0.031 & 0.28 & 21.2 \\
\hline 24.5 & 2.34 & 1950 & 59 & 5 & 0.029 & 0.28 & 27.6 \\
\hline 26.5 & 2.55 & 1944 & 65 & 6 & 0.040 & 0.32 & \\
\hline 28.5 & 2.76 & 1938 & 71 & 7 & 0.034 & 0.33 & \\
\hline
\end{tabular}

Table 18. ${ }^{210} \mathrm{~Pb}$ chronology of the Kesselsee (Brandenburg See 67) sediment core

\begin{tabular}{|c|c|c|c|c|c|c|c|}
\hline \multicolumn{2}{|c|}{ Depth } & \multicolumn{3}{|c|}{ Chronology } & \multicolumn{3}{|c|}{ Sedimentation Rate } \\
\hline & & Date & Age & & & & \\
\hline $\mathrm{cm}$ & $\mathrm{g} \mathrm{cm}^{-2}$ & $A D$ & $\mathrm{y}$ & \pm & $\mathrm{g} \mathrm{cm}^{-2} \mathrm{y}^{-1}$ & $\mathrm{~cm} \mathrm{y}^{-1}$ & $\pm(\%)$ \\
\hline 0.0 & 0.00 & 2009 & 0 & 0 & & & \\
\hline 0.5 & 0.02 & 2009 & 0 & 2 & 0.049 & 1.25 & 7.6 \\
\hline 2.5 & 0.08 & 2007 & 2 & 2 & 0.040 & 1.00 & 6.1 \\
\hline 4.5 & 0.16 & 2005 & 4 & 2 & 0.035 & 0.86 & 5.1 \\
\hline 8.5 & 0.32 & 2000 & 9 & 2 & 0.032 & 0.73 & 4.5 \\
\hline 12.5 & 0.50 & 1994 & 15 & 2 & 0.027 & 0.60 & 4.9 \\
\hline 14.5 & 0.59 & 1990 & 19 & 2 & 0.022 & 0.50 & 6.2 \\
\hline 16.5 & 0.69 & 1986 & 23 & 2 & 0.021 & 0.44 & 5.9 \\
\hline 18.5 & 0.79 & 1981 & 28 & 2 & 0.023 & 0.40 & 9.6 \\
\hline 20.5 & 0.90 & 1976 & 33 & 2 & 0.021 & 0.36 & 8.9 \\
\hline 22.5 & 1.02 & 1970 & 39 & 2 & 0.021 & 0.33 & 10.3 \\
\hline 24.5 & 1.14 & 1964 & 45 & 2 & 0.018 & 0.29 & 9.7 \\
\hline 26.5 & 1.27 & 1956 & 53 & 3 & 0.015 & 0.25 & 11.9 \\
\hline 28.5 & 1.39 & 1948 & 61 & 4 & 0.014 & 0.24 & 13.4 \\
\hline 30.5 & 1.52 & 1939 & 70 & 5 & 0.014 & 0.22 & 18.2 \\
\hline 32.5 & 1.65 & 1930 & 79 & 6 & 0.016 & 0.24 & 22.7 \\
\hline 34.5 & 1.78 & 1922 & 87 & 8 & 0.016 & 0.22 & 30.2 \\
\hline 36.5 & 1.92 & 1912 & 97 & 10 & 0.014 & 0.19 & 37.5 \\
\hline 39.5 & 2.15 & 1895 & 114 & 16 & 0.013 & 0.18 & 48.5 \\
\hline
\end{tabular}


Table 19. ${ }^{210} \mathrm{~Pb}$ chronology of the Schwarzersee (See 71) sediment core

\begin{tabular}{|c|c|c|c|c|c|c|c|}
\hline \multicolumn{2}{|c|}{ Depth } & \multicolumn{3}{|c|}{ Chronology } & \multicolumn{3}{|c|}{ Sedimentation Rate } \\
\hline & & Date & Age & & & & \\
\hline $\mathrm{cm}$ & $\mathrm{g} \mathrm{cm}^{-2}$ & $A D$ & $\mathrm{y}$ & \pm & $\mathrm{g} \mathrm{cm}^{-2} \mathrm{y}^{-1}$ & $\mathrm{~cm} \mathrm{y}^{-1}$ & $\pm(\%)$ \\
\hline 0.0 & 0.00 & 2009 & 0 & 0 & & & \\
\hline 0.5 & 0.01 & 2009 & 0 & 2 & 0.028 & 1.25 & 4.4 \\
\hline 2.5 & 0.07 & 2007 & 2 & 2 & 0.034 & 0.80 & 7.9 \\
\hline 4.5 & 0.15 & 2004 & 5 & 2 & 0.028 & 0.60 & 5.6 \\
\hline 8.5 & 0.33 & 1997 & 12 & 2 & 0.023 & 0.46 & 5.5 \\
\hline 10.5 & 0.44 & 1991 & 18 & 2 & 0.018 & 0.31 & 6.8 \\
\hline 12.5 & 0.57 & 1984 & 25 & 2 & 0.016 & 0.29 & 5.5 \\
\hline 14.5 & 0.67 & 1977 & 32 & 2 & 0.014 & 0.29 & 8.1 \\
\hline 16.5 & 0.79 & 1970 & 39 & 2 & 0.016 & 0.27 & 8.3 \\
\hline 18.5 & 0.91 & 1962 & 47 & 2 & 0.019 & 0.31 & 10.7 \\
\hline 20.5 & 1.04 & 1957 & 52 & 3 & 0.025 & 0.36 & 18.6 \\
\hline 22.5 & 1.17 & 1951 & 58 & 3 & 0.019 & 0.29 & 14.5 \\
\hline 24.5 & 1.29 & 1943 & 66 & 4 & 0.015 & 0.23 & 16.7 \\
\hline 28.5 & 1.56 & 1925 & 84 & 5 & 0.015 & 0.21 & 23.0 \\
\hline 32.5 & 1.83 & 1905 & 104 & 8 & 0.011 & 0.18 & 35.9 \\
\hline 35.5 & 2.04 & 1886 & 123 & 12 & 0.011 & 0.15 & 47.2 \\
\hline 38.5 & 2.26 & 1865 & 144 & 15 & 0.011 & 0.14 & 56.5 \\
\hline
\end{tabular}

Table 20. ${ }^{210} \mathrm{~Pb}$ chronology of the Heiligensee (Brandenburg See 72) sediment core

\begin{tabular}{|c|c|c|c|c|c|c|c|}
\hline \multirow{2}{*}{\multicolumn{2}{|c|}{ Depth }} & \multicolumn{3}{|c|}{ Chronology } & \multicolumn{3}{|c|}{ Sedimentation Rate } \\
\hline & & Date & Age & & & & \\
\hline $\mathrm{cm}$ & $\mathrm{g} \mathrm{cm}^{-2}$ & $A D$ & y & \pm & $\mathrm{g} \mathrm{cm}^{-2} \mathrm{y}^{-1}$ & $\mathrm{~cm} \mathrm{y}^{-1}$ & $\pm(\%)$ \\
\hline 0.0 & 0.00 & 2009 & 0 & 0 & & & \\
\hline 0.5 & 0.02 & 2009 & 0 & 1 & 0.077 & 0.83 & 10.3 \\
\hline 2.5 & 0.20 & 2006 & 3 & 2 & 0.060 & 0.53 & 8.3 \\
\hline 4.5 & 0.44 & 2001 & 8 & 2 & 0.039 & 0.31 & 8.4 \\
\hline 6.5 & 0.79 & 1993 & 16 & 2 & 0.054 & 0.31 & 11.3 \\
\hline 8.5 & 1.14 & 1988 & 21 & 2 & 0.081 & 0.38 & 15.4 \\
\hline 9.5 & 1.36 & 1985 & 24 & 2 & 0.082 & 0.40 & 16.4 \\
\hline 10.5 & 1.60 & 1983 & 26 & 3 & 0.126 & 0.50 & 22.8 \\
\hline 11.5 & 1.93 & 1981 & 28 & 3 & 0.215 & 0.50 & 53.4 \\
\hline 12.5 & 2.25 & 1979 & 30 & 3 & 0.092 & 0.50 & 24.7 \\
\hline 14.5 & 2.66 & 1975 & 34 & 3 & 0.105 & 0.44 & 27.0 \\
\hline 16.5 & 3.19 & 1970 & 39 & 4 & 0.142 & 0.50 & 37.8 \\
\hline 17.5 & 3.45 & 1969 & 40 & 4 & 0.208 & 0.67 & 71.2 \\
\hline 18.5 & 3.72 & 1967 & 42 & 4 & 0.063 & 0.33 & 26.6 \\
\hline 19.5 & 3.98 & 1963 & 46 & 5 & 0.086 & 0.29 & 36.0 \\
\hline 20.5 & 4.27 & 1960 & 49 & 5 & 0.086 & 0.27 & 32.7 \\
\hline 22.5 & 4.94 & 1952 & 57 & 7 & 0.087 & 0.34 & 41.7 \\
\hline 24.5 & 5.65 & 1948 & 61 & 8 & 0.139 & 0.43 & \\
\hline 27.5 & 6.48 & 1940 & 69 & 8 & 0.065 & 0.31 & \\
\hline 30.5 & 7.24 & 1929 & 80 & 10 & 0.071 & 0.24 & \\
\hline 33.5 & 8.07 & 1915 & 94 & 16 & 0.047 & 0.21 & \\
\hline
\end{tabular}


Table $21 .{ }^{210} \mathrm{~Pb}$ chronology of the Teufelssee (Brandenburg See 76) sediment core

\begin{tabular}{|c|c|c|c|c|c|c|c|}
\hline \multicolumn{2}{|c|}{ Depth } & \multicolumn{3}{|c|}{ Chronology } & \multicolumn{3}{|c|}{ Sedimentation Rate } \\
\hline & & Date & Age & & & & \\
\hline $\mathrm{cm}$ & $\mathrm{g} \mathrm{cm}^{-2}$ & $A D$ & $y$ & \pm & $\mathrm{g} \mathrm{cm}^{-2} \mathrm{y}^{-1}$ & $\mathrm{~cm} \mathrm{y}^{-1}$ & $\pm(\%)$ \\
\hline 0.0 & 0.00 & 2009 & 0 & 0 & & & \\
\hline 0.5 & 0.05 & 2008 & 1 & 1 & 0.033 & 0.25 & 12.8 \\
\hline 2.5 & 0.33 & 1999 & 10 & 2 & 0.033 & 0.22 & 12.8 \\
\hline 4.5 & 0.64 & 1990 & 19 & 2 & 0.033 & 0.21 & 12.8 \\
\hline 6.5 & 0.98 & 1979 & 30 & 2 & 0.033 & 0.18 & 12.8 \\
\hline 7.5 & 1.19 & 1973 & 36 & 2 & 0.033 & 0.16 & 12.8 \\
\hline 8.5 & 1.38 & 1967 & 42 & 3 & 0.033 & 0.19 & 12.8 \\
\hline 9.5 & 1.53 & 1963 & 46 & 3 & 0.033 & 0.21 & 12.8 \\
\hline 10.5 & 1.70 & 1958 & 51 & 4 & 0.033 & 0.20 & 12.8 \\
\hline 12.5 & 2.02 & 1948 & 61 & 5 & 0.033 & 0.20 & 12.8 \\
\hline 14.5 & 2.40 & 1938 & 71 & 6 & 0.050 & 0.26 & \\
\hline 16.5 & 2.78 & 1933 & 76 & 7 & 0.101 & 0.50 & \\
\hline 18.5 & 3.21 & 1930 & 79 & 7 & 0.178 & 0.80 & \\
\hline 20.5 & 3.67 & 1928 & 81 & 7 & 0.040 & 0.28 & \\
\hline 22.5 & 4.12 & 1916 & 93 & 9 & 0.033 & 0.15 & \\
\hline 24.5 & 4.59 & 1901 & 108 & 13 & 0.033 & 0.13 & \\
\hline
\end{tabular}

Table 22. ${ }^{210} \mathrm{~Pb}$ chronology of the Glabatzsee (Brandenburg See 79) sediment core

\begin{tabular}{|c|c|c|c|c|c|c|c|}
\hline \multicolumn{2}{|c|}{ Depth } & \multicolumn{3}{|c|}{ Chronology } & \multicolumn{3}{|c|}{ Sedimentation Rate } \\
\hline & & Date & Age & & & & \\
\hline $\mathrm{cm}$ & $\mathrm{g} \mathrm{cm}^{-2}$ & $A D$ & y & \pm & $\mathrm{g} \mathrm{cm}^{-2} \mathrm{y}^{-1}$ & $\mathrm{~cm} \mathrm{y}^{-1}$ & $\pm(\%)$ \\
\hline 0.0 & 0.00 & 2009 & 0 & 0 & & & \\
\hline 0.5 & 0.01 & 2009 & 0 & 1 & 0.026 & 0.63 & 6.1 \\
\hline 2.5 & 0.08 & 2005 & 4 & 2 & 0.021 & 0.59 & 5.1 \\
\hline 4.5 & 0.15 & 2002 & 7 & 2 & 0.017 & 0.50 & 4.1 \\
\hline 8.5 & 0.31 & 1993 & 16 & 2 & 0.018 & 0.43 & 4.4 \\
\hline 10.5 & 0.39 & 1988 & 21 & 2 & 0.016 & 0.38 & 5.4 \\
\hline 12.5 & 0.48 & 1982 & 27 & 2 & 0.015 & 0.34 & 5.1 \\
\hline 14.5 & 0.57 & 1976 & 33 & 2 & 0.015 & 0.29 & 6.2 \\
\hline 16.5 & 0.68 & 1968 & 41 & 2 & 0.015 & 0.27 & 8.7 \\
\hline 18.5 & 0.78 & 1962 & 47 & 2 & 0.015 & 0.28 & 9.5 \\
\hline 20.5 & 0.89 & 1954 & 55 & 3 & 0.015 & 0.28 & 11.1 \\
\hline 22.5 & 0.99 & 1947 & 62 & 3 & 0.015 & 0.30 & 11.1 \\
\hline 24.5 & 1.09 & 1941 & 68 & 4 & 0.015 & 0.28 & 11.1 \\
\hline 28.5 & 1.29 & 1926 & 83 & 5 & 0.015 & 0.26 & 11.1 \\
\hline 32.5 & 1.53 & 1910 & 99 & 6 & 0.015 & 0.25 & 11.1 \\
\hline 35.5 & 1.69 & 1899 & 110 & 9 & 0.015 & 0.25 & 11.1 \\
\hline 39.5 & 1.94 & 1882 & 127 & 16 & 0.015 & 0.24 & 11.1 \\
\hline
\end{tabular}


Table 23. ${ }^{210} \mathrm{~Pb}$ chronology of the Kleiner Lychensee (Brandenburg See 81) sediment core

\begin{tabular}{|c|c|c|c|c|c|c|c|}
\hline \multicolumn{2}{|c|}{ Depth } & \multicolumn{3}{|c|}{ Chronology } & \multicolumn{3}{|c|}{ Sedimentation Rate } \\
\hline $\mathrm{cm}$ & $\mathrm{g} \mathrm{cm}^{-2}$ & $\begin{array}{c}\text { Date } \\
\text { AD }\end{array}$ & $\begin{array}{l}\text { Age } \\
y\end{array}$ & \pm & $\mathrm{g} \mathrm{cm}^{-2} \mathrm{y}^{-1}$ & $\mathrm{~cm} \mathrm{y}^{-1}$ & $\pm(\%)$ \\
\hline 0.0 & 0.00 & 2009 & 0 & 0 & & & \\
\hline 0.5 & 0.01 & 2009 & 0 & 1 & 0.016 & 0.59 & 4.9 \\
\hline 2.5 & 0.06 & 2005 & 4 & 1 & 0.013 & 0.49 & 6.0 \\
\hline 4.5 & 0.12 & 2000 & 9 & 2 & 0.015 & 0.45 & 4.6 \\
\hline 6.5 & 0.20 & 1996 & 13 & 3 & 0.017 & 0.43 & 4.7 \\
\hline 8.5 & 0.26 & 1991 & 18 & 3 & 0.015 & 0.41 & 6.0 \\
\hline 10.5 & 0.34 & 1986 & 23 & 3 & 0.015 & 0.39 & 5.6 \\
\hline 12.5 & 0.42 & 1981 & 28 & 3 & 0.018 & 0.34 & 6.0 \\
\hline 14.5 & 0.55 & 1974 & 35 & 4 & 0.017 & 0.32 & 7.4 \\
\hline 16.5 & 0.66 & 1968 & 41 & 4 & 0.018 & 0.36 & 7.8 \\
\hline 18.5 & 0.76 & 1963 & 46 & 4 & 0.024 & 0.42 & 11.3 \\
\hline 20.5 & 0.86 & 1959 & 50 & 4 & 0.021 & 0.43 & 10.9 \\
\hline 22.5 & 0.95 & 1954 & 55 & 4 & 0.016 & 0.39 & 12.1 \\
\hline 24.5 & 1.03 & 1948 & 61 & 5 & 0.016 & 0.41 & 13.3 \\
\hline 26.5 & 1.10 & 1944 & 65 & 5 & 0.012 & 0.37 & 12.5 \\
\hline 28.5 & 1.18 & 1938 & 71 & 5 & 0.012 & 0.32 & 14.8 \\
\hline 30.5 & 1.26 & 1931 & 78 & 6 & 0.012 & 0.32 & 17.7 \\
\hline 32.5 & 1.33 & 1925 & 84 & 6 & 0.013 & 0.33 & 22.1 \\
\hline 34.5 & 1.42 & 1919 & 90 & 7 & 0.015 & 0.30 & 28.1 \\
\hline 37.5 & 1.56 & 1909 & 100 & 9 & 0.011 & 0.23 & 30.3 \\
\hline 41.5 & 1.77 & 1889 & 120 & 16 & 0.011 & 0.21 & 39.4 \\
\hline
\end{tabular}

Table 24. Tentative ${ }^{210} \mathrm{~Pb}$ chronology of the Baasee (Brandenburg See 86 ) sediment core

\begin{tabular}{|c|c|c|c|c|c|}
\hline \multicolumn{2}{|c|}{ Depth } & \multicolumn{2}{|c|}{ Chronology } & \multicolumn{2}{|c|}{ Sedimentation Rate } \\
\hline & & Date & Age & & \\
\hline $\mathrm{cm}$ & $\mathrm{g} \mathrm{cm}^{-2}$ & $A D$ & y & $\mathrm{g} \mathrm{cm}^{-2} \mathrm{y}^{-1}$ & $\mathrm{~cm} \mathrm{y}^{-1}$ \\
\hline 0.0 & 0.00 & 2009 & 0 & & \\
\hline 0.5 & 0.01 & 2009 & 0 & 0.072 & 2.05 \\
\hline 2.5 & 0.09 & 2008 & 1 & 0.070 & 1.67 \\
\hline 4.5 & 0.18 & 2006 & 3 & 0.070 & 1.48 \\
\hline 8.5 & 0.37 & 2004 & 5 & 0.070 & 1.37 \\
\hline 12.5 & 0.59 & 2001 & 8 & 0.066 & 1.18 \\
\hline 16.5 & 0.82 & 1997 & 12 & 0.063 & 1.02 \\
\hline 20.5 & 1.08 & 1993 & 16 & 0.062 & 0.94 \\
\hline 24.5 & 1.35 & 1988 & 21 & 0.059 & 0.88 \\
\hline 26.5 & 1.48 & 1986 & 23 & 0.055 & 0.55 \\
\hline 28.5 & 1.62 & 1981 & 28 & 0.033 & 0.45 \\
\hline 30.5 & 1.77 & 1977 & 32 & 0.039 & 0.51 \\
\hline 32.5 & 1.93 & 1973 & 36 & 0.043 & 0.54 \\
\hline 34.5 & 2.09 & 1970 & 39 & 0.048 & 0.58 \\
\hline 36.5 & 2.26 & 1966 & 43 & 0.049 & 0.54 \\
\hline 39.5 & 2.55 & 1960 & 49 & 0.044 & 0.44 \\
\hline 41.5 & 2.76 & 1955 & 54 & 0.039 & 0.36 \\
\hline
\end{tabular}


Table 25. ${ }^{210} \mathrm{~Pb}$ chronology of the Großsee (Brandenburg See 89) sediment core

\begin{tabular}{cccccccc}
\hline \multicolumn{2}{l}{ Depth } & \multicolumn{5}{c}{ Chronology } \\
\multicolumn{7}{c}{ Date } & Age \\
$\mathrm{cm}$ & $\mathrm{g} \mathrm{cm}^{-2}$ & AD & $\mathrm{y}$ & \pm & $\mathrm{g} \mathrm{cm}^{-2} \mathrm{y}^{-1}$ & $\mathrm{~cm} \mathrm{y}^{-1}$ & $\pm(\%)$ \\
\hline 0.0 & 0.00 & 2009 & 0 & 0 & & & \\
0.5 & 0.01 & 2009 & 0 & 1 & 0.030 & 0.83 & 3.4 \\
2.5 & 0.09 & 2006 & 3 & 2 & 0.032 & 0.72 & 3.5 \\
4.5 & 0.18 & 2003 & 6 & 2 & 0.031 & 0.60 & 4.0 \\
8.5 & 0.37 & 1996 & 13 & 2 & 0.023 & 0.50 & 3.8 \\
10.5 & 0.48 & 1991 & 18 & 2 & 0.020 & 0.40 & 4.0 \\
12.5 & 0.59 & 1986 & 23 & 2 & 0.020 & 0.36 & 5.3 \\
14.5 & 0.70 & 1980 & 29 & 2 & 0.022 & 0.33 & 5.7 \\
16.5 & 0.82 & 1974 & 35 & 2 & 0.019 & 0.30 & 7.4 \\
20.5 & 1.08 & 1960 & 49 & 2 & 0.017 & 0.27 & 8.9 \\
24.5 & 1.35 & 1944 & 65 & 2 & 0.017 & 0.24 & 11.3 \\
26.5 & 1.48 & 1935 & 74 & 3 & 0.015 & 0.21 & 13.7 \\
28.5 & 1.62 & 1925 & 84 & 4 & 0.012 & 0.17 & 15.8 \\
30.5 & 1.77 & 1911 & 98 & 5 & 0.011 & 0.14 & 13.5 \\
32.5 & 1.93 & 1897 & 112 & 8 & 0.011 & 0.13 & 13.5 \\
34.5 & 2.09 & 1881 & 128 & 14 & 0.011 & 0.13 & 13.5 \\
\hline
\end{tabular}

Table 26. ${ }^{210} \mathrm{~Pb}$ chronology of the Ziskensee (Brandenburg See 90 ) sediment core

\begin{tabular}{|c|c|c|c|c|c|c|c|}
\hline \multirow{2}{*}{\multicolumn{2}{|c|}{ Depth }} & \multicolumn{3}{|c|}{ Chronology } & \multicolumn{3}{|c|}{ Sedimentation Rate } \\
\hline & & Date & Age & & & & \\
\hline $\mathrm{cm}$ & $\mathrm{g} \mathrm{cm}^{-2}$ & $A D$ & $\mathrm{y}$ & \pm & $\mathrm{g} \mathrm{cm}^{-2} \mathrm{y}^{-1}$ & $\mathrm{~cm} \mathrm{y}^{-1}$ & $\pm(\%)$ \\
\hline 0.0 & 0.00 & 2009 & 0 & 0 & & & \\
\hline 1.0 & 0.02 & 2008 & 1 & 1 & 0.031 & 1.25 & 4.1 \\
\hline 2.5 & 0.07 & 2007 & 2 & 2 & 0.029 & 0.88 & 4.9 \\
\hline 4.5 & 0.15 & 2004 & 5 & 2 & 0.027 & 0.55 & 3.7 \\
\hline 8.5 & 0.35 & 1996 & 13 & 2 & 0.025 & 0.50 & 4.4 \\
\hline 12.5 & 0.54 & 1988 & 21 & 2 & 0.022 & 0.42 & 4.8 \\
\hline 16.5 & 0.76 & 1977 & 32 & 2 & 0.017 & 0.31 & 7.0 \\
\hline 20.5 & 0.98 & 1962 & 47 & 2 & 0.014 & 0.26 & 7.7 \\
\hline 24.5 & 1.18 & 1946 & 63 & 2 & 0.012 & 0.24 & 9.2 \\
\hline 28.5 & 1.37 & 1929 & 80 & 4 & 0.011 & 0.23 & 15.0 \\
\hline 30.5 & 1.47 & 1920 & 89 & 5 & 0.011 & 0.22 & 15.0 \\
\hline 32.5 & 1.57 & 1911 & 98 & 6 & 0.011 & 0.23 & 15.0 \\
\hline 34.5 & 1.66 & 1903 & 106 & 7 & 0.011 & 0.22 & 15.0 \\
\hline 36.5 & 1.76 & 1893 & 116 & 9 & 0.011 & 0.20 & 15.0 \\
\hline 38.5 & 1.87 & 1882 & 127 & 12 & 0.011 & 0.20 & 15.0 \\
\hline 40.5 & 1.98 & 1873 & 136 & 16 & 0.011 & 0.21 & 15.0 \\
\hline
\end{tabular}


Table 27. ${ }^{210} \mathrm{~Pb}$ chronology of the Schiebelsee (Brandenburg See 94) sediment core

\begin{tabular}{|c|c|c|c|c|c|c|c|}
\hline \multicolumn{2}{|c|}{ Depth } & \multicolumn{3}{|c|}{ Chronology } & \multicolumn{3}{|c|}{ Sedimentation Rate } \\
\hline & & Date & Age & & & & \\
\hline $\mathrm{cm}$ & $\mathrm{g} \mathrm{cm}^{-2}$ & $A D$ & $\mathrm{y}$ & \pm & $\mathrm{g} \mathrm{cm}^{-2} \mathrm{y}^{-1}$ & $\mathrm{~cm} \mathrm{y}^{-1}$ & $\pm(\%)$ \\
\hline 0.0 & 0.00 & 2009 & 0 & 0 & & & \\
\hline 0.5 & 0.01 & 2009 & 0 & 1 & 0.082 & 2.5 & 8.0 \\
\hline 2.5 & 0.09 & 2008 & 1 & 2 & 0.085 & 1.7 & 10.2 \\
\hline 4.5 & 0.20 & 2007 & 2 & 2 & 0.078 & 1.2 & 5.3 \\
\hline 8.5 & 0.48 & 2003 & 6 & 2 & 0.086 & 1.1 & 8.3 \\
\hline 12.5 & 0.80 & 1999 & 10 & 2 & 0.073 & 0.85 & 5.8 \\
\hline 16.5 & 1.18 & 1994 & 15 & 2 & 0.079 & 0.74 & 8.1 \\
\hline 18.5 & 1.47 & 1991 & 18 & 2 & 0.087 & 0.51 & 9.5 \\
\hline 20.5 & 1.93 & 1986 & 23 & 2 & 0.105 & 0.47 & 17.4 \\
\hline 22.5 & 2.31 & 1982 & 27 & 2 & 0.100 & 0.50 & 17.9 \\
\hline 24.5 & 2.61 & 1978 & 31 & 2 & 0.063 & 0.41 & 13.1 \\
\hline 26.5 & 2.95 & 1973 & 36 & 3 & 0.074 & 0.40 & 16.8 \\
\hline 28.5 & 3.34 & 1968 & 41 & 3 & 0.087 & 0.40 & 15.2 \\
\hline 32.5 & 4.18 & 1958 & 51 & 4 & 0.069 & 0.35 & 18.1 \\
\hline 36.5 & 4.89 & 1945 & 64 & 5 & 0.048 & 0.28 & 20.1 \\
\hline 38.5 & 5.31 & 1936 & 73 & 6 & 0.047 & 0.20 & 26.8 \\
\hline 40.5 & 5.76 & 1925 & 84 & 9 & 0.036 & 0.15 & 26.8 \\
\hline 42.5 & 6.28 & 1906 & 100 & 16 & 0.036 & 0.12 & 26.8 \\
\hline
\end{tabular}

Table 28. ${ }^{210} \mathrm{~Pb}$ chronology of the Bugsee (Brandenburg See 97) sediment core

\begin{tabular}{|c|c|c|c|c|c|c|c|}
\hline \multirow{2}{*}{\multicolumn{2}{|c|}{ Depth }} & \multicolumn{3}{|c|}{ Chronology } & \multicolumn{3}{|c|}{ Sedimentation Rate } \\
\hline & & Date & Age & & & & \\
\hline $\mathrm{cm}$ & $\mathrm{g} \mathrm{cm}^{-2}$ & $A D$ & $y$ & \pm & $\mathrm{g} \mathrm{cm}^{-2} \mathrm{y}^{-1}$ & $\mathrm{~cm} \mathrm{y}^{-1}$ & $\pm(\%)$ \\
\hline 0.0 & 0.00 & 2009 & 0 & 0 & & & \\
\hline 0.5 & 0.04 & 2009 & 0 & 1 & 0.12 & 0.83 & 12.8 \\
\hline 2.5 & 0.33 & 2006 & 3 & 2 & 0.11 & 0.71 & 13.1 \\
\hline 4.5 & 0.64 & 2003 & 6 & 2 & 0.08 & 0.50 & 10.0 \\
\hline 6.5 & 1.12 & 1998 & 11 & 2 & 0.11 & 0.40 & 12.6 \\
\hline 8.5 & 1.59 & 1993 & 16 & 2 & 0.10 & 0.44 & 15.6 \\
\hline 10.5 & 2.04 & 1989 & 20 & 2 & 0.11 & 0.44 & 17.7 \\
\hline 12.5 & 2.81 & 1984 & 25 & 2 & 0.25 & 0.57 & 25.4 \\
\hline 14.5 & 3.82 & 1982 & 27 & 3 & 0.34 & 0.80 & 80.3 \\
\hline 16.5 & 4.51 & 1979 & 30 & 3 & 0.11 & 0.57 & 28.1 \\
\hline 18.5 & 4.90 & 1975 & 34 & 3 & 0.10 & 0.50 & 26.4 \\
\hline 20.5 & 5.29 & 1971 & 38 & 4 & 0.07 & 0.44 & 24.4 \\
\hline 22.5 & 5.71 & 1966 & 43 & 4 & 0.10 & 0.36 & 28.3 \\
\hline 24.5 & 6.17 & 1960 & 49 & 5 & 0.07 & 0.27 & 29.1 \\
\hline 26.5 & 6.71 & 1951 & 58 & 7 & 0.06 & 0.21 & 36.0 \\
\hline 27.5 & 7.02 & 1946 & 63 & 8 & 0.06 & 0.18 & 38.3 \\
\hline
\end{tabular}


Table 29. Tentative ${ }^{210} \mathrm{~Pb}$ chronology of the Piechesee (Brandenburg See 102) sediment core

\begin{tabular}{cccccc}
\hline \multicolumn{2}{c}{ Depth } & \multicolumn{2}{c}{ Chronology } & \multicolumn{2}{l}{ Sedimentation Rate } \\
& \multicolumn{3}{c}{ Date } & Age & \\
$\mathrm{cm}$ & $\mathrm{g} \mathrm{cm}^{-2}$ & $\mathrm{AD}$ & $\mathrm{y}$ & $\mathrm{g} \mathrm{cm}^{-2} \mathrm{y}^{-1}$ & $\mathrm{~cm} \mathrm{y}^{-1}$ \\
\hline 0.0 & 0.00 & 2009 & 0 & & \\
0.5 & 0.02 & 2009 & 0 & 0.11 & 2.80 \\
2.5 & 0.09 & 2008 & 1 & 0.11 & 2.67 \\
4.5 & 0.18 & 2007 & 2 & 0.11 & 1.98 \\
8.5 & 0.41 & 2005 & 4 & 0.11 & 1.79 \\
12.5 & 0.65 & 2003 & 6 & 0.11 & 1.62 \\
16.5 & 0.93 & 2000 & 9 & 0.11 & 1.48 \\
20.5 & 1.22 & 1997 & 12 & 0.11 & 1.41 \\
24.5 & 1.53 & 1994 & 15 & 0.11 & 1.40 \\
28.5 & 1.83 & 1992 & 17 & 0.11 & 1.34 \\
30.5 & 2.00 & 1990 & 19 & 0.11 & 1.28 \\
32.5 & 2.15 & 1989 & 20 & 0.11 & 1.44 \\
34.5 & 2.30 & 1987 & 22 & 0.11 & 1.56 \\
36.5 & 2.43 & 1986 & 23 & 0.11 & 1.67 \\
38.5 & 2.55 & 1985 & 24 & 0.11 & 1.72 \\
\hline
\end{tabular}

Table 30. ${ }^{210} \mathrm{~Pb}$ chronology of the Aalgastsee (Brandenburg See 108) sediment core

\begin{tabular}{|c|c|c|c|c|c|c|}
\hline \multicolumn{2}{|c|}{ Depth } & \multicolumn{3}{|c|}{ Chronology } & \multicolumn{2}{|c|}{ Sedimentation Rate } \\
\hline & & Date & Age & & & \\
\hline $\mathrm{cm}$ & $\mathrm{g} \mathrm{cm}^{-2}$ & $A D$ & $\mathrm{y}$ & \pm & $\mathrm{g} \mathrm{cm}^{-2} \mathrm{y}^{-1}$ & $\mathrm{~cm} \mathrm{y}^{-1}$ \\
\hline 0.0 & 0.00 & 2009 & 0 & 0 & & \\
\hline 0.5 & 0.01 & 2008 & 1 & 1 & 0.03 & 0.5 \\
\hline 2.5 & 0.14 & 2004 & 5 & 2 & 0.03 & 0.4 \\
\hline 4.5 & 0.29 & 1998 & 11 & 3 & 0.03 & 0.3 \\
\hline 6.5 & 0.48 & 1990 & 19 & 4 & 0.03 & 0.3 \\
\hline 8.5 & 0.69 & 1983 & 26 & 5 & 0.04 & 0.4 \\
\hline 10.5 & 0.90 & 1979 & 30 & 5 & 0.05 & 0.5 \\
\hline 12.5 & 1.10 & 1975 & 34 & 5 & 0.05 & 0.5 \\
\hline 14.5 & 1.28 & 1971 & 38 & 6 & 0.05 & 0.5 \\
\hline 16.5 & 1.50 & 1967 & 42 & 6 & 0.05 & 0.5 \\
\hline 18.5 & 1.70 & 1963 & 46 & 6 & 0.06 & 0.6 \\
\hline 20.5 & 1.89 & 1960 & 49 & 7 & 0.11 & 1.1 \\
\hline 22.5 & 2.10 & 1959 & 50 & 7 & 0.62 & 2.6 \\
\hline
\end{tabular}


Table 31. Tentative ${ }^{210} \mathrm{~Pb}$ chronology of the Aalgastsee (Brandenburg See 111) sediment core

\begin{tabular}{|c|c|c|c|c|c|c|c|}
\hline \multicolumn{2}{|c|}{ Depth } & \multicolumn{3}{|c|}{ Chronology } & \multicolumn{3}{|c|}{ Sedimentation Rate } \\
\hline $\mathrm{cm}$ & $\mathrm{g} \mathrm{cm}^{-2}$ & $\begin{array}{c}\text { Date } \\
\text { AD }\end{array}$ & $\begin{array}{c}\text { Age } \\
y\end{array}$ & \pm & $\mathrm{g} \mathrm{cm}^{-2} \mathrm{y}^{-1}$ & $\mathrm{~cm} \mathrm{y}^{-1}$ & $\pm(\%)$ \\
\hline 0.0 & 0.00 & 2009 & 0 & 0 & & & \\
\hline 1.0 & 0.01 & 2009 & 0 & 1 & 0.032 & 1.25 & 3.9 \\
\hline 2.5 & 0.05 & 2007 & 2 & 1 & 0.033 & 0.78 & 4.8 \\
\hline 4.5 & 0.16 & 2004 & 5 & 2 & 0.036 & 0.67 & 5.1 \\
\hline 8.5 & 0.38 & 1998 & 11 & 2 & 0.036 & 0.62 & 4.4 \\
\hline 12.5 & 0.64 & 1991 & 18 & 2 & 0.040 & 0.55 & 6.3 \\
\hline 14.5 & 0.79 & 1987 & 22 & 2 & 0.032 & 0.44 & 9.0 \\
\hline 16.5 & 0.94 & 1982 & 27 & 2 & 0.026 & 0.33 & 6.0 \\
\hline 18.5 & 1.11 & 1975 & 34 & 3 & 0.024 & 0.29 & 8.6 \\
\hline 20.5 & 1.27 & 1968 & 41 & 3 & 0.022 & 0.29 & 7.9 \\
\hline 22.5 & 1.43 & 1961 & 48 & 4 & 0.022 & 0.27 & 9.7 \\
\hline 24.5 & 1.61 & 1953 & 56 & 5 & 0.024 & 0.23 & 11.7 \\
\hline 28.5 & 2.06 & 1935 & 74 & 6 & 0.025 & 0.22 & 19.0 \\
\hline 32.5 & 2.52 & 1916 & 93 & 7 & 0.025 & 0.20 & 19.0 \\
\hline 34.5 & 2.77 & 1907 & 102 & 9 & 0.025 & 0.20 & 19.0 \\
\hline 36.5 & 3.03 & 1896 & 113 & 12 & 0.025 & 0.20 & 19.0 \\
\hline 38.5 & 3.28 & 1886 & 123 & 16 & 0.025 & 0.20 & 19.0 \\
\hline
\end{tabular}


(a)

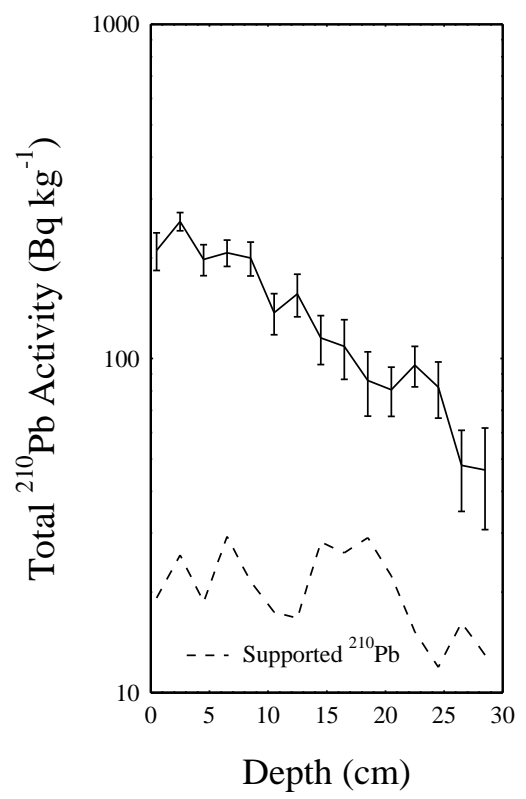

(b)

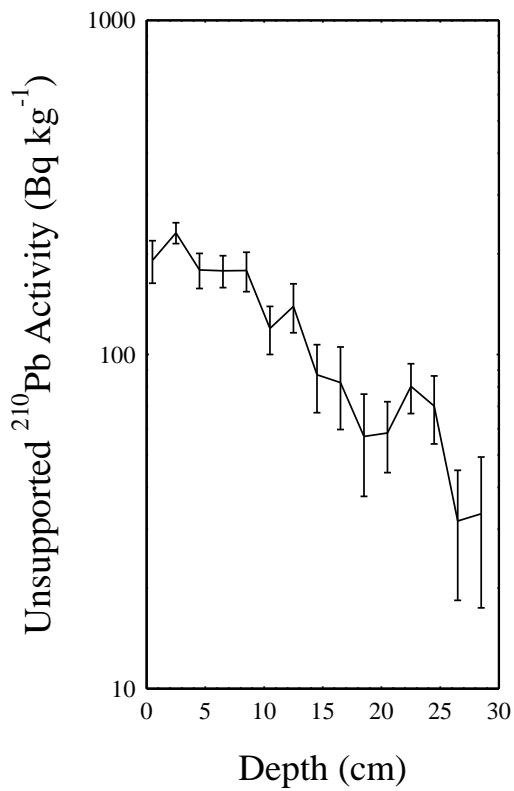

(c)

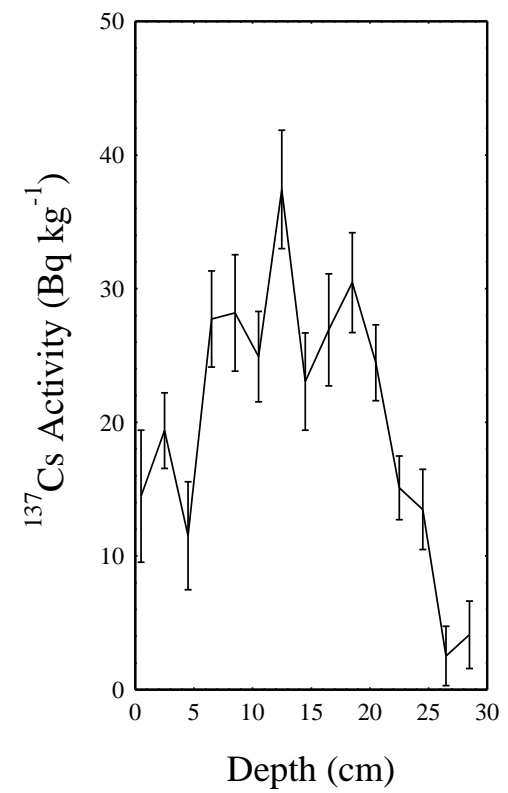

Figure 1.i. Fallout radionuclides in the Kleiner Treppelsee (Brandenburg See 23) sediment core showing (a) total and supported ${ }^{210} \mathrm{~Pb}$, (b) unsupported ${ }^{210} \mathrm{~Pb},(\mathrm{c}){ }^{137} \mathrm{Cs}$ concentrations versus depth.

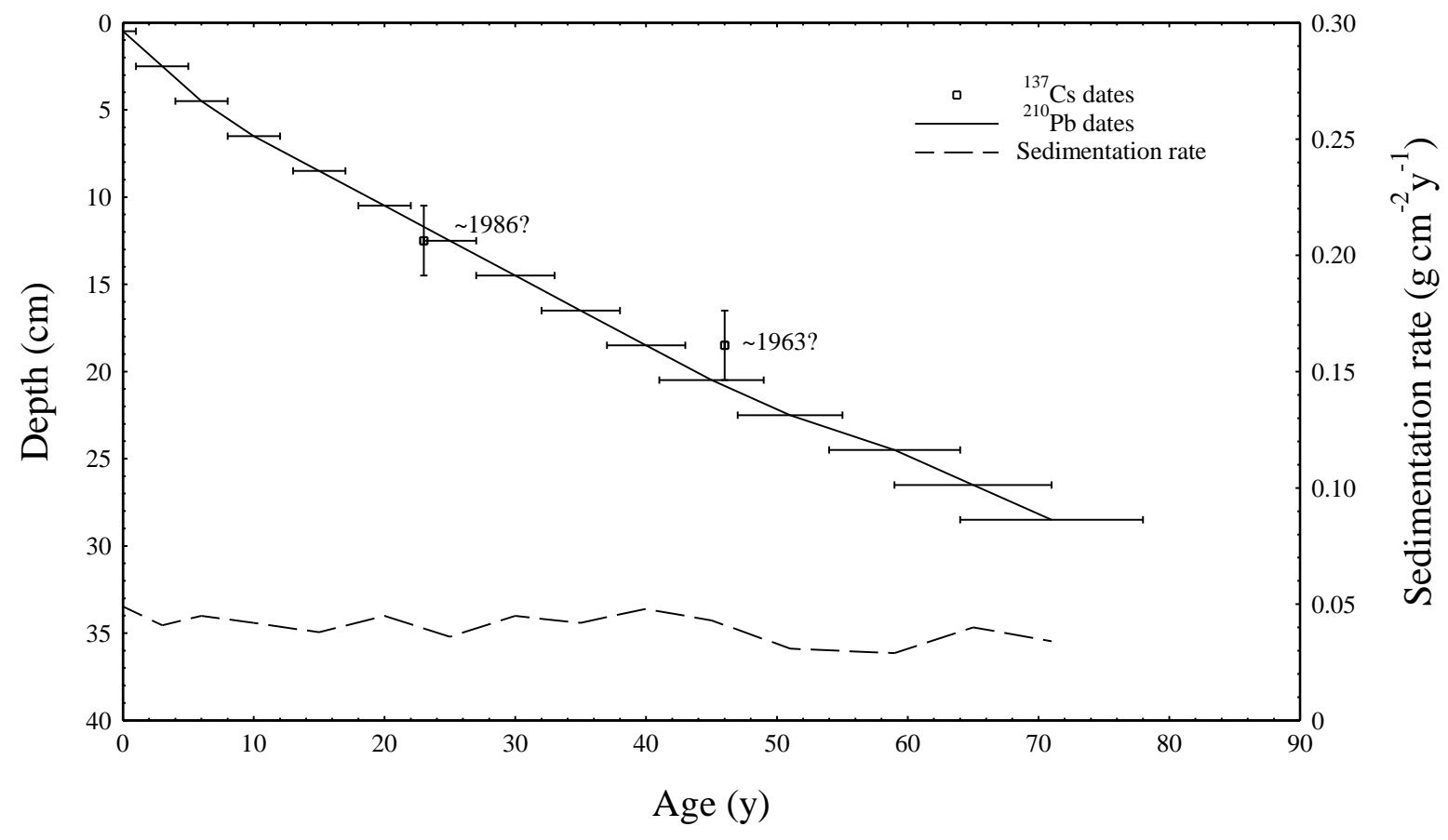

Figure 1.ii. Radiometric chronology of the Kleiner Treppelsee (See 23) sediment core showing the ${ }^{210} \mathrm{~Pb}$ dates and sedimentation rates and the possible 1963 and 1986 depths suggested by the ${ }^{137} \mathrm{Cs}$ record. 
(a)

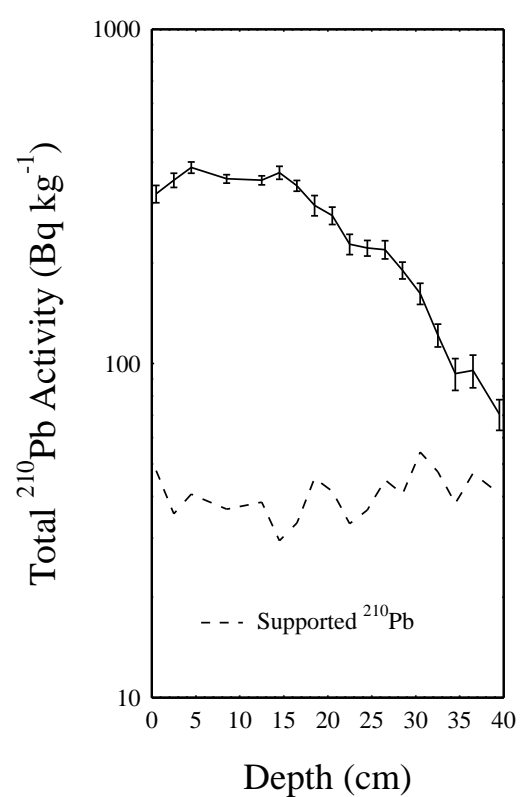

(b)

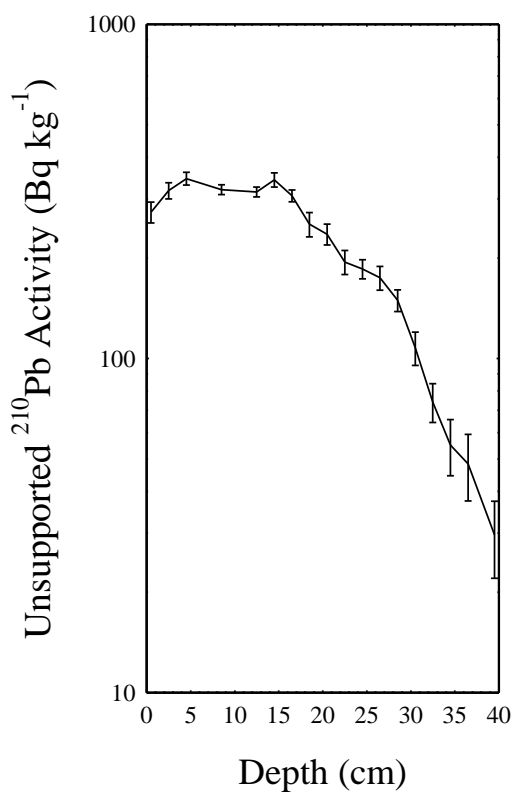

(c)

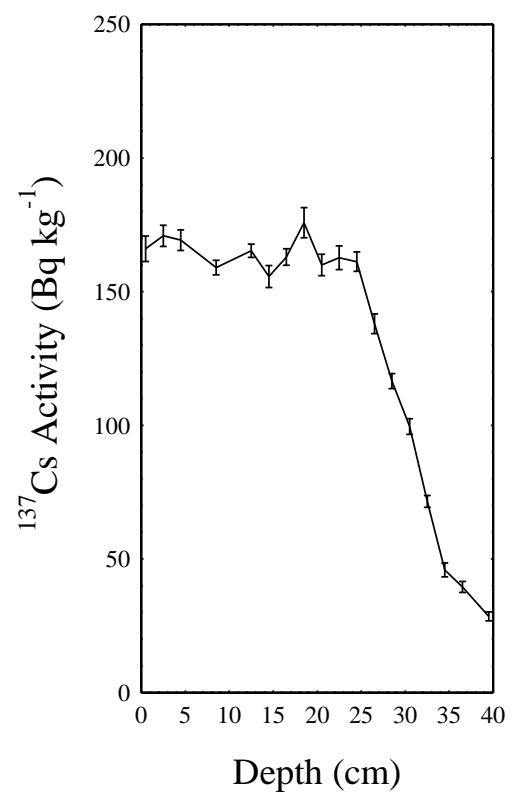

Figure 2.i. Fallout radionuclides in the Kesselsee (Brandenburg See 67) sediment core showing (a) total and supported ${ }^{210} \mathrm{~Pb}$, (b) unsupported ${ }^{210} \mathrm{~Pb}$, (c) ${ }^{137} \mathrm{Cs}$ concentrations versus depth.

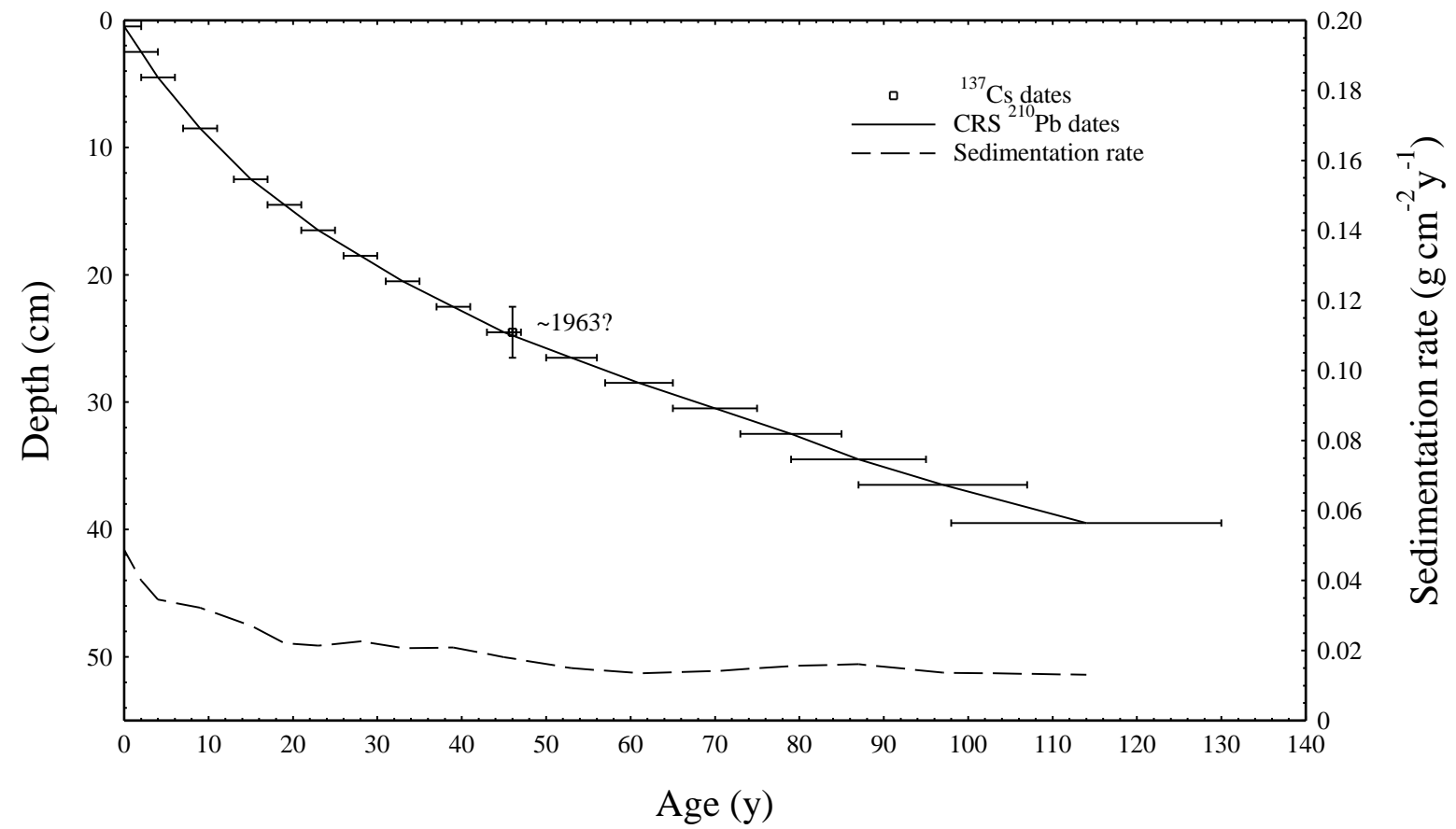

Figure 2.ii. Radiometric chronology of the Kesselsee (Brandenburg See 67) sediment core showing the CRS model ${ }^{210} \mathrm{~Pb}$ dates and sedimentation rates and the approximate 1963 depth suggested by the ${ }^{137} \mathrm{Cs}$ record. 
(a)

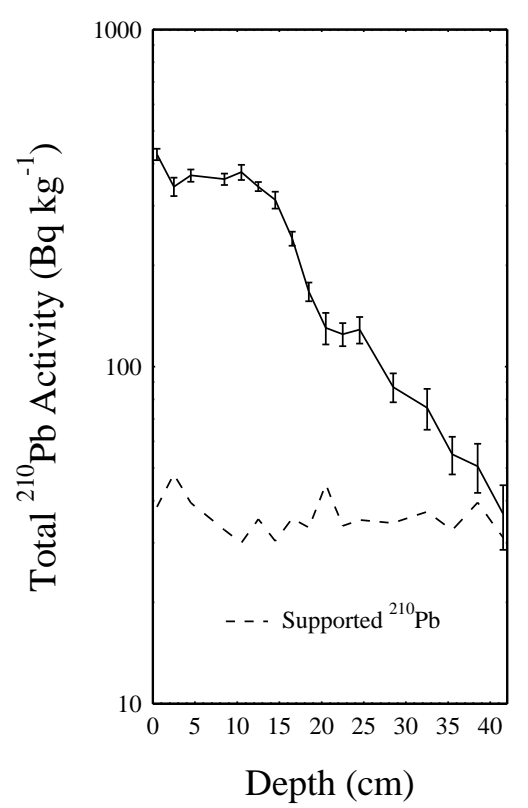

(b)

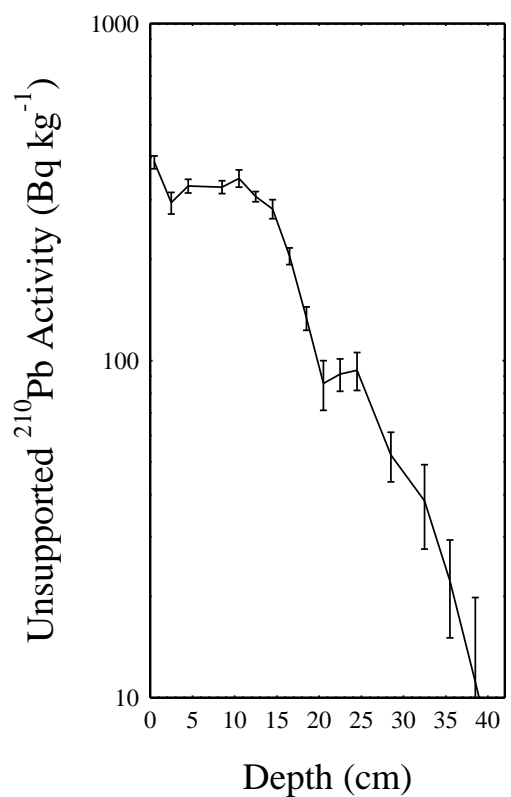

(c)

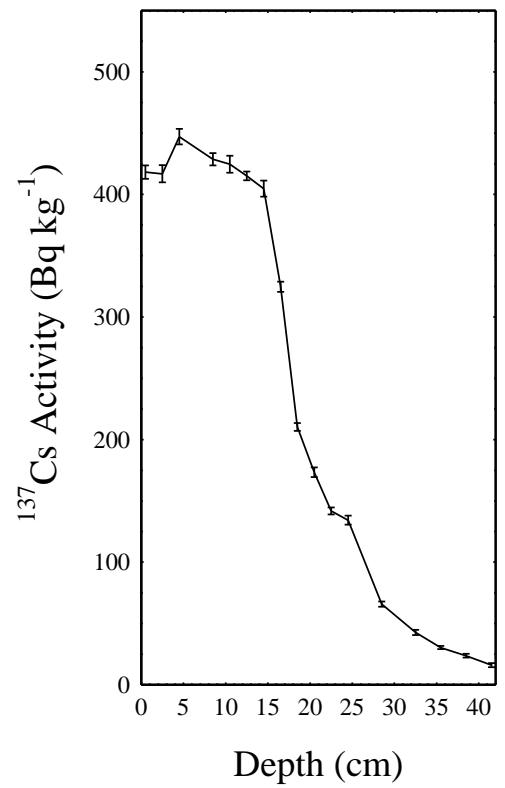

Figure 3.i. Fallout radionuclides in the Schwarzersee (See 71) sediment core showing (a) total and supported ${ }^{210} \mathrm{~Pb}$, (b) unsupported ${ }^{210} \mathrm{~Pb}$, (c) ${ }^{137} \mathrm{Cs}$ concentrations versus depth.

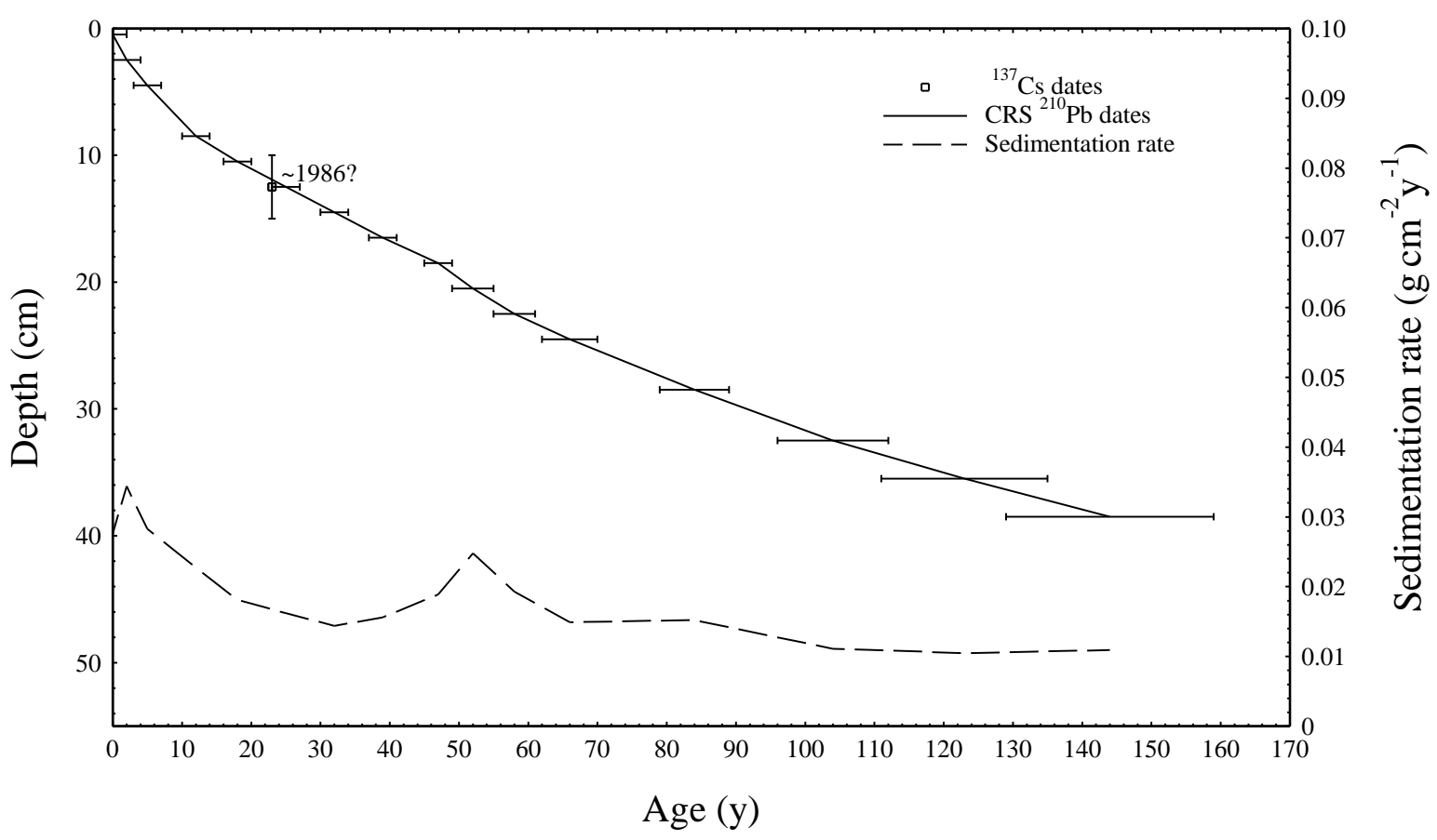

Figure 3.ii. Radiometric chronology of the Schwarzersee (See 71) sediment core showing the CRS model ${ }^{210} \mathrm{~Pb}$ dates and sedimentation rates and the approximate 1986 depth suggested by the ${ }^{137} \mathrm{Cs}$ record. 
(a)

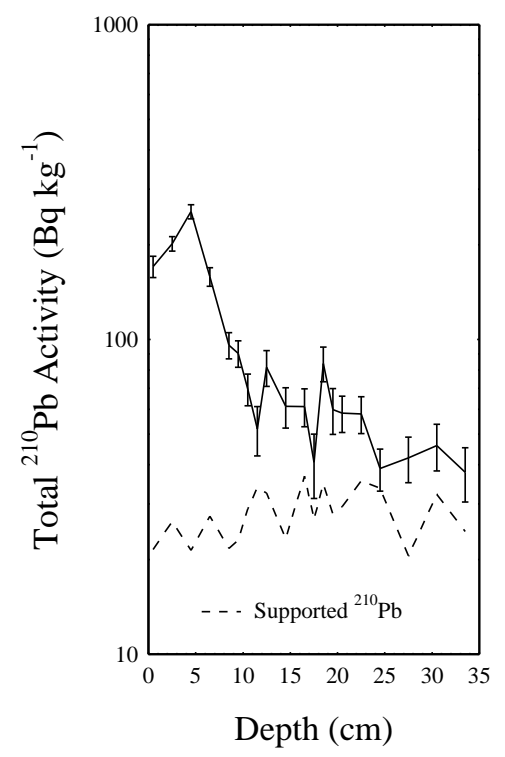

(b)

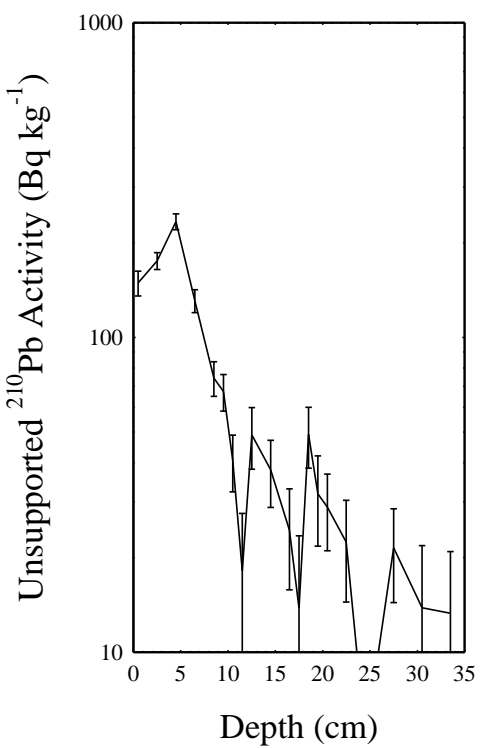

(c)

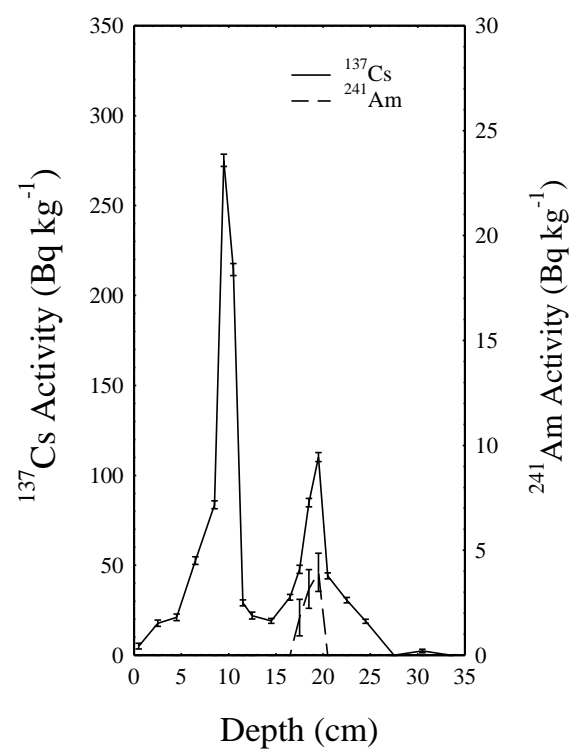

Figure 4.i. Fallout radionuclides in the Heiligensee (Brandenburg See 72) sediment core showing (a) total and supported ${ }^{210} \mathrm{~Pb}$, (b) unsupported ${ }^{210} \mathrm{~Pb}$, (c) ${ }^{137} \mathrm{Cs}$ and ${ }^{241} \mathrm{Am}$ concentrations versus depth.

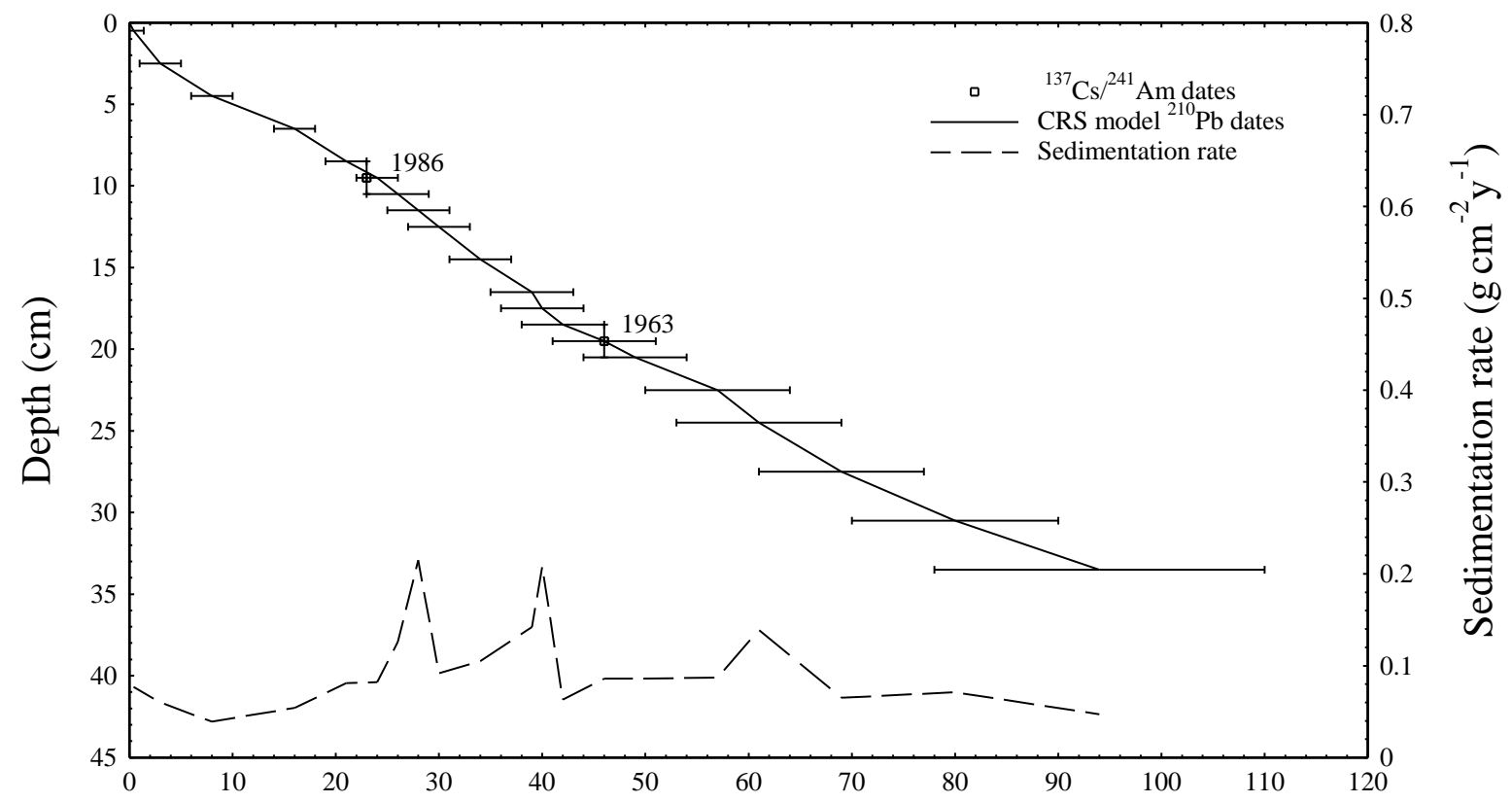

Age (y)

Figure 4.ii. Radiometric chronology of the Heiligensee (Brandenburg See 72) sediment core showing the 1986 and 1963 depths determined from the ${ }^{137} \mathrm{Cs} /{ }^{241} \mathrm{Am}$ record, together with the CRS model ${ }^{210} \mathrm{~Pb}$ dates and sedimentation rates following a small correction using the ${ }^{137} \mathrm{Cs} /{ }^{241} \mathrm{Am}$ dates as reference points. 
(a)

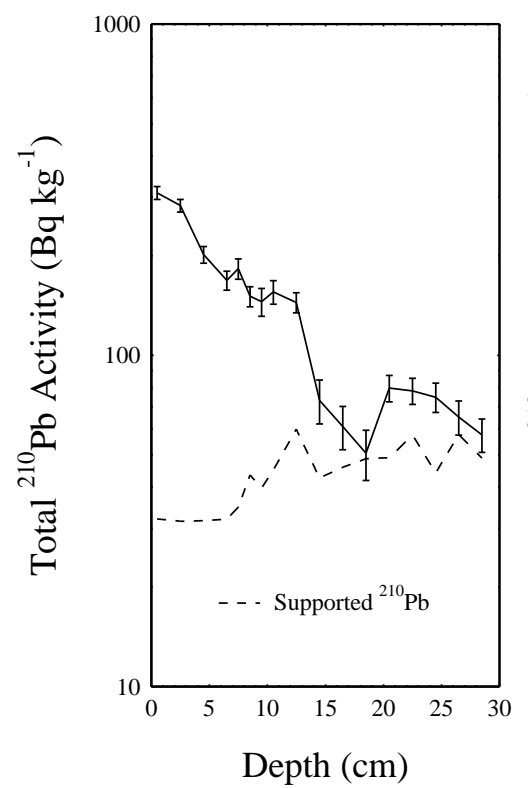

(b)

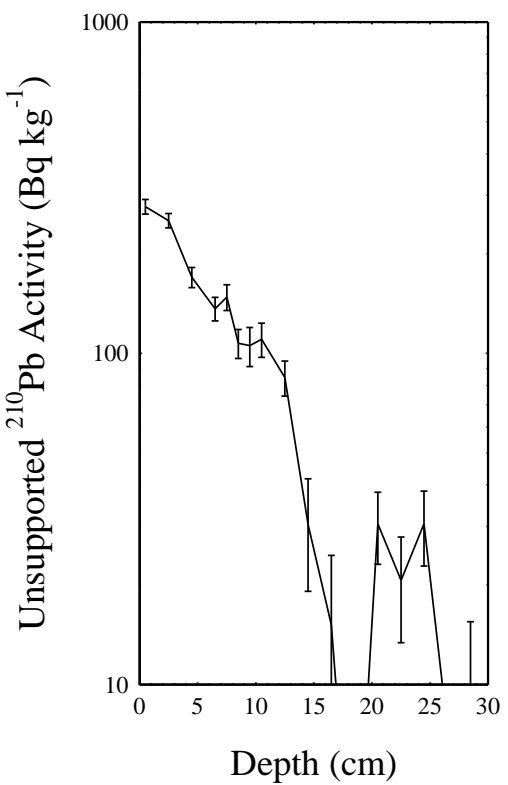

(c)

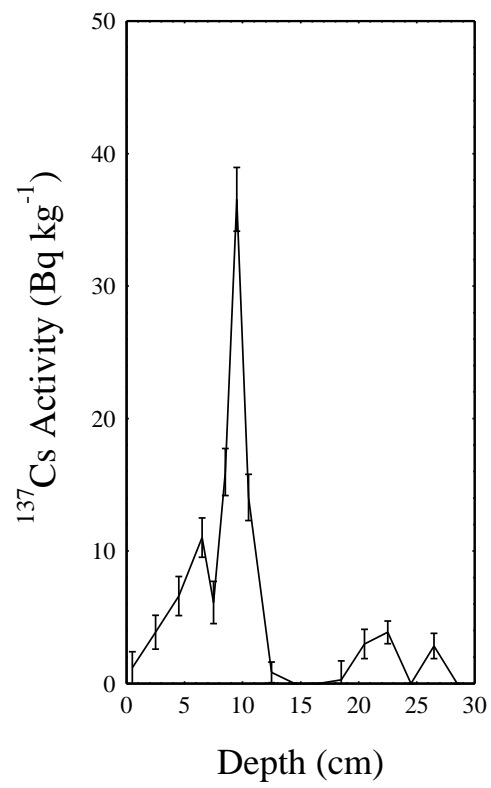

Figure 5.i. Fallout radionuclides in the Teufelssee (Brandenburg See 76) sediment core showing (a) total and supported ${ }^{210} \mathrm{~Pb}$, (b) unsupported ${ }^{210} \mathrm{~Pb}$, (c) ${ }^{137} \mathrm{Cs}$ concentrations versus depth.

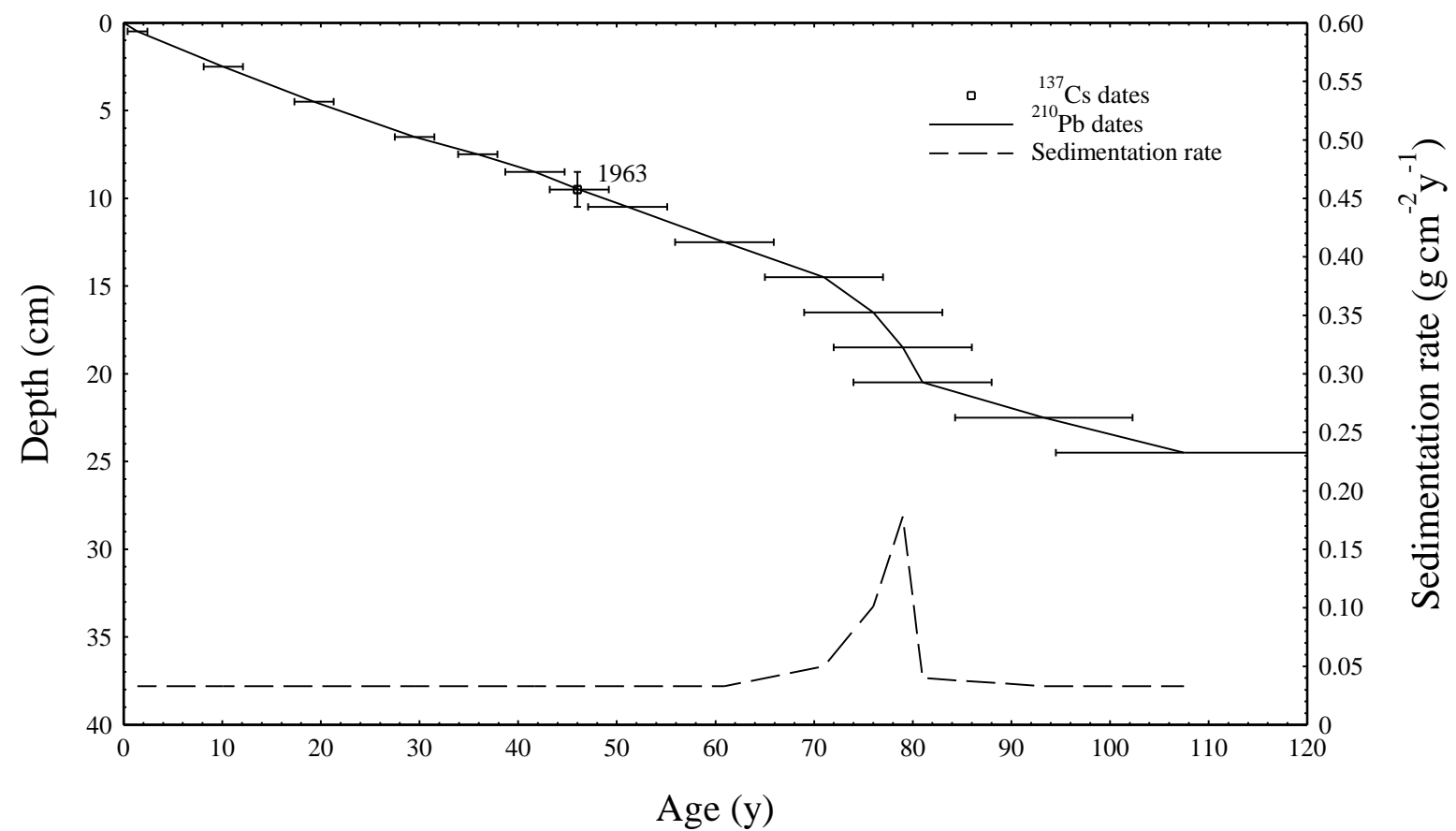

Figure 5.ii. Radiometric chronology of the Teufelssee (Brandenburg See 76) sediment core showing the 1963 depth determined from the ${ }^{137} \mathrm{Cs}$ record, together with ${ }^{210} \mathrm{~Pb}$ dates and sedimentation rates determined from the ${ }^{210} \mathrm{~Pb}$ record using the ${ }^{137} \mathrm{Cs}$ date and laminae counts as reference points. 
(a)

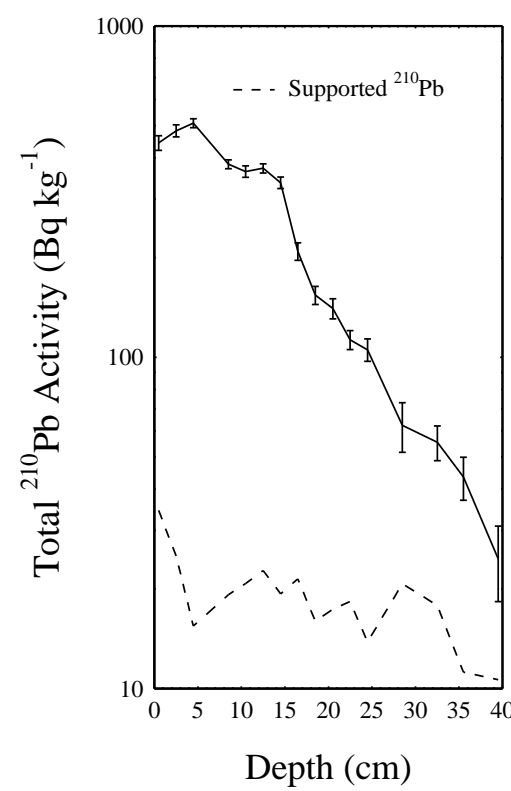

(b)

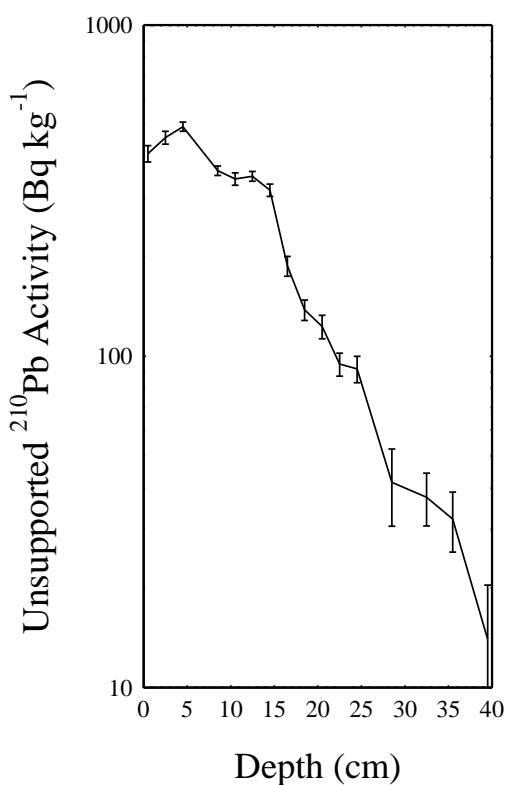

(c)

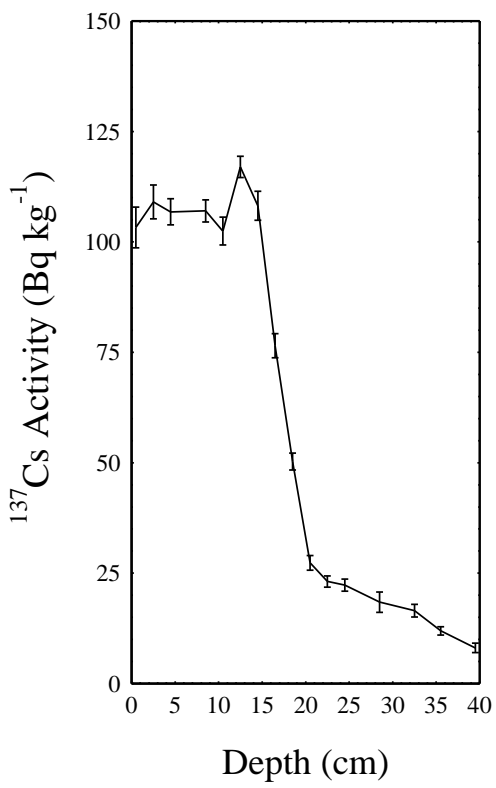

Figure 6.i. Fallout radionuclides in the Glabatzsee (Brandenburg See 79) sediment core showing (a) total and supported ${ }^{210} \mathrm{~Pb}$, (b) unsupported ${ }^{210} \mathrm{~Pb}$, (c) ${ }^{137} \mathrm{Cs}$ concentrations versus depth.

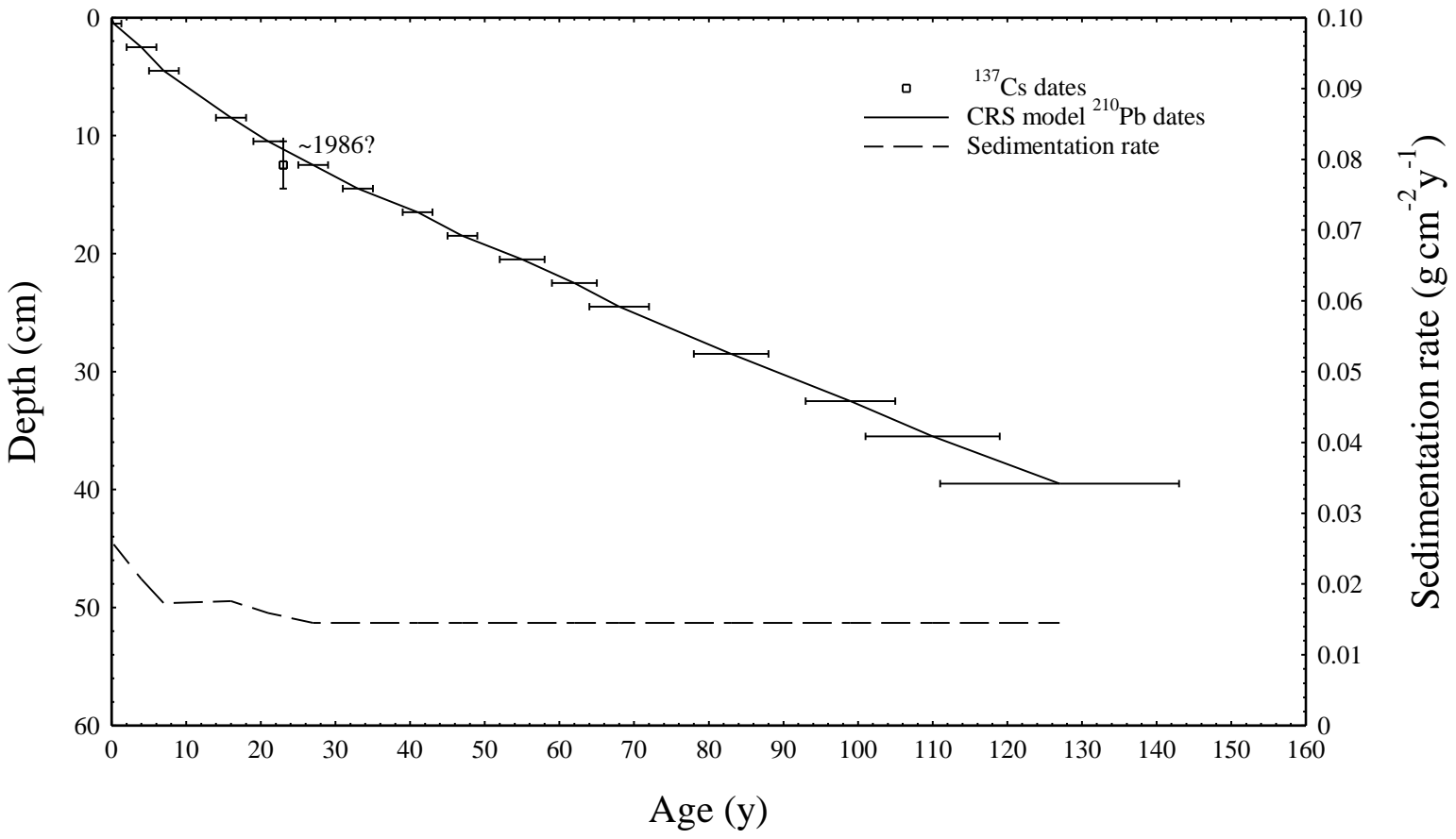

Figure 6.ii. Radiometric chronology of the Glabatzsee (Brandenburg See 79) sediment core showing CRS model ${ }^{210} \mathrm{~Pb}$ dates and sedimentation rates and the possible 1986 depth estimated from the ${ }^{137} \mathrm{Cs}$ record. 
(a)

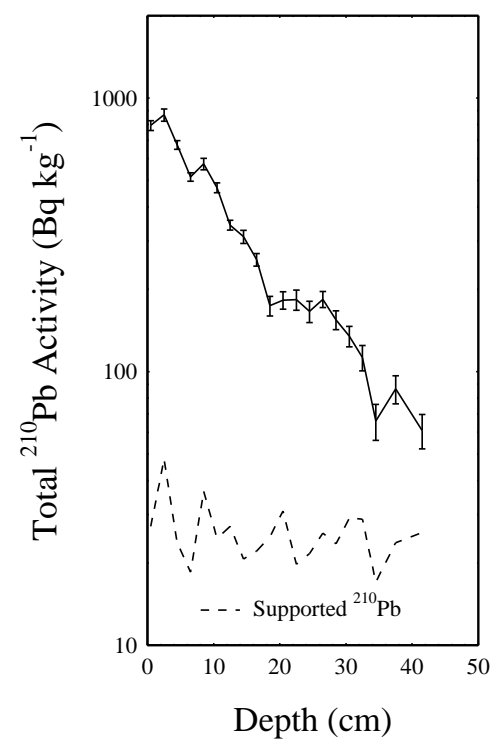

(b)

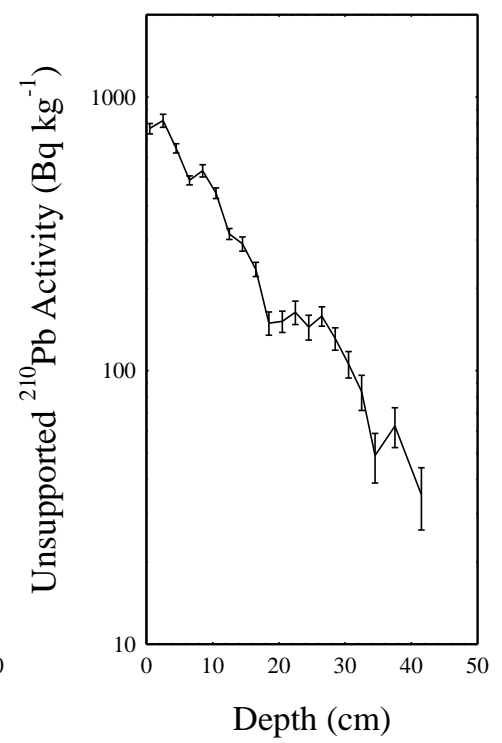

(c)

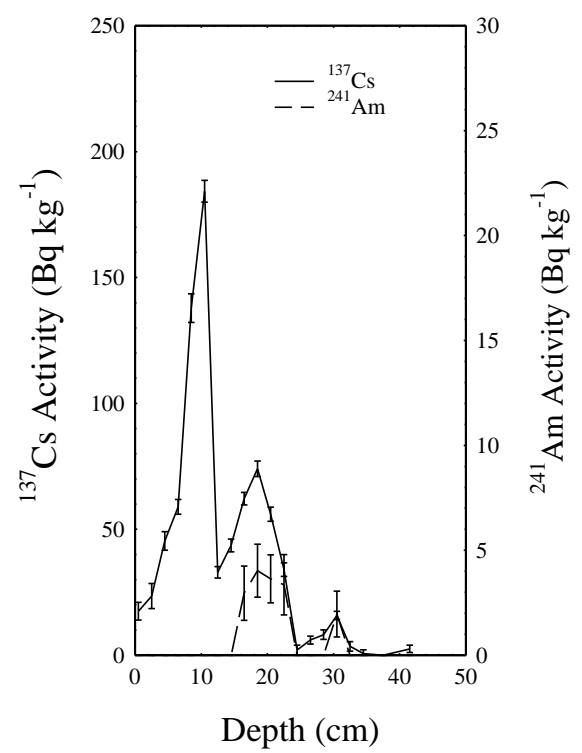

Figure 7.i. Fallout radionuclides in the Kleiner Lychensee (Brandenburg See 81) sediment core showing (a) total and supported ${ }^{210} \mathrm{~Pb}$, (b) unsupported ${ }^{210} \mathrm{~Pb}$, (c) ${ }^{137} \mathrm{Cs}$ and ${ }^{241} \mathrm{Am}$ concentrations versus depth.

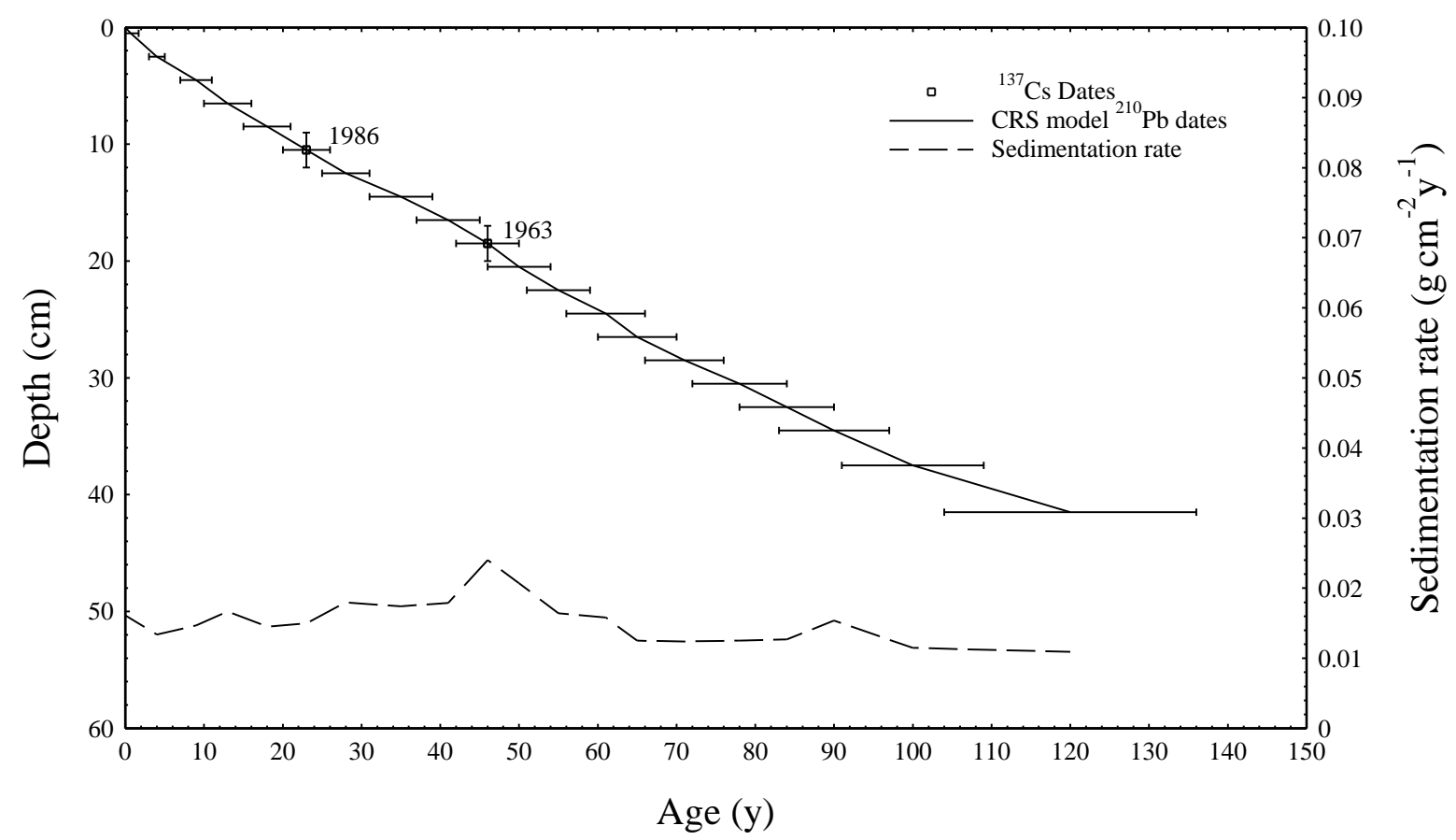

Figure 7.ii. Radiometric chronology of the Kleiner Lychensee (Brandenburg See 81) sediment core showing the 1986 and 1963 depths indicated by the ${ }^{137} \mathrm{Cs} /{ }^{241} \mathrm{Am}$ record together with the CRS model ${ }^{210} \mathrm{~Pb}$ dates and sedimentation rates following a small correction using the ${ }^{137} \mathrm{Cs} /{ }^{241} \mathrm{Am}$ dates as reference points. 
(a)

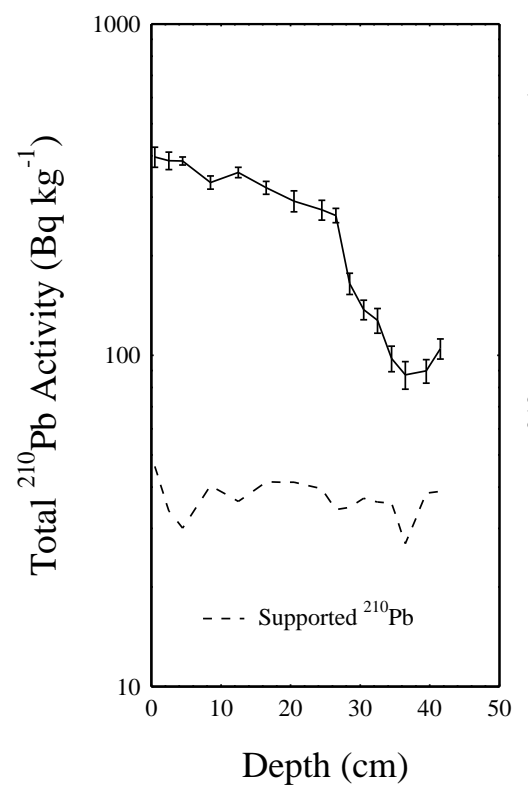

(b)

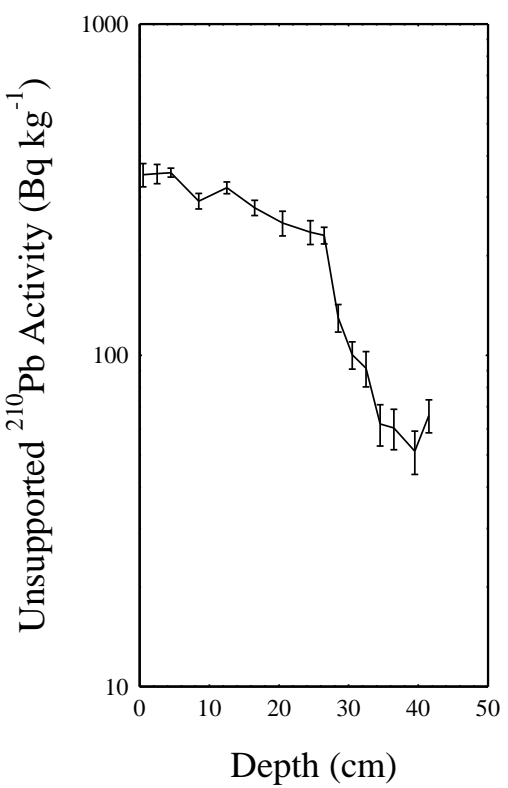

(c)

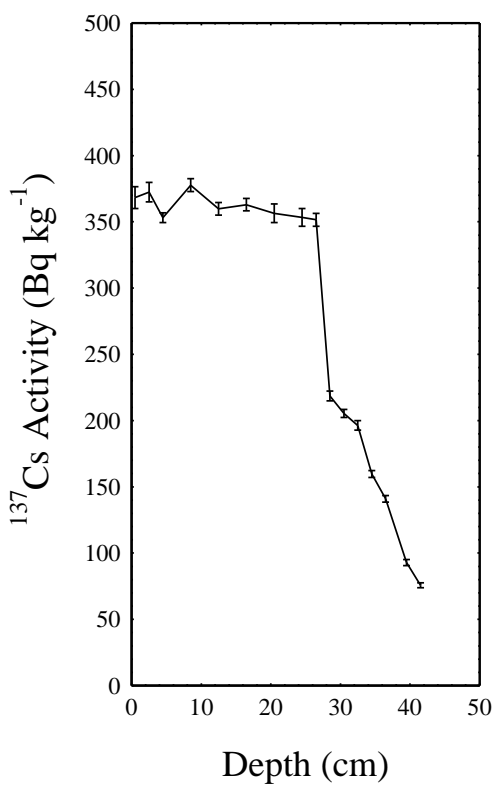

Figure 8.i. Fallout radionuclides in the Baasee (Brandenburg See 86) sediment core showing (a) total and supported ${ }^{210} \mathrm{~Pb}$, (b) unsupported ${ }^{210} \mathrm{~Pb}$, (c) ${ }^{137} \mathrm{Cs}$ concentrations versus depth.

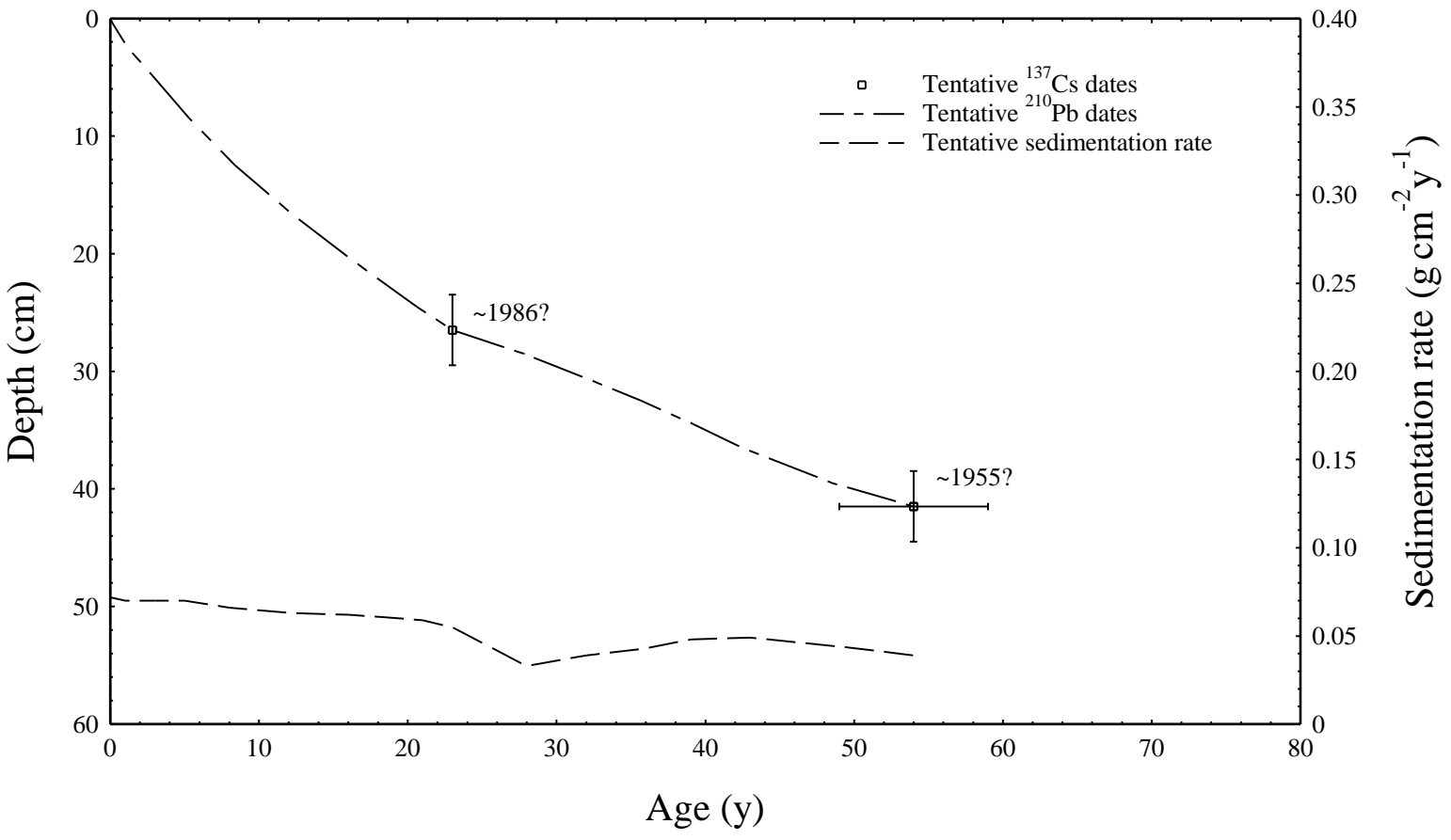

Figure 8.ii. Radiometric chronology of the Baasee (Brandenburg See 86) sediment core showing the tentative ${ }^{137} \mathrm{Cs}$ and ${ }^{210} \mathrm{~Pb}$ dates and sedimentation rates suggested by the radiometric records. 
(a)

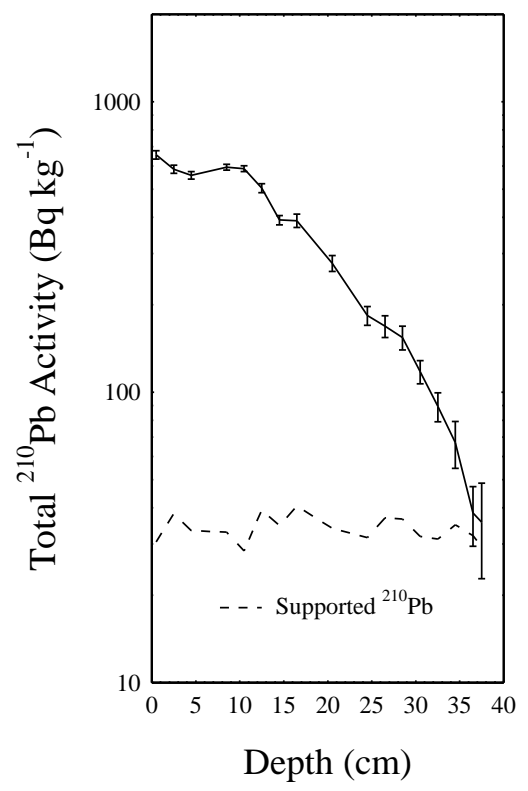

(b)

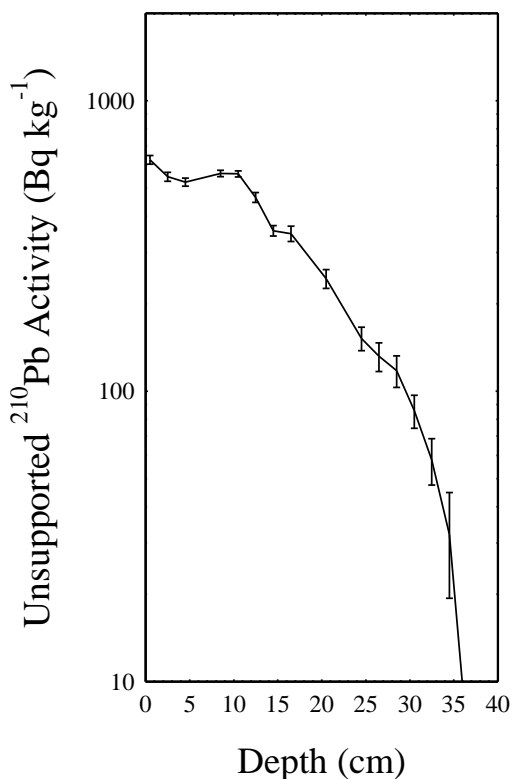

(c)



Figure 9.i. Fallout radionuclides in the Großsee (Brandenburg See 89) sediment core showing (a) total and supported ${ }^{210} \mathrm{~Pb}$, (b) unsupported ${ }^{210} \mathrm{~Pb}$, (c) ${ }^{137} \mathrm{Cs}$ concentrations versus depth.

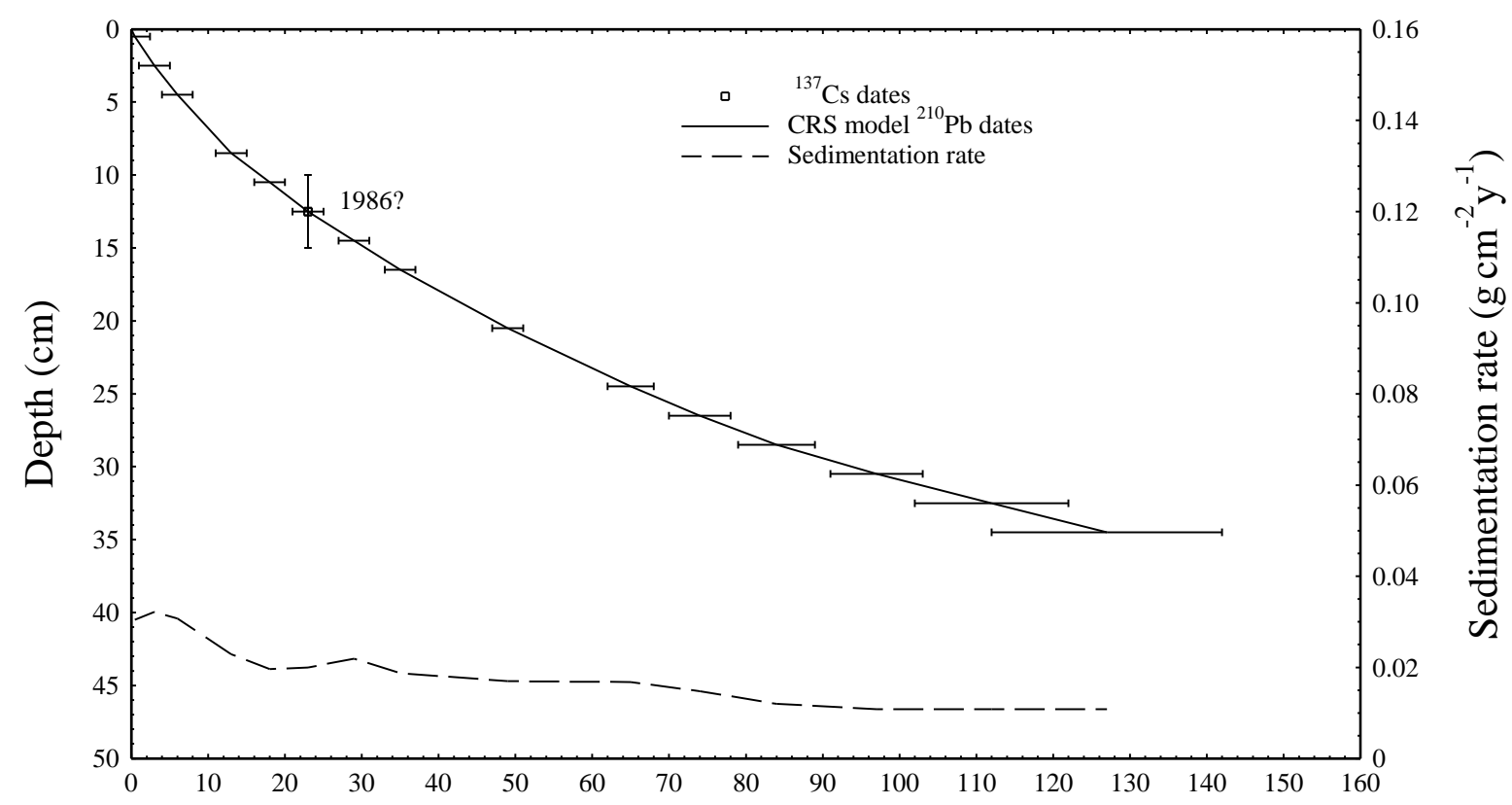

Age $(y)$

Figure 9.ii. Radiometric chronology of the Großsee (Brandenburg See 89) sediment core showing the CRS model ${ }^{210} \mathrm{~Pb}$ dates and sedimentation rates together with the suggested 1986 depth indicated by the ${ }^{137} \mathrm{Cs}$ record. 
(a)

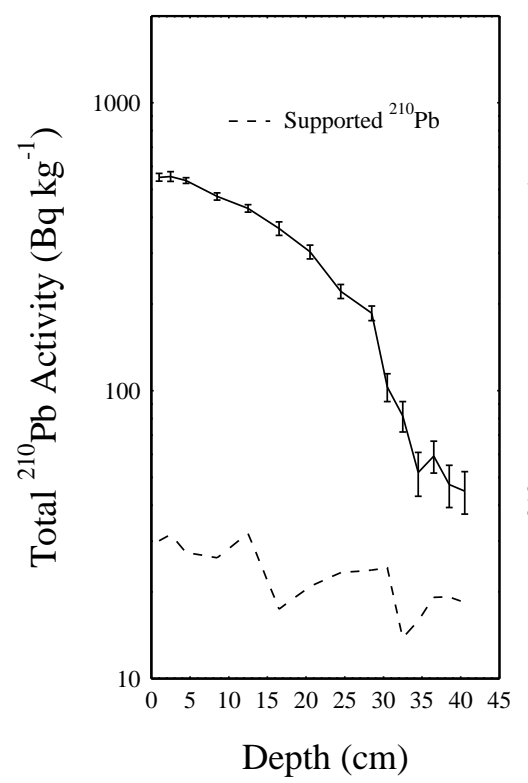

(b)

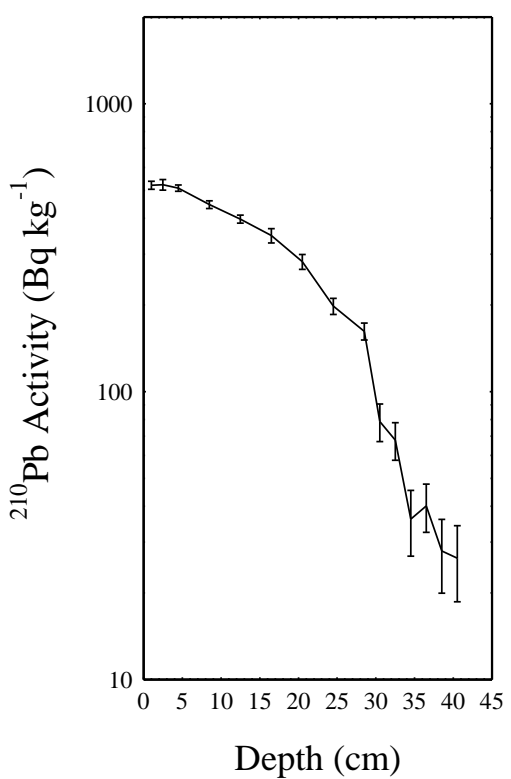

(c)

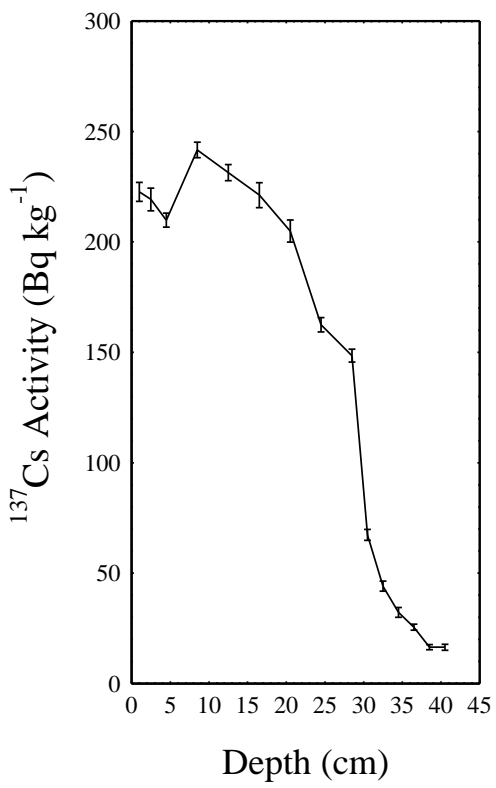

Figure 10.i. Fallout radionuclides in the Ziskensee (Brandenburg See 90) sediment core showing (a) total and supported ${ }^{210} \mathrm{~Pb}$, (b) unsupported ${ }^{210} \mathrm{~Pb}$, (c) ${ }^{137} \mathrm{Cs}$ concentrations versus depth.

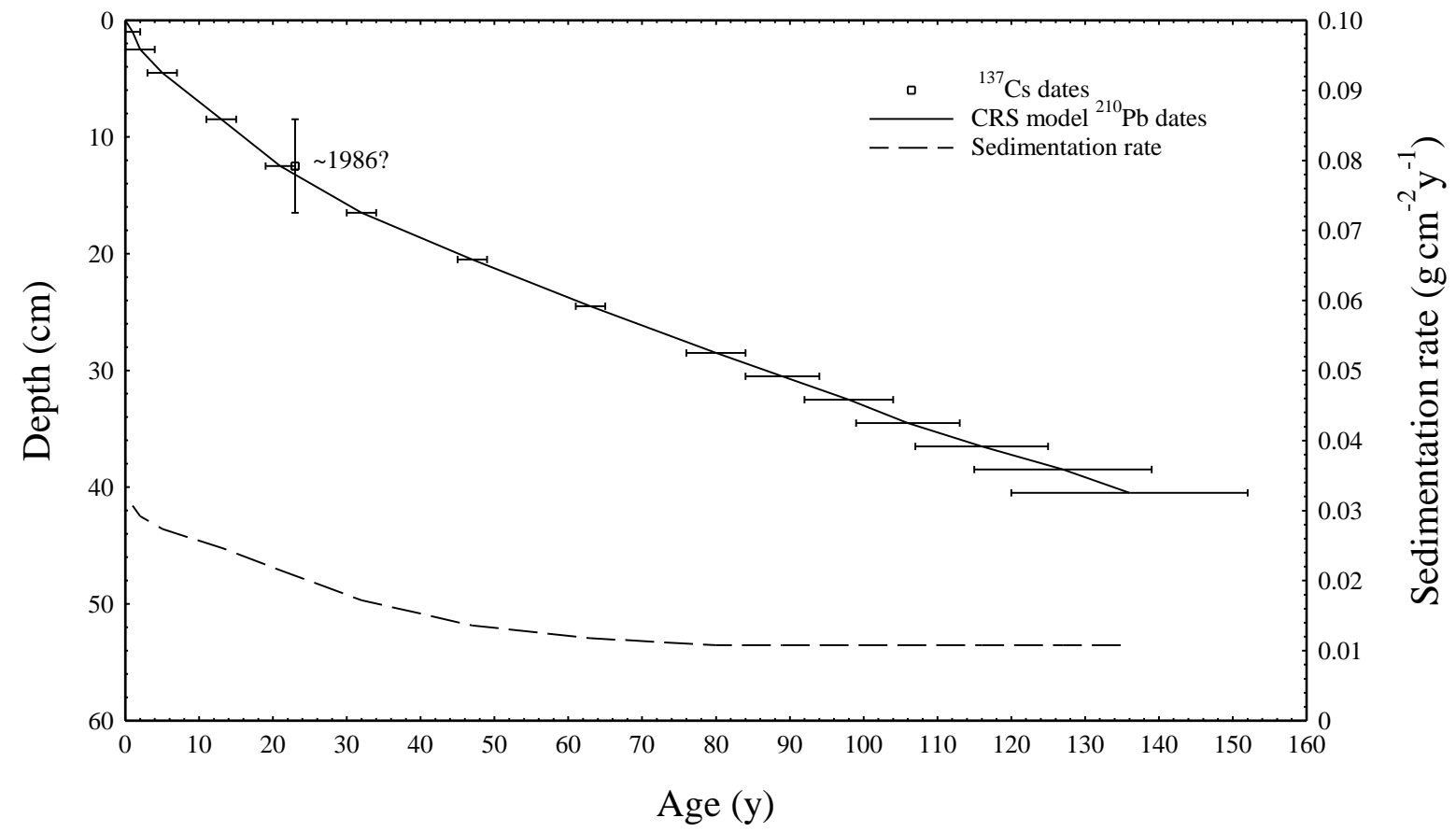

Figure 10.ii. Radiometric chronology of the Ziskensee (Brandenburg See 90) sediment core showing the CRS model ${ }^{210} \mathrm{~Pb}$ dates and sedimentation rates together with the possible 1986 depth suggested by the ${ }^{137} \mathrm{Cs}$ record. 
(a)

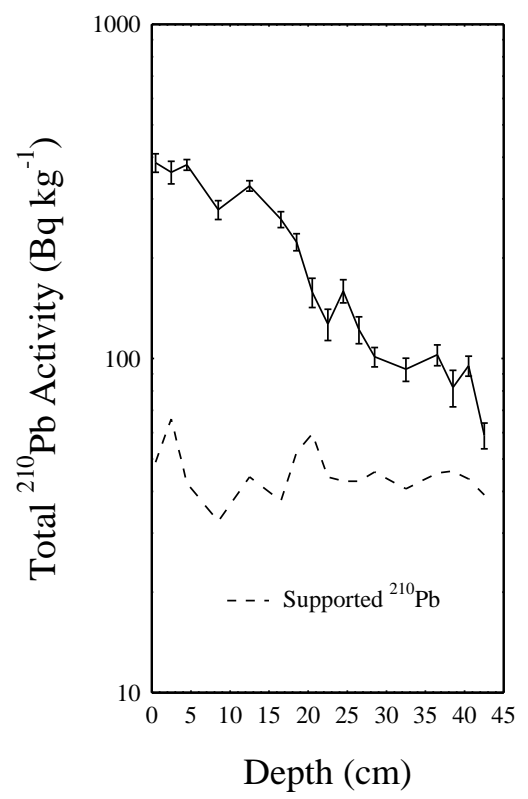

(b)

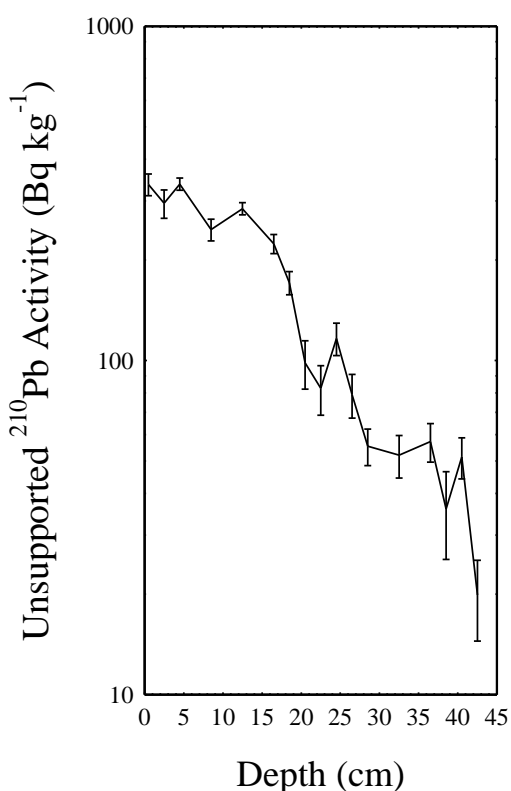

(c)

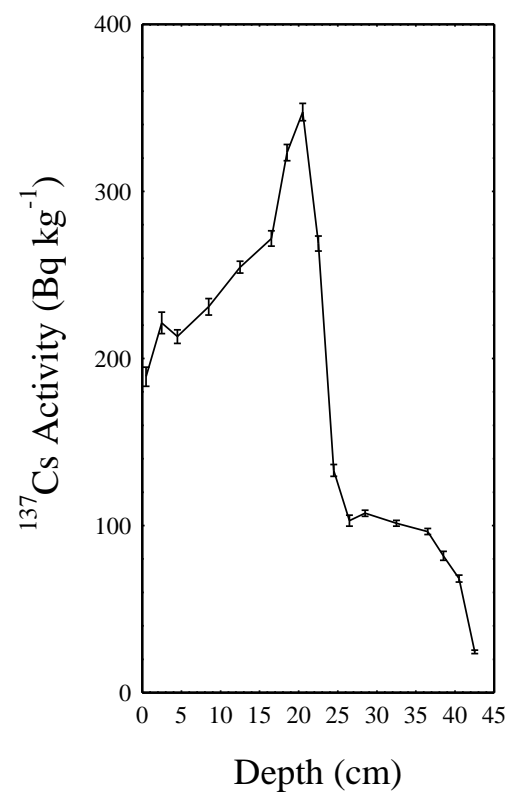

Figure 11.i. Fallout radionuclides in the Schiebelsee (Brandenburg See 94) sediment core showing (a) total and supported ${ }^{210} \mathrm{~Pb}$, (b) unsupported ${ }^{210} \mathrm{~Pb}$, (c) ${ }^{137} \mathrm{Cs}$ concentrations versus depth.

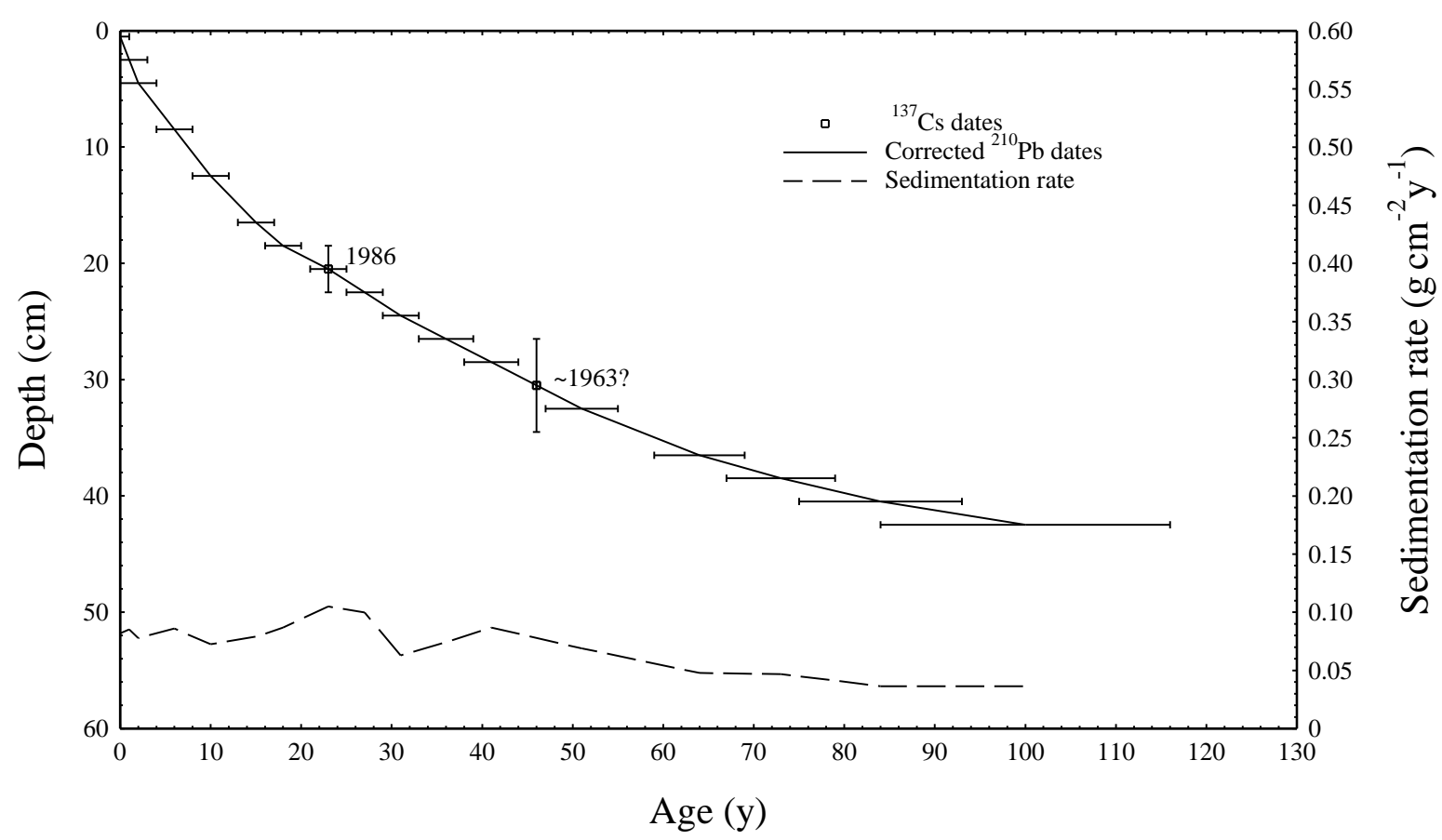

Figure 11.ii. Radiometric chronology of the Schiebelsee (Brandenburg See 94) sediment core showing the 1986 and possible 1963 depths indicated by the ${ }^{137} \mathrm{Cs}$ record and the corrected CRS model ${ }^{210} \mathrm{~Pb}$ dates and sedimentation rates calculated using the $1986{ }^{137} \mathrm{Cs}$ date as a reference level. 
(a)

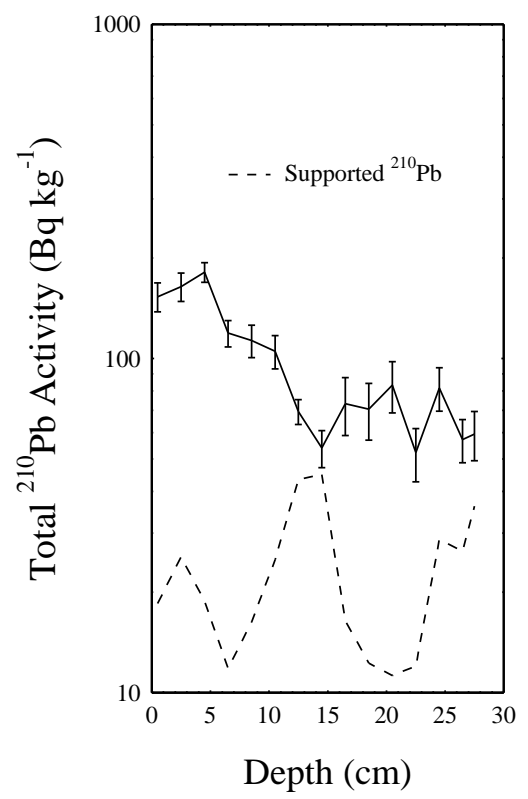

(b)

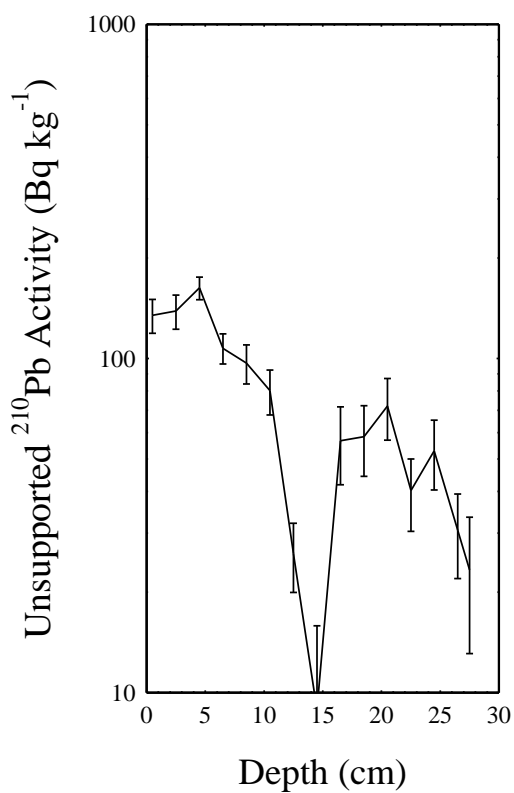

(c)

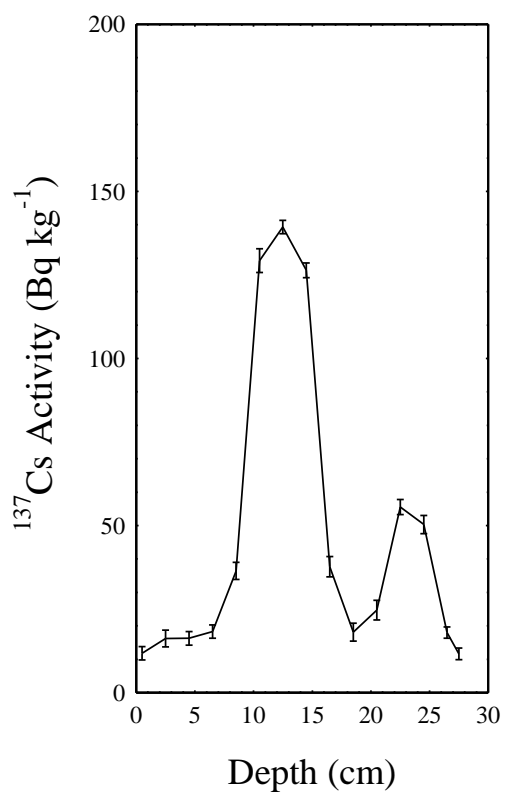

Figure 12.i. Fallout radionuclides in the Bugsee (Brandenburg See 97) sediment core showing (a) total and supported ${ }^{210} \mathrm{~Pb}$, (b) unsupported ${ }^{210} \mathrm{~Pb}$, (c) ${ }^{137} \mathrm{Cs}$ concentrations versus depth.

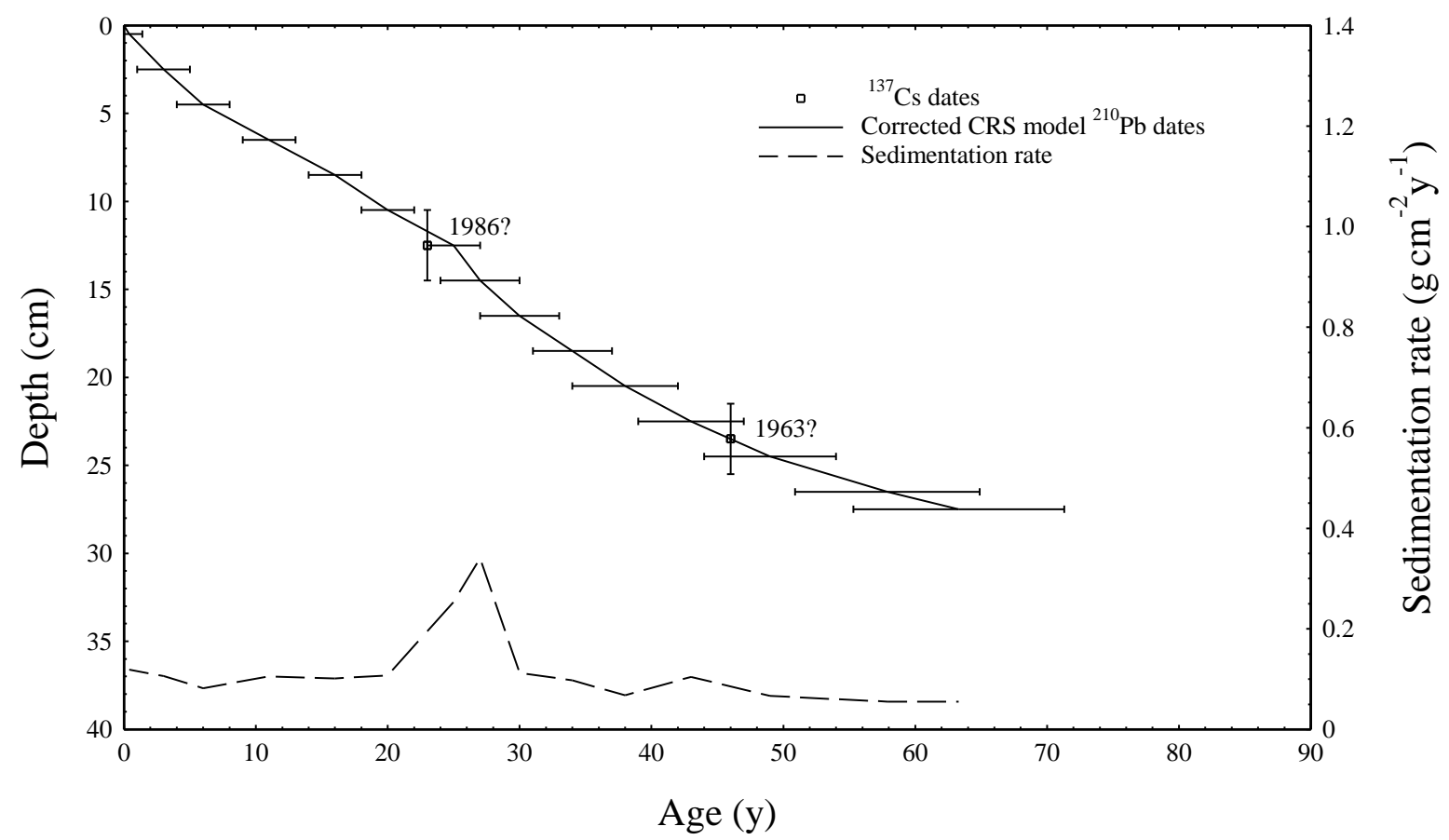

Figure 12.ii. Radiometric chronology of the Bugsee (Brandenburg See 97) sediment core showing the 1963 and 1986 depths suggested by the ${ }^{137} \mathrm{Cs}$ record, together with the CRS model ${ }^{210} \mathrm{~Pb}$ dates and sedimentation rates calculated using the $1963{ }^{137} \mathrm{Cs}$ date as a reference point 
(a)



(b)

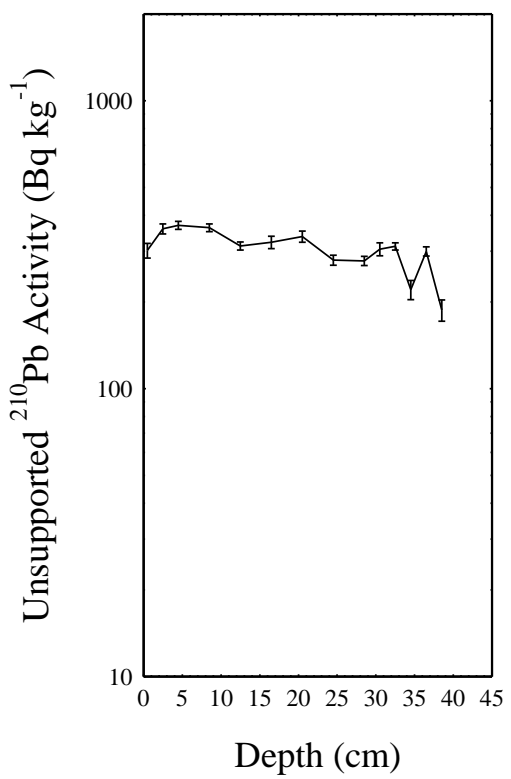

(c)

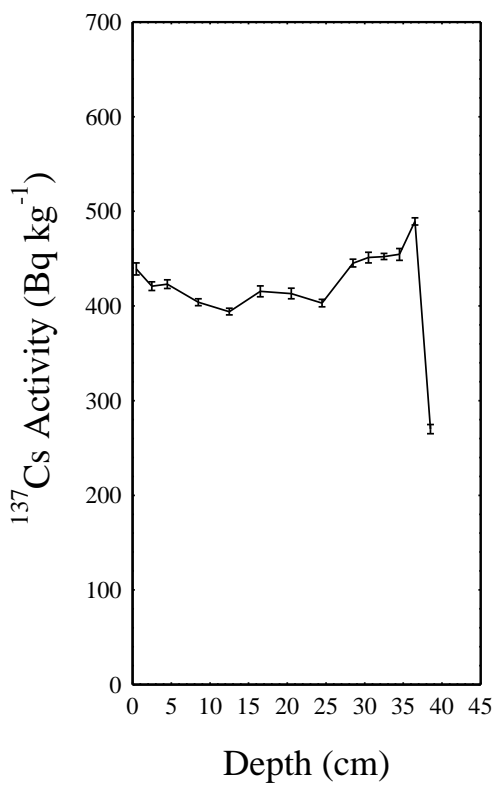

Figure 13.i. Fallout radionuclides in the Piechesee (Brandenburg See 102) sediment core showing (a) total and supported ${ }^{210} \mathrm{~Pb}$, (b) unsupported ${ }^{210} \mathrm{~Pb}$, (c) ${ }^{137} \mathrm{Cs}$ concentrations versus depth.

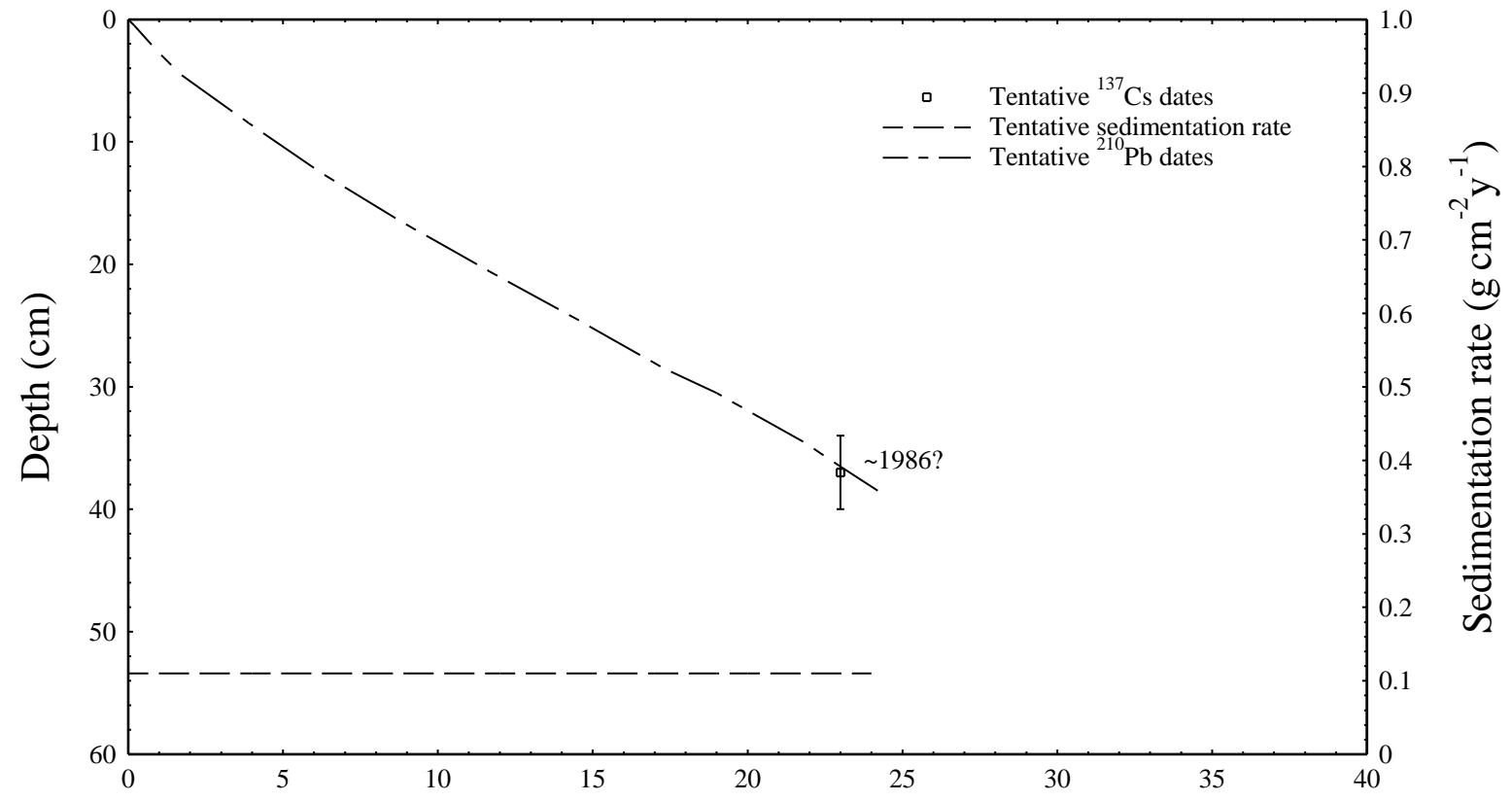

Age (y)

Figure 13.ii. Radiometric chronology of the Piechesee (Brandenburg See 102) sediment core showing the tentative ${ }^{137} \mathrm{Cs}$ and ${ }^{210} \mathrm{~Pb}$ dates and sedimentation rates suggested by the radiometric records 
(a)

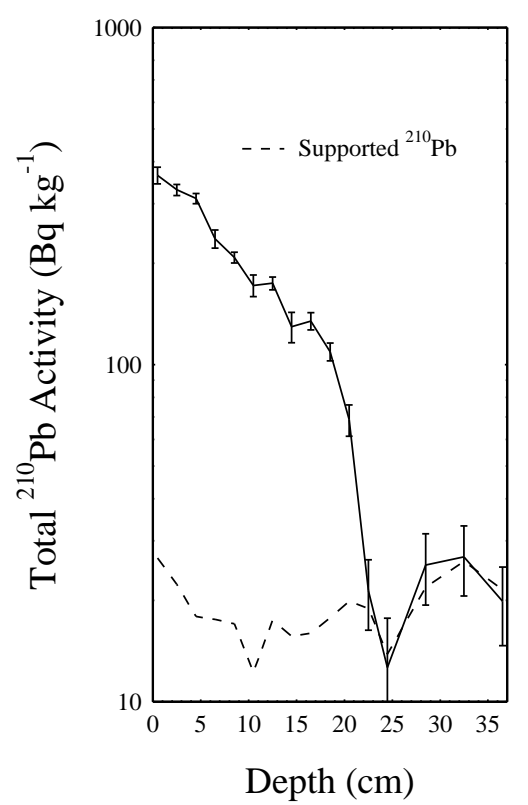

(b)

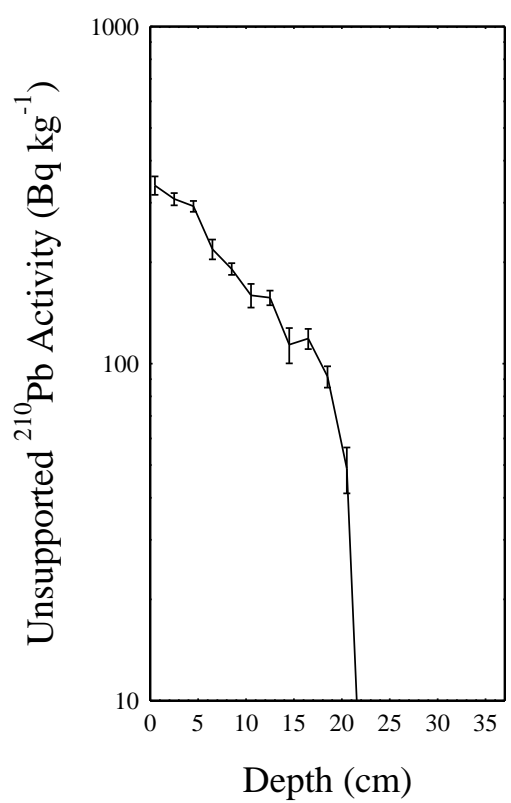

(c)

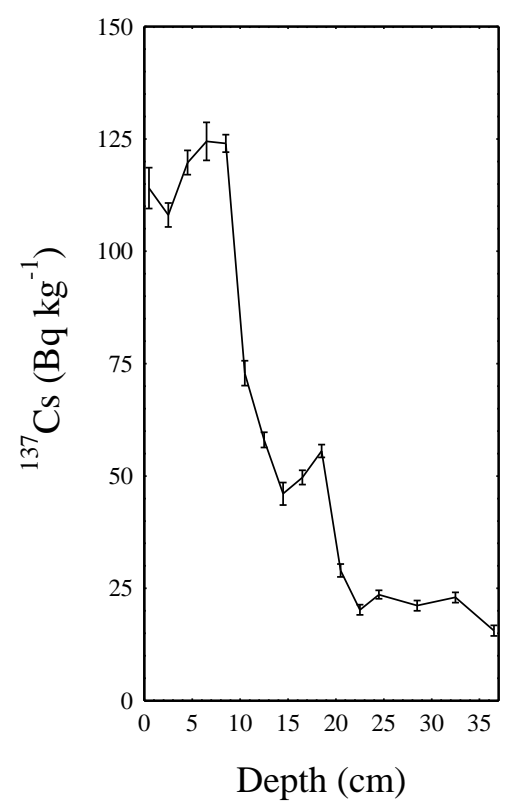

Figure 14.i. Fallout radionuclides in the Aalgastsee (Brandenburg See 108) sediment core showing (a) total and supported ${ }^{210} \mathrm{~Pb}$, (b) unsupported ${ }^{210} \mathrm{~Pb},(\mathrm{c}){ }^{137} \mathrm{Cs}$ concentrations versus depth.

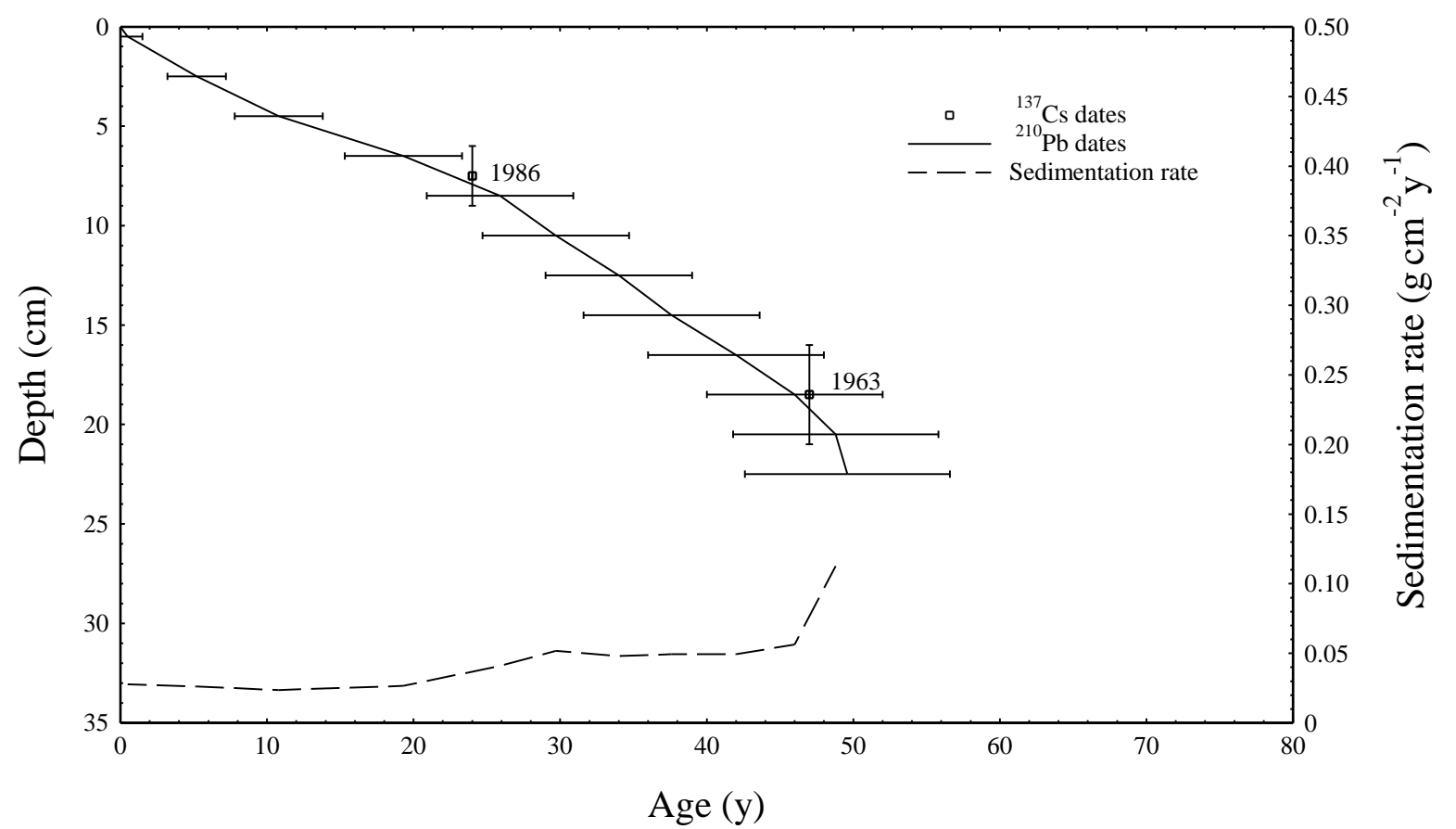

Figure 14.ii. Radiometric chronology of the Aalgastsee (Brandenburg See 108) sediment core showing the 1963 and 1986 depths suggested by the ${ }^{137} \mathrm{Cs}$ record, together with the CRS model ${ }^{210} \mathrm{~Pb}$ dates and sedimentation rates calculated using the ${ }^{137} \mathrm{Cs}$ dates as reference points. 
(a)

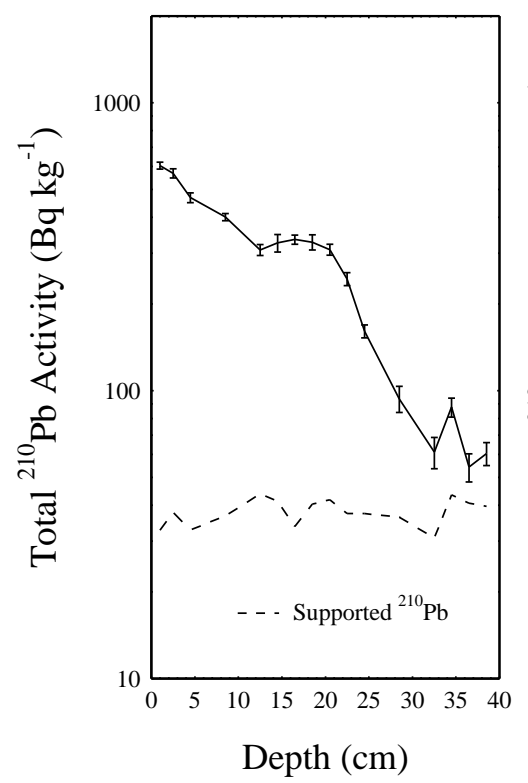

(b)

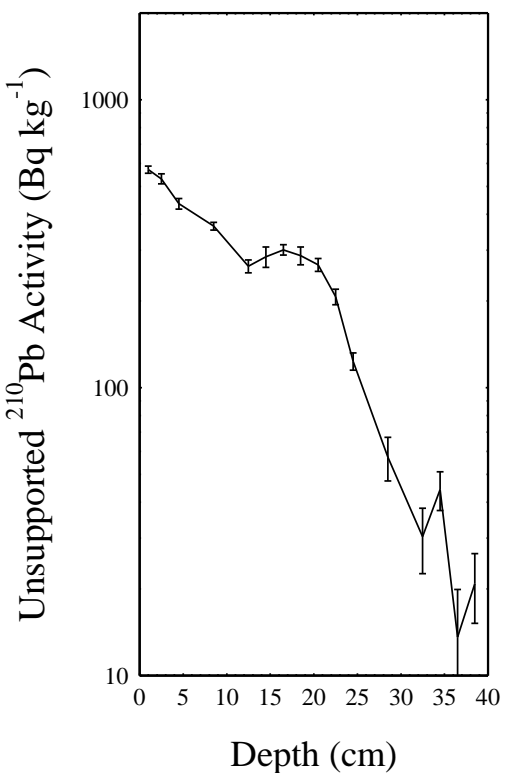

(c)

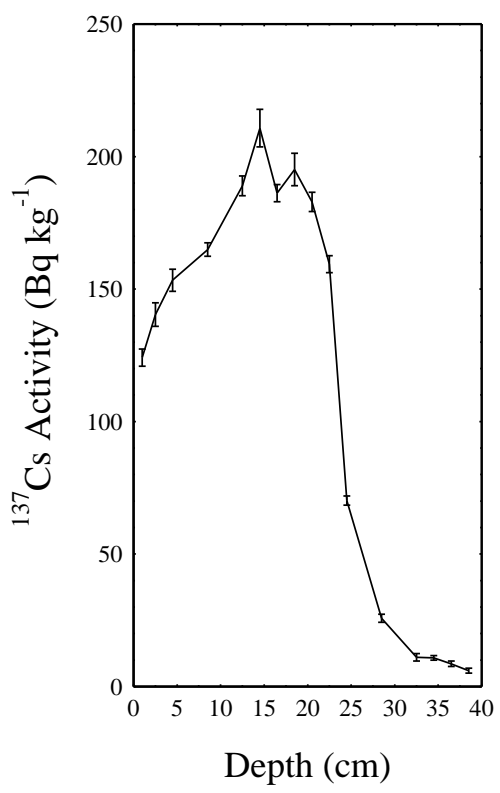

Figure 15.i. Fallout radionuclides in the Papensee (Brandenburg See 111) sediment core showing (a) total and supported ${ }^{210} \mathrm{~Pb}$, (b) unsupported ${ }^{210} \mathrm{~Pb}$, (c) ${ }^{137} \mathrm{Cs}$ concentrations versus depth.

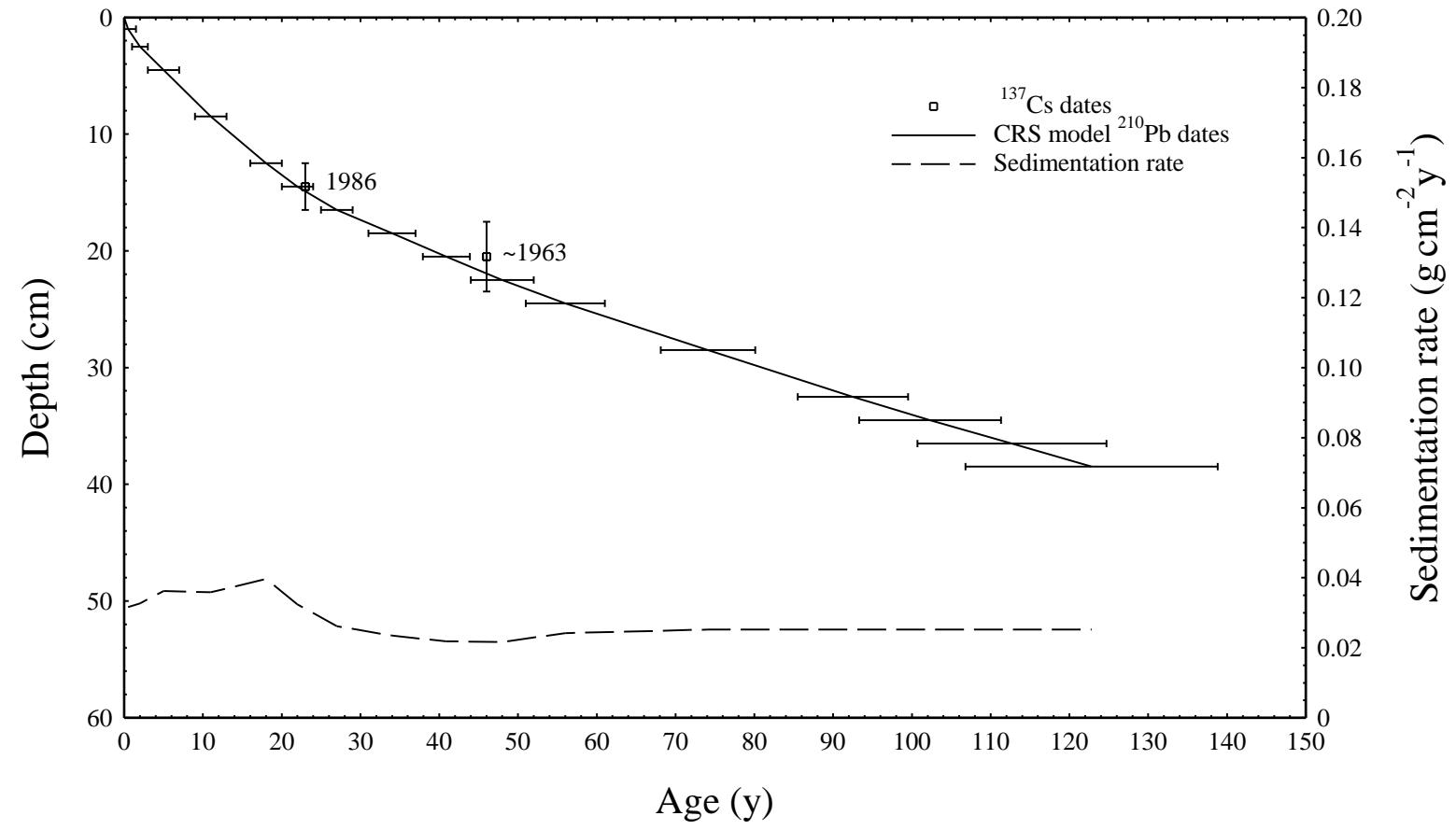

Figure 15.ii. Radiometric chronology of the Papensee (Brandenburg See 111) sediment core showing the CRS model ${ }^{210} \mathrm{~Pb}$ dates and sedimentation rates together with the 1986 and 1963 depths suggested by the ${ }^{137} \mathrm{Cs}$ record. 


\title{
Brandenburg Lake Dating Project
}

\section{Part II}

(September 2011)

\author{
From P.G. Appleby and G.T. Piliposian \\ Environmental Radioactivity Research Centre \\ University of Liverpool
}

\section{Work Program}

Dating by ${ }^{210} \mathrm{~Pb}$ and ${ }^{137} \mathrm{Cs}$ was carried out on sediment cores from a further 3 lakes in Brandenburg, eastern Germany, as listed below:

\author{
See 74 Dovinsee \\ See 101 Modderpfuhl \\ See 109 Grimnitzsee
}

$\begin{array}{cc}\text { Latitude } & \text { Longitude } \\ 52^{\circ} 59^{\prime} 53^{\prime \prime} \mathrm{N} & 13^{\circ} 47^{\prime} 17^{\prime \prime} \mathrm{E} \\ 52^{\circ} 40^{\prime} 46^{\prime \prime} \mathrm{N} & 13^{\circ} 54^{\prime} 30^{\prime \prime} \mathrm{E} \\ 52^{\circ} 58^{\prime} 43^{\prime \prime} \mathrm{N} & 13^{\circ} 46^{\prime} 37^{\prime \prime} \mathrm{E}\end{array}$

\section{Methods}

Sub-samples from each core were analysed for ${ }^{210} \mathrm{~Pb},{ }^{226} \mathrm{Ra}$, and ${ }^{137} \mathrm{Cs}$ by direct gamma assay in the Liverpool University Environmental Radioactivity Laboratory, using an Ortec HPGe GMX series coaxial low background intrinsic germanium detector (Appleby et al., 1986). ${ }^{210} \mathrm{~Pb}$ was determined via its gamma emissions at $46.5 \mathrm{keV}$, and ${ }^{226} \mathrm{Ra}$ by the $295 \mathrm{keV}$ and $352 \mathrm{keV} \gamma$-rays emitted by its daughter radionuclide ${ }^{214} \mathrm{~Pb}$ following 3 weeks storage in sealed containers to allow radioactive equilibration. ${ }^{137} \mathrm{Cs}$ was measured by its emissions at $662 \mathrm{keV}$. The absolute efficiencies of the detectors were determined using calibrated sources and sediment samples of known activity. Corrections were made for the effect of self absorption of low energy $\gamma$-rays within the sample (Appleby et al., 1992).

\section{Results}

The results of the radiometric analyses carried out on each core are given in Tables 1-3 and shown graphically in Figures $1 . i-3$.i. Supported ${ }^{210} \mathrm{~Pb}$ activity was assumed to be equal to the measured ${ }^{226} \mathrm{Ra}$ activity, and unsupported ${ }^{210} \mathrm{~Pb}$ activity calculated by subtracting supported ${ }^{210} \mathrm{~Pb}$ from the measured total ${ }^{210} \mathrm{~Pb}$ activity. Table 4 summarises a number of key radiometric parameters for all eighteen Brandenburg cores, including the maximum ${ }^{210} \mathrm{~Pb}$ concentration, the radiometric inventories, and the ${ }^{210} \mathrm{~Pb}$ flux. These data suggest that the three cores in the present study all had good records of atmospheric fallout.

${ }^{210} \mathrm{~Pb}$ dates for each core were calculated using the CRS ${ }^{210} \mathrm{~Pb}$ dating model (Appleby and Oldfield, 1978), and chronostratigraphic dates determined where possible from the ${ }^{137} \mathrm{Cs}$ records. Use of the alternative $\mathrm{CIC}$ dating model was precluded by non-monotonic variations in the unsupported ${ }^{210} \mathrm{~Pb}$ activity. Where there were reasonably well defined ${ }^{137} \mathrm{Cs}$ dates, and significant discrepancies with the raw CRS model ${ }^{210} \mathrm{~Pb}$ dates, corrections to the ${ }^{210} \mathrm{~Pb}$ dates were made using the ${ }^{137} \mathrm{Cs}$ dates as reference points (Appleby, 2001). Definitive chronologies for each core based on an assessment of all the relevant radiometric data are shown in Figures 1.ii-3.ii and given in detail in Tables 5-7.

\section{Dovinsee (Brandenburg See 74)}

Lead-210 Activity

Total ${ }^{210} \mathrm{~Pb}$ activity in this core (Figure $1 . \mathrm{i}(\mathrm{a})$ ) reached equilibrium with that of the supporting ${ }^{226} \mathrm{Ra}$ at a depth of around $34 \mathrm{~cm}$. The unsupported activity versus depth record (Figure 1.i(b)) is typical of many of the Brandenburg lakes in that there is little net decline in the upper sections of the core (in this case down to a depth of $20 \mathrm{~cm}$ ) and a much steeper decline in the deeper sections. Two possible 
explanations are extensive mixing of the upper sections, or a recent significant acceleration in the sedimentation rate.

\section{Artificial Fallout Radionuclides}

Results from previous Brandenburg lakes suggest that the main source of fallout in this region was from the atmospheric testing of nuclear weapons and, in some cases, the 1986 Chernobyl accident. The steep rise ${ }^{137} \mathrm{Cs}$ concentrations above a depth of around $30 \mathrm{~cm}$ (Figure 1.i(c)) most probably reflects the increasing levels of fallout in the late 1950s, and the peak values between $16-21 \mathrm{~cm}$ the period of maximum fallout in the early 1960s. A small fluctuation in concentrations within this depth range paralleled by a similar fluctuation in the ${ }^{210} \mathrm{~Pb}$ concentrations does however suggest that records in this part of the core have been influenced by sedimentological factors. In these circumstances the ${ }^{137} \mathrm{Cs} /{ }^{210} \mathrm{~Pb}$ activity ratio is sometimes a better guide to the 1963 depth. This occurs between $16-19 \mathrm{~cm}$. The slow decline in ${ }^{137} \mathrm{Cs}$ concentrations above $16.5 \mathrm{~cm}$ could be due to mixing, Chernobyl fallout, or further inputs of ${ }^{137} \mathrm{Cs}$ by erosion from the catchment.

\section{Core Chronology}

Dates calculated using the CRS ${ }^{210} \mathrm{~Pb}$ dating model place 1963 (the year of maximum weapons ${ }^{137} \mathrm{Cs}$ fallout) at a depth of about $22 \mathrm{~cm}$, a little below the range of values suggested by the ${ }^{137} \mathrm{Cs}$ record. Since ${ }^{210} \mathrm{~Pb}$ mixing models place 1963 at a depth of between $8-13 \mathrm{~cm}$, well above the ${ }^{137} \mathrm{Cs}$ peaks, mixing can be excluded as a source of the discrepancy. Other possible causes are a reduction change in the ${ }^{210} \mathrm{~Pb}$ supply rate at the core site in recent decades, or loss of a small amount of sediment from the top of the core shortly before or during coring. Since it is unlikely that the $20.5 \mathrm{~cm}$ sample containing the initial ${ }^{137} \mathrm{Cs}$ peak predates 1960 , a small correction to the ${ }^{210} \mathrm{~Pb}$ dates has been made (Appleby, 2001) using this as a reference level. The results of these calculations, shown in Figure 1.ii and given in detail in Table 5, suggest that up to around 1960 sedimentation rates were low and relatively uniform with a mean value of $0.022 \mathrm{~g} \mathrm{~cm}^{-2} \mathrm{y}^{-1}\left(0.14 \mathrm{~cm} \mathrm{y}^{-1}\right)$. Since then they appear to have increased significantly, present day value being around $0.08-0.09 \mathrm{~g} \mathrm{~cm}^{-2} \mathrm{y}^{-1}\left(0.90 \mathrm{~cm} \mathrm{y}^{-1}\right)$.

\section{Modderpfuhl (Brandenburg See 101)}

\section{Lead-210 Activity}

${ }^{210} \mathrm{~Pb} /{ }^{226} \mathrm{Ra}$ equilibrium in this core was reached, at a depth of around $35 \mathrm{~cm}$ (Figure 2.i(a)). The unsupported ${ }^{210} \mathrm{~Pb}$ profile (Figure $2 . \mathrm{i}(\mathrm{b})$ ) is similar to that in See 74 with an upper zone of relatively uniform activity extending in this case to a depth of around $15 \mathrm{~cm}$, and a deeper zone in which it declines more or less exponentially with depth. There are again two possible explanations for the uniform activity in the top $15 \mathrm{~cm}$, mixing of the near surface sediments by physical or biological processes, or a recent acceleration in the sedimentation rate. The record in the deeper zone suggests an earlier period of slower and relative uniform sedimentation.

\section{Artificial Fallout Radionuclides}

The ${ }^{137} \mathrm{Cs}$ activity versus depth profile has a relatively well defined peak at $14.5 \mathrm{~cm}$ that most probably records the 1963 fallout maximum from the atmospheric testing of nuclear weapons.

\section{Core Chronology}

${ }^{210} \mathrm{~Pb}$ dates calculated using the CRS model place 1963 at a depth of $15.5 \mathrm{~cm}$, in relatively good agreement with the value suggested by the ${ }^{137} \mathrm{Cs}$ record. This level of agreement makes it unlikely that the ${ }^{210} \mathrm{~Pb}$ profile was significantly affected by surficial mixing. A small correction to the ${ }^{210} \mathrm{~Pb}$ dates has been made using the $1963{ }^{137} \mathrm{Cs}$ date as a reference level (Appleby, 2001). The results of these calculations, shown in Figure 2.ii and given in detail in Table 6, suggest that sedimentation rates were low and relatively uniform up to the mid 1960s, the mean value over a period of a century or more being $0.011 \mathrm{~g} \mathrm{~cm}^{-2} \mathrm{y}^{-1}\left(0.17 \mathrm{~cm} \mathrm{y}^{-1}\right)$. Since then they appear to have increased significantly, to a present day value of more than $0.04 \mathrm{~g} \mathrm{~cm}^{-2} \mathrm{y}^{-1}\left(0.75 \mathrm{~cm} \mathrm{y}^{-1}\right)$. 


\section{Grimnitzsee (Brandenburg See 109)}

\section{Lead-210 Activity}

This core did not quite reach the ${ }^{210} \mathrm{~Pb} /{ }^{226} \mathrm{Ra}$ equilibrium depth. At the base of the core total ${ }^{210} \mathrm{~Pb}$ activity still significantly exceeded that of the supporting ${ }^{226} \mathrm{Ra}$ (Figure $3 . \mathrm{i}(\mathrm{a})$ ). The unsupported ${ }^{210} \mathrm{~Pb}$ activity versus depth profile (Figure 3.i(b)) again had an upper zone of relatively slow decline, in this case extending right down to a depth of $33 \mathrm{~cm}$. Below this transition point concentrations declined steeply and more or less exponentially with depth, suggesting as in the other cores an earlier period of slow and relatively uniform sedimentation.

\section{Artificial Fallout Radionuclides}

${ }^{137} \mathrm{Cs}$ concentrations have a relatively well defined maximum value in the $16-17 \mathrm{~cm}$ section (Figure 3.i(c)). Given that high ${ }^{137} \mathrm{Cs}$ concentrations extend down to a depth of $25 \mathrm{~cm}$ it is more likely that this feature records fallout from the 1986 Chernobyl accident than the 1963 nuclear weapons fallout peak. Fallout from Chernobyl has been detected in a number of other Brandenburg sites. Since this feature does coincide with a similar peak in the ${ }^{210} \mathrm{~Pb}$ profile (Figure 3.i(b)) it is however possible that the precise shape of the record in this part of the core has been influenced by sedimentological factors. Although there is no obvious feature identifying the early 1960 s nuclear weapons fallout peak, it is likely that the high concentrations at $25 \mathrm{~cm}$ mainly reflect weapons test fallout.

\section{Core Chronology}

${ }^{210} \mathrm{~Pb}$ dates calculated using the CRS model place 1986 at a depth of $13.5 \mathrm{~cm}$, and 1960 at a depth of $25 \mathrm{~cm}$, supporting the suggestion that the high concentrations around $16.5 \mathrm{~cm}$ do record the 1986 fallout event and that those around $25 \mathrm{~cm}$ probably date from the early 1960s. Making a correction to the ${ }^{210} \mathrm{~Pb}$ results that was consistent with a date of 1986 for the $16-17 \mathrm{~cm}$ sample did however prove problematic. Since there is some doubt about the provenance of the ${ }^{137} \mathrm{Cs}$ peak in this sample, the results for this core, shown in Figure 3.ii and given in detail in Table 7, are those given by the raw ${ }^{210} \mathrm{~Pb}$ calculations alone. These indicate a mean sedimentation rate in the section of the core below $33 \mathrm{~cm}$ of $0.012 \mathrm{~g} \mathrm{~cm}^{-2} \mathrm{y}^{-1}\left(0.14 \mathrm{~cm} \mathrm{y}^{-1}\right)$ from the middle of the $19^{\text {th }}$ century through to the $1930 \mathrm{~s}$. During the latter half of the $20^{\text {th }}$ century this has increased steadily to a present day value of more than $0.07 \mathrm{~g} \mathrm{~cm}^{-2} \mathrm{y}^{-1}\left(0.90 \mathrm{~cm} \mathrm{y}^{-1}\right)$. Because of the possible inconsistency with the ${ }^{137} \mathrm{Cs}$ record the ${ }^{210} \mathrm{~Pb}$ chronology for this core should however be regarded with some caution.

\section{References}

Appleby, P.G. (2001): Chronostratigraphic techniques in recent sediments, in Tracking Environmental Change Using Lake Sediments Volume 1: Basin Analysis, Coring, and Chronological Techniques, (eds W M Last \& J P Smol), Kluwer Academic, pp. 171-203.

Appleby, P.G., Nolan, P.J., Gifford, D.W., Godfrey, M.J., Oldfield, F., Anderson, N.J. \& Battarbee, R.W. (1986): ${ }^{210} \mathrm{~Pb}$ dating by low background gamma counting. Hydrobiologia, 141: 21-27.

Appleby, P.G. \& Oldfield, F. (1978): The calculation of ${ }^{210} \mathrm{~Pb}$ dates assuming a constant rate of supply of unsupported ${ }^{210} \mathrm{~Pb}$ to the sediment. Catena, 5: 1-8.

Appleby, P.G., Richardson, N. \& Nolan, P.J. (1992): Self-absorption corrections for well-type germaniun detectors. Nucl. Inst. \& Methods B, 71: 228-233. 
Table 1. Fallout radionuclide concentrations in the Dovinsee (Brandenburg See 74) sediment core

\begin{tabular}{|c|c|c|c|c|c|c|c|c|c|}
\hline \multicolumn{10}{|c|}{${ }^{210} \mathrm{~Pb}$} \\
\hline \multicolumn{2}{|c|}{ Depth } & \multicolumn{2}{|c|}{ Total } & \multicolumn{2}{|c|}{ Unsupported } & \multicolumn{2}{|c|}{ Supported } & \multicolumn{2}{|c|}{${ }^{137} \mathrm{Cs}$} \\
\hline $\mathrm{cm}$ & $\mathrm{g} \mathrm{cm}^{-2}$ & $\mathrm{~Bq} \mathrm{~kg}{ }^{-1}$ & \pm & $\mathrm{Bq} \mathrm{kg}{ }^{-1}$ & \pm & $\mathrm{Bq} \mathrm{kg}{ }^{-1}$ & \pm & $\mathrm{Bq} \mathrm{kg}{ }^{-1}$ & \pm \\
\hline 0.5 & 0.04 & 239.8 & 13.1 & 193.0 & 13.4 & 46.9 & 2.8 & 239.4 & 4.2 \\
\hline 2.5 & 0.20 & 257.0 & 12.9 & 207.8 & 13.2 & 49.2 & 2.8 & 241.8 & 3.6 \\
\hline 4.5 & 0.41 & 241.0 & 11.3 & 200.2 & 11.5 & 40.8 & 2.0 & 244.3 & 3.2 \\
\hline 8.5 & 0.88 & 233.9 & 9.1 & 200.8 & 9.2 & 33.1 & 1.7 & 246.4 & 3.3 \\
\hline 12.5 & 1.30 & 237.3 & 7.8 & 206.5 & 7.9 & 30.8 & 1.4 & 248.3 & 2.6 \\
\hline 14.5 & 1.55 & 226.7 & 9.6 & 193.0 & 9.8 & 33.7 & 2.0 & 256.8 & 3.2 \\
\hline 16.5 & 1.79 & 205.5 & 9.4 & 169.3 & 9.6 & 36.2 & 2.0 & 262.2 & 2.8 \\
\hline 18.5 & 2.05 & 188.9 & 10.3 & 155.3 & 10.5 & 33.6 & 2.1 & 238.8 & 3.2 \\
\hline 20.5 & 2.31 & 231.5 & 8.3 & 197.8 & 8.5 & 33.7 & 1.6 & 250.5 & 2.5 \\
\hline 22.5 & 2.57 & 149.9 & 10.2 & 116.9 & 10.4 & 33.0 & 2.3 & 196.8 & 3.0 \\
\hline 24.5 & 2.90 & 105.6 & 9.9 & 77.4 & 10.2 & 28.1 & 2.3 & 127.1 & 2.6 \\
\hline 26.5 & 3.26 & 148.2 & 9.7 & 113.3 & 9.9 & 34.9 & 1.9 & 113.9 & 2.7 \\
\hline 28.5 & 3.58 & 115.2 & 9.3 & 85.4 & 9.5 & 29.8 & 2.0 & 116.6 & 2.4 \\
\hline 31.5 & 4.04 & 99.8 & 10.0 & 68.1 & 10.2 & 31.7 & 2.2 & 70.8 & 2.2 \\
\hline 33.5 & 4.33 & 44.5 & 6.4 & 9.0 & 6.6 & 35.5 & 1.8 & 26.4 & 1.4 \\
\hline
\end{tabular}

Table 2. Fallout radionuclide concentrations in the Modderpfuhl (Brandenburg See 101) sediment core

\begin{tabular}{|c|c|c|c|c|c|c|c|c|c|}
\hline \multicolumn{10}{|c|}{${ }^{210} \mathrm{~Pb}$} \\
\hline \multicolumn{2}{|c|}{ Depth } & \multicolumn{2}{|c|}{ Total } & \multicolumn{2}{|c|}{ Unsupported } & \multicolumn{2}{|c|}{ Supported } & \multicolumn{2}{|c|}{${ }^{137} \mathrm{Cs}$} \\
\hline $\mathrm{cm}$ & $\mathrm{g} \mathrm{cm}^{-2}$ & $\mathrm{~Bq} \mathrm{~kg}^{-1}$ & \pm & $\mathrm{Bq} \mathrm{kg}{ }^{-1}$ & \pm & $\mathrm{Bq} \mathrm{kg}{ }^{-1}$ & \pm & $\mathrm{Bq} \mathrm{kg}{ }^{-1}$ & \pm \\
\hline 0.5 & 0.01 & 461.8 & 29.1 & 412.0 & 29.8 & 49.8 & 6.3 & 359.5 & 8.5 \\
\hline 2.5 & 0.09 & 479.3 & 16.2 & 445.3 & 16.5 & 33.9 & 2.9 & 370.8 & 4.8 \\
\hline 4.5 & 0.22 & 452.8 & 14.6 & 419.3 & 14.8 & 33.4 & 2.5 & 384.1 & 4.6 \\
\hline 8.5 & 0.55 & 456.7 & 12.4 & 425.3 & 12.5 & 31.4 & 1.9 & 387.2 & 4.4 \\
\hline 10.5 & 0.70 & 427.0 & 15.5 & 394.6 & 15.7 & 32.4 & 2.5 & 399.1 & 4.5 \\
\hline 12.5 & 0.88 & 450.1 & 12.2 & 422.7 & 12.3 & 27.4 & 2.0 & 411.1 & 4.2 \\
\hline 14.5 & 1.02 & 462.6 & 13.0 & 433.8 & 13.1 & 28.8 & 1.9 & 432.2 & 4.8 \\
\hline 15.5 & 1.10 & 371.8 & 13.1 & 335.3 & 13.3 & 36.5 & 2.2 & 349.5 & 4.2 \\
\hline 16.5 & 1.16 & 305.3 & 15.9 & 268.4 & 16.2 & 36.9 & 3.1 & 268.3 & 4.5 \\
\hline 18.5 & 1.29 & 244.1 & 10.4 & 204.8 & 10.6 & 39.4 & 2.0 & 198.2 & 3.4 \\
\hline 20.5 & 1.42 & 190.6 & 9.3 & 156.6 & 9.5 & 34.1 & 1.9 & 132.4 & 2.4 \\
\hline 22.5 & 1.56 & 165.3 & 9.9 & 134.3 & 10.1 & 31.0 & 2.0 & 98.4 & 2.2 \\
\hline 24.5 & 1.69 & 149.4 & 10.7 & 124.8 & 10.9 & 24.7 & 2.1 & 79.1 & 2.3 \\
\hline 26.5 & 1.81 & 103.4 & 7.5 & 74.3 & 7.6 & 29.2 & 1.7 & 59.5 & 1.7 \\
\hline 28.5 & 1.95 & 59.7 & 8.3 & 29.4 & 8.5 & 30.3 & 1.8 & 38.4 & 1.7 \\
\hline 30.5 & 2.09 & 58.3 & 7.4 & 24.0 & 7.6 & 34.3 & 1.7 & 30.9 & 1.3 \\
\hline 32.5 & 2.22 & 56.9 & 7.1 & 27.5 & 7.3 & 29.4 & 1.4 & 23.9 & 1.1 \\
\hline 36.5 & 2.54 & 27.7 & 6.8 & -6.7 & 7.1 & 34.3 & 1.7 & 17.1 & 1.3 \\
\hline
\end{tabular}


Table 3. Fallout radionuclide concentrations in the Grimnitzsee (Brandenburg See 109) sediment core

\begin{tabular}{|c|c|c|c|c|c|c|c|c|c|}
\hline \multicolumn{10}{|c|}{${ }^{210} \mathrm{~Pb}$} \\
\hline \multicolumn{2}{|c|}{ Depth } & \multicolumn{2}{|c|}{ Total } & \multicolumn{2}{|c|}{ Unsupported } & \multicolumn{2}{|c|}{ Supported } & \multicolumn{2}{|c|}{${ }^{137} \mathrm{Cs}$} \\
\hline $\mathrm{cm}$ & $\mathrm{g} \mathrm{cm}^{-2}$ & $\mathrm{~Bq} \mathrm{~kg}{ }^{-1}$ & \pm & $\mathrm{Bq} \mathrm{kg}^{-1}$ & \pm & $\mathrm{Bq} \mathrm{kg}^{-1}$ & \pm & $\mathrm{Bq} \mathrm{kg}{ }^{-1}$ & \pm \\
\hline 0.5 & 0.02 & 377.2 & 13.9 & 332.6 & 14.1 & 44.6 & 2.6 & 351.1 & 5.1 \\
\hline 2.5 & 0.17 & 402.5 & 13.5 & 369.9 & 13.7 & 32.5 & 2.3 & 322.3 & 4.2 \\
\hline 4.5 & 0.34 & 400.0 & 15.6 & 368.3 & 15.9 & 31.7 & 2.5 & 330.1 & 4.3 \\
\hline 8.5 & 0.71 & 404.4 & 10.0 & 369.5 & 10.2 & 34.9 & 1.7 & 336.1 & 3.2 \\
\hline 12.5 & 1.09 & 364.6 & 11.4 & 326.8 & 11.6 & 37.9 & 2.1 & 350.4 & 3.3 \\
\hline 14.5 & 1.27 & 305.7 & 18.4 & 264.1 & 18.8 & 41.6 & 4.0 & 358.3 & 5.9 \\
\hline 16.5 & 1.40 & 366.2 & 13.9 & 326.4 & 14.1 & 39.8 & 2.7 & 384.3 & 4.3 \\
\hline 18.5 & 1.57 & 265.4 & 11.6 & 231.4 & 11.9 & 34.0 & 2.4 & 367.1 & 4.3 \\
\hline 20.5 & 1.73 & 246.0 & 9.4 & 208.4 & 9.6 & 37.7 & 1.7 & 342.6 & 3.5 \\
\hline 24.5 & 2.09 & 230.5 & 12.1 & 201.5 & 12.3 & 29.0 & 2.4 & 305.1 & 4.7 \\
\hline 28.5 & 2.37 & 202.7 & 16.9 & 174.5 & 17.2 & 28.3 & 3.2 & 225.6 & 5.0 \\
\hline 32.5 & 2.72 & 199.2 & 9.2 & 166.7 & 9.4 & 32.5 & 1.7 & 197.0 & 2.6 \\
\hline 36.5 & 3.03 & 95.6 & 9.6 & 63.1 & 9.8 & 32.5 & 2.1 & 41.6 & 1.8 \\
\hline 38.5 & 3.18 & 90.0 & 7.5 & 59.3 & 7.6 & 30.6 & 1.5 & 28.3 & 1.6 \\
\hline 40.5 & 3.35 & 62.5 & 8.9 & 33.8 & 9.1 & 28.8 & 2.0 & 18.9 & 1.5 \\
\hline 41.5 & 3.45 & 54.2 & 6.1 & 22.4 & 6.3 & 31.8 & 1.6 & 17.9 & 1.1 \\
\hline
\end{tabular}

Table 4. Radionuclide parameters for the Brandenburg lake sediment cores

\begin{tabular}{|c|c|c|c|c|c|c|c|c|}
\hline \multirow[t]{2}{*}{ Core } & \multicolumn{2}{|c|}{$\begin{array}{l}\text { Maximum } \\
\text { activity }\end{array}$} & \multicolumn{2}{|c|}{ Inventory } & \multicolumn{2}{|c|}{ Flux } & \multicolumn{2}{|c|}{$\begin{array}{c}{ }^{137} \mathrm{Cs} \\
\text { Inventory }\end{array}$} \\
\hline & $\mathrm{Bq} \mathrm{kg}^{-1}$ & \pm & $\mathrm{Bq} \mathrm{m}^{-2}$ & \pm & $\mathrm{Bq} \mathrm{m}^{-2} \mathrm{y}^{-1}$ & \pm & $\mathrm{Bq} \mathrm{m}^{-2}$ & \pm \\
\hline \multicolumn{9}{|c|}{ New cores } \\
\hline See 74 & 208 & 13 & 6283 & 146 & 196 & 5 & 8210 & 123 \\
\hline See 101 & 434 & 13 & 5983 & 125 & 186 & 4 & 5602 & 96 \\
\hline See 109 & 370 & 14 & 8106 & 173 & 252 & 6 & 9124 & 144 \\
\hline \multicolumn{9}{|c|}{ Original cores } \\
\hline See 23 & 191 & 28 & 3229 & 159 & 101 & 6 & 584 & 27 \\
\hline See 67 & 274 & 20 & 4334 & 92 & 135 & 4 & 2685 & 38 \\
\hline See 71 & 388 & 17 & 3484 & 93 & 109 & 3 & 4840 & 75 \\
\hline See 72 & 233 & 13 & 3581 & 179 & 112 & 6 & 3405 & 59 \\
\hline See 76 & 277 & 14 & 3994 & 154 & 124 & 5 & 247 & 15 \\
\hline See 79 & 494 & 15 & 3402 & 77 & 106 & 3 & 1000 & 18 \\
\hline See 81 & 820 & 46 & 4377 & 95 & 136 & 3 & 673 & 15 \\
\hline See 86 & 356 & 11 & 5683 & 141 & 177 & 7 & 7443 & 141 \\
\hline See 89 & 626 & 22 & 6120 & 134 & 191 & 4 & 3853 & 62 \\
\hline See 90 & 523 & 22 & 5269 & 123 & 164 & 4 & 3123 & 58 \\
\hline See 94 & 337 & 14 & 7242 & 212 & 226 & 7 & 10337 & 157 \\
\hline See 97 & 139 & 16 & 4597 & 233 & 143 & 8 & 4458 & 105 \\
\hline See 102 & 369 & 12 & 10031 & 196 & 312 & 34 & 10729 & 162 \\
\hline See 108 & 338 & 21 & 3372 & 91 & 105 & 3 & 2045 & 34 \\
\hline See 111 & 572 & 17 & 5880 & 138 & 183 & 5 & 3108 & 53 \\
\hline
\end{tabular}


Table 5. ${ }^{210} \mathrm{~Pb}$ chronology of the Dovinsee (Brandenburg See 74 ) sediment core

\begin{tabular}{|c|c|c|c|c|c|c|c|}
\hline \multicolumn{2}{|c|}{ Depth } & \multicolumn{3}{|c|}{ Chronology } & \multicolumn{3}{|c|}{ Sedimentation Rate } \\
\hline $\mathrm{cm}$ & $\mathrm{g} \mathrm{cm}^{-2}$ & $\begin{array}{c}\text { Date } \\
A D\end{array}$ & $\begin{array}{c}\text { Age } \\
y\end{array}$ & \pm & $\mathrm{g} \mathrm{cm}^{-2} \mathrm{y}^{-1}$ & $\mathrm{~cm} \mathrm{y}^{-1}$ & $\pm(\%)$ \\
\hline 0.0 & 0.00 & 2009 & 0 & 0 & & & \\
\hline 0.5 & 0.04 & 2009 & 0 & 1 & 0.090 & 1.25 & 8.6 \\
\hline 2.5 & 0.20 & 2007 & 2 & 1 & 0.079 & 0.80 & 8.3 \\
\hline 4.5 & 0.41 & 2004 & 5 & 2 & 0.075 & 0.60 & 8.2 \\
\hline 8.5 & 0.88 & 1997 & 12 & 2 & 0.061 & 0.53 & 8.4 \\
\hline 12.5 & 1.30 & 1989 & 20 & 2 & 0.046 & 0.43 & 9.7 \\
\hline 14.5 & 1.55 & 1983 & 26 & 2 & 0.041 & 0.33 & 11.6 \\
\hline 16.5 & 1.79 & 1977 & 32 & 3 & 0.039 & 0.31 & 13.8 \\
\hline 18.5 & 2.05 & 1970 & 39 & 4 & 0.034 & 0.24 & 17.0 \\
\hline 20.5 & 2.31 & 1961 & 48 & 4 & 0.022 & 0.19 & 15.6 \\
\hline 22.5 & 2.57 & 1949 & 60 & 5 & 0.022 & 0.15 & 15.6 \\
\hline 24.5 & 2.90 & 1933 & 76 & 7 & 0.022 & 0.13 & 15.6 \\
\hline 26.5 & 3.26 & 1917 & 92 & 9 & 0.022 & 0.13 & 15.6 \\
\hline 28.5 & 3.58 & 1902 & 107 & 11 & 0.022 & 0.14 & 15.6 \\
\hline 31.5 & 4.04 & 1881 & 128 & 14 & 0.022 & 0.14 & 15.6 \\
\hline 33.5 & 4.33 & 1867 & 142 & 17 & 0.022 & 0.15 & 15.6 \\
\hline
\end{tabular}

Table 6. ${ }^{210} \mathrm{~Pb}$ chronology of the Modderpfuhl (Brandenburg See 101) sediment core

\begin{tabular}{|c|c|c|c|c|c|c|c|}
\hline \multicolumn{2}{|c|}{ Depth } & \multicolumn{3}{|c|}{ Chronology } & \multicolumn{3}{|c|}{ Sedimentation Rate } \\
\hline & & Date & Age & & & & \\
\hline $\mathrm{cm}$ & $\mathrm{g} \mathrm{cm}^{-2}$ & $A D$ & y & \pm & $\mathrm{g} \mathrm{cm}^{-2} \mathrm{y}^{-1}$ & $\mathrm{~cm} \mathrm{y}^{-1}$ & $\pm(\%)$ \\
\hline 0.0 & 0.00 & 2009 & 0 & 0 & & & \\
\hline 0.5 & 0.01 & 2008 & 1 & 2 & 0.044 & 1.25 & 8.9 \\
\hline 2.5 & 0.09 & 2007 & 2 & 2 & 0.038 & 0.75 & 6.6 \\
\hline 4.5 & 0.22 & 2003 & 6 & 2 & 0.036 & 0.43 & 7.0 \\
\hline 8.5 & 0.55 & 1993 & 16 & 2 & 0.026 & 0.35 & 8.7 \\
\hline 10.5 & 0.70 & 1986 & 23 & 2 & 0.023 & 0.25 & 10.7 \\
\hline 12.5 & 0.88 & 1977 & 32 & 3 & 0.016 & 0.20 & 13.4 \\
\hline 14.5 & 1.02 & 1966 & 43 & 4 & 0.011 & 0.17 & 14.1 \\
\hline 15.5 & 1.10 & 1959 & 50 & 5 & 0.011 & 0.17 & 14.1 \\
\hline 16.5 & 1.16 & 1954 & 55 & 5 & 0.011 & 0.17 & 14.1 \\
\hline 18.5 & 1.29 & 1942 & 67 & 7 & 0.011 & 0.17 & 14.1 \\
\hline 20.5 & 1.42 & 1931 & 78 & 8 & 0.011 & 0.17 & 14.1 \\
\hline 22.5 & 1.56 & 1918 & 91 & 10 & 0.011 & 0.17 & 14.1 \\
\hline 24.5 & 1.69 & 1907 & 102 & 11 & 0.011 & 0.17 & 14.1 \\
\hline 26.5 & 1.81 & 1896 & 113 & 13 & 0.011 & 0.17 & 14.1 \\
\hline 28.5 & 1.95 & 1883 & 126 & 15 & 0.011 & 0.17 & 14.1 \\
\hline 30.5 & 2.09 & 1872 & 137 & 16 & 0.011 & 0.17 & 14.1 \\
\hline 32.5 & 2.22 & 1860 & 149 & 18 & 0.011 & 0.17 & 14.1 \\
\hline
\end{tabular}


Table 7. ${ }^{210} \mathrm{~Pb}$ chronology of the Grimnitzsee (Brandenburg See 109) sediment core

\begin{tabular}{|c|c|c|c|c|c|c|c|}
\hline \multicolumn{2}{|c|}{ Depth } & \multicolumn{3}{|c|}{ Chronology } & \multicolumn{3}{|c|}{ Sedimentation Rate } \\
\hline $\mathrm{cm}$ & $\mathrm{g} \mathrm{cm}^{-2}$ & $\begin{array}{c}\text { Date } \\
\text { AD }\end{array}$ & $\begin{array}{c}\text { Age } \\
y\end{array}$ & \pm & $\mathrm{g} \mathrm{cm}^{-2} \mathrm{y}^{-1}$ & $\mathrm{~cm} \mathrm{y}^{-1}$ & $\pm(\%)$ \\
\hline 0.0 & 0.00 & 2009 & 0 & 0 & & & \\
\hline 0.5 & 0.02 & 2009 & 0 & 1 & 0.075 & 1.03 & 4.8 \\
\hline 2.5 & 0.17 & 2007 & 2 & 1 & 0.063 & 0.81 & 4.3 \\
\hline 4.5 & 0.34 & 2004 & 5 & 2 & 0.058 & 0.61 & 4.9 \\
\hline 8.5 & 0.71 & 1997 & 12 & 2 & 0.047 & 0.50 & 3.8 \\
\hline 12.5 & 1.09 & 1988 & 21 & 2 & 0.040 & 0.45 & 4.6 \\
\hline 14.5 & 1.27 & 1983 & 26 & 2 & 0.038 & 0.49 & 7.8 \\
\hline 16.5 & 1.40 & 1980 & 29 & 2 & 0.034 & 0.46 & 5.5 \\
\hline 18.5 & 1.57 & 1975 & 34 & 2 & 0.037 & 0.44 & 6.4 \\
\hline 20.5 & 1.73 & 1971 & 38 & 2 & 0.037 & 0.38 & 6.3 \\
\hline 24.5 & 2.09 & 1959 & 50 & 2 & 0.027 & 0.35 & 8.0 \\
\hline 28.5 & 2.37 & 1947 & 62 & 2 & 0.021 & 0.25 & 11.4 \\
\hline 32.5 & 2.72 & 1927 & 82 & 3 & 0.012 & 0.17 & 11.1 \\
\hline 36.5 & 3.03 & 1900 & 109 & 6 & 0.012 & 0.15 & 11.1 \\
\hline 38.5 & 3.18 & 1886 & 123 & 8 & 0.012 & 0.14 & 11.1 \\
\hline 40.5 & 3.35 & 1872 & 137 & 13 & 0.012 & 0.13 & 11.1 \\
\hline 41.5 & 3.45 & 1863 & 146 & 16 & 0.012 & 0.12 & 11.1 \\
\hline
\end{tabular}


(a)

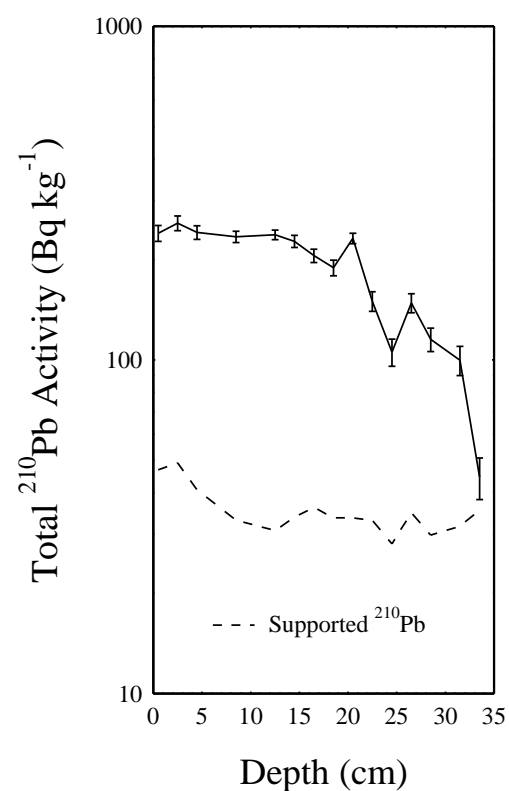

(b)

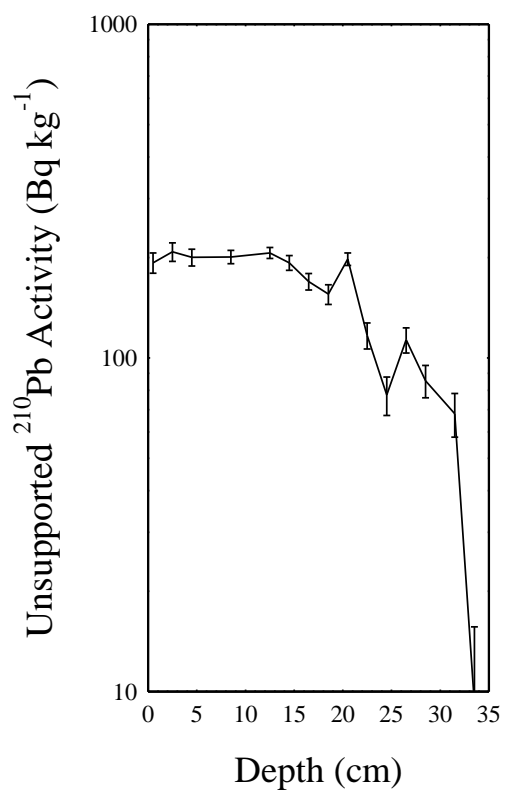

(c)

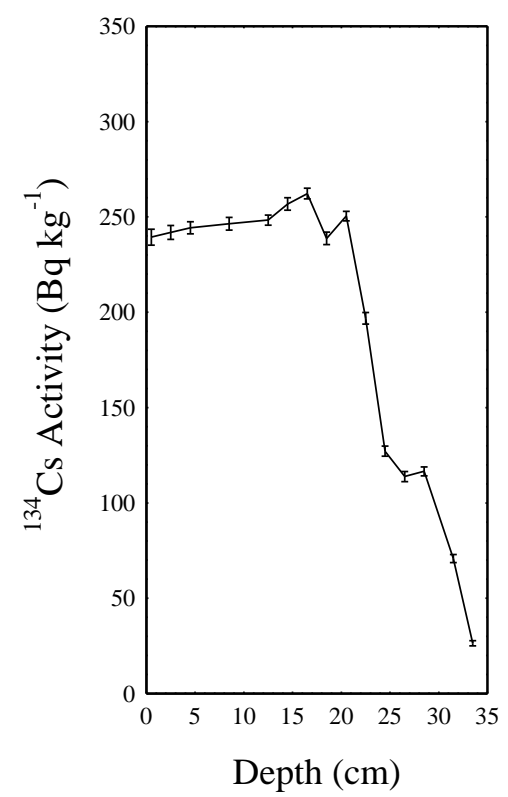

Figure 1.i. Fallout radionuclides in the Dovinsee (Brandenburg See 74) sediment core showing (a) total and supported ${ }^{210} \mathrm{~Pb}$, (b) unsupported ${ }^{210} \mathrm{~Pb}$, (c) ${ }^{137} \mathrm{Cs}$ concentrations versus depth.

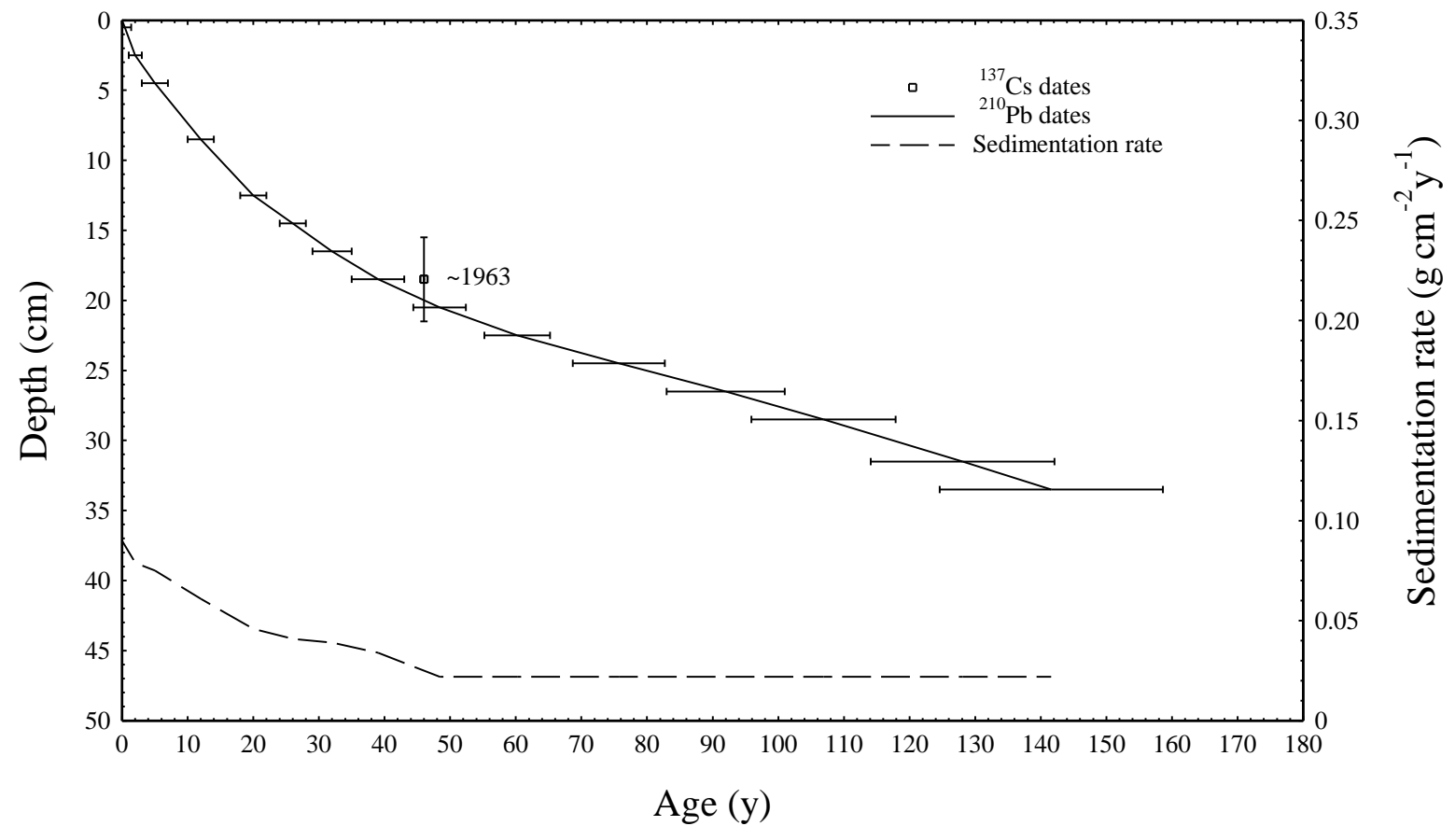

Figure 1.ii. Radiometric chronology of the Dovinsee (Brandenburg See 74) sediment core showing the ${ }^{210} \mathrm{~Pb}$ dates and sedimentation rates and the approximate 1963 depth suggested by the ${ }^{137} \mathrm{Cs}$ record. A small correction to the ${ }^{210} \mathrm{~Pb}$ dates has been made using the ${ }^{137} \mathrm{Cs}$ date as a reference point. 
(a)

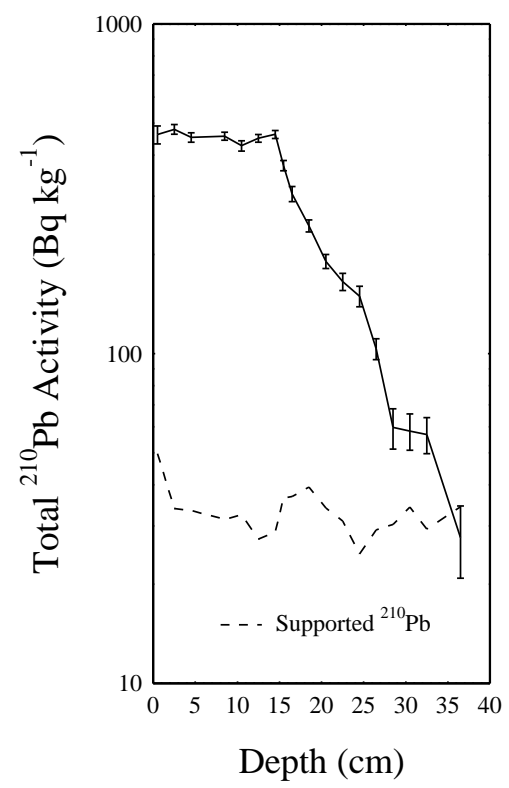

(b)

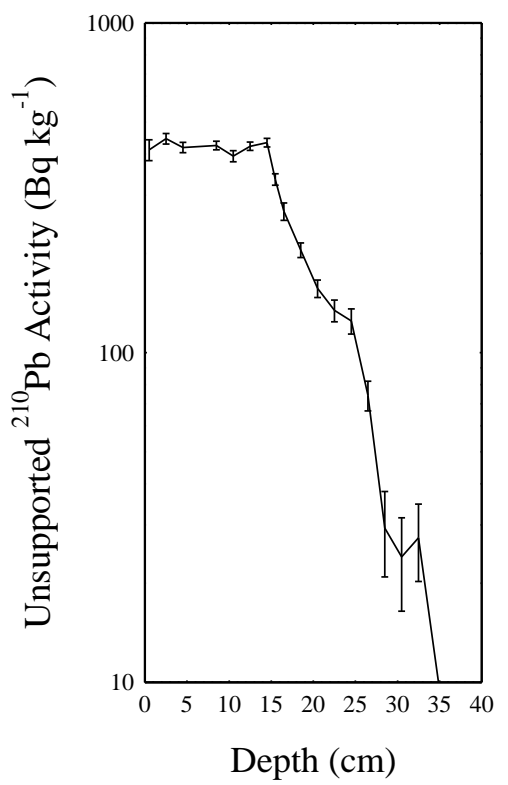

(c)

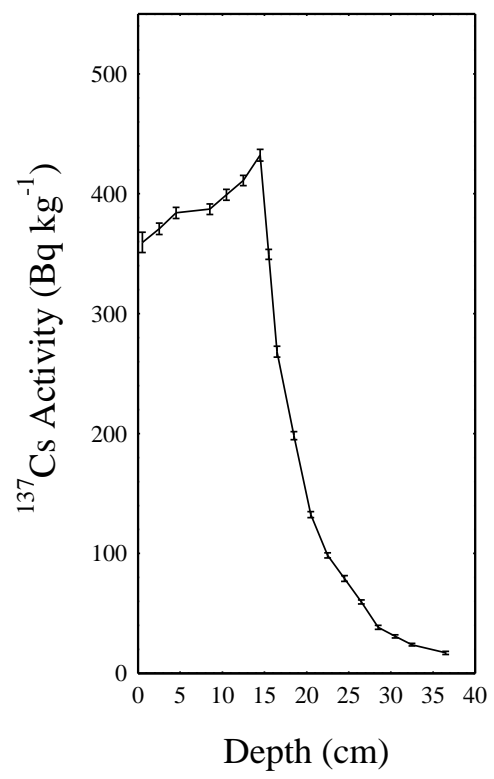

Figure 2.i. Fallout radionuclides in the Modderpfuhl (Brandenburg See 101) sediment core showing (a) total and supported ${ }^{210} \mathrm{~Pb}$, (b) unsupported ${ }^{210} \mathrm{~Pb}$, (c) ${ }^{137} \mathrm{Cs}$ concentrations versus depth.

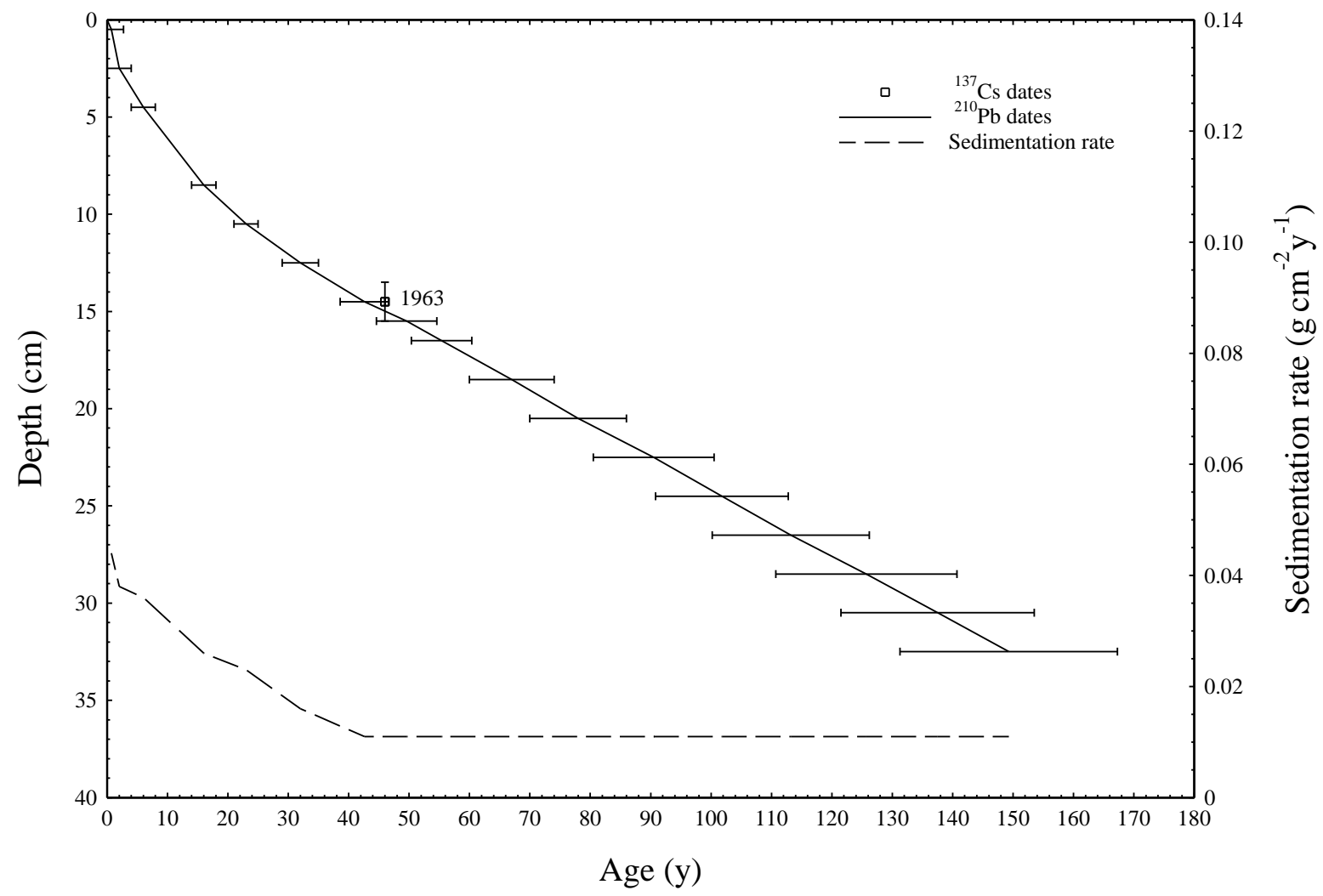

Figure 2.ii. Radiometric chronology of the Modderpfuhl (Brandenburg See 101) sediment core showing the CRS model ${ }^{210} \mathrm{~Pb}$ dates and sedimentation rates and the approximate 1963 depth suggested by the ${ }^{137} \mathrm{Cs}$ record. 
(a)

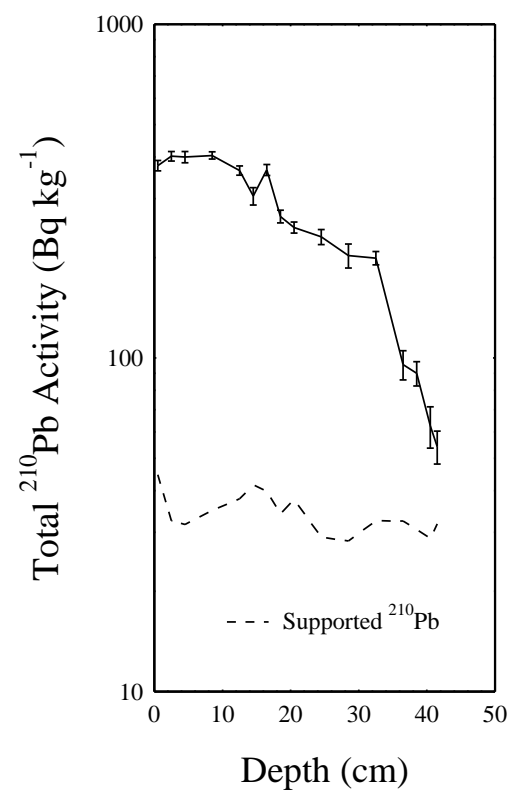

(b)

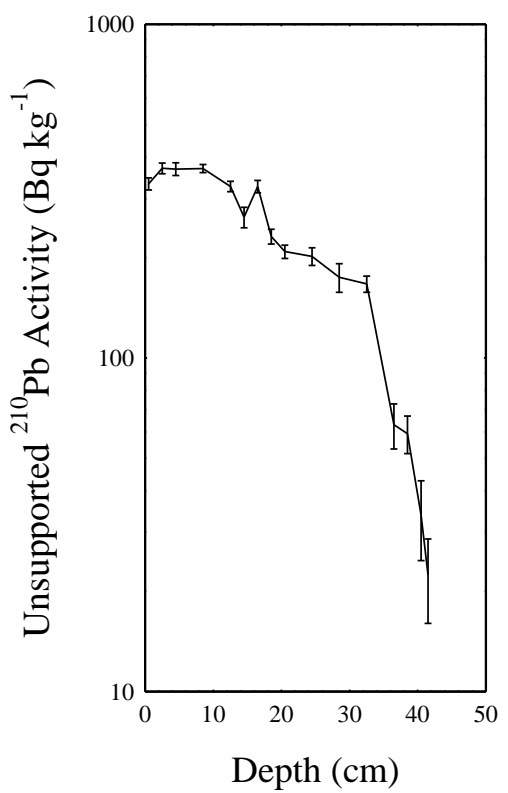

(c)

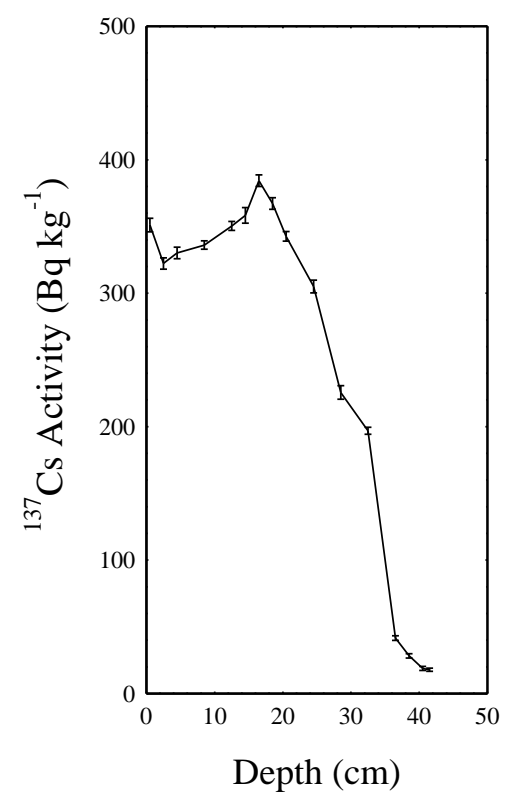

Figure 3.i. Fallout radionuclides in the Grimnitzsee (Brandenburg See 109) sediment core showing (a) total and supported ${ }^{210} \mathrm{~Pb}$, (b) unsupported ${ }^{210} \mathrm{~Pb}$, (c) ${ }^{137} \mathrm{Cs}$ concentrations versus depth.

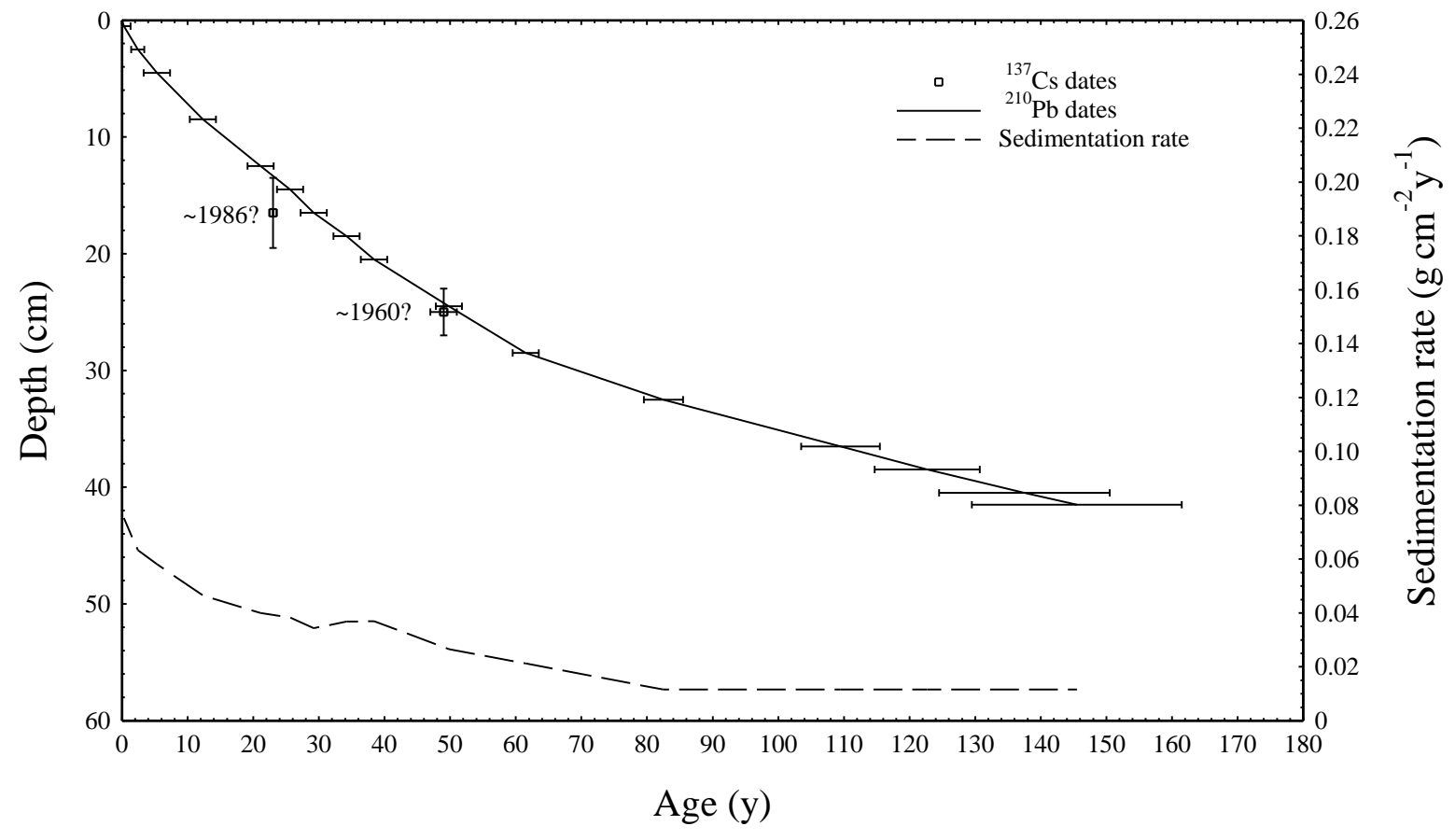

Figure 3.ii. Radiometric chronology of the Grimnitzsee (Brandenburg See 109) sediment core showing the CRS model ${ }^{210} \mathrm{~Pb}$ dates and sedimentation rates and possible 1986 and 1963 depths suggested by the ${ }^{137} \mathrm{Cs}$ record. 
Appendix II

\section{Pollen sample preparation}




\section{Pollen sample preparation}

- In the test tube Lycopodium clavatum spore tablets were dissolved in warm water.

- Sample $\left(1 \mathrm{~cm}^{2}\right)$ was added to the test tube with the dissolved L. clavatum spores and mixed using a shaking device (VF2, Janke \& Kunkel, IKA-Labortechnik).

- The test tube was fulfilled with dest. water.

- The sample was centrifuged (Megafuge 1, Heraeus) by 3500 turns/min. for 5 min. and the supernatant water was decanted.

- A solution of $10 \%$ potassium hydroxide $(\mathrm{KOH})$ was added to the sample and both were heated for $5 \mathrm{~min}$. in a water bath at $90^{\circ} \mathrm{C}$ to dissolve humic acids and disaggregated the sample.

- Sample was washed with dest. water (two times) and again centrifuged (3500 turns/min. for 5 min.).

- A solution of $10 \%$ Hydrochloric acid $(\mathrm{HCl})$ was added to dissolve carbonate material, the material in the test tube was mixed using shaking device.

- Sample was washed with dest. water (two times) and centrifuged (3500 turns/min. for $5 \mathrm{~min}$.).

- A solution of $40 \%$ hydrofluoric acid (HF) was added to the sample and heated for $30 \mathrm{~min}$ in a water bath $\left(90^{\circ} \mathrm{C}\right)$ to remove silicate material from the sample.

- The test tube was filled with dest. water and then centrifuged (3500 turns/min. for 5 min.), the supernatant was decanted.

- A solution of $10 \%$ Hydrochloric acid $(\mathrm{HCl})$ was added and for 30 min heated in a water bath (ca. $100^{\circ} \mathrm{C}$ ) to dissolve colloidal silica and silicofluorides.

- Sample was washed with dest. water (three times) and centrifuged (3500 turns/min. for 5 min.)

- The sample was dehydrated using acetic acid $\left(\mathrm{CH}_{3} \mathrm{COOH}\right)$, sample was vibrated, centrifuged (3500 turns/min. for $5 \mathrm{~min}$.) and then the supernatant acid decanted.

- A mixture of 9 parts acetic anhydride $\left.\left(\mathrm{CH}_{3} \mathrm{CO}\right)_{2} \mathrm{O}\right)$ and 1 part concentrated sulphuric acid $\left(\mathrm{H}_{2} \mathrm{SO}_{4}\right)$ was applied and heated for $2 \mathrm{~min}$. in a water bath at ca. $90^{\circ} \mathrm{C}$, to clean the sample.

- The rest of the test tube was filled with acetic acid $\left(\mathrm{CH}_{3} \mathrm{COOH}\right)$, centrifuged (3500 turns/min. for $5 \mathrm{~min}$.) and the supernatant acid decanted.

- The test tube was filled up to $1 / 3$ with dest. water and some Safranin was added for staining the pollen and spore grains. The test tube was further filled with alcohol, the components were mixed and centrifuged ( 3500 turns/min. for $5 \mathrm{~min}$.), the supernatant water and alcohol was decanted. 


\section{Curriculum vitae}

Full name: Isabelle Matthias

Born on: 07.05.1983

Born in: Stadthagen, Germany

Nationality: German

Practical experiences

2009-2013

Scientific Co-Worker at the Department of Palynology an Climate Dynamics, Georg-August-University, Göttingen

2010-2012 Co-Worker in the project: Towards quantitative vegetation reconstructions in Greece (DAAD-project)

2008-2009 Scientific assistant at the Department of Palynology an Climate Dynamics and at the Department of Landscape Ecology, GeorgAugust-University, Göttingen

2006-2008 Student assistant at the Department of Landscape Ecology, GeorgAugust-University, Göttingen

2005-2006 Student assistant at the Department Geography and High Mountain Geomorphology, Georg-August-University, Göttingen

\section{Publications}

2014 Matthias, I. \& Giesecke, T. (2014): Insights into pollen source area, transport and deposition from modern pollen accumulation rates in lake sediments. Quaternary Science Reviews, 87: 12-23

2013 Niemann, H., Matthias, I., Michalzik B. \& H. Behling (2013): Late Holocene human impact and environmental change inferred from a multi-proxy lake sediment record in the Loja region, southeastern Ecuador. Quaternary International, 308-309: 253-264

Davis, B.A.S., Zanon, M., Collins, P., Mauri, A., Bakker, J., Barboni, D., Barthelmes, A., Beaudouin, C., Bjune, A.E., Bozilova, E., Bradshaw, R.H.W.,Brayshay, B.A., Brewer, S., Brugiapaglia, E., Bunting, J., Connor, S.E., de Beaulieu, J.-L., Edwards, K., Ejarque, A., Fall, P., Florenzano, A.,Fyfe, R., Galop, D., Giardini, M., Giesecke, T., Grant, M.J., Guiot J., Jahns, S., Jankovská, V., Juggins, S., Kahrmann, M., Karpińska-Kołaczek, M., Kołaczek, P., Kühl, N., Kuneš, P.,Lapteva, E.G., Leroy, S.A.G., Leydet, M., López Sáez, J.A., Masi, A., Matthias, I., Mazier, F., Meltsov, V., Mercuri, A.M., Miras, Y., Mitchell, F.J.G., Morris, J.L., Naughton, F., Nielsen, A.B., Novenko, E., Odgaard, B., Ortu, E., Overballe-Petersen, M.V., Pardoe, H.S., Peglar, S.M., Pidek, I.A., Sadori, L., Seppä, H., Severova, E., Shaw, H., Święta-Musznicka, J. Theuerkauf, M., Tonkov, S., Veski, S., van der Knaap P.(W.O.), van Leeuwen, J.F.N., Woodbridge, J., Zimny, M. \& Kaplan, J.O. (2013): The European Modern Pollen Database (EMPD) project. Vegetation History and Archaeobotany, 22: 521530 
2012 Matthias, I., Nielsen, A.B. \& T. Giesecke (2012): Evaluating the effect of flowering age and forest structure on pollen productivity estimates. In: Vegetation history and Archaeobotany, 21: 471-484

\section{Voluntary work}

2010-2014 Equal opportunities officer (decentral) at the Faculty of Biology and Psychology, Georg-August-University, Göttingen

\section{Conferences}

2013

9th PMP International Meeting in Prague, (Czech Republic):

Matthias, I. \& Giesecke, T.: Towards quantitative reconstructions using pollen accumulation rates from lake sediments, a case study in Brandenburg (NE-Germany). [oral presentation]

23. Jahrestreffen des Arbeitskreises Vegetationsgeschichte der Reinhold-Tüxen-Gesellschaft, Brandenburg an der Havel, Germany: Matthias, I. \& Giesecke, T: Der Zusammenhang von

Pollenakkumulationsraten aus Seesedimenten und der umgebenen Vegetation. [oral presentation]

2012 22. Jahrestreffen des Arbeitskreises Vegetationsgeschichte der Reinhold-Tüxen-Gesellschaft vom 28. September bis 01. Oktober 2012, Bonn (Germany): Matthias, I.: Relative Pollenproduktionsraten für Brandenburg. [oral presentation]

2011 XVIII INQUA Congress, 21-27 Juni 2011, Bern (Switzerland): Matthias, I., Nielsen, A.B. \& Giesecke T.: Evaluating the effect of flowering age and forest structure on pollen productivity estimates. [Poster]

2009 NordForsk-LANDCLIM-Workshop 2, 07.10.09-10.10.09 in Tallinn (Estonia): Matthias, I.: An approach to pollen based quantification of land cover in Brandenburg, Germany. [Poster]

Pollen Monitoring Programme, from 22.04.09-27.04.09, in Taxiarchis-Chalkidiki (Greece): Matthias, I. \& Giesecke, T.: Towards quantitative reconstructions of land cover using pollen data. [Poster]

2007 Status Symposium der DFG Forschergruppe 816, 20.09.07-21.09.07. Honorable Consejo Provincial de Loja, Salón de la Provincia (Equador): Matthias, I. \& Behling, H.: Environment and settlement history of Laguna Daniel Alvarez, Loja, southeastern Ecuadorian Andes during the last ca. 1400 yr BP. [Poster]

\section{Education}

Since 2009 PhD-Program (Biology) at the Georg-August-University of Göttingen, Albrecht-von-Haller Institute of Plant Sciences, Department of Palynology and Climate Dynamics

2013 Completion scholarship from the Faculty of Biology and Psychology and the Albrecht-von-Haller Institute of Plant Sciences, GeorgAugust-University of Göttingen 


\begin{tabular}{|c|c|}
\hline 2011-2012 & Maternity and parental leave \\
\hline 2010 & GISLERS Summer School 2010 in Salzburg (Österreich) \\
\hline 2008 & $\begin{array}{l}\text { Graduation in Geography (Dipl.-Geogr.) at the Georg-August- } \\
\text { University of Göttingen. Major subject: Botany, Geology; Thesis } \\
\text { title: Rekonstruktion der Umwelt- und Siedlungsgeschichte von Loja } \\
\text { durch Multiproxy-Analysen an limnischen Sedimenten der Laguna } \\
\text { Daniel Alvarez in Südecuador }\end{array}$ \\
\hline 3-2008 & Studies of Geography at the Georg-August-University of Göttingen \\
\hline 2003 & Abitur at the Wilhelm-Busch Gymnasium in Stadthagen \\
\hline
\end{tabular}

Göttingen, 10.06.2014 